UNIVERSIDAD POLITÉCNICA DE MADRID ESCUELA TÉCNICA SUPERIOR DE INGENIERÍA AGRONÓMICA, ALIMENTARIA Y DE BIOSISTEMAS

\title{
MÉTODO DE SEGMENTACIÓN BASADO EN LA ESTRUCTURA FRACTAL DEL MAPA DE SINGULARIDADES. APLICACIÓN A IMÁGENES DE USO AGRÍCOLA
}

TESIS DOCTORAL

Juan José Martín Sotoca

Ingeniero de Telecomunicación 

DEPARTAMENTO DE INGENIERÍA AGROFORESTAL

ESCUELA TÉCNICA SUPERIOR DE INGENIERÍA AGRONÓMICA,

ALIMENTARIA Y DE BIOSISTEMAS

UNIVERSIDAD POLITÉCNICA DE MADRID

\title{
MÉTODO DE SEGMENTACIÓN BASADO EN LA ESTRUCTURA FRACTAL DEL MAPA DE SINGULARIDADES. APLICACIÓN A IMÁGENES DE USO AGRÍCOLA
}

\section{TESIS DOCTORAL}

\author{
Juan José Martín Sotoca \\ Ingeniero de Telecomunicación
}

\section{Directores}

Ana María Tarquis Alfonso

Dra. Ingeniera Agrónoma

Juan Bautista Grau Olivé

Dr. Ingeniero Agrónomo 

A mis padres y hermano 
Método de segmentación basado en la estructura fractal del mapa de singularidades.

Aplicación a imágenes de uso agrícola 


\section{AGRADECIMIENTOS}

Quiero expresar mi más sincero agradecimiento a los directores de esta tesis doctoral: Ana María Tarquis Alfonso y Juan Bautista Grau Olivé, por todo el tiempo y esfuerzo que han dedicado a guiarme hasta la consecución de esta gran meta. Mi agradecimiento también muy especial a Antonio Saa Requejo por su colaboración inestimable que ha ayudado enormemente a la elaboración de esta tesis doctoral.

Asimismo aprovecho para agradecer a todos los integrantes del Programa de Doctorado de Sistemas Complejos su apoyo durante todos estos largos años de trabajo. En especial quiero agradecérselo a Rosa María Benito y a Juan Carlos Losada por haberme prestado su ayuda siempre que lo he necesitado.

Finalmente quiero dar las gracias al equipo que compone el Centro de Estudios e Investigación para la Gestión de Riesgos Agrarios y Medioambientales (CEIGRAM) por haberme acogido con cariño durante todos estos años. Su apoyo también ha contribuido a que esta tesis se haya completado con éxito.

\section{AGRADECIMIENTOS INSTITUCIONALES}

El autor agradece al equipo SIMBIOS (Universidad de Aberdeen, UK) por las tomografías de suelos proporcionadas para esta tesis. 
Método de segmentación basado en la estructura fractal del mapa de singularidades.

Aplicación a imágenes de uso agrícola 


\section{LISTA DE CONTENIDOS}

LISTA DE CONTENIDOS 1

LISTA DE FIGURAS

LISTA DE TABLAS

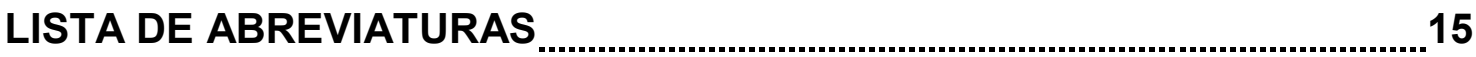

RESUMEN

SUMMARY

CAPÍTULO 1 - INTRODUCCIÓN

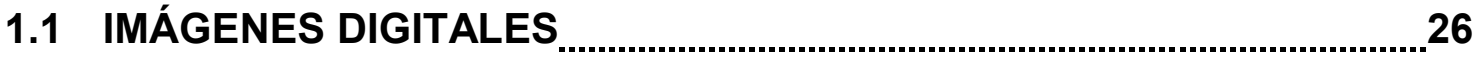

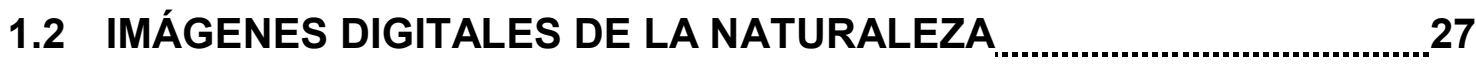

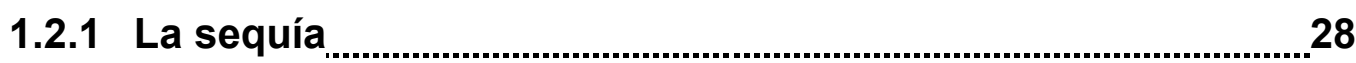

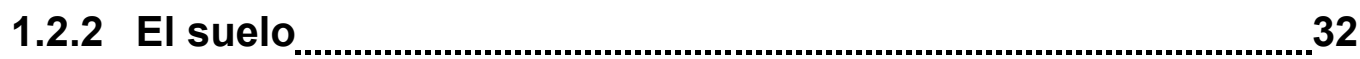

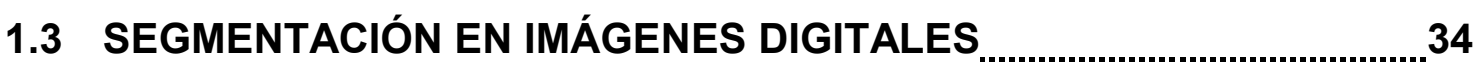

1.3.1 Definición

1.3.2 Técnicas de segmentación …………………………………......... 35

1.3.2.1 Zonificación en mapas de NDVI ........................................36

1.3.2.2 Binarización en imágenes digitales de suelos …............37

1.4 ANÁLISIS FRACTAL EN IMÁGENES DIGITALES DE LA NATURALEZA

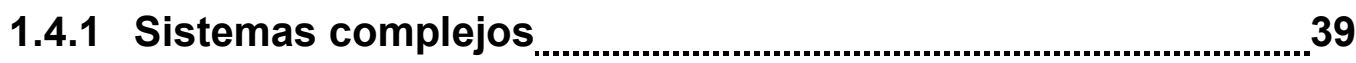

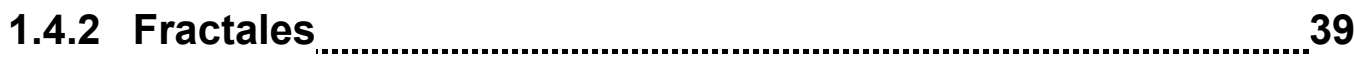

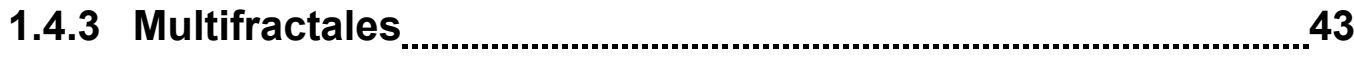

1.4.4 Fractales en la Naturaleza

1.4.4.1 Propiedades multifractales en mapas de NDVI

1.4.4.2 Propiedades multifractales en imágenes de suelos ..... 50 
1.4.5 Segmentación basada en las propiedades fractales del mapa de singularidades

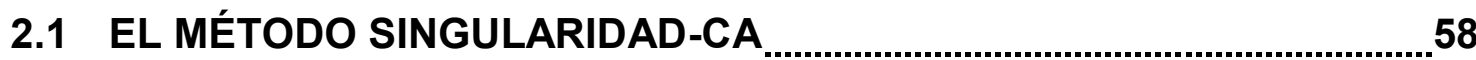

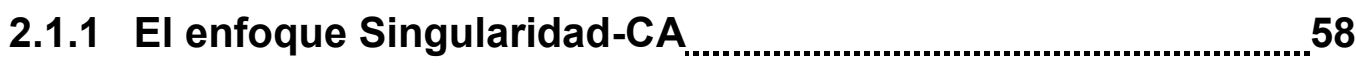

2.1.2 Implementación del método S-CA ............................................ 58

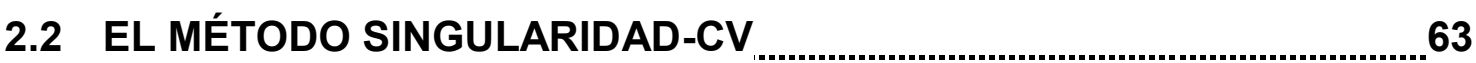

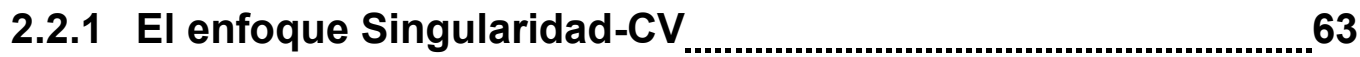

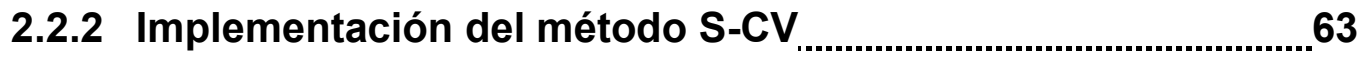

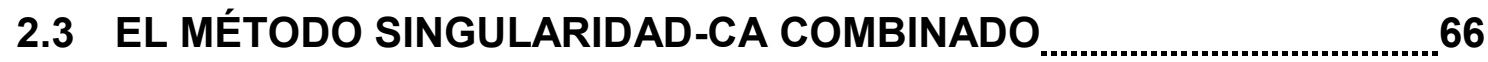

2.3.1 El enfoque Singularidad-CA Combinado .................................66

2.3.2 Implementación del método S-CA Combinado ...........................67

2.4 PRINCIPALES MÉTODOS DE BINARIZACIÓN GLOBALES

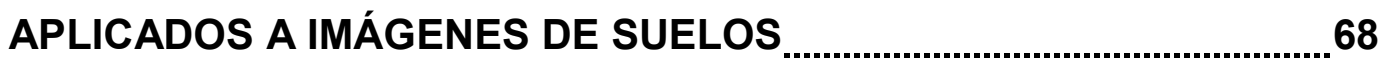

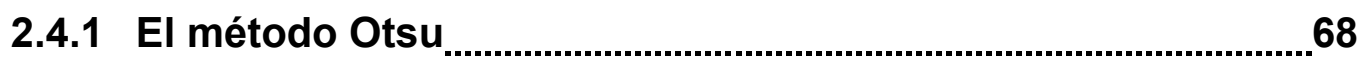

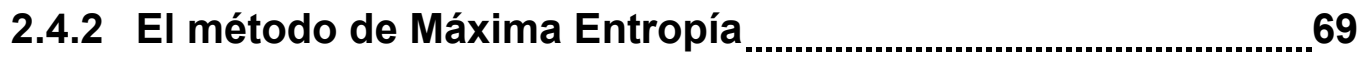

2.4.3 El método Iterativo ..................................................................... 70

2.4.4 Criterio de comparación: clasificación errónea de poros ......70

2.5 EL MÉTODO DE LOS MULTIFRACTALES TRUNCADOS …................... 71

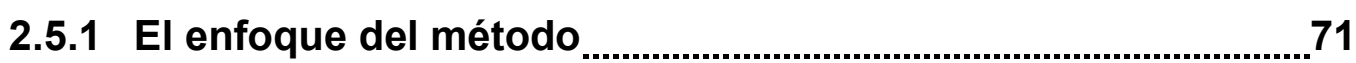

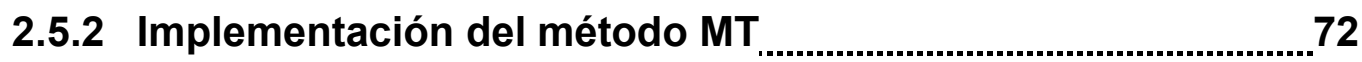

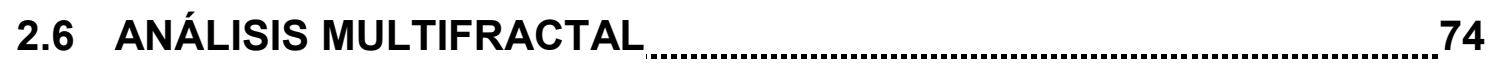

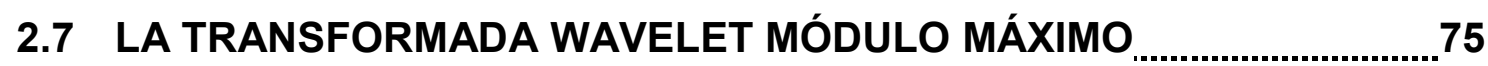

CAPÍTULO 3 - MAPAS DE SINGULARIDAD APLICADOS A ÍNDICES DE VEGETACIÓN 79

3.1 INTRODUCCIÓN

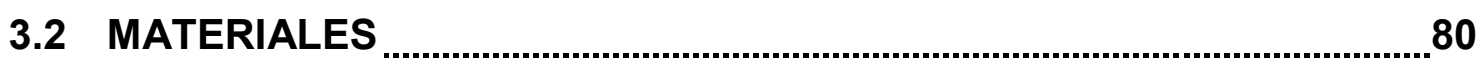

3.2.1 Normalized Difference Vegetation Index (NDVI) ......................80 
3.2.2 Área de estudio 81

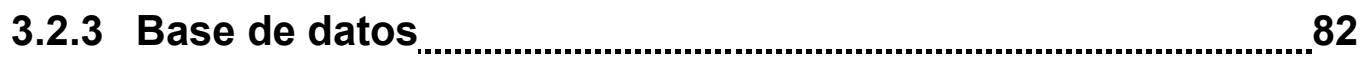

3.3 RESULTADOS

3.3.1 Análisis Multifractal ..................................................................... 83

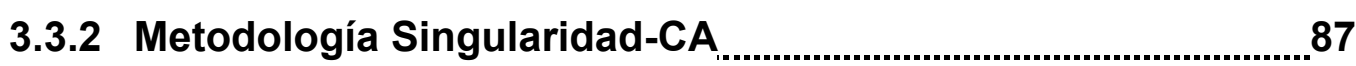

3.3.3 Las zonas no singulares ………………………....................... 91

CAPÍTULO 4 - NUEVO MÉTODO DE SEGMENTACIÓN BASADO EN LAS PROPIEDADES FRACTALES DEL MAPA DE SINGULARIDADES EN

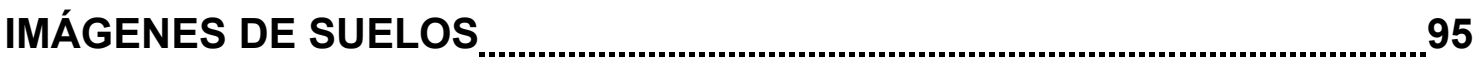

4.1 INTRODUCCIÓN

4.2 MATERIALES

4.3 RESULTADOS

4.3.1 La imagen sintética de suelo ......................................................97

4.3.2 Mapas de singularidades ........................................................ 99

4.3.3 El método CA

4.3.4 Evaluación del método Singularidad-CA

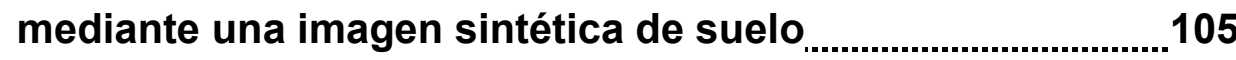

4.3.5 Comparación de los diferentes métodos de segmentación usando una TAC de suelo real 109

CAPÍTULO 5 - SEGMENTACIÓN LOCAL EN 3D BASADA EN LAS PROPIEDADES FRACTALES DEL MAPA DE SINGULARIDADES EN IMÁGENES DE SUELOS .............................................................................. 113

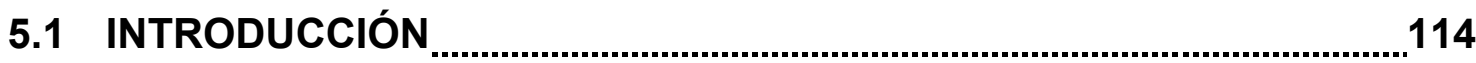

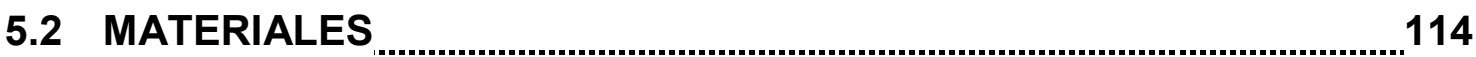

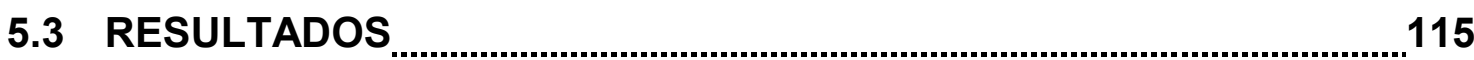

5.3.1 La imagen sintética de suelo en 3D

5.3.2 Las imágenes en 3D de suelo en escala de grises …...........117

5.3.3 Los mapas de singularidades en 3D .......................................119

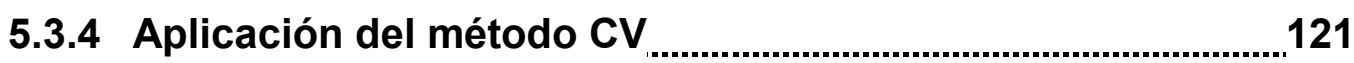


5.3.5 Evaluación del método Singularidad-CV mediante una imagen sintética en 3D de suelo

5.3.6 Comparación de los diferentes métodos de segmentación usando TAC de suelo real

CAPÍTULO 6 - COMBINACIÓN DE MÉTODOS DE SEGMENTACIÓN GLOBALES Y DE ESCALAMIENTO LOCAL PARA DETECTAR EL ESPACIO DE POROS EN IMÁGENES DE SUELOS 135

6.1 INTRODUCCIÓN

6.2 MATERIALES

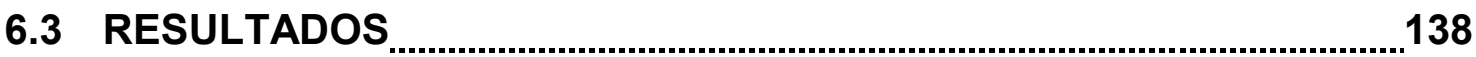

6.3.1 Evaluación del método Singularidad-CA Combinado ............138

6.3.1.1 El método S-CA Combinado aplicado al "conjunto ejemplo" 138

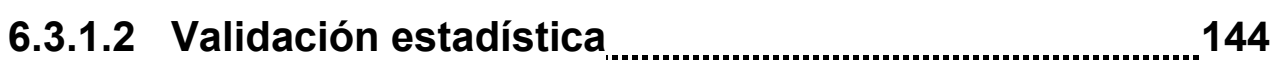

6.3.2 Comparación de los métodos de RL y TWMM aplicados al método S-CA Combinado 147

6.3.2.1 Los métodos RL y TWMM aplicados

al "conjunto ejemplo". 147

6.3.2.2 Validación estadística 150

CAPÍTULO 7 - CONCLUSIONES 153

7.1 CONCLUSIONES 154

7.2 FUTURAS LÍNEAS DE INVESTIGACIÓN 161 


\section{LISTA DE FIGURAS}

Fig. 1.1 - Izquierda: tomografía en 3D de una muestra de suelo (Fuente: SIMBIOS, Universidad de Aberdeen). Derecha: imagen satelital de MODIS/Terra del índice de vegetación NDVI de la costa oeste de USA (Fuente: Land Processes Distributed Active Archive Center).

28

Fig. 1.2 - Sensores multiespectrales. Izquierda: satélite NOAA 19 con el sensor AVHRR a bordo (Fuente: NASA). Derecha: satélite Terra con el sensor MODIS a bordo (Fuente: NASA).

29

Fig. 1.3 - Izquierda: comarcas agrarias en la Comunidad Autónoma de Madrid. (Fuente: Wikimedia Commons). Derecha: distribución gaussiana con los umbrales en el seguro español de compensación de los daños por sequía en pastos.

Fig. 1.4 - 5 iteraciones de la curva de Koch.

42

Fig. 1.5 - Izquierda: alfombra de Sierpinski como ejemplo de SFI. Centro: conjunto de Mandelbrot como ejemplo de algoritmo de escape (Fuente: Wikimedia Commons). Derecha: proceso ALD como ejemplo de proceso estocástico (Fuente: Wikimedia Commons).

43

Fig. 1.6 - Construcción de un multifractal de Sierpinski. Izquierda: generador y sus valores $\mathrm{p}_{\mathrm{i}}$. Derecha: multifractal de Sierpinski después de la $5^{\mathrm{a}}$ iteración.

Fig. 1.7 - Mapa de singularidades del multifractal de Sierpinski. 45

Fig. 1.8 - Espectro multifractal de la alfombra de Sierpinski (círculo rojo) y del multifractal de Sierpinski (curva negra). 46

Fig. 1.9 - Ejemplo de cascada multiplicativa binomial aleatoria $\left(p_{1}=2 / 3, p_{2}=\right.$ $1 / 3$ ) hasta la $3^{a}$ iteración aplicada a una distribución de probabilidad constante. 
Fig. 1.10 - Ejemplos de estructuras fractales y multifractales en la Naturaleza. Arriba Izquierda: brócoli romanesco (fractal). Abajo Izquierda: nubes (multifractal). Derecha: sistema respiratorio humano (fractal). (Fuente: Pixabay.com)

Fig. 1.11 - Izquierda: método CA donde $c(x)$ representa la concentración de un elemento químico. Derecha: ejemplo de gráfica en escala log-log del método CA. Las distintas pendientes corresponden a los valores de $\beta_{1}, \beta_{2} y \beta_{3}$. Los puntos de cambio de pendiente corresponden a los valores de concentración $\mathrm{K}_{\text {th1 }}, \mathrm{K}_{\mathrm{th} 2} \mathrm{y} \mathrm{K}_{\mathrm{th} 3}$. 51

Fig. 1.12 - Interpretación geométrica de las singularidades positivas y negativas. 54

Fig. 2.1 - Izquierda: ventana deslizante utilizada en los mapas satelitales de NDVI. Derecha: ventana deslizante utilizada en las TAC de suelos. 59

Fig. 2.2 - Gráficos log-log resultantes de la aplicación del método CA a mapas de NDVI. Los puntos de cambio de pendiente han sido calculados mediante el método de regresión lineal por mínimos cuadrados. Fuente: Martín-Sotoca et al., (2017c).

Fig. 2.3 - Gráfico superior: distribución acumulada Área $(\alpha \geq C)$ en escala loglog (método CA). Gráfico inferior: transformada wavelet módulo máximo en función del parámetro de escala de la wavelet. 62

Fig. 2.4 -Cubo deslizante utilizado en las tomografías computarizadas de suelos. 64

Fig. 2.5 - Gráfico superior: distribución acumulada $f(\alpha)$ en escala log-log (método CV). Gráfico inferior: transformada wavelet módulo máximo en función de la escala de la wavelet. 66

Fig. 2.6 - De izquierda a derecha: 1) espacio de poros detectado por el método S-CA, 2) espacio de poros detectado por un método global interpretado como una máscara (en este caso, el método de Máxima Entropía), 3) solapamiento de ambos espacios, y 4) espacio de poros detectado por el método S-CA Combinado. 68 
Fig. 2.7 - Ejemplo de creación del espacio de poros en imágenes 2D (superior) e imágenes 3D (inferior) generadas por el método MT. La delimitación del espacio de poros viene definido por los umbrales de truncado $V G_{t h 1}$ y $V G_{t h 2}$.

Fig. 2.8 - Ejemplo de reducción de contraste en imágenes 2D (superior) e imágenes 3D (inferior) generadas por el método MT.

Fig. 3.1 - Imagen RGB del área rectangular ( 300 × 280 píxeles) utilizada en este estudio (fecha de captura por MODIS: 15/04/2011). En línea discontinua aparece el contorno de la CAM y sus seis comarcas agrícolas: (1) LozoyaSomosierra, (2) Guadarrama, (3) área Metropolitana, (4) Campiña, (5) Sudoeste y (6) Las Vegas.

Fig. 3.2 - Resultados del espectro multifractal de los mapas NDVI de cada estación. (Izquierda) año 2005 y (derecha) año 2011.

Fig. 3.3 - (Arriba) mapas NDVI (247 x 247 píxeles), y (abajo) mapas de singularidades (247 × 247 píxeles) para cada fecha analizada del año 2005. La línea discontinua representa los límites de la Comunidad Autónoma de Madrid.

88

Fig. 3.4 - (Arriba) mapas NDVI (247 x 247 píxeles), y (abajo) mapas de singularidades ( $247 \times 247$ píxeles) para cada fecha analizada del año 2011. La línea discontinua representa los límites de la Comunidad Autónoma de Madrid.

89

Fig. 3.5. Aplicación del método CA. Distribuciones acumuladas en escala loglog con el cruce de las dos rectas de regresión (en rojo) obteniendo (arriba) los umbrales inferiores: $\quad \alpha_{\text {Tmin }}($ invierno $)=1.973, \quad \alpha_{\text {Tmin }}($ primavera $)=1.961$, $\alpha_{T \min }($ verano $)=1.988 \quad$ y $\quad \alpha_{T \min }($ otoño $)=1.979 ; \quad$ y (abajo) los umbrales superiores: $\quad, \quad \alpha_{\text {Tmax }}($ invierno $)=2.057, \quad \alpha_{\text {Tmax }}($ primavera $)=2.028$, $\alpha_{T \max }($ verano $)=2.074$ and $\alpha_{T \max }($ otoño $)=2.047$, para cada fecha analizada del año 2005. 90

Fig. 3.6. Aplicación del método CA. Distribuciones acumuladas en escala loglog con el cruce de las dos rectas de regresión (en rojo) obteniendo (arriba) los 
umbrales inferiores: $\quad \alpha_{\text {Tmin }}($ invierno $)=1.965, \quad \alpha_{\text {Tmin }}($ primavera $)=1.953$, $\alpha_{\text {Tmin }}($ verano $)=1.997$ y $\alpha_{\text {Tmin }}($ otoño $)=1.999 ;$ y (abajo) los umbrales superiores: $\quad, \quad \alpha_{\text {Tmax }}($ invierno $)=2.036, \quad \alpha_{\text {Tmax }}($ primavera $)=2.029$, $\alpha_{\text {Tmax }}($ verano $)=2.059$ and $\alpha_{\text {Tmax }}($ otoño $)=2.055$, para cada fecha analizada del año 2011. 91

Fig. 3.7 - Zonas no singulares mostradas como píxeles en color negro, donde $\alpha_{\text {Tmin }} \leq \alpha(x) \leq \alpha_{\text {Tmax }}$, para todas las fechas analizadas del 2005 y 2011. La línea discontinua representa los límites de la CAM. 92

Fig. 3.8 - Intersección de las dos zonas no singulares (2005 y 2011) de cada estación (píxeles coloreados en negro). La línea discontinua representa los límites de la CAM. 94

Fig. 4.1 - Generador de un multifractal de Sierpinski ( $1^{\mathrm{a}}$ iteración). 97

Fig. 4.2 - Proceso de truncamiento en el método de los MT (paso i). A la izquierda: dos realizaciones de un multifractal aleatorio de Sierpinski. En el medio: multifractal filtrado (filtro paso-bajo) mediante una función rectangular. A la derecha: multifractales truncados con dos umbrales diferentes. 98

Fig. 4.3 - Resultados para los pasos ii, iii y iv en la construcción de una imagen sintética de suelo mediante el método de los MT.

Fig. 4.4 - Arriba: imágenes en escala de grises de las muestras TAC reales (246 x 246 píxeles) y de la imagen sintética de suelo (215 x 215 píxeles). Abajo: histogramas de escala de grises de cada imagen. 100

Fig. 4.5 - Arriba: mapas de singularidades de las muestras TAC reales (246 x 246 píxeles) y de la imagen sintética de suelo (215 x 215 píxeles). Abajo: histogramas de los exponentes de singularidad de cada imagen. 101

Fig. 4.6 - Distribuciones log-log acumuladas obtenidas mediante el método CA. Los círculos señalan los puntos de cambio de pendiente. 103

Fig. 4.7 - Arriba: Distribuciones acumuladas en escala log-log con los puntos de cambio de pendiente. Abajo: método TWMM aplicado a las distribuciones de 
arriba. Las líneas de máximos convergen hacia los puntos de cambio de pendiente.

104

Fig. 4.8 - Arriba: imágenes en escala de grises de todas las imágenes de suelo. Medio: imágenes binarizadas después de aplicar el método Singularidad-CA (el espacio de poros está coloreado en negro). Abajo: solapamiento de las imágenes en escala de grises con los bordes de las imágenes binarizadas.

105

Fig. 4.9 - Arriba: espacio de poros real (ground-truth) de la imagen sintética. Abajo: imágenes binarizadas obtenidas aplicando los diferentes métodos de segmentación (Otsu, Iterativo, Máxima Entropía y Singularidad-CA) a la imagen sintética de suelo (el espacio de poros está coloreado en negro). 106

Fig. 4.10 - Comparación de la DTP acumulada (izquierda) y la DAP acumulada (derecha) para la imagen sintética de suelo y los métodos de segmentación comparados.

107

Fig. 4.11 - Imágenes binarizadas obtenidas aplicando los diferentes métodos de segmentación (Otsu, Iterativo, Máxima Entropía y Singularidad-CA) a las tres muestras en 2D de la TAC de suelo real (el espacio de poros está coloreado en negro).

109

Fig. 4.12 - Comparación de la DTP acumulada (arriba) y la DAP acumulada (abajo) para las tres muestras de la TAC de suelo y los métodos de segmentación comparados. En la muestra 3 el método de Otsu y el Iterativo obtienen los mismos resultados.

111

Fig. 5.1 - Cubo generador de un multifractal de Sierpinski en 3D (1ª iteración). El generador es representado en tres capas para una mejor visualización de las probabilidades iniciales $p_{i}(\mathrm{i}=1, \ldots, 27)$. 115

Fig. 5.2 - Etapa de truncamiento en el método MT (paso i). Izquierda: dos realizaciones de un multifractal aleatorio de Sierpinski en 3D. Medio: multifractales filtrados (filtro paso-bajo) mediante una función rectangular. Derecha: multifractales en 3D truncados mediante dos umbrales diferentes. 
Fig. 5.3 - Resultados de los pasos ii, iii y iv en la construcción de una imagen sintética de suelo en 3D mediante el método MT.

Fig. 5.4 - Arriba: imágenes en escala de grises de las tomografías reales en 3D ( 246 × 246 x 246 vóxeles) y de la imagen sintética de suelo en 3D $(215$ x 215 x 215 vóxeles). Abajo: histogramas de escala de grises de cada imagen.

118

Fig. 5.5 - Arriba: mapas de singularidades de las tomografías reales en 3D (246 x 246 x 246 vóxeles) y de la imagen sintética de suelo en 3D $(215 \times 215 \times 215$ vóxeles). Abajo: histogramas de los exponentes de singularidad de cada imagen.

Fig. 5.6 - Arriba: Distribuciones log-log acumuladas obtenidas mediante el método CV con los puntos de cambio de pendiente. Abajo: el método TWMM aplicado a las distribuciones anteriores. Las líneas de módulo máximo convergen hacia los puntos de cambio de pendiente.

122

Fig. 5.7 - Arriba: mapas de singularidades en 3D de todas las imágenes de suelo. Abajo: imágenes binarizadas después de aplicar el método SingularidadCV (el espacio de poros está coloreado en negro).

123

Fig. 5.8 - Imágenes binarizadas obtenidas aplicando los diferentes métodos de segmentación (Otsu, Máxima Entropía y Singularidad-CV) a la imagen sintética de suelo en 3D (el espacio de poros está coloreado en negro). La imagen superior-izquierda corresponde con el espacio de poros real (ground-truth) de la imagen sintética.

124

Fig. 5.9 - Comparación de la DTP (arriba) y el DTP acumulada (abajo) para la imagen sintética de suelo en 3D y los métodos de segmentación analizados.

126

Fig. 5.10 - Histogramas con valores en escala de grises apilados para las dos tomografías reales de suelo en $3 \mathrm{D}$. El espacio de poros y los valores de fondo están representados por los colores azul y rojo respectivamente.

128

Fig. 5.11 - Imágenes binarizadas obtenidas aplicando los diferentes métodos de segmentación (Otsu, Máxima Entropía y Singularidad-CV) a las dos 
tomografías reales de suelo. El espacio de poros está coloreado en negro.

Fig. 5.12 - Poro de tamaño máximo para las dos tomografías reales de suelo y los métodos de segmentación comparados.

131

Fig. 5.13 - Comparación de la DTP (arriba) y la DTP acumulada (abajo) en las dos tomografías reales de suelo y los métodos de segmentación comparados.

133

Fig. 6.1 - (Arriba): espacios de poros reales (representados por píxeles en negro) de las imágenes sintéticas de suelo obtenidas mediante el método de los multifractales truncados (MT). (Medio): imágenes en valores de grises (VG) de las imágenes sintéticas. (Abajo): histogramas de VG de las imágenes sintéticas

Fig. 6.2 - (Arriba): mapas de singularidades (paso i), aplicación del método CA (paso ii) y detección del umbral mediante TWMM (paso iii), en la metodología Singularidad-CA. (Abajo): espacios de poros (representados por píxeles en negro) detectado por el método S-CA (sólo se muestran las imágenes 2, 3 y 4 como ejemplos).

Fig. 6.3 - (Arriba): espacios de poros detectados por el método S-CA. (Medio): espacios de poros detectados por el método de Máxima Entropía (los umbrales de VG se muestran en la Tabla 6.2). (Abajo): espacios de poros combinados resultado del solapamiento de ambos métodos ("y" lógico). Todos los espacios de poros están representados por píxeles negros. (Sólo se muestran las imágenes sintéticas 2, 3 y 4 como ejemplos). 140

Fig. 6.4 - (Arriba): porosidades obtenidas por todos los métodos analizados comparado con las porosidades reales. (Abajo): Errores relativos de la porosidad para todos los métodos analizados. (Para el conjunto ejemplo). ....141

Fig. 6.5 - CEP calculada para todos los métodos analizados. (Para el conjunto ejemplo).

142

Fig. 6.6 - Espacios de poros reales comparados con los espacios de poros obtenidos por los métodos de Máxima Entropía, S-CA y S-CA Combinado. 
Todos los espacios de poros están representados por píxeles negros. (Sólo se muestran las imágenes sintéticas 2,3 y 4 como ejemplos).

Fig. 6.7 - (Arriba): porosidades medias obtenidas por todos los métodos analizados comparado con las porosidades medias reales. (Abajo): errores relativos medios de la porosidad para todos los métodos analizados. La información numérica de las barras de error se muestra en la Tabla 6.3.......145

Fig. 6.8 - CEP media calculada para todos los métodos analizados. La información numérica de las barras de error se muestra en la Tabla 6.3.

Fig. 6.9 - (Arriba): aplicación del método de $\mathrm{RL}$ a las distribuciones acumuladas de VS (escala log-log). Las rectas a y b fueron obtenidas con $R^{2}>$ 0.98. (Abajo): aplicación del método de TWMM a las mismas distribuciones. (Sólo se muestran las imágenes 1 y 2 como ejemplos).

Fig. 6.10 - (Arriba): Porosidades obtenidas por el método S-CA Combinado comparada con las porosidades reales utilizando los métodos de RL y TWMM. (Abajo): errores relativos de la porosidad para ambas metodologías. (Para el conjunto ejemplo).

Fig. 6.11 - CEP calculada por el método S-CA Combinado utilizando los métodos de RL y TWMM. (Para el conjunto ejemplo). 150

Fig. 6.12 - (Arriba): porosidades medias obtenidas por el método S-CA Combinado comparada con las porosidades medias reales utilizando los métodos de RL y TWMM. (Abajo): errores relativos medios de la porosidad para ambas metodologías. La información numérica de las barras de error se muestra en la Tabla 6.4 .

Fig. 6.13 - CEP media calculada por el método S-CA Combinado utilizando los métodos de RL y TWMM. La información numérica de las barras de error se muestra en la Tabla 6.4 . 


\section{LISTA DE TABLAS}

Tabla 3.1 - Valores extremos de los exponentes de singularidad $\left(\alpha_{\max }, \alpha_{\min }\right)$, su diferencia $\left(\Delta \alpha=\alpha_{\max }-\alpha_{\min }\right)$, valores extremos de las dimensiones fractales $\left(f\left(\alpha_{\max }\right), f\left(\alpha_{\min }\right)\right)$ y su diferencia $\left(\Delta f=f\left(\alpha_{\max }\right)-f\left(\alpha_{\min }\right)\right)$ para todas las fechas y años analizados (2005 y 2011).

Tabla 3.2 - Porcentaje (\%) de zonas no singulares respecto del área total para todas las fechas analizadas (estaciones) y años $(2005,2011)$. La fila inferior muestra el \% de zonas no singulares de la intersección de dichos años.

Tabla 4.1 - Principales estadísticos de la variable singularidad $(\alpha)$ para cada imagen de suelo: media, mediana, varianza, asimetría y curtosis.

Tabla 4.2 - Comparación del número de poros, tamaño máximo de poro (en píxeles), tamaño medio de poro (en píxeles), porosidad total y clasificación errónea de poros (CEP) en la imagen sintética de suelo para los distintos métodos de segmentación analizados.

107

Tabla 4.3 - Comparación del número de poros, tamaño máximo de poro (en píxeles), tamaño medio de poro (en píxeles) y porosidad total de las tres muestras de la TAC de suelo real para los distintos métodos de segmentación analizados.

110

Tabla 5.1 - Comparación de: número de poros, tamaño máximo, medio y mediano de poro (en vóxeles), porosidad total y clasificación errónea de poros (CEP), para los distintos métodos de segmentación analizados.

125

Tabla 5.2 - Comparación del número de poros, tamaño máximo, medio y mediano de poro (en vóxeles) y porosidad total en las dos tomografías reales de suelo para los distintos métodos de segmentación analizados. 130

Tabla 6.1. Media y desviación estándar de la porosidad de 50 realizaciones (imágenes sintéticas) para cada rango. 
Tabla 6.2 - Umbrales de VG obtenidos por el método de Máxima Entropía y umbrales de VS obtenidos por el método S-CA (utilizando los métodos de RL y TWMM) para las imágenes sintéticas del conjunto ejemplo.

Tabla 6.3 - Desviaciones estándar de: la porosidad $(P)$, el error relativo de la porosidad (ER) y la clasificación errónea de poros (CEP), para los tres métodos analizados.

146

Tabla 6.4 - Desviaciones estándar de: la porosidad (P), el error relativo de la porosidad (ER) y la clasificación errónea de poros (CEP), utilizando los métodos de RL y TWMM.

152 


\section{LISTA DE ABREVIATURAS}

2D

3D

ALD

AMF

AVHRR

CA

CAM

CEP

CV

DAP

DTP

EMF

EOS

EVI

IV

LP DAAC

MODIS

MT

NASA

NDVI
2 Dimensiones

3 Dimensiones

Agregación Limitada por Difusión

Análisis MultiFractal

Advanced Very High Resolution Radiometer

Concentración-Área

Comunidad Autónoma de Madrid

Clasificación Errónea de Poros

Concentración-Volumen

Distribución de Áreas de Poro

Distribución de Tamaños de Poro

Espectro MultiFractal

Earth Observing System

Enhanced Vegetation Index

Índice de Vegetación

Land Processes Distributed Active Archive Center

Moderate Resolution Imaging Spectroradiometer

Multifractales Truncados

National Aeronautics and Space Administration

Normalized Difference Vegetation Index 
NOAA

National Oceanic and Atmospheric Administration

RBG

Ruido Blanco Gaussiano

RGB

Red Green Blue

$\mathbf{R L}$

Regresión Lineal

RSR

Relación Señal-Ruido

SAVI

Soil Adjusted Vegetation Index

S-CA

Singularidad-CA

S-CV

Singularidad-CV

SFI

Sistemas de Funciones Iteradas

SIG

Sistema de Información Geográfica

TAC

Tomografía Axial Computarizada

TIFF

Tagged Image File Format

TWC

Transformada Wavelet Continua

TWMM

Transformada Wavelet Módulo Máximo

UTM

Universal Transverse Mercator

VEG

Valores Extremos Generalizados

VG

Valores de Grises

VS

Valores de Singularidades

WGS84

World Geodetic System 1984 


\section{RESUMEN}

Esta tesis se centra en el estudio de dos procesos complejos con origen en la Naturaleza, a saber, el fenómeno de la sequía y la estructura interna del suelo. Este estudio se realiza mediante imágenes digitales de los mismos: los mapas de índices de vegetación satelitales y las tomografías axiales computarizadas (TAC) de suelos, respectivamente.

El análisis de imágenes digitales constituye un campo de investigación en continuo crecimiento. Una de las herramientas más utilizadas en el análisis de imágenes es la segmentación, es decir, la identificación de regiones de interés que comparten ciertas propiedades morfológicas, estadísticas, etc. Las técnicas de segmentación ya han sido aplicadas a ambos tipos de imágenes con distintos propósitos. En los mapas de índices de vegetación normalmente se requiere realizar una zonificación del área de estudio con el propósito de encontrar regiones que compartan propiedades estadísticas. La delimitación de estas regiones, también denominadas zonas homogéneas, es muy útil para una mejor cuantificación de los daños por sequía en el contexto de los seguros agrarios indexados. Este tipo de seguros establece indemnizaciones a los agricultores cuando se producen episodios de sequía en sus cultivos (normalmente pastos). Estos daños son cuantificados mediante un índice de vegetación. En el caso de las TAC de suelos se ha aplicado mayoritariamente la binarización por métodos de umbralización tanto global como local con el objetivo de delimitar del espacio de poros. El conocimiento del espacio de poros de un tipo de suelo resulta de mucha utilidad para el estudio de sus propiedades físicas, químicas y microbiológicas.

La autosimilitud fractal o multifractal es una propiedad que comparten muchas imágenes digitales de procesos con origen en la Naturaleza, y no es una excepción para el tipo de imágenes que se están analizando en esta tesis a pesar de las escalas tan diferentes que representan ambos tipos de imágenes (cientos de metros para los mapas satelitales y micras para suelos). Numerosos estudios han demostrado que los mapas de índices de vegetación 
y las imágenes digitales de suelos tienen propiedades multifractales en un rango de escalas determinado.

Trabajos precedentes descritos en Cheng et al. (1994) han utilizado las propiedades fractales que aparecen en la distribución espacial de la concentración de un elemento químico para la detección de yacimientos minerales. En estos trabajos se han utilizado las propiedades fractales de un mapa de concentraciones para realizar una binarización, donde la región de interés la constituía el yacimiento mineral, es decir, una anomalía en la concentración del elemento químico.

La adaptación de esta metodología nos ha permitido introducir un método alternativo a la zonificación de regiones estadísticamente homogéneas en los mapas de índices de vegetación, al que hemos denominado método "Singularidad-Concentración-Área" (S-CA) (Martín-Sotoca et al., 2017c). En el caso de las imágenes de suelos hemos podido aplicar el mismo método S-CA para la delimitación del espacio de poros (Martín-Sotoca et al., 2017a). En la versión tridimensional hemos denominado al nuevo método como "Singularidad-Concentración-Volumen" (S-CV) (Martín-Sotoca et al., 2016).

Ambos métodos, S-CA y S-CV, se fundamentan en el hallazgo de tramos lineales en los gráficos log-log de las distribuciones acumuladas de la variable espacial "exponente de singularidad", poniendo de manifiesto las propiedades autosimilares de la misma. Estos tramos lineales nos han permitido establecer umbrales de segmentación en ambos tipos de imágenes, tal como sucedía en los mapas de concentración en el trabajo de Cheng et al. (1994).

Para la evaluación de los métodos S-CA y S-CV en la delimitación del espacio de poros en TAC se ha realizado la comparación con los siguientes métodos tradicionales de binarización: Otsu, Iterativo y Máxima Entropía. Para ello se ha utilizado una imagen sintética de suelo con un espacio de poros previamente definido. Esta imagen sintética ha sido obtenida mediante un nuevo método al que hemos denominado como método de los Multifractales Truncados (MT). Este método replica de forma satisfactoria las características de las TAC de suelos, a saber, histogramas unimodales y distribuciones espaciales autosimilares (Martín-Sotoca et al., 2016; 2017a). Los métodos S-CA y S-CV 
han demostrado ser más eficaces en la delimitación de los poros de tamaño mediano y grande obteniendo porosidades y distribuciones de tamaños de poros más cercanas a las reales.

El principal inconveniente de los métodos S-CA y S-CV es la introducción de pequeños poros de forma incorrecta debido a la amplificación que hacen estos métodos de las anomalías de intensidad en la TAC. Es por ello que también se presenta en esta tesis una mejora del método S-CA al que denominamos "SCA Combinado" (Martín-Sotoca et al., 2017b). La combinación del método SCA con un método de umbralización global (el método de Máxima Entropía) permite mejorar los parámetros de porosidad y clasificación errónea de poros, al eliminar la mayoría de los poros pequeños incorrectamente detectados por el método original. 


\section{SUMMARY}

This thesis focuses in the study of two complex processes originating in Nature, namely, the drought event and the internal soil structure. This study is performed by the following digital images: maps of satellite Vegetation Indexes (VI) and soil Computed Tomographies (CT), respectively.

The analysis of digital images is a research field in continuous growth. One of the most useful tools in this analysis is the segmentation process. Segmentation identifies regions of interest $(\mathrm{ROI})$ in images which share some morphological or statistical properties. Segmentation techniques have already been applied to both types of images with different purposes.

In the case of maps of $\mathrm{VI}$, a zoning of the study area is usually required with the aim to find regions which share statistical properties. The delimitation of these regions, also known as homogeneous zones, is very useful to better quantify the damage by drought in the context of the agricultural index-based insures. This damage is quantified by vegetation indexes. This type of insure establishes compensations to farmers when a drought event occurs and crops (normally pastures) result damaged.

In the case of soil CT, a binarization of the image is required with the aim of delimiting the pore space. Binarization is usually achieved by global or local thresholding methods. The knowledge of the soil pore space is very important to understand its physical, chemical and microbiological properties.

Many digital images of processes originating in Nature share the fractal or multifractal self-similarity property. The digital images analysed in this thesis, despite such different scales representing (hundreds of metres for satellite maps and microns for CT images), also own this special property and numerous studies demonstrate the multifractal behaviour in a range of scales.

Previous studies described in Cheng et al. (1994) have taken advantage of fractal properties appearing in the spatial distribution of a chemical 
concentration map to detect mineral deposits. In these studies, binarization is based on the fractal properties of the concentration map. The ROI (mineral deposit) consists of an anomaly in the concentration map.

The adaptation of this methodology has allowed us to introduce an alternative method, named as the "Singularity-Concentration-Area" (S-CA) method, with the aim of:

1) Detecting statistically homogeneous regions in maps of VI (MartínSotoca et al., 2017c).

2) Delimiting the pore space in soil CT images. In this case we have dealt with 2D images (Martín-Sotoca et al., 2017a) and 3D images (Martín-Sotoca et al., 2016). The 3D version of this method is named as the "Singularity-Concentration-Volume" (S-CV) method.

Both methods, S-CA and S-CV, are based on the existence of linear segments in accumulated distributions of singularity maps, revealing the self-similar properties of the analysed images. These linear segments have allowed us to establish segmentation thresholds in both types of images, as it happened in the concentration maps (Cheng et al., 1994).

To assess the S-CA and S-CV methods in delimiting the pore space of soil CT images, a comparison has been performed among the following traditional segmentation methods: Otsu, Iterative and Maximum Entropy. To do so, we have used a synthetic soil image with a well-defined pore space. This synthetic soil image has been obtained by the new Truncated Multifractal (TM) method (Martín-Sotoca et al., 2016; 2017a). This method replicates successfully the soil CT characteristics, namely, non-bimodal histograms and self-similar spatial distributions. S-CA and S-CV methods have demonstrated to be more efficient in delimiting medium and large-size pores, obtaining porosities and pore size distributions closer to the real ones.

The main drawback of S-CA and S-CV methods is the incorrect detection of small-size pores due to high sensitivity to small intensity anomalies in soil CT images. To solve this issue, an improved S-CA method is introduced in this thesis, named as the "Combining S-CA method" (Martín-Sotoca et al., 2017b). 
The combination of the S-CA method with a global thresholding method (the Maximum Entropy method) improves the porosity and the Misclassification Error, by eliminating most of the small-size pores incorrectly detected by the original method. 


\section{CAPÍTULO 1}

\section{INTRODUCCIÓN}




\subsection{IMÁGENES DIGITALES}

La cantidad de información generada hoy en día excede cualquier previsión realizada en los últimos años. De hecho, se ha acuñado un nuevo término para denominar a este nuevo paradigma: el Big Data. La definición más aceptada del concepto "Big Data" es: toda aquella información (estructurada y no estructurada) que por su volumen y variedad no puede ser procesada por las herramientas tradicionales ya que excedería los tiempos de respuesta y/o costes.

Esta tesis va a tratar con un tipo particular de información: la imagen digital. Podemos definir la imagen digital como una función de intensidad, $I(x, y)$ en el caso bidimensional y $I(x, y, z)$ en el caso tridimensional, donde $(x, y, z)$ son coordenadas espaciales y el valor $I$ es proporcional a la intensidad de la imagen en ese punto. Las imágenes digitales pueden ser de dos tipos: ráster o vectoriales.

- Las imágenes tipo ráster se representan mediante una matriz de datos, de forma que cada elemento de la matriz se corresponde con la definición de un pixel de la imagen. Al número de píxeles por pulgada utilizados en el proceso de adquisición se le conoce como "resolución". Generalmente ésta se expresa en dpi (dots per inch = puntos por pulgada). Cuanto mayor es la resolución, mayor es la fidelidad de la imagen a la realidad, es decir, se obtienen más detalles de ella.

- Las imágenes tipo vectorial se representan mediante entidades geométricas (fórmulas matemáticas) tales como círculos, rectángulos 0 segmentos. Dado que una imagen vectorial está compuesta solamente por entidades matemáticas, se le pueden aplicar fácilmente transformaciones geométricas a la misma (ampliación, expansión, etc.), mientras que una imagen de tipo ráster, compuesta por píxeles, no podrá ser sometida a dichas transformaciones sin sufrir una pérdida de información. 
Las imágenes digitales que tratará esta tesis serán de tipo ráster. Para el caso de imágenes en 2 dimensiones (2D) los elementos de la matriz se denominarán píxeles, en el caso de 3 dimensiones (3D) se denominarán vóxeles.

El procesado y análisis de imágenes digitales requiere de la tecnología desarrollada para trabajar con el Big Data. Podemos encontrar multitud de dispositivos (escáner de rayos $\mathrm{X}$, cámaras multiespectrales a bordo de drones, aviones y satélites artificiales, etc) que generan imágenes digitales utilizadas por muchas disciplinas científicas tales como la medicina, la meteorología, la geología, la agricultura, la oceanografía, etc. Esta ingente y variada cantidad de información puede ser combinada dando lugar a un verdadero Big Data. Un ejemplo claro de sistema que hace uso de las herramientas desarrolladas para el Big Data son los Sistemas de Información Geográfica (SIG) donde cada vez se maneja mayor información a diferentes escalas. Por ejemplo, para un área geográfica determinada se puede combinar información topográfica, de vegetación, humedad, geológica, vías de transporte, poblaciones, etc.

\subsection{IMÁGENES DIGITALES DE LA NATURALEZA}

Las imágenes digitales son una importante fuente de información para entender y explicar diferentes procesos físicos en general. Esta tesis tratará de contribuir al entendimiento de dos procesos complejos con origen en la Naturaleza, a saber, "la estructura del suelo" y "el fenómeno de la sequía", mediante el análisis de tipos particulares de imágenes digitales (ver fig. 1.1).

A continuación pasamos a describir brevemente los fundamentos de ambos procesos, así como los tipos de imágenes digitales seleccionadas en cada caso. 

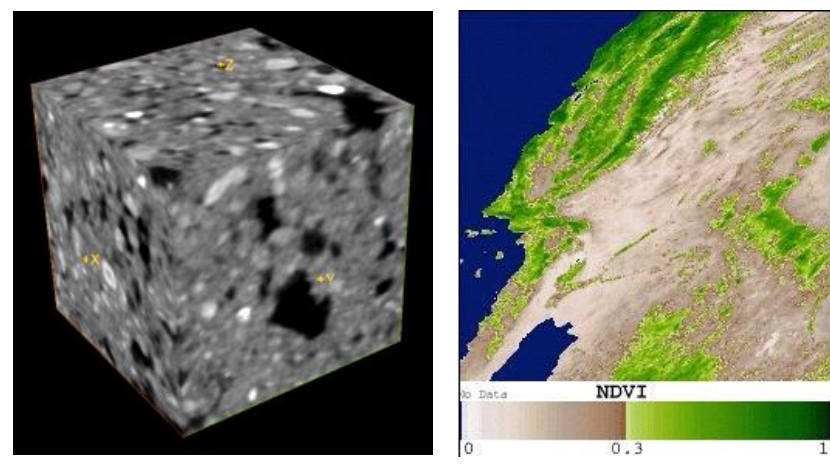

Fig. 1.1 - Izquierda: tomografía en 3D de una muestra de suelo (Fuente: SIMBIOS, Universidad de Aberdeen). Derecha: imagen satelital de MODIS/Terra del índice de vegetación NDVI de la costa oeste de USA (Fuente: Land Processes Distributed Active Archive Center).

\subsubsection{La sequía}

La sequía es uno de los fenómenos naturales con mayor impacto tanto en nuestro planeta como en la vida del ser humano, llegando a ser un desastre natural en casos extremos. La sequía puede ser definida de manera general como la escasez temporal de agua, en comparación con el suministro normal, durante un periodo continuado de tiempo. Esta definición puede ser descrita como conceptual, ya que no establece variables como el inicio, el fin o la intensidad de la sequía, ni tan siquiera detalla otras variables climáticas (Gouveia et al., 2009). Una definición más precisa de la sequía, también llamada operacional, nos lleva a establecer diferentes tipos dependiendo de la disciplina científica desde donde es abordada. La clasificación más aceptada establece 4 tipos de definición de sequía dependiendo de la variable utilizada (Keyantash and Dracup, 2002):

- Meteorológica: Se basa en las precipitaciones y mide sus desviaciones respecto a la media durante un período determinado de tiempo.

- Agrícola: Se basa en la cantidad de humedad que necesita un determinado cultivo para desarrollarse. Por tanto, no sólo depende de las precipitaciones que se produzcan sino que también depende de la capacidad de retención de agua del suelo, tipo de cultivo, hábitos de enraizamiento y la etapa de desarrollo del cultivo (Hayes, 2004). 
- Hidrológica: Se basa en la cantidad de agua disponible en superficie (ríos, lagos, embalses) y subterránea.

- Socioeconómica: Se basa en los daños económicos provocados por una disminución en los recursos hídricos. En este caso es determinante la manera en que la economía y la sociedad desarrollan sus actividades. Determinados sistemas socioeconómicos son más vulnerables a la escasez de agua.

La cuantificación de la sequía es una de las tareas más importante a la hora de caracterizar este fenómeno natural. Generalmente esta cuantificación es abordada mediante dos métodos diferentes (Sepulcre-Canto et al., 2012):

1) A través de índices convencionales basados en datos a nivel de suelo, tales como la temperatura, precipitación, humedad, etc.

2) A través de índices basados en teledetección (Dalezios et al., 2014) utilizando satélites y drones. Estas aeronaves tienen sensores radiométricos multiespectrales instalados (AVHRR, MODIS, etc) que detectan diferentes bandas de frecuencia (fig. 1.2). La combinación de estas bandas de frecuencia da lugar a diferentes tipos de índices.
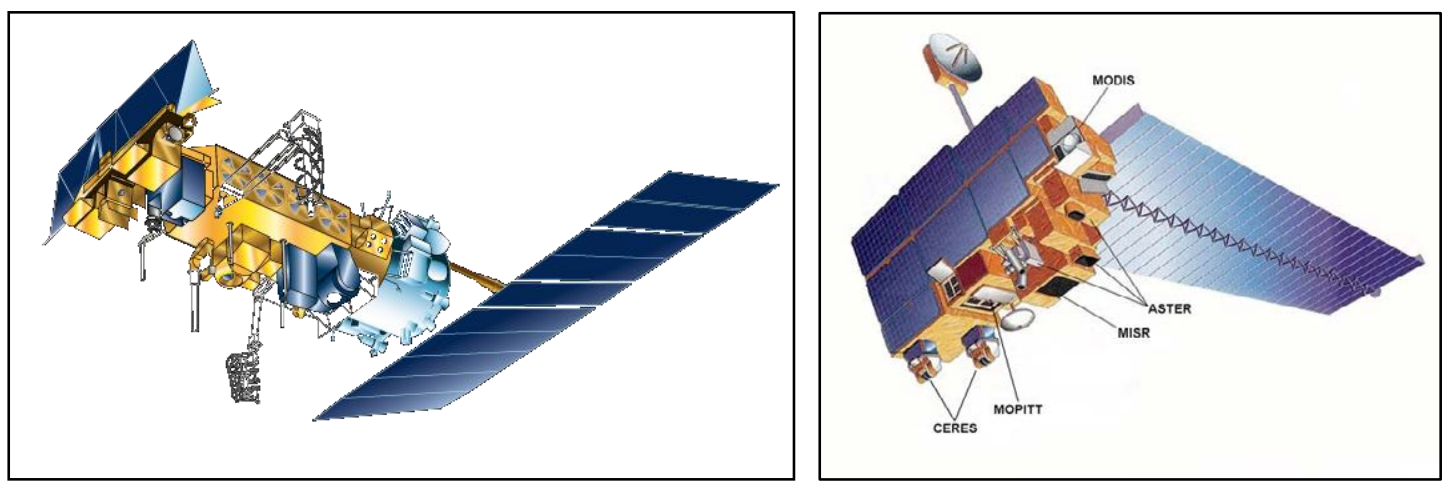

Fig. 1.2 - Sensores multiespectrales. Izquierda: satélite NOAA 19 con el sensor AVHRR a bordo (Fuente: NASA). Derecha: satélite Terra con el sensor MODIS a bordo (Fuente: NASA).

Entre los índices de teledetección más utilizados está el grupo de los "índices de vegetación" (IV) que son capaces de cuantificar la actividad fotosintética de 
las plantas. Existe una relación entre la fotosíntesis y la radiación absorbida/reflejada por la vegetación. La clorofila absorbe mayoritariamente la luz visible (de 0.4 a $0.7 \mu \mathrm{m}$ ) para que la fotosíntesis se produzca, mientras que la estructura celular de las hojas refleja mayoritariamente la banda del infrarrojo cercano (de 0.7 a $1.1 \mu \mathrm{m}$ ). Los IV son normalmente utilizados para cuantificar la sequía ya que se establece una correlación entre la actividad fotosintética y las variables agrícolas (precipitaciones, humedad, tipo de cultivo, etc) que condicionan un suceso de sequía agrícola. Existen varias definiciones de IV donde se tienen en cuenta diferentes factores en función de las características de la zona de estudio. Se definen a continuación tres de los IV más utilizados:

- Índice de Vegetación de Diferencia Normalizada (Normalized Difference Vegetation Index, NDVI). Es el más utilizado por su sencillez de interpretación. Se basa fundamentalmente en el principio de que la vegetación sana absorbe mayoritariamente la luz visible y refleja el infrarrojo cercano. Intenta mitigar el efecto de las nubes y la nieve restando la banda visible del rojo.

- Índice de Vegetación Ajustado al Suelo (Soil Adjusted Vegetation Index, SAVI). Se trata de un índice muy adecuado para trabajos en zonas semiáridas, donde la contribución del suelo es muy importante. Así, cuando se realice un estudio sobre una zona de estas características, este índice resultará más consistente que el NDVI, gracias a esa mayor distinción entre el suelo y la vegetación.

- Índice de Vegetación Mejorado (Enhanced Vegetation Index, EVI). Este índice fue diseñado para tener en cuenta las zonas con alta densidad de biomasa, las variaciones estructurales de la cubierta vegetal y la influencia atmosférica.

Mediante la teledetección somos capaces de obtener imágenes digitales de la superficie terrestre en forma de mapas de IV a intervalos regulares con distintos niveles de resolución. Cuando utilizamos los IV para cuantificar la sequía agrícola interpretamos estos mapas como variables aleatorias regionalizadas donde cada pixel de la imagen representa una realización de un proceso estocástico. Bajo esta interpretación la sequía es definida como un 
suceso estadístico donde el valor del IV es extremadamente bajo y persiste en el tiempo en una determinada localización. Para ello se definen umbrales en los valores del IV por debajo de los cuales se entiende que un suceso de sequía tiene lugar.

Podemos encontrar esta metodología en la cuantificación de la sequía en los seguros agrarios indexados. Un ejemplo de este tipo de seguros es el "seguro español de compensación de los daños por sequía en pastos", que utiliza el NDVI como índice que mide la cantidad de agua disponible para el pasto (BOE, 2013). Este seguro tiene como objeto indemnizar a los ganaderos cuando se produce un evento sequía en pastos y tienen que proporcionar un alimento suplementario al ganado. En este seguro, la sequía se produce cuando el valor del NDVI queda por debajo de un umbral durante un periodo de tiempo continuado. Estos umbrales son calculados haciendo la suposición de que las distribuciones estadísticas del NDVI son gaussianas. El cálculo del umbral NDVI se realiza de la siguiente forma:

$$
N D V I_{\text {umbral }}(\boldsymbol{x}, t)=\mu(\boldsymbol{x}, t)-k_{i} \sigma(\boldsymbol{x}, t),
$$

donde $x$ representa una zona homogénea (comarca agrícola), $t$ representa el periodo del año, $\mu(\boldsymbol{x}, t)$ es la media de la distribución estadística del NDVI para cada zona y periodo del año, $k_{i}$ es un factor definido por el seguro denominado "estrato" que establece dos niveles del umbral NDVI ( $\left.k_{1}=0.7, k_{2}=1.5\right), \mathrm{y}$ $\sigma(x, t)$ es la desviación típica de la distribución del NDVI (fig. 1.3). Los dos niveles del umbral $\left(k_{1}, k_{2}\right)$ son utilizados por el seguro para definir dos tipos de cobertura. Contratar una cobertura de estrato 1 supone recibir la indemnización cuando los valores de NDVI no son tan bajos como en el caso del estrato 2 . 

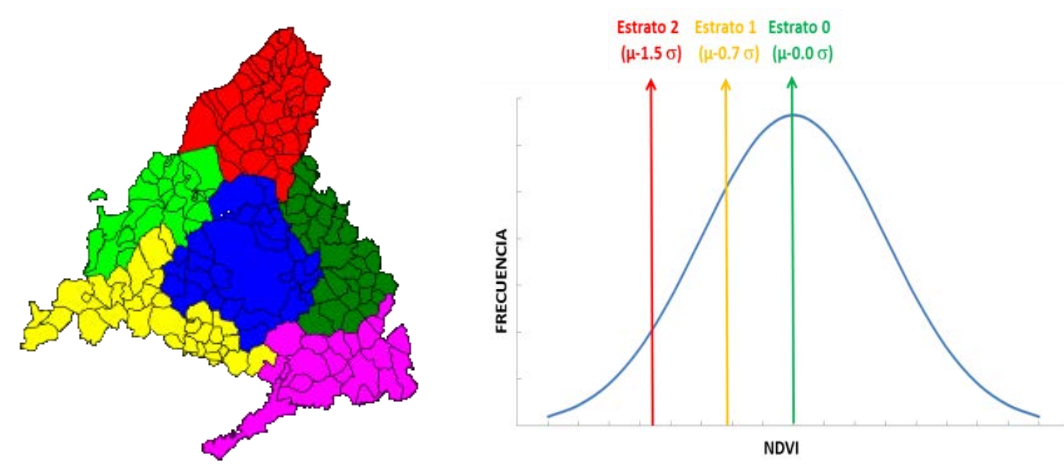

Fig. 1.3 - Izquierda: comarcas agrarias en la Comunidad Autónoma de Madrid. (Fuente: Wikimedia Commons). Derecha: distribución gaussiana con los umbrales en el seguro español de compensación de los daños por sequía en pastos.

Las imágenes digitales que se van a utilizar en esta tesis para el estudio del fenómeno de la sequía serán del tipo de "mapas satelitales de NDVI".

\subsubsection{El suelo}

Hoy en día, la importancia del suelo no sólo radica en ser el sustrato del crecimiento de las plantas, tiene otras muchas implicaciones tanto medioambientales como socioeconómicas. El estudio del suelo está directamente relacionado con algunos de los retos más importantes que la humanidad tiene en los próximos años, a saber, el efecto invernadero, la seguridad alimenticia, la disponibilidad de agua, la bioenergía, la recuperación de tierras degradadas, etc.

El suelo es un sistema complejo compuesto por sólidos (minerales y materia orgánica), líquidos y gases, en el que interactúan procesos de tipo físico, químico y biológico dando lugar a distintas configuraciones en su estructura interna. Desde un punto de vista estructural, el suelo se define como una mezcla de componentes sólidos y huecos. Las características de los componentes huecos, denominados técnicamente como "espacio de poros", afectan significativamente a procesos tales como la circulación de agua, la aireación de las raíces, el transporte de nutrientes o el crecimiento de microorganismos. Por tanto, cada vez es más importante obtener una descripción estructural del suelo lo más exacta posible, es decir, que se 
aproxime lo mejor posible a la realidad (Vogel, 2000; Dullien, 2012; Rockhold et al., 2004; Young et al., 2008; Pajor et al., 2010; Kravchenko et al, 2011).

Cuando se describe el espacio de poros de un suelo es necesario especificar algunos parámetros cuyo principal objetivo es caracterizar sus propiedades geométricas. Algunos de los parámetros más importantes, por su posterior utilización en modelos de suelos, son la "porosidad" y la "distribución de tamaño de poros". La porosidad es el parámetro que nos ayuda a cuantificar el volumen disponible para los procesos de transporte de líquidos y gases, así como para el almacenamiento y retención de agua. La distribución de tamaño de poros se utiliza principalmente para la estimación de la humedad retenida y la permeabilidad del suelo (Flint and Flint, 2002).

Estos parámetros pueden ser obtenidos mediante diferentes métodos. La mayoría de ellos son técnicas invasivas que destruyen o alteran en alguna medida la estructura interna de la muestra de suelo. Algunos ejemplos de estas técnicas invasivas son:

- Método gravimétrico por saturación de agua: La diferencia de peso entre la muestra de suelo saturada con agua y la muestra desprovista de agua mediante secado nos proporciona el volumen del espacio de poros.

- Método por desorción de agua: A una muestra de suelo, inicialmente saturada de agua, se la somete a una presión creciente para que vaya eliminado el agua. Por teoría de capilaridad los poros grandes son drenados en primer lugar. A medida que aumentamos la presión se drenan poros cada vez más pequeños.

- Método por adsorción de mercurio: Se aumenta progresivamente la presión para forzar al mercurio a penetrar en los poros de la muestra de suelo. Los poros de gran tamaño son los que se llenan en primer lugar.

- Método por impregnación o intrusión de una sustancia: Se introduce en la muestra una sustancia como por ejemplo una resina o una sustancia fosforescente. La muestra es cortada en finas secciones y puede ser fotografiada mediante cámaras especiales, microscopio 
electrónico o micro-sonda de electrones. En este caso es necesario aplicar un método de segmentación para identificar la zona de poros.

Entre las técnicas no invasivas podemos encontrar:

- Método por densidad de las partículas: La densidad de las partículas (zona de sólidos) puede ser estimada asumiendo un contenido mineral mayoritariamente de cuarzo con densidad de $2.65 \mathrm{~g} \cdot \mathrm{cm}^{-3}$.

- Método volumétrico por picnometría de gas (He): El volumen que ocupa el gas en la muestra de suelo es calculado mediante un picnómetro.

- Tomografía axial computarizada (TAC): Se combinan distintas imágenes de rayos $\mathrm{X}$ tomadas por un escáner desde distintos ángulos. $\mathrm{A}$ partir de estas imágenes un software construye una imagen bidimensional que permite ver secciones del objeto desde cualquier ángulo, incluso realiza reconstrucciones en 3D (Stock, 1999). La TAC ha probado ser muy efectiva capturando la estructura en 3D del suelo y ha sido ampliamente utilizada en numerosos estudios (Wang et al., 2011; Houston et al., 2013b; Ojeda-Magaña et al., 2014). La principal ventaja de esta técnica es que no altera la estructura interna de la muestra de suelo a la vez que suministra imágenes en 3D. Como contrapartidas, añade ruido de alta frecuencia, pueden aparecer "objetos extraños" por el efecto "beam hardening" y proporciona bajo contraste en la interfaz sólido-poro (Van Geet et al., 2000; Ketcham and Carlson, 2001; Wildenschild et al., 2002; Cortina-Januchs et al., 2011). Por tanto, es muy importante la elección del método de delimitación de la zona de poros.

Las imágenes digitales que se van a utilizar en esta tesis para el estudio de la estructura interna del suelo serán del tipo "tomografía axial computarizada". 


\subsection{SEGMENTACIÓN EN IMÁGENES DIGITALES}

\subsubsection{Definición}

Una imagen digital proporciona mucha información que generalmente necesita ser organizada para entender mejor los procesos que la originan. La organización más habitual que podemos realizar inicialmente es dividir la imagen en zonas que compartan alguna característica o propiedad. Estas propiedades pueden ser de tipo estadístico (intensidad y textura), morfológico/geométrico (forma), etc. De todas las zonas encontradas normalmente estaremos interesados en alguna en especial a la que denominamos "objeto", al resto de regiones las denominaremos "fondo". A la técnica matemática consistente en dividir un conjunto de datos (en nuestro caso una imagen digital) en subconjuntos no solapados o disjuntos (regiones o zonas) que comparten alguna propiedad se la denomina "segmentación".

Normalmente la segmentación viene precedida por una fase de preprocesamiento de la imagen donde se transforma la imagen original en otra más adecuada para facilitar la posterior segmentación. Por tanto, el preprocesamiento tiene como objetivo mejorar la imagen y principalmente hace uso de técnicas tales como la mejora del contraste así como la supresión de ruido (Jain, 1989). Entre las técnicas de mejora de contraste podemos destacar: la expansión del contraste, la ecualización del histograma y técnicas basadas en características específicas de la imagen digital como son la transformada wavelet, la lógica difusa y la morfología matemática.

\subsubsection{Técnicas de segmentación}

Las técnicas de segmentación de imágenes de niveles de gris están generalmente basadas en una de estas dos propiedades básicas: la discontinuidad y la similitud de los valores de intensidad. De acuerdo con estas propiedades, las técnicas de segmentación se pueden clasificar en:

- Técnicas basadas en discontinuidad o detección de bordes: La segmentación se realiza de acuerdo a cambios bruscos (bordes) del 
nivel de gris. Dentro de las principales técnicas de segmentación basadas en la detección de bordes se encuentran los operadores basados en la primera derivada (gradiente) y segunda derivada (laplaciano) de la variación de los niveles de gris de una imagen. Los operadores matemáticos más conocidos son Roberts, Prewitt, Sobel y Canny.

- Técnicas basadas en similitud o detección de regiones: La segmentación consiste en dividir una imagen en zonas mediante el análisis de características de los píxeles de acuerdo con un criterio de homogeneidad. Entre las técnicas más utilizadas están las basadas en la umbralización (Otsu, entropía, etc), en el agrupamiento de regiones (k-means, Fuzzy c-means, etc) y en el crecimiento de regiones.

Dado que en esta tesis se analizan dos tipos particulares de imágenes digitales, a saber, mapas satelitales de NDVI y TAC de suelos, a continuación se resume el uso particular de las técnicas de segmentación en cada tipo de imagen.

\subsubsection{Zonificación en mapas de NDVI}

El concepto de zonificación en mapas de NDVI se refiere a la segmentación o clasificación de regiones que comparten características similares de tipo estadístico en la variable aleatoria "NDVI". Cada una de estas regiones constituirá una zona de píxeles homogéneos en el mapa, es decir, una zona con alta correlación espacial en las distribuciones estadísticas identificadas.

Para el caso de la cuantificación de la sequía mediante mapas de NDVI, la zonificación constituye el primer paso para decidir si en una localización está teniendo lugar un evento de tipo sequía. Como ya hemos señalado anteriormente la sequía se decide en función del cálculo de un umbral en el NDVI. Las localizaciones situadas dentro de una misma región homogénea compartirán los mismos umbrales de NDVI. De la misma forma, dichos umbrales podrán ser distintos entre diferentes regiones, ya que éstos están 
basados en la media y la varianza, o directamente mediante percentiles, de las distribuciones estadísticas de cada región identificada.

Para el caso español del "seguro de compensación de los daños por sequía en pastos" la zonificación o identificación de regiones homogéneas se hace en base a demarcaciones territoriales administrativas, tales como las comarcas agrícolas (conjunto de municipios), donde se establece a priori que existe correlación espacial. Para cada una de estas zonas se calculan los umbrales del NDVI suponiendo que todas las distribuciones son gaussianas. Sin embargo, en el trabajo realizado por Martín-Sotoca (2014) podemos encontrar que las distribuciones estadísticas en pastos no tienen por qué seguir modelos gaussianos, es más, muchas veces siguen distribuciones de tipo valores extremos generalizados (VEG) o de tipo Gumbel.

\subsubsection{Binarización en imágenes digitales de suelos}

Cuando queremos segmentar una imagen en dos clases diferentes (objeto y fondo) normalmente utilizamos el término "binarización" en lugar de "segmentación". Los métodos de binarización son utilizados para delimitar el espacio de poros en imágenes de suelos tanto en 2D como en 3D. En este caso, la zona buscada (objeto) será el espacio de poros y la zona descartada (fondo) será el espacio de sólidos. Los métodos de binarización utilizados para separar el espacio de poros del espacio de sólidos son principalmente métodos de umbralización (Sezgin and Sankur, 2004), en los que se calcula un umbral que puede ser global o local. Los métodos de umbralización global calculan un único umbral que es aplicado a toda la imagen. Por otro lado, los métodos de umbralización local establecen un umbral basado en las propiedades locales de la imagen, por lo que este valor varía en cada pixel/voxel de la imagen. El uso de la binarización por medio de umbralización es una excelente opción en imágenes donde los objetos de interés se pueden diferenciar de aquellos que no lo son, como, por ejemplo, en imágenes donde existen regiones u objetos luminosos sobre un fondo oscuro. En estos casos los histogramas son fuertemente bimodales. 
En Sezgin y Sankur (2004) se proporciona una revisión de las diferentes estrategias de cálculo de umbrales. Los autores clasifican los métodos de umbralización en seis grupos: métodos basados en la forma del histograma, métodos basados en clustering (agrupamiento), métodos basados en la entropía, métodos basados en atributos del objeto, métodos espaciales y métodos de umbralización local (los 5 primeros grupos pertenecen a los métodos de umbralización global). Una revisión de la literatura nos revela que los métodos basados en clustering más conocidos son el método Iterativo (Ridler and Calvard, 1978) y el método de Otsu (Otsu, 1979). Entre los métodos más utilizados basados en la entropía podemos encontrar el método de máxima entropía (Kapur et al., 1985), el método de máxima entropía de Renyi (Sahoo et al. 1997) y el método de la mínima entropía cruzada (Li and Lee, 1993). El método de umbralización local más conocido es el "kriging de indicadores" (Oh and Lindquist, 1999), que está basado en las correlaciones espaciales locales. Más recientemente, podemos encontrar una nueva versión del método de kriging de indicadores denominado como "kriging de indicadores de ventana adaptativa" (Houston et al., 2013a) que mejora significativamente los resultados de segmentación. Se han seguido otras estrategias locales, como por ejemplo, el método de Otsu extendido mediante la minimización de la varianza intra-clase (Hapca et al., 2013), que obtiene mejores resultados que el método original.

Dada la gran variedad de métodos de segmentación por umbralización que podemos aplicar a las imágenes digitales necesitamos realizar comparaciones entre ellos para poder evaluarlos correctamente. A la hora de comparar el funcionamiento de los diferentes métodos podemos seguir diferentes estrategias:

1. Realizar medidas de porosidad y distribución de tamaño de poros directamente sobre la muestra real a la que se le van a aplicar los métodos de segmentación. Ya han sido descritas anteriormente las técnicas más utilizadas para este fin. El procedimiento sería tomar las imágenes previamente a la realización de las medidas, ya que como hemos visto, muchas de ellas son técnicas invasivas o destructivas de la muestra. A continuación se puede comparar el resultado obtenido por 
los distintos métodos de segmentación con los obtenidos mediante las técnicas físicas de medición.

2. Construir o diseñar una imagen sintética de suelo donde se definen de antemano todas las características que va a tener el espacio de poros. Los resultados obtenidos para cada uno de los métodos se segmentación se pueden comparar con los definidos inicialmente en la imagen sintética. Podemos encontrar ejemplos de imágenes sintéticas de suelo en 2D y 3D en los trabajos de Zhang (2001), Schlüter et al. (2010) y Wang et al. (2011).

Las TAC de suelos presentan como principal inconveniente el bajo contraste que aparece en la interfaz sólido-poro dando lugar a histogramas de niveles de grises muy unimodales, y por tanto dificultando el trabajo de los métodos de segmentación tradicionales basados en umbrales globales.

\subsection{ANÁLISIS FRACTAL EN IMÁGENES DIGITALES DE LA NATURALEZA}

\subsubsection{Sistemas complejos}

Un sistema complejo es aquel que por la interdependencia de sus elementos, normalmente dependencias no lineales, surgen una serie de propiedades nuevas, denominadas emergentes, que no pueden explicarse analizando cada una de sus partes individuales. Por tanto, un sistema complejo es algo más que la simple suma de sus elementos constitutivos. Nos encontramos sistemas complejos en multitud de disciplinas tan dispares como la economía, la meteorología, la ecología, la biología, la física, la geología, las ciencias sociales, etc (Solé y Bascompte, 2006). En algunas ocasiones las propiedades emergentes (de tipo geométrico o estadístico) de los sistemas complejos son de carácter fractal e incluso multifractal. 


\subsubsection{Fractales}

El término fractal fue propuesto originariamente por el matemático Benoît Mandelbrot y procede del latín "fractus" que significa fragmentado, quebrado (Mandelbrot, 1977). En su definición más sencilla un fractal es un objeto geométrico cuya estructura básica se repite a diferentes escalas, es decir, posee la propiedad de la autosimilitud, y cuya dimensión fractal es un número no entero (Mandelbrot, 1982; 2002). A continuación se explican las dos características de todo objeto que es definido como fractal: la autosemejanza y la dimensión fractal.

Un objeto posee la propiedad de autosemejanza o autosimilitud cuando el todo es similar a una parte del mismo y puede presentarse en diferentes grados: autosimilitud exacta, cuasi-autosimilitud y autosimilitud estadística. La autosimilitud exacta es la que impone una repetición geométrica idéntica del objeto a diferentes escalas y se da en los llamados "fractales deterministas". La cuasi-autosimilitud permite cierta deformación de la estructura geométrica básica a distintas escalas. Por último, la autosimilitud estadística permite que sea una medida estadística de un objeto/proceso la que resulte invariante ante un cambio de escala. Este tipo de autosimilitud se da en los llamados "fractales aleatorios".

Una característica muy importante de los objetos geométricos y los procesos estadísticos con autosimilitud es la aparición de leyes de potencias ante un cambio de escala:

- En el caso de objetos geométricos con autosimilitud exacta nos encontramos con la ley de potencias:

$$
N(r)=r^{-\alpha}
$$

donde $N(r)$ es el número de copias más pequeñas del objeto que son reescaladas por un factor $r$ (cambio de escala) y $\alpha$ se suele denominar como la "dimensión de autosemejanza".

- En el caso de procesos estocásticos con autosimilitud estadística nos encontramos con leyes de potencias del tipo: 


$$
X(\lambda t)=\lambda^{H} X(t),
$$

donde $X(t)$ es un proceso estocástico, $\lambda$ es el factor de escala y $H$ es el denominado "exponente de Hurst". La igualdad en la expresión (1.3) es a nivel de distribuciones estadísticas.

La segunda característica que debe tener un objeto para que sea fractal es que su dimensión fractal sea un número fraccionario. El concepto de dimensión fractal es, como su propio nombre indica, un concepto de dimensión y por tanto intenta cuantificar cómo llena el espacio un objeto geométrico.

Desde un punto de vista topológico (espacios topológicos), la definición de dimensión más básica y con la que estamos más familiarizados es la de "dimensión topológica", que únicamente puede tomar valores enteros. La manera más sencilla de definir la dimensión topológica es mediante la definición por inducción de Henri Poincaré donde:

1. La dimensión topológica del conjunto vacío es -1.

2. Un conjunto tiene dimensión topológica $\mathrm{n}$ cuando los entornos de todos los puntos del conjunto tienen una frontera o borde de dimensión (n-1).

Según la definición de Poincaré, la dimensión topológica de un punto es 0 , de una recta es 1 , de un plano es 2 , y así sucesivamente. Muchas veces la dimensión topológica es insuficiente para explicar cómo llena el espacio un determinado objeto geométrico.

Como ejemplo de esta última afirmación se muestra la curva de Koch. Este extraño objeto geométrico fue creado por el matemático sueco Niels Fabian Helge von Koch en 1904. Para su construcción partimos de un segmento rectilíneo de longitud la unidad (ver fig. 1.4). En la primera iteración dividimos el segmento en tres partes iguales y sustituimos el elemento central por dos segmentos de tamaño igual al elemento sustituido, formando un diente de sierra. En la segunda iteración realizamos el mismo procedimiento con cada uno de los cuatro nuevos segmentos. En la iteración enésima tendremos $4^{n}$ segmentos de longitud $3^{-n}$. La dimensión topológica de la curva de Koch es 1 , 
sin embargo esta curva tiene una longitud infinita cuando $\mathrm{n}$ tiende a infinito, lo que nos sugiere que la dimensión topológica es, en este caso, insuficiente para explicar las rarezas de este objeto matemático.

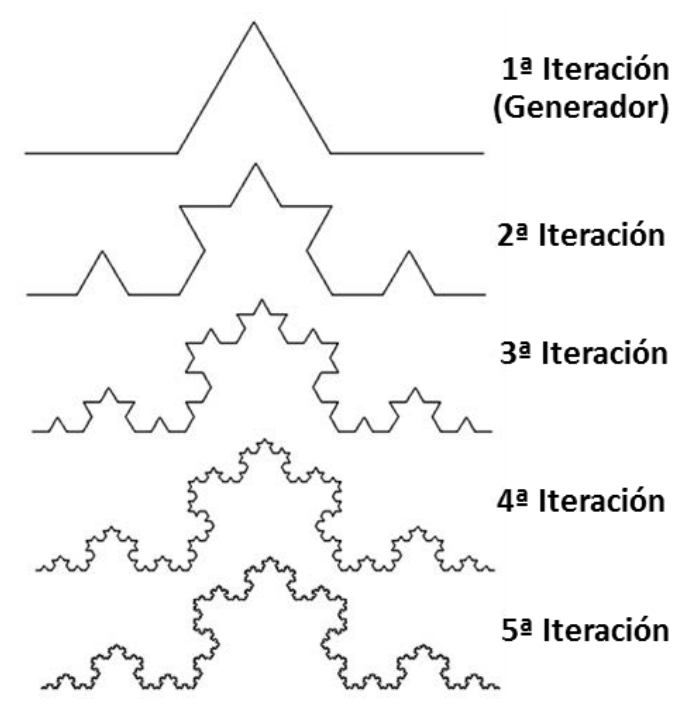

Fig. 1.4 - 5 iteraciones de la curva de Koch.

Desde un punto de vista métrico (espacio métrico), la cuantificación de la dimensión se puede abordar de distintas formas. Una de las formas más utilizadas es la que se propone en la teoría de la medida (Falconer, 2003), rama de las matemáticas que estudia las funciones medibles e integrables. En esta disciplina se generaliza el concepto de dimensión a todo tipo de objetos geométricos dando como resultado varias caracterizaciones de la dimensión. Las dos caracterizaciones más conocidas que proporciona la teoría de la medida son: la dimensión de Hausdorff-Besicovitch y la dimensión por conteo de cajas (box-counting). En la mayoría de los casos ambas dimensiones coinciden por lo que se utiliza normalmente la dimensión por conteo de cajas por ser más fácil de calcular.

La dimensión por conteo de cajas es la manera más utilizada para calcular la dimensión fractal de un objeto donde podemos llegar a leyes de potencia del tipo:

$$
N(r) \sim r^{-D}
$$

donde $N(r)$ es el $n^{\circ}$ de celdas (conjuntos con forma de caja) de tamaño $r$ que recubren al objeto y $\mathrm{D}$ es la dimensión fractal por conteo de cajas. En objetos 
con autosimilitud exacta la dimensión de autosemejanza coincide con la dimensión por conteo de cajas.

En el caso de la curva de Koch obtenemos los siguientes resultados cuando calculamos la dimensión por conteo de cajas:

- $\quad N_{n}=4^{n} \rightarrow n^{\circ}$ de conjuntos que recubren el objeto en la iteración $n$.

- $r=\left(\frac{1}{3}\right)^{n} \rightarrow$ tamaño de los conjuntos que recubren el objeto en la iteración $n$.

- Utilizando la expresión 1.4 obtenemos que: $D=\frac{\log 4}{\log 3}=1.261$

Existen varias técnicas para generar objetos fractales (De Guzmán et al., 1993; Barnsley, 1993). Los fractales estrictamente autosimilares se pueden crear mediante los llamados Sistemas de Funciones Iteradas (SFI). Ejemplos de este tipo de fractales son: el conjunto de Cantor, la alfombra de Sierpinski, el triángulo de Sierpinski, el copo de nieve de Koch o la Esponja de Menger. Los fractales cuasi-autosimilares se pueden crear mediante los llamados algoritmos de escape. Ejemplos de este tipo de fractales son: el conjunto de Mandelbrot y los conjuntos de Julia. Los fractales aleatorios (con autosimilitud estadística) son generados mediante procesos estocásticos. Algunos ejemplos de estos procesos son el movimiento browniano, vuelos de Lévy, procesos de agregación limitada por difusión (ALD), etc. En la fig. 1.5 mostramos un ejemplo de cada técnica.
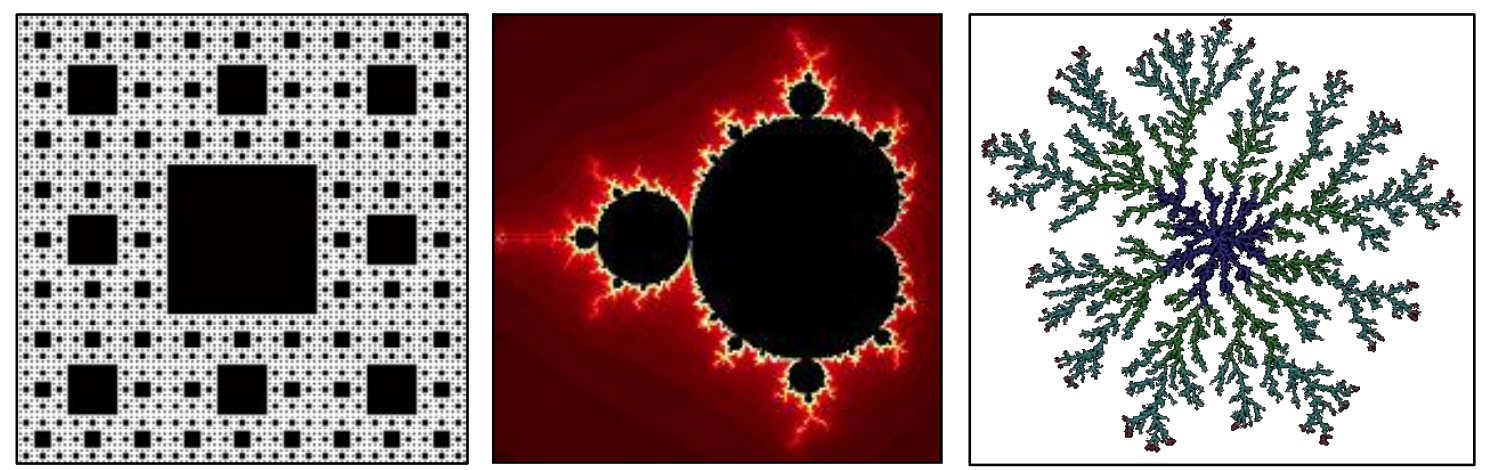

Fig. 1.5 - Izquierda: alfombra de Sierpinski como ejemplo de SFI. Centro: conjunto de Mandelbrot como ejemplo de algoritmo de escape (Fuente: Wikimedia Commons). Derecha: proceso ALD como ejemplo de proceso estocástico (Fuente: Wikimedia Commons). 


\subsubsection{Multifractales}

El término multifractal es una generalización del término fractal. En ocasiones algunos objetos geométricos con propiedades autosimilares no se pueden explicar mediante una única dimensión fractal global. Esto sucede normalmente cuando estos objetos en cada punto pueden tomar un rango de valores distintos de intensidad (niveles de grises). En los objetos fractales examinados hasta el momento los valores que tomaba cada punto eran dos, o cero o uno. En los objetos multifractales se puede calcular una magnitud local que varía en cada punto que se denomina "exponente de singularidad o de "Hölder" y que forma un conjunto continuo de valores. Por tanto, la primera condición necesaria para que el objeto geométrico en cuestión sea un multifractal es que se cumpla la siguiente ley de potencias en cada punto $x$ del objeto:

$$
\lim _{r \rightarrow 0} \sum_{x_{i} \in B(x, r)} I\left(x_{i}\right) \sim r^{\alpha(x)},
$$

donde $I(x)$ es la función que a cada punto $x$ le asigna un nivel de grises (por ejemplo, 0 - 255), $B(x, r)$ representa un intervalo centrado en $x$ y diámetro $r$, y $\alpha(\boldsymbol{x})$ es el exponente de singularidad. Es habitual pintar en un mapa la localización espacial de todos los exponentes de singularidad dando lugar a los llamados "mapas de singularidades".

Como ejemplo de este tipo de objetos se muestra el multifractal de Sierpinski. Su construcción es similar a la alfombra de Sierpinski (ver fig. 1.5), conjunto fractal de dimensión fractal 1.892, descrito por primera vez en 1916 por Waclaw Sierpinski. Para la construcción del multifractal de Sierpinski se parte de un cuadrado con valor de intensidad en cada punto la unidad $(I(x, y)=1, \forall x, y \in$ $[0,1])$. En la primera iteración se crea el llamado "generador", dividiendo el cuadrado en nueve partes iguales y asignando a la pieza central el valor cero y al resto de piezas los valores $p_{i} \neq 0$ de tal forma que se cumpla:

$$
\sum_{i=1}^{9} p_{i}=1
$$

En la segunda iteración se aplica el generador (mediante la multiplicación) sobre cada pieza de la primera iteración. En la iteración $n$ se aplica el 
generador sobre cada pieza cuadrada de la iteración (n-1). En la fig. (1.6) se muestra el resultado de aplicar el generador en 5 iteraciones.

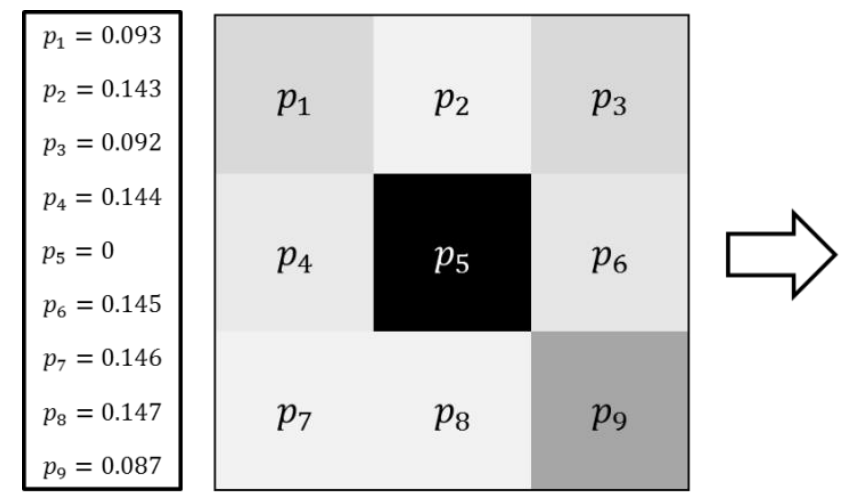

1ㅇ Iteración (generador)

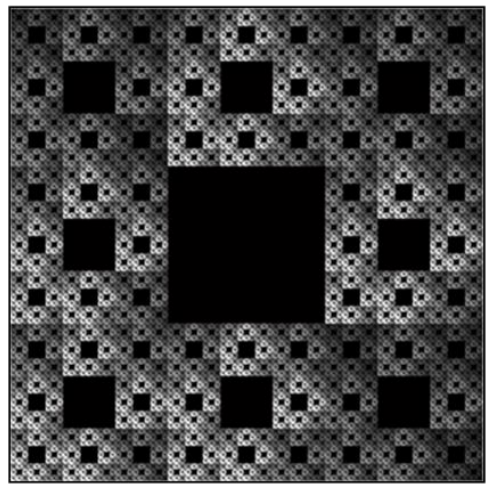

5o Iteración

Fig. 1.6 - Construcción de un multifractal de Sierpinski. Izquierda: generador y sus valores $p_{i}$. Derecha: multifractal de Sierpinski después de la $5^{a}$ iteración.

En la figura 1.7 se muestra el mapa de singularidades del multifractal de Sierpinski construido.
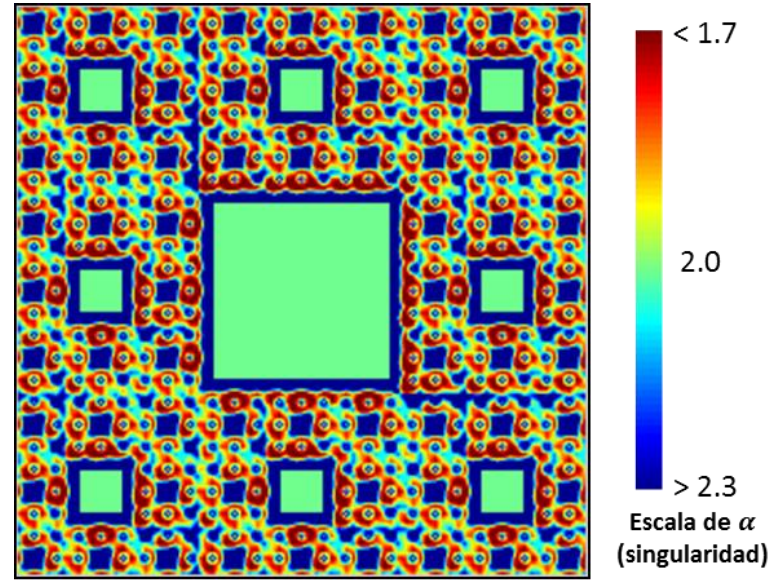

Fig. 1.7 - Mapa de singularidades del multifractal de Sierpinski.

La segunda característica particular de los multifractales es que el conjunto de exponentes de singularidad con un mismo valor a su vez forma un conjunto con dimensión fractal, es decir, aparece la propiedad de autosimilitud en la distribución de los exponentes de singularidad. Cuando se hace un análisis multifractal es bastante habitual obtener estos dos parámetros, los exponentes de singularidad y su dimensión fractal, relacionados mediante una función llamada espectro multifractal o espectro de singularidades. Para el cálculo del 
espectro multifractal normalmente se utiliza el método de los momentos junto con la transformada de Legendre (Falconer, 2003). Podemos resumir de forma intuitiva que el espectro multifractal nos da información sobre la variedad (rango de valores de los exponentes) y cantidad (cuantificado mediante su dimensión fractal) de los exponentes de singularidad. En la figura 1.8 se muestra el espectro multifractal tanto de la alfombra de Sierpinski (círculo rojo) como del multifractal de Sierpinski (curva negra). En dicha figura se aprecia claramente que la alfombra es fractal (monofractal) por tener un único valor en el espectro multifractal con $f(\alpha)=1.892$, mientras que el multifractal de Sierpinski posee un rango continuo de valores de dimensiones fractales.

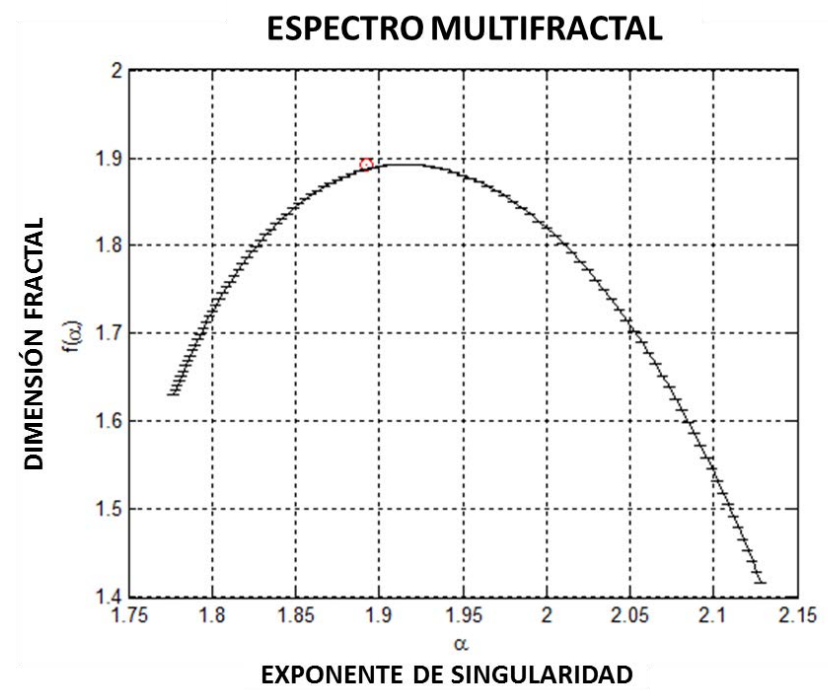

Fig. 1.8 - Espectro multifractal de la alfombra de Sierpinski (círculo rojo) y del multifractal de Sierpinski (curva negra).

Existen varias formas de abordar el análisis multifractal. A continuación se explican brevemente dos formas de realizar un análisis multifractal de una magnitud dada.

1. Desde un punto de vista métrico (teoría de la medida). Se construye una función medida $(\mu)$ de la función $I(x)$ que se va a analizar (Falconer, 2003). La función medida queda definida por la expresión:

$$
\mu(B(\boldsymbol{x}, r))=\int_{B} I(\boldsymbol{x}) d \boldsymbol{x}=\sum_{x_{i} \in B(x, r)} I\left(x_{i}\right),
$$


donde $B(\boldsymbol{x}, r)$ representa un intervalo centrado en $\boldsymbol{x}$ y diámetro $r$. La medida tendrá la propiedad multifractal si se verifica:

$$
\lim _{r \rightarrow 0} \mu(B(\boldsymbol{x}, r)) \sim r^{\alpha(x)}
$$

donde $\alpha(\boldsymbol{x})$ es el exponente de singularidad.

2. Desde un punto de vista geoestadístico (Arneodo et al., 2002). La magnitud $I(\boldsymbol{x})$ es considerada como una variable aleatoria regionalizada y la función de estructura (momentos de la semivarianza) puede tener propiedades de escalado multifractales si se verifica:

$$
\left\langle|I(\boldsymbol{x}+d)-I(\boldsymbol{x})|^{q}\right\rangle \sim d^{\xi(q)},
$$

donde $\langle>$ indica la media y $\xi(q)$ son los exponentes de la función de estructura.

Nos encontramos con multifractales en muchos ámbitos de la ciencia. Por ejemplo en física, los multifractales describen de forma satisfactoria el comportamiento de algunos fluidos turbulentos; en astronomía, la distribución espacial de las galaxias sigue una pauta multifractal; en medicina, los latidos del corazón también se pueden estudiar desde un punto de vista multifractal para detectar anomalías; en economía, las series temporales de los mercados de valores responden a dinámicas multifractales, etc.

La técnica más utilizada para la construcción de multifractales probabilísticos es la llamada "cascada multiplicativa". Esta técnica sigue un proceso iterativo en el que en cada paso se modifica una distribución densidad de probabilidad inicialmente constante. Cabe señalar que para la construcción del multifractal de Sierpinski hemos seguido esta técnica.

En la fig. 1.9 se muestra un caso especial de cascada multiplicativa denominada "binomial". Esta construcción parte de un segmento con valor de intensidad la unidad en cada punto $(I(\boldsymbol{x})=1, \forall x \in[0,1])$. En la primera iteración se crea el llamado "generador", dividiendo el segmento en dos partes 
iguales (piezas) y asignando a las piezas los valores $p_{i} \neq 0\left(p_{1}=2 / 3, p_{2}=1 / 3\right.$ en el caso de la fig. 1.9), de tal forma que se cumpla:

$$
\sum_{i=1}^{2} p_{i}=1
$$

En la segunda iteración se aplica el generador sobre cada una de las piezas de la primera iteración, es decir, se aplican los pesos $\left(p_{1}, p_{2}\right)$ a cada una de las piezas de la primera iteración resultando dos nuevas piezas. Podemos aleatorizar el multifractal permitiendo que el generador tome valores $\left(p_{1}, p_{2}\right)$ o $\left(p_{2}, p_{1}\right)$ en cada iteración. En la iteración $\mathrm{n}$ se aplica el generador sobre cada pieza de la iteración ( $n-1)$. Así, en la iteración $n$ tendremos $2^{n}$ piezas con una distribución cada vez más "enmarañada", hasta el punto de convertirse en una distribución multifractal.

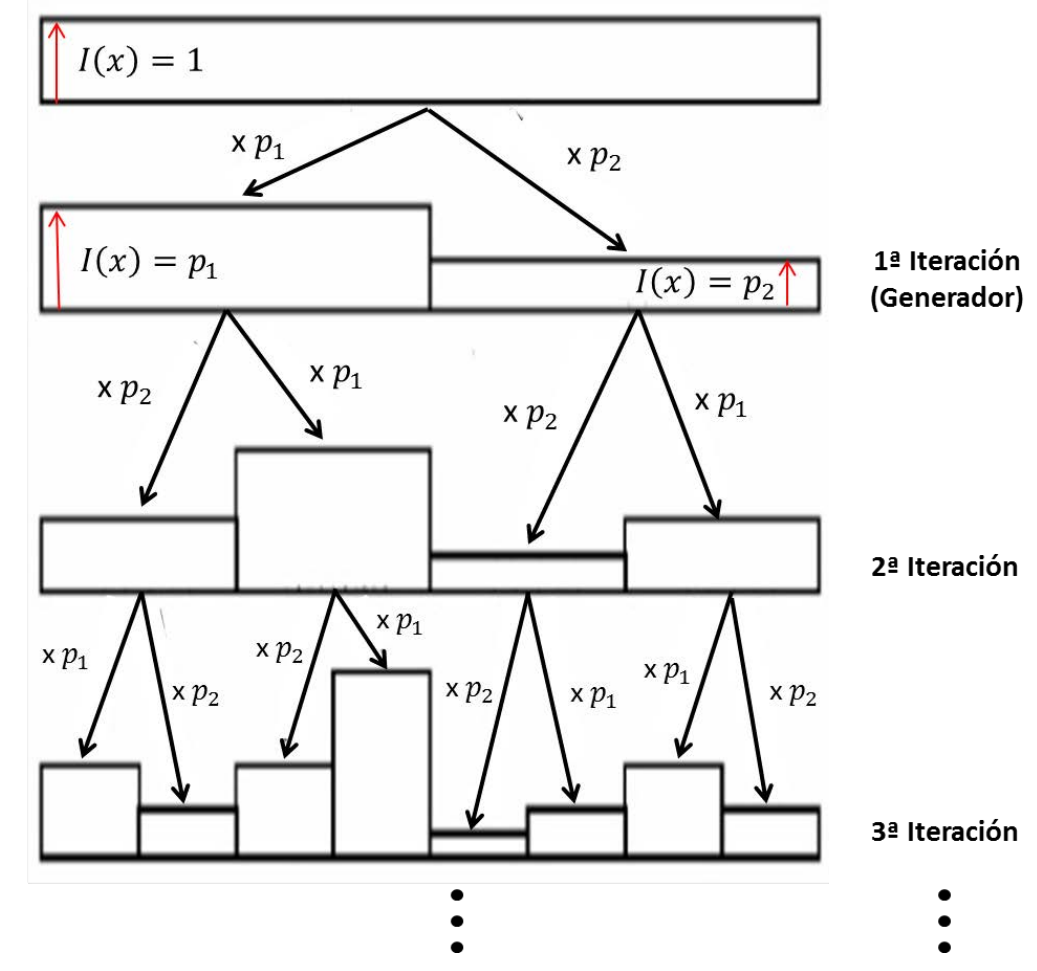

Fig. 1.9 - Ejemplo de cascada multiplicativa binomial aleatoria $\left(p_{1}=2 / 3, p_{2}=1 / 3\right)$ hasta la $3^{\mathrm{a}}$ iteración aplicada a una distribución de probabilidad constante.

Las propiedades emergentes de un sistema complejo en algunas ocasiones tienen características de tipo fractal o multifractal. Esto significa que estos sistemas pueden generar algún objeto físico de tipo fractal cuasi-determinista o aleatorio en un determinado rango de escalas, o que los procesos que 
describen dichos sistemas pueden tener medidas estadísticas invariantes ante un cambio de escala, también en un rango determinado. Estas estructuras, muy frecuentes en la Naturaleza, pueden ser capturadas mediante imágenes digitales.

\subsubsection{Fractales en la Naturaleza}

Los procesos que se dan en la Naturaleza como los geológicos, biológicos, climáticos, etc., son claros ejemplos de sistemas complejos en los que se ha comprobado que aparecen propiedades emergentes de tipo fractal o multifractal. Ejemplos de fractales en la Naturaleza, también denominados prefractales, los podemos encontrar en formaciones vegetales como los helechos, el brócoli (ver fig. 1.10), la distribución de las ramas en los árboles, etc.; en animales como la concha de algunos moluscos, el sistema circulatorio y respiratorio (ver fig. 1.10), etc. Ejemplos de multifractales en la Naturaleza los podemos encontrar en procesos tales como: formación de nubes (ver fig. 1.10), precipitaciones, huracanes, avalanchas de tierra, terremotos, etc. (Schertzer and Lovejoy, 1987; Scheuring and Riedi, 1994; Turcotte, 1997; Veneziano, 2002; Sornette, 2004; Malamud et al., 2004; Saravia et al., 2012).
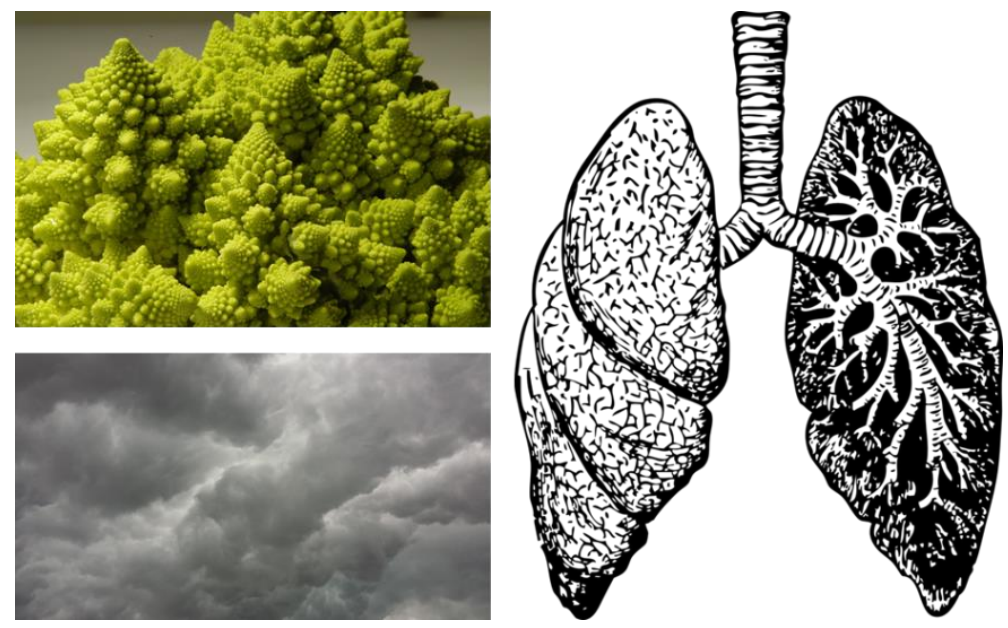

Fig. 1.10 - Ejemplos de estructuras fractales y multifractales en la Naturaleza. Arriba Izquierda: brócoli romanesco (fractal). Abajo Izquierda: nubes (multifractal). Derecha: sistema respiratorio humano (fractal). (Fuente: Pixabay.com) 
De los dos procesos de la Naturaleza sobre los que versa esta tesis se han realizado numerosos estudios donde se buscan variables que satisfagan comportamientos de tipo fractal/multifractal. En ambos casos, se utilizan imágenes digitales como punto de partida del análisis.

\subsubsection{Propiedades multifractales en mapas de NDVI}

Se han realizado numerosos estudios para verificar si existen comportamientos de tipo multifractal en imágenes satelitales de IV. Los trabajos de Poveda y Salazar (2004), Alonso et al. (2005, 2007 y 2008) y Lovejoy et al. (2008) han mostrado que mapas de IV, tales como el NDVI, tienen características multifractales en un rango determinado de escalas.

\subsubsection{Propiedades multifractales en imágenes de suelos}

Para el estudio de la estructura interna del suelo se están utilizando cada vez con más frecuencia imágenes del tipo TAC, principalmente por las ventajas de no alterar la estructura interna del suelo y de disponer de información en 3D.

De las TAC de suelos se han obtenido sus espectros multifractales tanto para las imágenes en escala de grises como para las imágenes binarizadas mediante algún método de segmentación (espacio de poros). De estos estudios se desprende que la estructura interna de un suelo posee características de tipo multifractal en un determinado rango de escalas (Grau et al., 2006; Bird et al., 2006; Tarquis et al., 2009, 2012; Piñuela et al., 2010; Zhou et al., 2011; González-Torre et al., 2016, 2017). En cambio para las imágenes binarizadas se concluye que para escalas muy pequeñas el comportamiento multifractal desaparece. En trabajos como el de Kravchenko et al. (2009) y Dathe et al. (2006) se concluye que aunque las imágenes binarizadas de suelos no sean multifractales en el sentido matemáticamente estricto, el formalismo multifractal puede generar "pseudo-espectros multifractales" en un rango de escalas que nos puede ayudar a caracterizar el espacio de poros. También existen trabajos 
(Tarquis et al., 2008) donde se analiza la influencia de la umbralización en el cálculo de los parámetros del análisis multifractal.

\subsubsection{Segmentación basada en las propiedades fractales del mapa de singularidades}

Uno de los primeros trabajos en utilizar un enfoque multifractal en el contexto de la segmentación fueron realizados por Agterberg et al. (1993) y Cheng et al. (1994). Estos trabajos se encontraban en el ámbito de la exploración de elementos químicos y el objetivo era detectar zonas candidatas a ser yacimientos minerales. Inicialmente se trabajaba con mapas de concentración de elementos químicos, como oro, plata, arsénico, plomo o cobre, y sobre estos mapas se aplicaba el método de segmentación de Concentración-Área (CA). Este método consiste en ir calculando el área acumulada que ocupa un determinado elemento químico para distintos valores de concentración. Al dibujar en un gráfico log-log el área acumulada respecto a la variable concentración aparecen tramos lineales, lo cual significa que para un determinado rango de concentraciones aparecen relaciones en leyes de potencias (ver fig. 1.11).

\begin{tabular}{|c|}
\hline $\begin{array}{c}\text { ÁREA ACUMULADA DE LA } \\
\text { CONCENTRACIÓN } \mathrm{c}(\boldsymbol{x})\end{array}$ \\
\hline \hline $\operatorname{Area}(c(\boldsymbol{x}) \geq K) \propto K^{\beta_{i}}$ \\
\hline $\log ($ Area $)=\beta_{i} \log K+$ cte \\
\hline
\end{tabular}

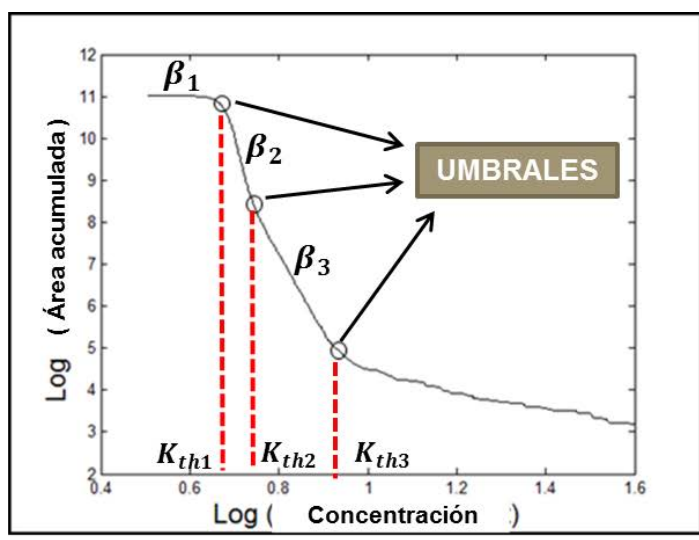

Fig. 1.11 - Izquierda: método CA donde $c(x)$ representa la concentración de un elemento químico. Derecha: ejemplo de gráfica en escala log-log del método CA. Las distintas pendientes corresponden a los valores de $\beta_{1}, \beta_{2} y \beta_{3}$. Los puntos de cambio de pendiente corresponden a los valores de concentración $\mathrm{K}_{\mathrm{th} 1}, \mathrm{~K}_{\mathrm{th} 2} \mathrm{y} \mathrm{K}_{\mathrm{th} 3}$. 
Los procesos con propiedades autosimilares generalmente muestran relaciones de leyes de potencias en alguna de sus variables, por tanto este método de segmentación consigue poner de manifiesto estas propiedades en sistemas con distribuciones espaciales complejas. Los umbrales de segmentación en el método CA están localizados en los valores de la concentración donde los tramos lineales cambiaban de pendiente, es decir, el cambio de pendiente delimita zonas con propiedades autosimilares distintas (valores $K_{t h 1}, K_{t h 2} y K_{t h 3}$ en la fig. 1.11). Existe una versión del método en 3D denominado método de Concentración-Volumen (CV) donde se remplaza el concepto de área por el de volumen (Afzal et al., 2011).

En una segunda etapa los mapas de concentración fueron sustituidos por mapas de singularidades, ya que estos últimos presentan dos grandes ventajas:

a) Amplifican los valores anómalos de las concentraciones locales ya que actúan como un filtro paso-alto (Liu et al., 2013).

b) Establecen una preclasificación de las zonas de concentración en función del valor que toma el exponente de singularidad en cada localización.

Los mapas de singularidad de concentraciones minerales pueden ser interpretados de dos formas diferentes:

1. La primera interpretación se basa en el enfoque métrico del análisis multifractal (ver expresión 1.8). Cuando calculamos los exponentes de singularidad de mapas de concentración $c(x)$ en 2D obtenemos la mayoría de los valores en el entorno de $\alpha(\boldsymbol{x})=2$, es decir,

$$
\mu(B(\boldsymbol{x}, r))=\lim _{r \rightarrow 0} \int_{B} c(\boldsymbol{x}) d \boldsymbol{x} \sim r^{2}=k r^{2},
$$

donde $B(\boldsymbol{x}, r)$ es un entorno centrado en la localización $\boldsymbol{x}=(x, y)$ y radio $r$, y $\mu(B(\boldsymbol{x}, r))$ representa la cantidad de un elemento químico en dicho entorno. Para obtener la concentración media $C_{m}$ dividimos la expresión 
1.11 entre $r^{E}$ (donde $E$ es la dimensión topológica, en este caso $E=2$ ), obteniendo la expresión:

$$
C_{m}(B(\boldsymbol{x}, r))=\frac{\mu(B(\boldsymbol{x}, r))}{r^{E}}=\frac{k r^{2}}{r^{2}}=k
$$

Por tanto, las localizaciones con $\alpha(\boldsymbol{x})=2$ representan localizaciones con concentraciones medias constantes $(k)$ y se suelen denominar localizaciones "no singulares".

En Cheng $(2001 ; 2007)$ las localizaciones con $\alpha(\boldsymbol{x}) \neq 2$ se denominan localizaciones "singulares" y se distingue entre las localizaciones con singularidades positivas, con $\alpha(\boldsymbol{x})<2$, donde el valor de la concentración media $C_{m}(B(\boldsymbol{x}, r))$ tiende a infinito cuando $r \rightarrow 0$, y por tanto corresponden a localizaciones con un anormal aumento en la concentración (ver fig. 1.12):

$$
\alpha(x)<2 \quad C_{m}(B(x, r))=\frac{k r^{\alpha(x)}}{r^{2}}=k r^{\alpha(x)-2} \rightarrow \infty
$$

y las localizaciones con singularidades negativas, con $\alpha(\boldsymbol{x})>2$, donde el valor de la concentración media tiende a cero cuando $r \rightarrow 0$, y por tanto corresponden a localizaciones con una anormal disminución en la concentración (ver fig. 1.12):

$$
\alpha(\boldsymbol{x})>2 \quad C_{m}(B(\boldsymbol{x}, r))=\frac{k r^{\alpha(x)}}{r^{2}}=k r^{\alpha(\boldsymbol{x})-2} \rightarrow 0 .
$$

Para calcular el umbral de segmentación que identifica las zonas de alta probabilidad de encontrar altas concentraciones de mineral se utiliza el método CA aplicado al mapa de singularidades. El método CA identifica tramos lineales en el gráfico log-log de la distribución acumulada de exponentes de singularidad, con un valor de cambio de pendiente que es el utilizado como umbral. 


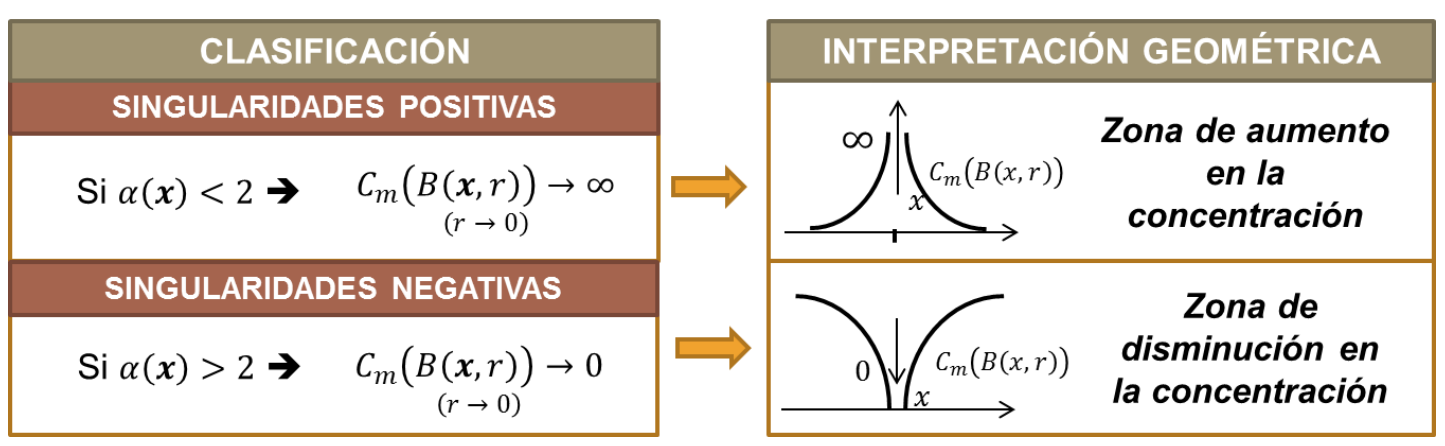

Fig. 1.12 - Interpretación geométrica de las singularidades positivas y negativas.

2. La segunda interpretación se basa en un enfoque de tipo geoestadístico, donde el mapa de concentraciones se considera como una variable aleatoria regionalizada continua $c(\boldsymbol{x})$. El valor de la concentración en cada punto $\boldsymbol{x}=(x, y)$ se corresponde con una realización de la variable aleatoria regionalizada. Cuando esta variable representa a procesos con propiedades multifractales (verificando la expresión 1.8), las distribuciones estadísticas en cada punto pueden ser descritas por distribuciones de tipo Pareto o de valores extremos. Por tanto el análisis multifractal tiene mucho sentido en procesos donde los valores extremos o anómalos son importantes (Lavallee et al., 1993; Cheng et al., 1994; Cheng and Agterberg, 1996; Agterberg, 1995). A través de los exponentes de singularidad podemos identificar las zonas de la variable regionalizada donde las distribuciones son de tipo normal o log-normal (localizaciones no singulares con $\alpha(\boldsymbol{x}) \sim E$ ), y donde las distribuciones son de tipo Pareto (localizaciones singulares con $\alpha(\boldsymbol{x}) \neq E$ ), donde $E$ es la dimensión topológica de la imagen, es decir, $E=2$ para un mapa en 2D (Cheng, 2007; Cheng, 2008). La mayoría de las técnicas estadísticas que requieren una suposición de normalidad (Journel \& Huijbregts, 1978) en la variable de estudio no son adecuadas para estudiar procesos donde aparecen distribuciones de tipo Pareto o de valores extremos, tal como sucede en los procesos multifractales. 


\subsection{OBJETIVOS DE LA TESIS}

A lo largo de esta introducción hemos expuesto que muchos procesos con origen en la Naturaleza poseen propiedades de tipo fractal y/o multifractal. En numerosos estudios de la distribución espacial de la sequía y la estructura interna del suelo, a través de mapas de NDVI y TAC de suelos, se ha comprobado que aparecen propiedades de tipo multifractal. Estas propiedades tan especiales nos hace plantearnos si podríamos aprovechar esta peculiaridad para realizar una segmentación alternativa a las tradicionales. En el apartado 1.4 de esta introducción ya se ha presentado una técnica de segmentación basada en propiedades fractales en el ámbito de la detección de yacimientos minerales.

El objetivo principal de esta tesis será la extrapolación y adaptación de la metodología expuesta en los trabajos de Cheng et al. (1994) a los mapas de NDVI y las TAC de suelos, y la validación de los resultados obtenidos.

El objetivo de esta tesis se puede desglosar en los siguientes puntos:

1. Delimitación de regiones homogéneas, con estadísticas gaussianas, en mapas de NDVI aplicando el método de segmentación "Singularidad-CA" (S-CA).

2. Delimitación del espacio de poros en TAC de suelos aplicando el método de segmentación S-CA en la versión 2D y "Singularidad-CV" (S-CV) en la versión 3D.

3. Evaluación y validación del método de segmentación S-CA y S-CV aplicado a TAC de suelos.

4. Mejora del método S-CA. Definición y evaluación del método de segmentación "S-CA Combinado" para la delimitación del espacio de poros en TAC (versión 2D).

Para la consecución de los puntos 3 y 4 es necesario disponer de medidas objetivas de parámetros tales como la porosidad total o las distribuciones de tamaño de poros de las muestras de suelo analizadas. Ante la dificultad de obtener dichas medidas nos planteamos el reto de construir nuestras propias 
imágenes sintéticas de suelo. De este esfuerzo surgió nuestro último objetivo para esta tesis.

5. Definición de un nuevo método para crear imágenes sintéticas de suelo. Este nuevo método lo hemos llamado: el método de los "Multifractales Truncados" (MT) y se implementa en la versión 2D y 3D.

A continuación se detallan los capítulos que se han elaborado para atender con los objetivos planteados:

- Capítulo 3. Mapas de singularidad aplicados a Índices de Vegetación.

- Este capítulo recoge los resultados obtenidos en el artículo MartínSotoca et al. (2017c).

- Objetivos abordados: 1).

- Capítulo 4. Nuevo método de segmentación basado en las propiedades fractales del mapa de singularidades en imágenes de suelos.

- Este capítulo recoge los resultados obtenidos en el artículo MartínSotoca et al. (2017a).

- Objetivos abordados: 2), 3) y 5) en la versión 2D.

- Capítulo 5. Segmentación local en 3D basada en las propiedades fractales del mapa de singularidades en imágenes de suelos.

- Este capítulo recoge los resultados obtenidos en el artículo MartínSotoca et al. (2016).

- Objetivos abordados: 2), 3) y 5) en la versión 3D.

- Capítulo 6. Combinación de métodos de segmentación globales y de escalamiento local para detectar el espacio de poros en imágenes de suelos.

- Este capítulo recoge los resultados obtenidos en el artículo MartínSotoca et al. (2017b).

- Objetivos abordados: 4) en la versión 2D. 


\section{CAPÍTULO 2}

\section{MÉTODOS}




\subsection{EL MÉTODO SINGULARIDAD-CA}

\subsubsection{El enfoque Singularidad-CA}

El método S-CA está basado principalmente en la existencia de propiedades autosimilares en los mapas de singularidades de las imágenes digitales en $2 \mathrm{D}$ objeto de estudio. Cuando calculamos las distribuciones acumuladas de los valores de singularidad de estas imágenes usando el método CA, estas autosimilitudes se ponen de manifiesto mediante tramos lineales (relaciones de leyes de potencias) en un gráfico con escala log-log. Las diferentes pendientes que aparecen en el gráfico revelan la existencia de diferentes conjuntos con propiedades autosimilares, y los puntos de cambio de pendiente nos ofrecen la posibilidad de definir umbrales en los subconjuntos que han aparecido (MartínSotoca et al., 2017a; 2017c).

\subsubsection{Implementación del método Singularidad-CA}

La implementación del método S-CA fue realizada usando MATLAB ${ }^{\text {TM }}$ R2013a. A continuación se detallan los pasos a seguir:

i) El primer paso consiste en obtener el mapa de singularidades de la imagen digital tipo ráster $I_{k}=I(x, y)$. Para ello, utilizamos la interpretación métrica del análisis multifractal donde definimos una medida $\mu$ sobre la imagen digital. La definición más sencilla de medida para un conjunto cuadrado $S(\boldsymbol{x}, r)$ centrado en el pixel $\boldsymbol{x}$ y lado $r$ píxeles es:

$$
\mu(S(\boldsymbol{x}, r))=\sum_{k \in S(x, r)} I_{k},
$$

donde $I_{k}$ es la intensidad del pixel $k$. La intensidad de cada píxel toma valores entre 0 y $I_{\max }$ (por ejemplo entre 0 y 255 ).

Utilizamos el método de enventanado (Cheng, 2001) para obtener los exponentes de singularidad de la imagen. Usando una ventana deslizante (por ejemplo cuadrada) de lado variable $r_{\min }=r_{1}<r_{2}<\cdots<r_{n}=r_{\max }$, aplicamos la siguiente expresión: 


$$
\alpha(x)=\lim _{r \rightarrow r_{\min }} \frac{\ln \mu(S(x, r))}{\ln r},
$$

donde el lado $r$ de la ventana deslizante es siempre un número impar entero de píxeles y el mínimo valor es $r_{\min }=1$. Dependiendo de los valores $r_{\min }$ y $r_{\text {max }}$ elegidos tendremos a nuestra disposición más o menos valores para calcular la pendiente $\alpha(x)$ utilizando el método de regresión lineal de mínimos cuadrados. En la Fig. 2.1 se muestran los valores de $r_{\min }$ y $r_{\max }$ utilizados para los dos tipos de imágenes analizadas.

$$
r_{\min }=3<\cdots<19=r_{\max }
$$

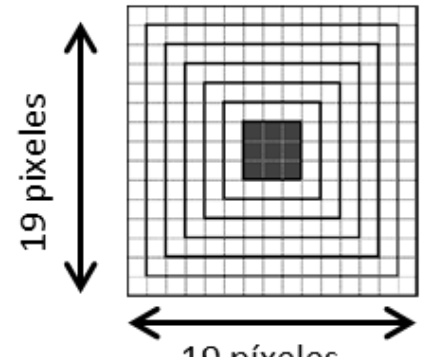

19 píxeles

$$
r_{\min }=3<\cdots<15=r_{\max }
$$

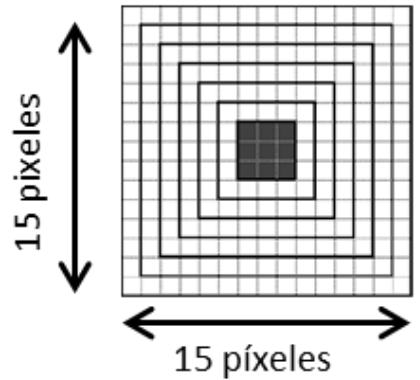

Fig. 2.1 - Izquierda: ventana deslizante utilizada en los mapas satelitales de NDVI. Derecha: ventana deslizante utilizada en las TAC de suelos.

Dependiendo del tipo de imágenes digitales que vayamos a analizar utilizamos las dos interpretaciones existentes del mapa de singularidades planteadas en los trabajos de Cheng (2001 y 2008). Se presentan los siguientes casos:

a) Para los mapas satelitales de NDVI utilizamos la interpretación geoestadística en la que los mapas de singularidades quedan clasificados en dos zonas estadísticamente diferentes: las zonas con $\alpha(\boldsymbol{x}) \sim 2$, donde domina la estadística de tipo normal o log-normal, y las zonas con $\alpha(\boldsymbol{x}) \neq 2$, donde domina la estadística de tipo Pareto. Puesto que el objetivo se ha establecido en la búsqueda y delimitación de zonas homogéneas con estadística gaussiana, la zona del mapa de 
singularidades que nos interesa será aquella con $\alpha(\boldsymbol{x}) \sim 2$ (zonas no singulares).

b) Para las TAC de suelos utilizamos la interpretación métrica donde los mapas nos dan información sobre dos áreas bien diferenciadas: las zonas con $\alpha(\boldsymbol{x})<2$, que definen áreas con un aumento de la concentración media, y las zonas con $\alpha(\boldsymbol{x})>2$, con una disminución de la concentración media. Ya que el objetivo se ha establecido en la búsqueda y delimitación del espacio de poros, la zona del mapa de singularidades que nos interesa será aquella con $\alpha(\boldsymbol{x})>2$.

ii) En el segundo paso se calculan los umbrales que delimitan las zonas buscadas del mapa de singularidades para los dos tipos de imágenes. El método utilizado para el cálculo de umbrales es el método CA por tener ambas imágenes propiedades autosimilares. La aplicación de este método consiste en calcular el área que ocupan los valores $\alpha(x)$ mayores que un valor dado C mediante la expresión:

$$
\text { Área }(\alpha \geq C)=N \text { o de píxeles }(\alpha \geq C)
$$

Cuando representamos esta función en un gráfico log-log aparecen tramos lineales con sus respectivos puntos de cambio de pendiente. Dependiendo del tipo de imagen procederemos de diferente forma:

a) En los mapas satelitales de NDVI necesitamos dos umbrales que delimiten los valores de $\alpha$ en las cercanías de 2 , es decir, buscamos un entorno $\left[\alpha_{\text {Tmin }}, \alpha_{\text {Tmax }}\right]$ de $\alpha=2$. Para calcular el valor del umbral inferior $\alpha_{\text {Tmin }}$ utilizamos la expresión 2.3 mientras que para calcular el umbral superior $\alpha_{T \max }$ utilizamos la expresión complementaria:

$$
\text { Área }(\alpha<C)=N^{\circ} \text { de píxeles }(\alpha<C)
$$


b) En las TAC de suelos necesitamos un único valor umbral $\alpha_{t h}$ de segmentación en la zona $\alpha(\boldsymbol{x})>2$, es decir, buscamos los valores de $\alpha(\boldsymbol{x})>\alpha_{t h}$. Para calcular el valor de este umbral $\alpha_{t h}$ utilizamos la expresión 2.3.

Para encontrar con exactitud el valor de los puntos de cambio $\alpha_{T \min }, \alpha_{T \max }$ y $\alpha_{t h}$ utilizamos los métodos planteados en el siguiente paso.

iii) En el tercer paso se calculan los valores de los puntos de cambio de pendiente de las distribuciones acumuladas obtenidas mediante el método CA. Utilizamos diferentes métodos dependiendo del tipo de imágenes analizadas:

a) En los mapas satelitales de NDVI utilizamos el método de regresión lineal utilizado en los trabajos de Cheng et al. (1994). Para los tramos lineales se realiza un ajuste por mínimos cuadrados, de tal forma que la intersección de las regresiones lineales constituye el punto buscado. En la Fig. 2.2 se muestra un ejemplo procedente de Martín-Sotoca et al. (2017c) donde se obtienen los umbrales inferior $\alpha_{T \min }$ y superior $\alpha_{T \max }$ de un mapa de NDVI.

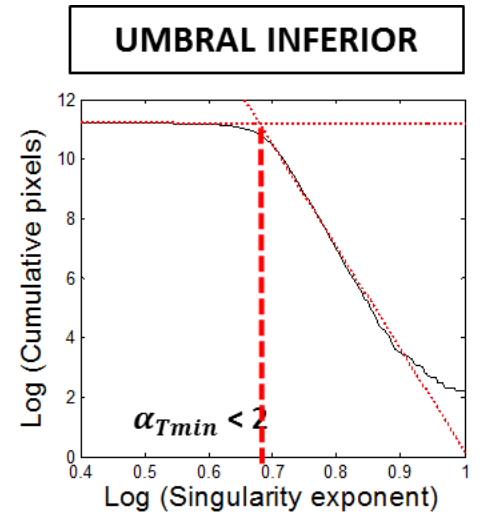

№ píxeles $(\alpha(\boldsymbol{x}) \geq C) \propto C^{\gamma_{i}}$

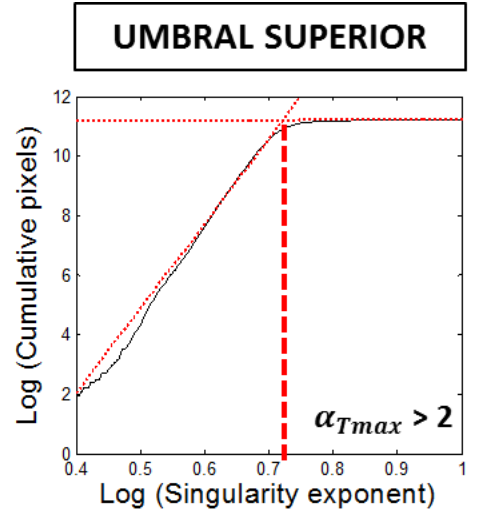

Noo píxeles $(\alpha(\boldsymbol{x})<C) \propto C^{\tau_{i}}$

Fig. 2.2 - Gráficos log-log resultantes de la aplicación del método CA a mapas de NDVI. Los puntos de cambio de pendiente han sido calculados mediante el método de regresión lineal por mínimos cuadrados. Fuente: Martín-Sotoca et al. (2017c). 
b) En las TAC de suelos utilizamos el método de la Transformada Wavelet Módulo Máximo (TWMM). Una de las ventajas de esta transformación es la de detectar puntos "especiales" en una función $f(x)$. Si utilizamos una wavelet de segundo momento nulo (ver apéndice A), como por ejemplo la denominada "sombrero Mejicano", la TWMM detecta con precisión los puntos de $f(\alpha)$ de máxima curvatura. En el caso concreto que estamos tratando, aplicamos la transformada wavelet sobre la distribución acumulada de valores de singularidad:

$$
f(x)=f(\alpha)=\text { Área }(\alpha \geq C)
$$

En la Fig. 2.3 se muestra un ejemplo de la aplicación de la TWMM a una distribución acumulada de una TAC de suelo. En la transformada (gráfico inferior de la Fig. 2.3) se puede ver como el módulo máximo converge hacia los puntos de máxima curvatura de la función Área $\alpha \geq$ $C$ ) a medida que disminuimos la escala (scale parameter) de la wavelet.

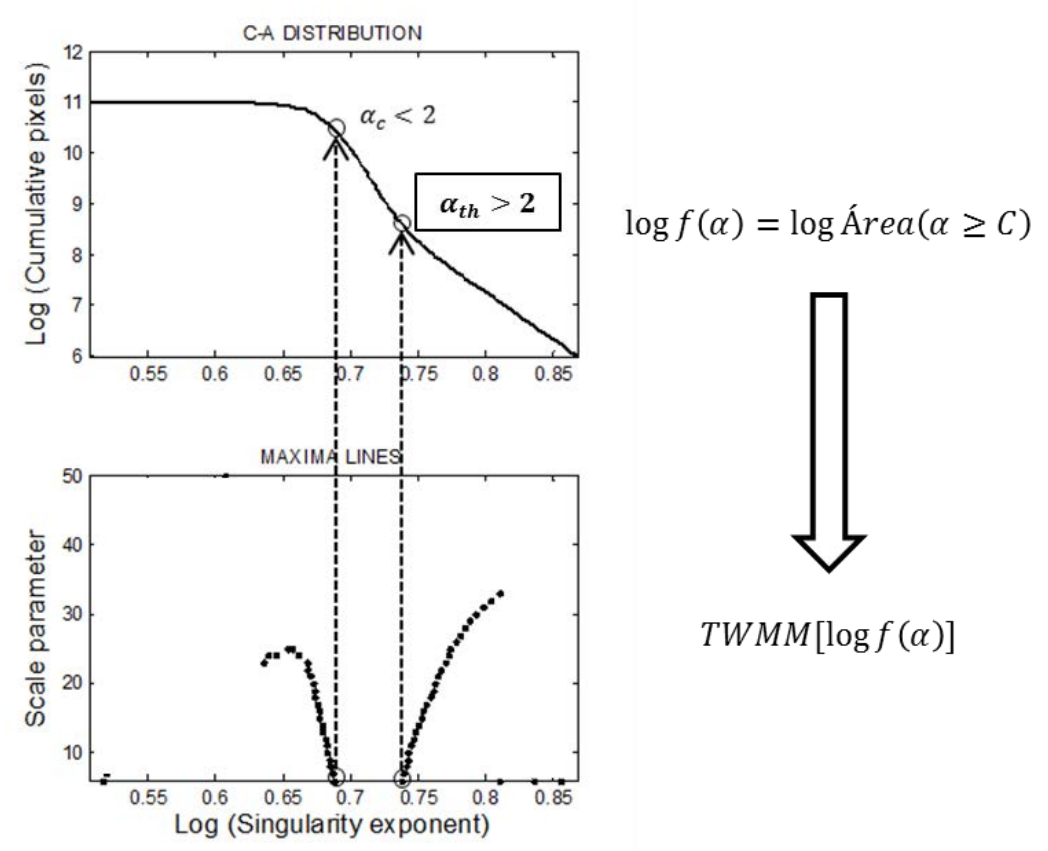

Fig. 2.3 - Gráfico superior: distribución acumulada Área $(\alpha \geq C)$ en escala log-log (método CA). Gráfico inferior: transformada wavelet módulo máximo en función del parámetro de escala de la wavelet. 
El umbral de segmentación buscado será aquel que se encuentre en la zona de $\alpha>2$ (zona de disminución de la concentración media) más cercano a $\alpha=2$. En la fig. 2.3 se ha recuadrado el valor $\alpha_{t h}$ que cumple con las condiciones exigidas.

\subsection{EL MÉTODO SINGULARIDAD-CV}

\subsubsection{El enfoque Singularidad-CV}

El método de S-CV es una extensión del método anteriormente expuesto a imágenes en $3 \mathrm{D}$ de suelo. Este método se basa en los mismos principios de autosimilitud que el S-CA por lo que se van a seguir los mismos pasos en su implementación (Martín-Sotoca et al., 2016).

\subsubsection{Implementación del método Singularidad-CV}

La implementación del método S-CV fue realizada usando MATLAB ${ }^{\text {TM }}$ R2013a. A continuación se detallan los pasos a seguir:

i) El primer paso consiste en obtener el mapa de singularidades de la imagen digital tipo ráster $I_{k}=I(x, y, z)$. Definimos la medida $\mu$ para un cubo $V(\boldsymbol{x}, r)$ centrado en el vóxel $\boldsymbol{x}$ y lado $r$ vóxeles:

$$
\mu(V(\boldsymbol{x}, r))=\sum_{k \in V(\boldsymbol{x}, r)} I_{k}
$$

donde $I_{k}$ es la intensidad del vóxel $k$. La intensidad de cada vóxel toma valores entre 0 y $I_{\max }$ (por ejemplo entre 0 y 255).

Igualmente utilizamos el método de enventanado (Cheng, 2001) para obtener los exponentes de singularidad de la imagen. Usando un cubo deslizante de lado variable $r_{\min }=r_{1}<r_{2}<\cdots<r_{n}=r_{\max }$, aplicamos la siguiente expresión: 


$$
\alpha(x)=\lim _{r \rightarrow r_{\text {min }}} \frac{\ln \mu(V(x, r))}{\ln r}
$$

donde el lado $r$ del cubo deslizante es siempre un número impar entero de vóxeles y el mínimo valor es $r_{\min }=1$. Dependiendo de los valores $r_{\min } \mathrm{y}$ $r_{\text {max }}$ elegidos tendremos a nuestra disposición más o menos valores para calcular la pendiente $\alpha(x)$ utilizando el método de regresión lineal de mínimos cuadrados. En la Fig. 2.4 se muestran los valores de $r_{\min }$ y $r_{\max }$ utilizados para las TAC de suelos analizadas.

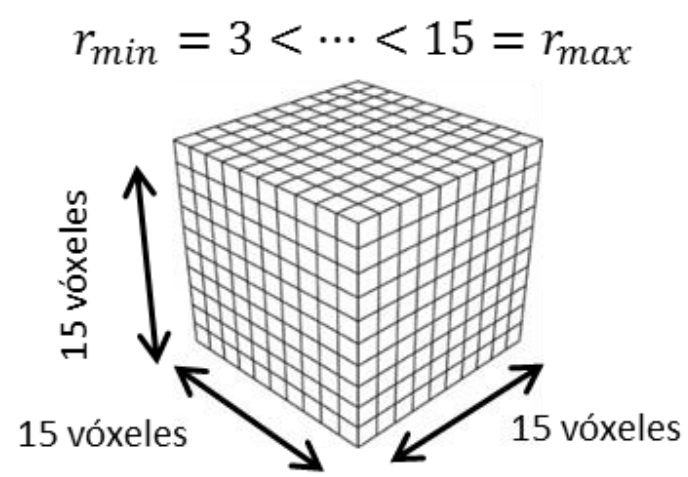

Fig. 2.4 -Cubo deslizante utilizado en las tomografías computarizadas de suelos.

Para las TAC en 3D de suelos utilizamos la interpretación métrica de los mapas de singularidades donde nos dan información sobre dos volúmenes bien diferenciadas: las zonas $\operatorname{con} \alpha(\boldsymbol{x})<3$, que definen volúmenes con un aumento de la concentración media, y las zonas con $\alpha(\boldsymbol{x})>3$, que definen volúmenes con una disminución de la concentración media. Puesto que el objetivo que se ha establecido es la búsqueda y delimitación del espacio de poros de una TAC de suelos, la zona del mapa de singularidades que nos interesa será aquella con $\alpha(\boldsymbol{x})>3$.

ii) En el segundo paso se calculan los umbrales que delimitan las zonas buscadas del mapa de singularidades. El método utilizado para el cálculo de umbrales es el método CV. La aplicación de este método consiste en 
calcular el volumen que ocupan los valores $\alpha(x)$ mayores que un valor dado C mediante la expresión:

$$
\operatorname{Volumen}(\alpha \geq C)=N^{\circ} \text { de vóxeles }(\alpha \geq C)
$$

Cuando representamos esta función en un gráfico log-log aparecen tramos lineales con sus respectivos puntos de cambio de pendiente. Al igual que en las imágenes en 2D de suelos, en las TAC de suelos necesitamos un único valor umbral $\alpha_{t h}$ de segmentación en la zona $\alpha(\boldsymbol{x})>3$, es decir, buscamos los valores de $\alpha(\boldsymbol{x})>\alpha_{t h}$. Para calcular el valor de este umbral $\alpha_{t h}$ utilizamos la expresión 2.8 .

iii) En el tercer paso se calculan los valores $\alpha$ de los puntos de cambio de pendiente de las distribuciones acumuladas obtenidas del método $\mathrm{CV}$. Al igual que para las imágenes en $2 \mathrm{D}$ de suelos utilizamos el método de la TWMM de la función $f(x)$, con la wavelet del tipo "sombrero Mejicano". Por tanto, aplicamos la transformada sobre la distribución acumulada de valores de singularidad:

$$
f(x)=f(\alpha)=\operatorname{Volumen}(\alpha \geq C)
$$

En la Fig. 2.5 se muestra un ejemplo de la aplicación de la TWMM a una distribución acumulada de valores de singularidad. En la transformada (gráfico inferior de la Fig. 2.5) se puede ver como el módulo máximo converge hacia los puntos de máxima curvatura de la función $f(\alpha)$ a medida que disminuimos la escala (scale parameter) de la wavelet. 


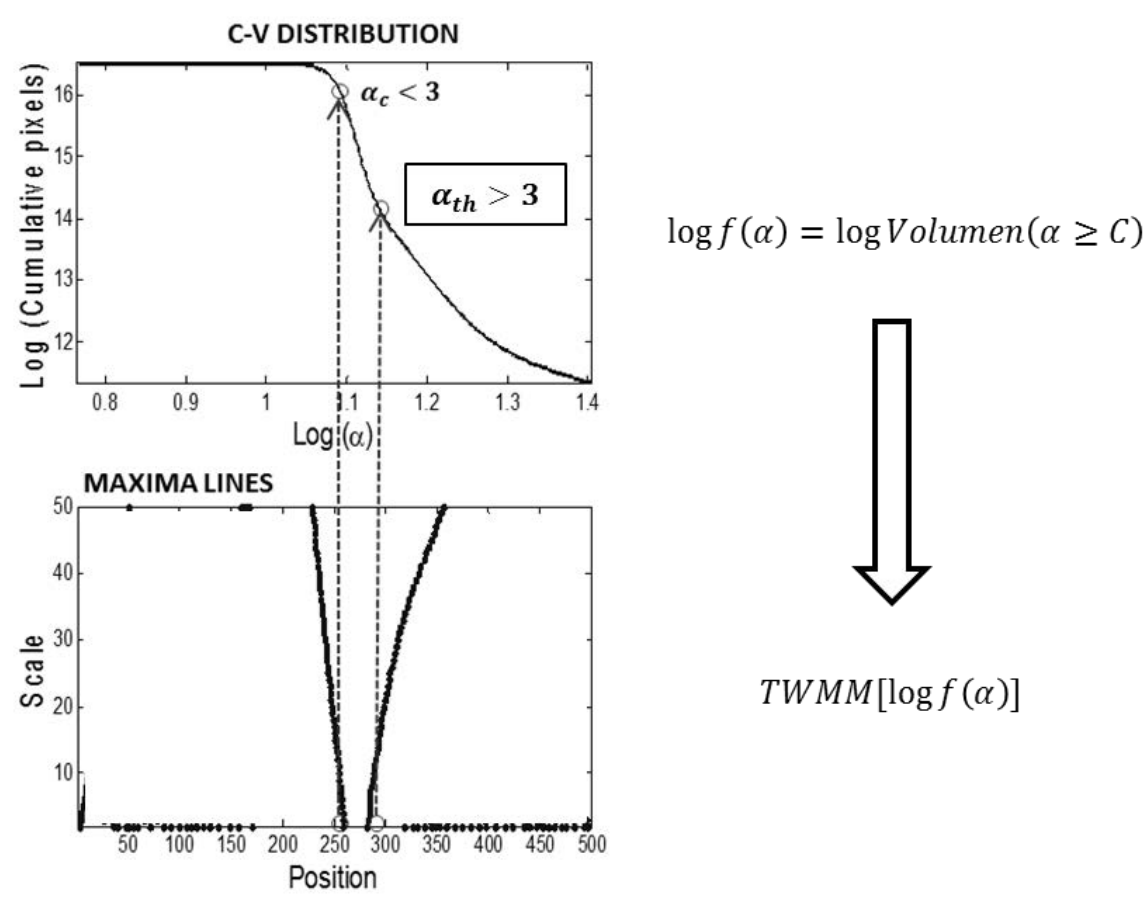

Fig. 2.5 - Gráfico superior: distribución acumulada $f(\alpha)$ en escala log-log (método CV). Gráfico inferior: transformada wavelet módulo máximo en función de la escala de la wavelet.

El umbral de segmentación buscado será aquel que se encuentre en la zona de $\alpha>3$ (zona de disminución de la concentración media) más cercano a $\alpha=3$. En la Fig. 2.5 se ha recuadrado el valor $\alpha_{t h}$ que cumple con las condiciones exigidas

\subsection{EL MÉTODO SINGULARIDAD-CA COMBINADO}

\subsubsection{El enfoque Singularidad-CA Combinado}

El método S-CA Combinado es una mejora del método S-CA con aplicación a TAC en 2D de suelos. El principal inconveniente del método S-CA es la detección errónea de poros de pequeño tamaño debido a la gran sensibilidad del método a las pequeñas fluctuaciones de intensidad de la imagen digital. 
El nuevo método combina el espacio de poros obtenido por un método de segmentación global con el obtenido por el método de segmentación local SCA (Martín-Sotoca et al., 2017b).

Al método de segmentación global se le pide que cumpla con las siguientes condiciones:

a) Tiene que sobrestimar el tamaño de los poros medianos y grandes.

b) Tiene que ser poco sensible a las fluctuaciones de intensidad de la imagen digital.

Gracias a la condición a) el nuevo método combinado no modifica los poros de mediano y gran tamaño detectados por el S-CA, y gracias a la condición b) los pequeños poros incorrectamente detectados son eliminados por el método global.

El método global seleccionado para combinarlo con el S-CA es el método de Máxima Entropía. Las pruebas realizadas con el método Otsu también ofrecieron resultados aceptables ya que este método también satisface las condiciones a) y b). Sin embargo, el método de Máxima Entropía fue elegido por sobrestimar en más cuantía los poros de mediano y gran tamaño.

\subsubsection{Implementación del método Singularidad-CA Combinado}

La implementación de este método fue realizada usando MATLAB ${ }^{\text {TM }}$ R2013a. A continuación se detallan los pasos a seguir:

i) El primer paso consiste en obtener los espacios de poros de una TAC de suelo en 2D mediante el método S-CA (ver sección 2.1.2) y mediante el método de Máxima Entropía (ver sección 2.4.2).

ii) El segundo paso consiste en la combinación de ambos espacios de poros mediante el operador lógico " $Y$ ". De manera equivalente, podemos decir que estamos aplicando una máscara (espacio de poros detectado por el método de Máxima Entropía) al espacio de poros detectado por el método S-CA. Un ejemplo de este procedimiento se muestra en la Fig. 2.6. 


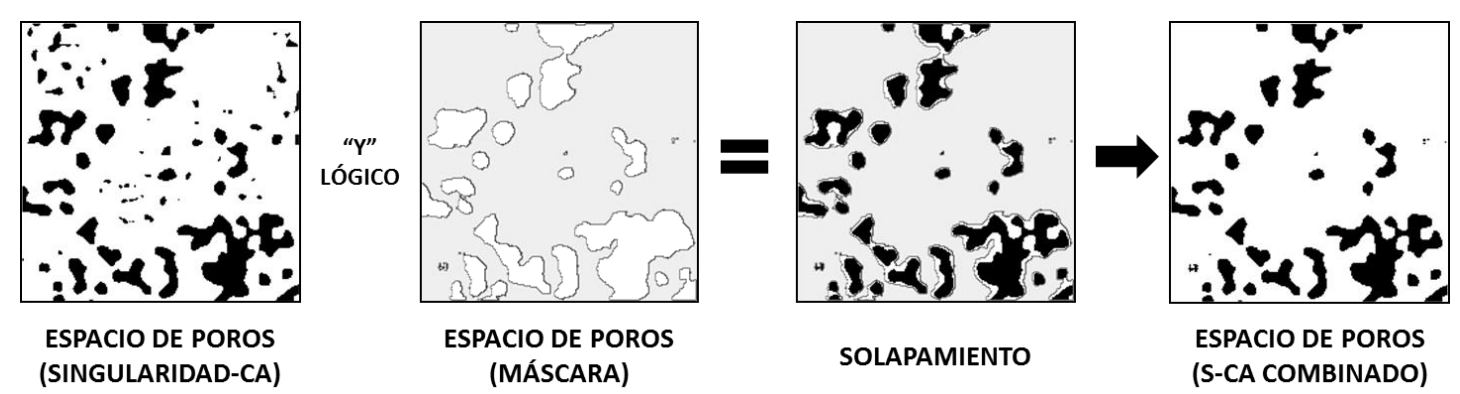

Fig. 2.6 - De izquierda a derecha: 1) espacio de poros detectado por el método S-CA, 2) espacio de poros detectado por un método global interpretado como una máscara (en este caso, el método de Máxima Entropía), 3) solapamiento de ambos espacios, y 4) espacio de poros detectado por el método S-CA Combinado.

\subsection{PRINCIPALES MÉTODOS DE BINARIZACIÓN GLOBALES APLICADOS A IMÁGENES DE SUELOS. CRITERIO DE COMPARACIÓN.}

\subsubsection{El método Otsu}

El método Otsu es un método de umbralización (Otsu, 1979) basado en la clasificación o agrupamiento de píxeles (clustering) y que asume la existencia de dos clases de píxeles (histogramas bimodales). Estas dos clases son generalmente conocidas por el nombre de "fondo" y "objeto". El objetivo de este método es encontrar un umbral óptimo en los VG de la imagen que minimice la varianza intra-clase $\sigma_{\text {intra }}^{2}$, definida como:

$$
\sigma_{\text {intra }}^{2}=\omega_{f} \sigma_{f}^{2}+\omega_{o} \sigma_{o}^{2}
$$

donde $\left(\omega_{f}, \omega_{o}\right)$ and $\left(\sigma_{f}^{2}, \sigma_{o}^{2}\right)$ son los pesos y las varianzas de las clases fondo y objeto respectivamente. De forma equivalente, se puede seguir la estrategia de maximizar la varianza "entre-clases" $\sigma_{\text {entre }}^{2}$, que es computacionalmente más eficiente, definida como: 


$$
\sigma_{\text {entre }}^{2}=\omega_{f} \omega_{o}\left(\mu_{f}-\mu_{o}\right)^{2},
$$

donde $\left(\omega_{f}, \omega_{o}\right)$ and $\left(\mu_{f}, \mu_{o}\right)$ son respectivamente los pesos y las medias de cada clase.

Este método dispone de funciones ya existentes en MATLAB ${ }^{\text {TM }}$ R2013a.

\subsubsection{El método de Máxima Entropía}

El método de Máxima Entropía es un método de umbralización que utiliza la entropía de la distribución de los VG de la imagen para obtener un umbral óptimo (Kapur et al., 1985). Este método no asume inicialmente la existencia de dos clases, por lo que puede ser utilizado para distribuciones que no sean bimodales. Normalmente se busca segmentar la imagen en dos clases (fondo y objeto) por lo que, a continuación, se presenta este método en su versión de dos clases. El método de Máxima Entropía busca la maximización de la entropía total de las dos clases de píxeles. Se define la entropía total $H_{T}$ como la suma de las entropías de cada una de las clases:

$$
H_{T}(z)=H_{f}(z)+H_{o}(z),
$$

donde $H_{f}(z)$ y $H_{o}(z)$ son las entropías de cada clase (fondo y objeto, respectivamente), definidas como:

$$
\begin{aligned}
& H_{f}(z)=-\sum_{i=0}^{z} \frac{p_{i}}{\sum_{j=0}^{z} p_{j}} \ln \frac{p_{i}}{\sum_{j=0}^{z} p_{j}^{\prime}} \\
& H_{o}(z)=-\sum_{i=z+1}^{255} \frac{p_{i}}{\sum_{j=z+1}^{255} p_{j}} \ln \frac{p_{i}}{\sum_{j=z+1}^{255} p_{j}^{\prime}}
\end{aligned}
$$

donde $p_{i}$ es la probabilidad del VG igual a $i, \mathrm{y} z$ es el VG umbral que separa ambas clases. Por claridad en la exposición se han escogido los VG en el rango de 0 a 255. El método selecciona el umbral óptimo $z_{o p}$ que maximiza la entropía total $H_{T}$, es decir: 


$$
z=z_{\text {op }} \text { tal que } \frac{d H_{T}(z)}{d z}=0
$$

La implementación de este método fue realizada usando MATLAB ${ }^{\mathrm{TM}} \mathrm{R} 2013 \mathrm{a}$.

\subsubsection{El método Iterativo}

El método Iterativo presupone que el histograma de la imagen digital es la suma de dos distribuciones Gaussianas: el fondo y el objeto (Ridler and Calvard, 1978). Si definimos la distribución de "fondo" como $f(z)$ y la distribución del objeto como $o(z)$, donde $z$ son los VGs, la distribución conjunta $p(z)$ puede ser escrita como:

$$
p(z)=F f(z)+H o(z),
$$

donde $F+H=1$. El umbral óptimo $z=z_{o p}$ satisface la igualdad:

$$
F f\left(z_{o p}\right)=H o\left(z_{o p}\right)
$$

Si además se asume que las desviaciones estándar de ambas distribuciones son iguales $\left(\sigma_{f}=\sigma_{o}=\sigma\right)$ y que existe equiprobabilidad $(F=H)$, el umbral óptimo puede ser calculado mediante iteraciones sucesivas. Finalmente obtenemos que:

$$
z_{o p}=\frac{\mu_{f}+\mu_{o}}{2}
$$

donde $\mu_{f}$ y $\mu_{o}$ son las medias de las distribuciones de "fondo" y "objeto" respectivamente.

La implementación de este método fue realizada usando MATLAB ${ }^{\mathrm{TM}}$ R2013a. 


\subsubsection{Criterio de comparación: Clasificación Errónea de Poros}

La Clasificación Errónea de Poros (CEP) es el criterio más conocido para comparar métodos de segmentación cuando la información "ground-truth" está disponible (Yasnoff et al., 1977). El "ground-truth" es la información verdadera o la realidad de la imagen de suelo. La mayoría de los estudios consideran este parámetro como el criterio más objetivo a la hora de comparar métodos de segmentación (Zhang, 1996, 2001; Sezgin \& Sankur, 2004; Wang et al., 2011). Para calcular este parámetro utilizamos la expresión:

$$
C E P=1-\frac{P+S}{T}
$$

donde $\mathrm{P}$ es el número de píxeles/vóxeles de tipo poro que coinciden en la imagen "ground-truth" y en la imagen segmentada, $S$ es el número de píxeles/vóxeles de tipo sólido que coinciden en la imagen "ground-truth" y en la imagen segmentada, y $\mathrm{T}$ es el número total de píxeles/vóxeles de la imagen. CEP puede tomar valores entre 0 y 1 ; cuando CEP $=0$, hay una perfecta coincidencia entre el "ground-truth" y la imagen segmentada; cuando CEP = 1 , la falta de coincidencia es total.

La implementación de este método fue realizada usando MATLAB ${ }^{\mathrm{TM}} \mathrm{R} 2013 \mathrm{a}$.

\subsection{EL MÉTODO DE LOS MULTIFRACTALES TRUNCADOS.}

\subsubsection{El enfoque del método}

El método MT es un método alternativo en la creación de imágenes sintéticas de suelo basado principalmente en realzar las propiedades de escalamiento del espacio de poros de las imágenes reales de suelo. Podemos encontrar distintos y variados métodos en la literatura actual que simulan imágenes reales de suelo, como por ejemplo: Zhang (2001), Schlüter et al. (2010), Wang et al. (2011), etc. 
El método MT se centra inicialmente en la simulación de TAC de suelos que se caracterizan por:

a) Tener histogramas de VG muy unimodales.

b) Mostar una distribución espacial de poros con propiedades autosimilares.

c) Incluir también un espacio de "guijarros" con propiedades autosimilares.

d) Mostrar un bajo contraste en la interfaz sólido-poro.

El nuevo método básicamente define una imagen "ground-truth" de suelo compuesta por el espacio de poros y un espacio "de fondo" que incluye como novedad un espacio de "guijarros". El espacio de "guijarros" trata de simular los destellos o gránulos de gran intensidad que aparecen típicamente en las TAC reales de suelos. El método MT es capaz de simular tanto imágenes de 2D como en 3D (Martín-Sotoca et al., 2017a; 2016).

\subsubsection{Implementación del método de los Multifractales Truncados.}

La implementación de este método fue realizada usando MATLAB ${ }^{T M} R 2013 a$. $A$ continuación se detallan los pasos a seguir:

i) La delimitación del espacio de poros y guijarros se consigue truncando un multifractal de Sierpinski en 2D/3D. Previamente al truncado, se aplica un filtro paso-bajo sobre la medida multifractal para transformarla en una función más "suave". Ambos espacios son creados truncando el multifractal en distintos $V G_{t h 1}$ y $V G_{t h 2}$ (para el espacio de poros y guijarros, respectivamente). El solapamiento de ambos espacios constituirá el "ground-truth" de la imagen de suelo. En este paso se consigue replicar las propiedades de escalamiento de ambos espacios.

En la Fig. 2.7 se muestra un ejemplo de creación del espacio de poros en el caso de imágenes 2D y 3D. 

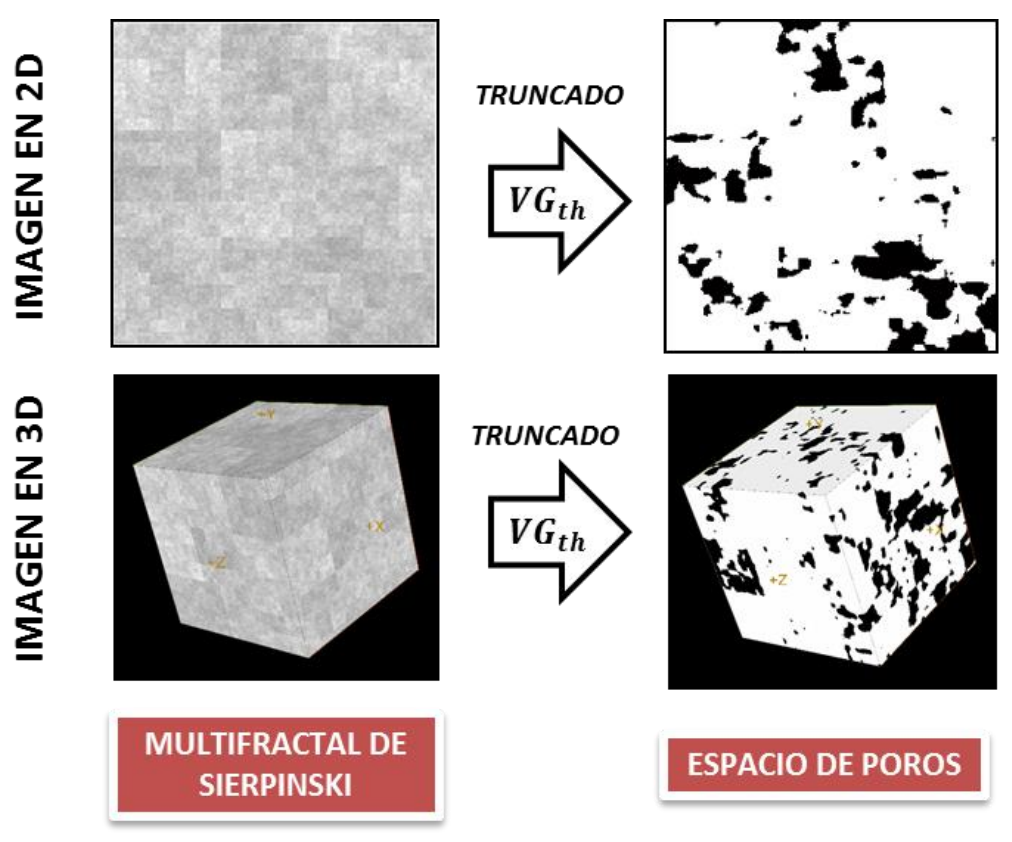

ESPACIO DE POROS

Fig. 2.7 - Ejemplo de creación del espacio de poros en imágenes 2D (superior) e imágenes 3D (inferior) generadas por el método MT. La delimitación del espacio de poros viene definido por los umbrales de truncado $V G_{t h 1}$ y $V G_{t h 2}$.

ii) Una vez definidas las zonas que van a constituir los espacios de poros, de guijarros, y por exclusión, de fondo, se realiza la asignación de VG medios a cada una de estas zonas para construir el esqueleto del histograma de la imagen sintética final. De esta manera, al espacio de poros se le asigna el $V G_{\text {Poros }}=0, \mathrm{y}$ al resto de zonas se les asignan los valores medios $V G_{\text {Fondo }}$ y $V G_{\text {Guijarros }}$.

iii) En este paso se añade un Ruido Blanco Gaussiano (RBG) a la imagen con el objetivo de simular la variabilidad característica de las TAC de suelos reales. Al final de este paso ya hemos conseguido simular una imagen sintética de suelo de alta resolución.

iv) El paso final consiste en filtrar la imagen previa mediante un filtro paso-bajo con el objetivo de reducir el contraste de la imagen sintética de suelo. El motivo de este último paso es la simulación de una de las características de las TAC reales de suelo, a saber, el bajo contraste en la interfaz sólido- 
poro. En la Fig. 2.8 se muestra un ejemplo de reducción del contraste de una imagen sintética de alta resolución obtenida en el paso 3.
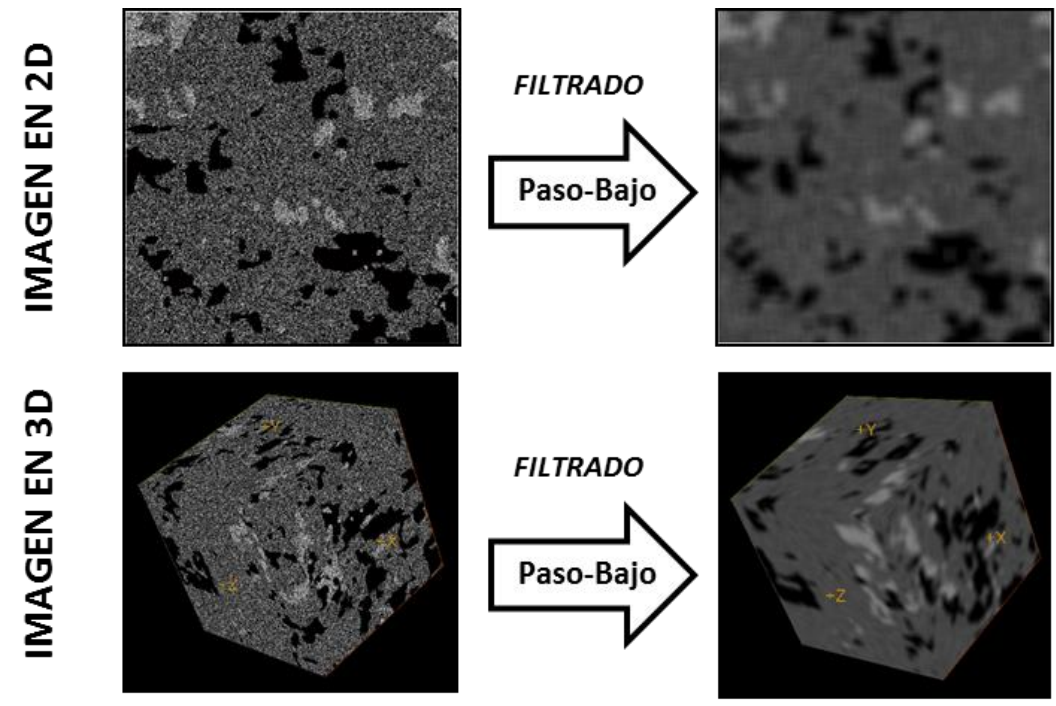

IMAGEN SINTÉTICA

IMAGEN SINTÉTICA

ALTA RESOLUCIÓN

BAJO CONTRASTE

Fig. 2.8 - Ejemplo de reducción de contraste en imágenes 2D (superior) e imágenes 3D (inferior) generadas por el método MT.

\subsection{ANÁLISIS MULTIFRACTAL}

El objetivo del análisis multifractal (AMF) es estudiar como una distribución de probabilidad normalizada o medida $\mu(x)$ varía con la escala. Consideremos una rejilla de celdas de tamaño $r$ que cubre una medida o distribución de masa $\mu(x)$ en $\mathbb{R}$, con una longitud total $L$. La medida $M_{i}(r)$ de una celda $i$ de tamaño $r$ vendrá definida por:

$$
M_{i}(r)=\int_{x_{i}}^{x_{i}+r} \mu(x) d x
$$

Entonces la distribución de probabilidad normalizada de la celda $i$ está definida por: 


$$
\mu_{i}(r)=\frac{M_{i}(r)}{\left.\sum_{j=1}^{N(r)} M_{j}(r)\right)}
$$

donde $N(r)$ es el $\mathrm{n}^{\circ}$ de celdas $i$ de tamaño $r$ contenidas en la longitud $L$.

Para una medida multifractal, la "función de partición" $\chi(q, r)$ tiene propiedades de escalamiento (Evertsz and Mandelbrot, 1992), es decir,

$$
\chi(q, r)=\sum_{j=1}^{N(r)} \mu_{j}^{q}(r) \sim r^{\tau(q)},
$$

Donde $\tau(q)$ es una función no lineal de $q$ denominada "función de exponentes de masa" (Feder, 1989). Para cada $q, \tau(q)$ puede ser obtenida como la pendiente de un gráfico log-log de $\chi(q, r)$ dependiendo de $r$. Este método es conocido como el "método de los momentos", ya que la función partición representa los momentos estadísticos de la medida $\mu_{i}$ (Halsey et al., 1986).

Los exponentes de singularidad o de Hölder $\alpha$ pueden ser calculados mediante la transformación de Legendre de la función $\tau(q)$ como:

$$
\alpha(q)=\frac{d \tau(q)}{d q}
$$

El $\mathrm{n}^{\circ}$ de celdas de tamaño $r$ con el mismo exponente $\alpha, N_{\alpha}(r)$, está relacionado con el tamaño de la celda mediante la expresión:

$$
N_{\alpha}(r) \propto r^{-f(\alpha)}
$$

Por tanto, $f(\alpha)$ es un exponente de escalamiento que corresponde a la dimensión fractal del conjunto $N_{\alpha}(r)$. El parámetro $f(\alpha)$ puede ser calculado como: 


$$
f(\alpha)=q \alpha(q)-\tau(q)
$$

Las propiedades de las funciones $\alpha(q), \tau(q)$ y $f(\alpha)$ han sido presentadas por diferentes autores (Feder, 1989; Schertzer and Lovejoy, 1991; Cheng and Agterberg, 1996).

El espectro multifractal (EMF), es decir, el gráfico de $\alpha$ vs. $f(\alpha)$, caracteriza cuantitativamente la variabilidad de la medida o distribución de probabilidad estudiada. Las asimetrías a derecha o izquierda indican si el escalamiento es dominante en valores pequeños o grandes respectivamente. La anchura del EMF indica el grado de variabilidad global de la medida (Tarquis et al., 2001).

La implementación de estos métodos fue realizada usando MATLAB ${ }^{\text {TM }}$ R2013a.

\subsection{LA TRANSFORMADA WAVELET MÓDULO MÁXIMO}

La Transformada Wavelet Continua (TWC) de una función $f(t) \in L^{2}(\mathbb{R})$ es una transformación espacio-escala definida por el producto interno:

$$
W f(u, s)=\left\langle f, \psi_{u, s}\right\rangle=\int_{-\infty}^{\infty} f(t) \frac{1}{\sqrt{s}} \psi^{*}\left(\frac{t-u}{s}\right) d t
$$

donde $t, u \in \mathbb{R}$ y $s \in \mathbb{R}^{+}$(escala). La familia de funciones $\psi_{u, s}(t) \in L^{2}(\mathbb{R})$ son las denominadas "wavelets", las cuales son una versión desplazada y escalada de la función $\psi(t)$. Esta última es la denominada "wavelet madre":

$$
\psi_{u, s}(t)=\frac{1}{\sqrt{s}} \psi\left(\frac{t-u}{s}\right) .
$$

La función $\psi(t)$ debe satisfacer las propiedades de "media-cero" (primer momento nulo) y "rápido decaimiento" para asegurar que existe la transformada inversa. 
La TWC es utilizada para estudiar la regularidad local de una función con el objetivo de encontrar puntos de la función con propiedades especiales (singulares). Con este fin, es necesario exigir a la wavelet que tenga momentos nulos, es decir, la wavelet madre debe ser ortogonal a polinomios de orden $\mathrm{n}$ :

$$
\int_{-\infty}^{\infty} x^{m} \psi(t) d t=0,0 \leq m<n
$$

En este caso, podemos interpretar la TWC como un operador diferencial multiescala de orden n. La teoría desarrollada por Mallat (Mallat, 1999) establece que podemos eliminar la redundancia de la TWC y sólo usar la TW Módulo Máximo (TWMM) a la hora de detectar los puntos singulares de una función. Estos máximos están definidos por los máximos locales de $|W f(u, s)|$ en cada escala $s$ y están localizados en líneas conectadas en el plano espacioescala. Estas líneas se denominan líneas máximas. Una característica importante de estas líneas máximas, en el contexto de la detección de puntos singulares, es que al menos una línea máxima converge hacia cada punto singular.

El método de TWMM ha probado ser un método muy eficaz a la hora de localizar puntos especiales en una función (Mallat and Hwang, 1992). Por ejemplo, cuando la wavelet madre tiene el primer momento nulo, las líneas de modulo máximo son utilizadas para localizar discontinuidades asociadas a bordes en imágenes. Cuando la wavelet tiene el segundo momento nulo, las líneas máximas son utilizadas para localizar puntos de máxima curvatura.

Este método dispone de funciones ya existentes en MATLAB ${ }^{\text {TM }}$ R2013a. 


\section{CAPÍTULO 3}

\section{MAPAS DE SINGULARIDAD APLICADOS A ÍNDICES DE VEGETACIÓN}




\subsection{INTRODUCCIÓN}

El objeto de estudio en este capítulo son los mapas de NDVI. La distribución espacial de los índices de vegetación, en concreto del NDVI, tiene carácter multifractal, tal como se ha explicado anteriormente, por lo que la obtención de mapas de singularidades está justificada.

El objetivo del siguiente caso de estudio es:

a) Primero, verificar en qué condiciones los mapas de NDVI utilizados poseen carácter multifractal. Para ello se utilizan las herramientas proporcionadas por el análisis multifractal.

b) Por último, estudiar si los mapas de singularidad pueden ser aplicados para delimitar áreas de interés (zonificación) en los mapas de NDVI. Aplicaremos, por primera vez en este contexto, la metodología S-CA para encontrar los lugares donde los valores del NDVI siguen distribuciones normales o log-normales (zonas no singulares).

\subsection{MATERIALES}

\subsubsection{Normalized Difference Vegetation Index (NDVI)}

EI NDVI muestra la actividad fotosintética de la vegetación (Flynn, 2006). La actividad fotosintética está relacionada con la humedad que los cultivos necesitan para desarrollarse apropiadamente, de tal forma que cuanta más disponibilidad hay de humedad, mayor es la actividad fotosintética. Por tanto es razonable estudiar la sequía a través del NDVI, excepto para los casos de sequía fisiológica. Existen otros índices de vegetación que incorporan de una manera más exacta los efectos del suelo y las influencias atmosféricas, sin embargo, por simplicidad y facilidad en la interpretación, usaremos el NDVI en esta tesis. Para el cálculo del NDVI se utiliza la siguiente expresión:

$$
N D V I=\frac{I R c-R}{I R c+R}
$$


donde $I R c$ y $R$ son los valores de reflectancia en las bandas del infrarrojo cercano y el rojo respectivamente. El rango de valores que puede tomar el NDVI es de -1 a 1 . Valores por debajo de cero indican que no existe actividad fotosintética y son característicos de áreas con gran acumulación de agua como ríos, lagos, embalses, etc. Cuanto más alto es el valor del NDVI, mayor es la actividad fotosintética.

\subsection{2 Área de estudio}

Para el estudio espacial consideramos una región rectangular que incluye a la totalidad de la Comunidad Autónoma de Madrid (CAM), España. Este área consiste en $300 \times 280$ píxeles, donde cada píxel representa una superficie de $500 \mathrm{~m} \times 500 \mathrm{~m}$ (ver Fig. 3.1).

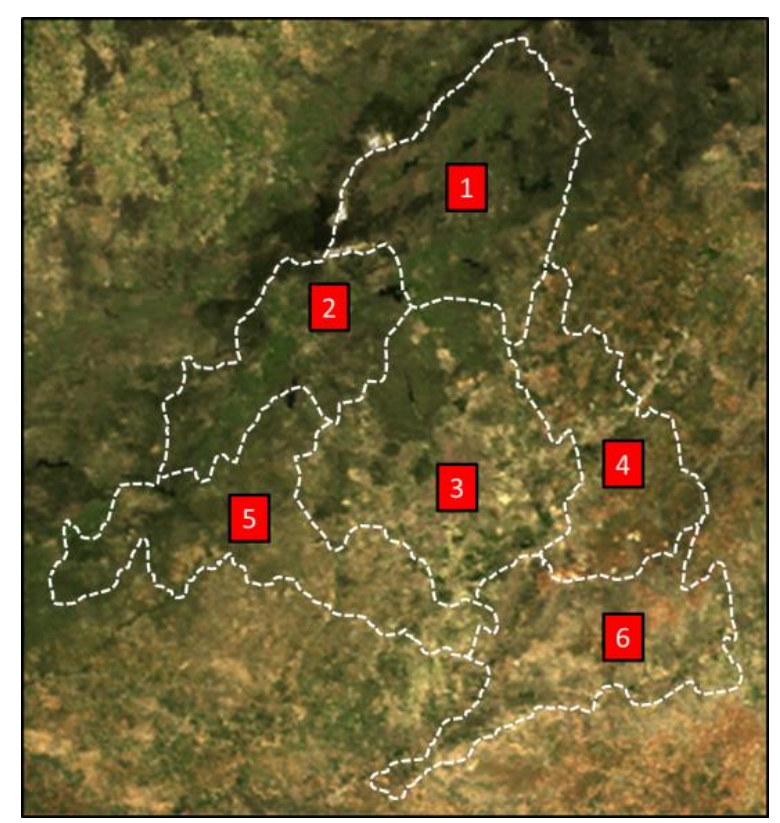

Fig. 3.1 - Imagen RGB del área rectangular ( 300 × 280 píxeles) utilizada en este estudio (fecha de captura por MODIS: 15/04/2011). En línea discontinua aparece el contorno de la CAM y sus seis comarcas agrícolas: (1) Lozoya-Somosierra, (2) Guadarrama, (3) área Metropolitana, (4) Campiña, (5) Sudoeste y (6) Las Vegas.

Las coordenadas UTM_30 de los límites del área rectangular corresponden a los siguientes píxeles: 
(1) Esquina superior izquierda: $360162 \mathrm{~m} \mathrm{E}, 4560040 \mathrm{~m} \mathrm{~N}$.

(2) Esquina superior derecha: $499662 \mathrm{~m} \mathrm{E}, 4560040 \mathrm{~m} \mathrm{~N}$.

(3) Esquina inferior izquierda: $360162 \mathrm{~m} \mathrm{E}, 4410540 \mathrm{~m} \mathrm{~N}$.

(4) Esquina inferior derecha: $499662 \mathrm{~m} \mathrm{E}, 4410540 \mathrm{~m} \mathrm{~N}$.

Este rectángulo abarca una extensión de $150 \mathrm{Km}$ x $140 \mathrm{Km}$, conteniendo dos formaciones geográficas bien distintas: una cadena montañosa y la planicie del río Tajo, separadas por estribaciones. El rango de alturas está entre $430 \mathrm{~m}$ en el último tramo del río Alberche (en el sudeste), y los $2428 \mathrm{~m}$ del pico de Peñalara (en el norte).

A pesar de que la zona seleccionada no es muy grande presenta dos climas muy distintos como resultado de su localización entre la cordillera del Sistema Central y el valle del río Tajo. En Guadarrama y Ayllón, zonas más altas del norte (por encima de los $1200 \mathrm{~m}$ ), el clima es de montaña. Esto implica temperaturas muy frías en invierno y suaves en verano. En estas zonas las precipitaciones son abundantes, pudiendo ser superiores a $1500 \mathrm{~mm}$ al año, en forma de nieve durante el invierno y parte de la primavera y otoño (Sotelo Pérez, 2013).

El resto de la CAM tiene un clima continental mediterráneo con veranos cálidos, atenuados en el piedemonte y extremos en la llanura. En estas zonas los inviernos son fríos con temperaturas por debajo de los $8^{\circ} \mathrm{C}$, con frecuentes heladas por las noches y nevadas ocasionales. Por el contrario, los veranos son cálidos, con temperaturas medias por encima de los $24^{\circ} \mathrm{C}$ en julio y agosto, y con máximas que con frecuencia exceden los $35^{\circ} \mathrm{C}$. Las lluvias generalmente no superan los $700 \mathrm{~mm}$ al año y están concentradas especialmente en primavera y otoño (Sotelo Pérez, 2013).

\subsubsection{Base de datos}

Para el cálculo de NDVI de la zona de estudio se ha utilizado la información suministrada por el satélite de investigación científica Terra (EOS AM-1). Este 
satélite fue puesto en órbita por la NASA el 18 de diciembre de 1999. El sensor MODIS ((Moderate Resolution Imaging Spectroradiometer) a bordo del satélite suministra la información de las bandas de frecuencia necesarias para el cálculo del NDVI. La información de MODIS está organizada en "productos". EI producto utilizado en esta tesis es el MOD09A1 (LP DAAC, 2014). MOD09A1 proporciona siete bandas de frecuencia: banda $1(620-670 \mathrm{~nm})$, banda 2 (841$876 \mathrm{~nm})$, banda $3(459-479 \mathrm{~nm})$, banda 4 (545-565 nm), 5 banda (1230-1250 $\mathrm{nm})$, banda $6(1628-1652 \mathrm{~nm})$ y banda $7(2105-2155 \mathrm{~nm})$. Las bandas utilizadas para calcular el NDVI son: banda 1 para la frecuencia del rojo y banda 2 para la frecuencia del infrarrojo cercano. MOD09A1 proporciona imágenes georeferenciadas con una resolución de pixel de 500 m x 500 m. Este producto realiza una combinación de las mejores reflectancias de cada pixel en un periodo de 8 días. El formato de fichero utilizado es TIFF con información georeferenciada UTM_30 y modelo de geoide WGS 84.

En este estudio se comparan los resultados obtenidos de cuatro fechas representativas de cada estación astronómica, de dos años distintos: 2005 (año seco) y 2011 (año húmedo). Las fechas seleccionadas son las siguientes:

- Invierno: 17 de enero de 2005 y 25 de enero de 2011.

- Primavera: 23 de abril de 2005 y 15 de abril de 2011.

- Verano: 20 de Julio de 2005 y 20 de julio de 2011.

- Otoño: 24 de octubre de 2005 y 24 de octubre de 2011.

\subsection{RESULTADOS}

\subsubsection{Análisis multifractal}

Para la realización del análisis multifractal las imágenes iniciales de $300 \times 280$ píxeles fueron recortadas y centradas para obtener imágenes de 256 × 256 píxeles. El motivo de este ajuste fue poder aplicar correctamente el método de los momentos utilizado para calcular el EMF. Los valores de NDVI fueron 
calculados para cada pixel y la distribución espacial de los mapas de NDVI fueron considerados como una medida o distribución de probabilidad normalizada $\mu$ en $\mathrm{R}^{2}$. Para asegurar la validez del análisis multifractal todos los valores negativos del NDVI fueron convertidos a cero, tal como se ha realizado en otros trabajos (Alonso et al., 2017).

Sea $A\left(a_{j, k}\right)$ la matriz de 256 filas x 256 columnas de valores de NDVI. Primero normalizamos la matriz, de tal forma que la probabilidad de la celda $i$ sea:

$$
\mu_{i}=\frac{\sum_{j, k \in \text { celdai }} a_{j, k}}{\sum_{j=1}^{256} \sum_{k=1}^{256} a_{j, k}}
$$

A continuación el análisis multifractal fue aplicado a todos los mapas de NDVI previamente especificados (cuatro fechas distintas por año). En todos los casos se encontró una relación lineal en el gráfico log-log de la función de partición $\chi(q, r)$ vs. la escala $(r)$ para un rango desde $2^{2}$ píxeles $\left(2 \mathrm{Km}\right.$ de lado) a $2^{8}$ píxeles (128 $\mathrm{Km}$ de lado) con un $\mathrm{R}^{2}$ superior a 0.98 . De cada una de las pendientes obtenidas para cada $q$ resulta la función no lineal de exponentes de masa $\tau(q)$, la cual refleja la estructura de jerarquía de escalas propia de las medidas multifractales. El valor $\tau(q=1)=0$ muestra el carácter conservativo de la medida. Los EMF fueron estimados en un intervalo de $q= \pm 10$, con incrementos de 1 (ver Fig. 3.2).
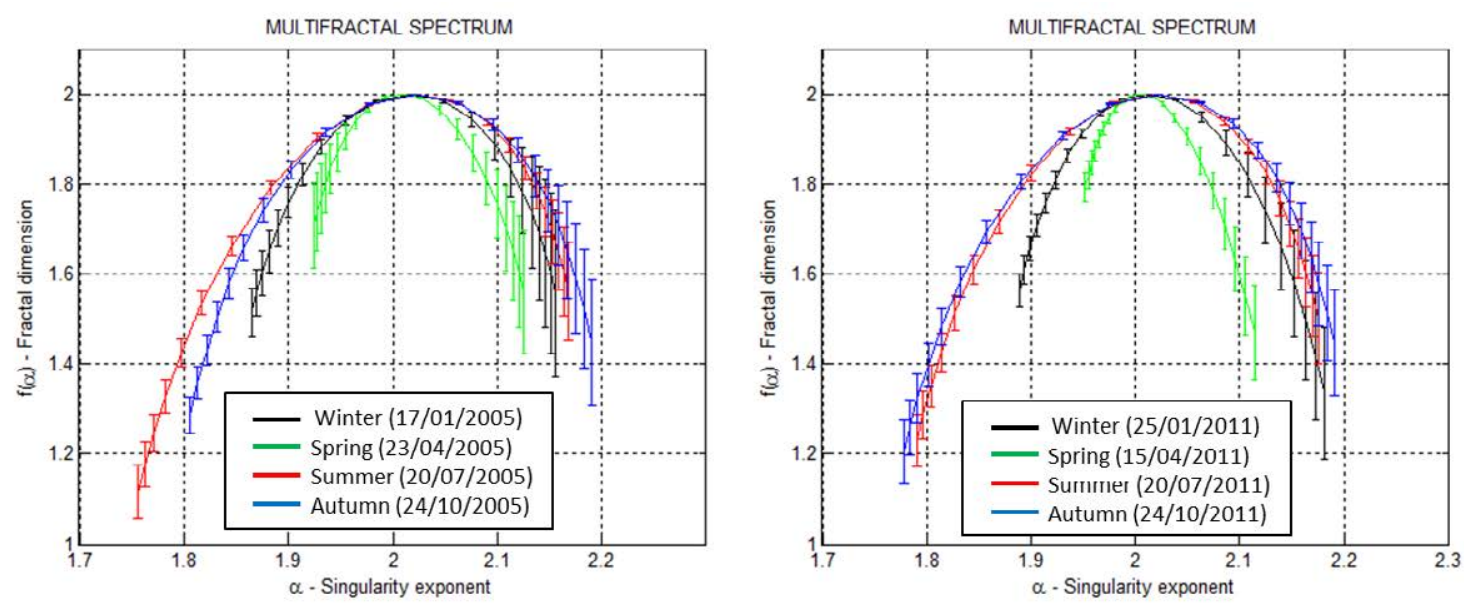

Fig. 3.2 - Resultados del espectro multifractal de los mapas NDVI de cada estación. (Izquierda) año 2005 y (derecha) año 2011. 
Todos los EMF resultaron curvas parabólicas convexas con distintas simetrías dependiendo de la estación del año del mapa de NDVI estudiado. En un sistema fractal el EMF consiste en único punto, por tanto los resultados obtenidos apoyan la hipótesis de comportamiento multifractal de los mapas de NDVI, en acuerdo con otros trabajos previos (Lovejoy et al., 2008; Alonso et al., 2017).

Los EMF muestran importantes diferencias en amplitud y simetría. Estos conceptos pueden ser cuantificados mediante la diferencia entre los valores de singularidad extremas $\left(\Delta \alpha=\alpha_{\max }-\alpha_{\min }\right)$ y la diferencia de sus respectivos valores de $f(\alpha)\left(\Delta f=f\left(\alpha_{\max }\right)-f\left(\alpha_{\min }\right)\right)$. De esta forma, cuanto más ancho sea $\Delta \alpha$, mayor será la complejidad de la estructura de los mapas de NDVI estudiados; y cuanto más ancho sea $\Delta f$, mayor será la asimetría presentada en los EMF. Siguiendo otros trabajos que usan estos conceptos diremos que la simetría es "a derechas" si $\Delta f<0$, y la simetría es "a izquierdas" si $\Delta f>0$ (Alonso et al., 2017). En la Tabla 3.1 se muestran todos estos valores para todas las estaciones y años analizados.

\begin{tabular}{|c|c|c|c|c|c|c|}
\hline 2005 & $\alpha_{\min }$ & $\alpha_{\max }$ & $\Delta \alpha$ & $f\left(\alpha_{\min }\right)$ & $f\left(\alpha_{\max }\right)$ & $\Delta f$ \\
\hline Winter (17/01/2005) & 1.87 & 2.16 & 0.29 & 1.52 & 1.56 & 0.04 \\
\hline Spring $(23 / 04 / 2005)$ & 1.92 & 2.13 & 0.21 & 1.71 & 1.56 & -0.15 \\
\hline Summer $(20 / 07 / 2005)$ & 1.76 & 2.17 & 0.41 & 1.12 & 1.56 & 0.44 \\
\hline Autumn $(24 / 10 / 2005)$ & 1.81 & 2.19 & 0.38 & 1.29 & 1.45 & 0.16 \\
\hline 2011 & $\alpha_{\min }$ & $\alpha_{\max }$ & $\Delta \alpha$ & $f\left(\alpha_{\min }\right)$ & $f\left(\alpha_{\max }\right)$ & $\Delta f$ \\
\hline Winter $(25 / 01 / 2011)$ & 1.89 & 2.18 & 0.29 & 1.56 & 1.34 & -0.22 \\
\hline Spring $(15 / 04 / 2011)$ & 1.95 & 2.11 & 0.16 & 1.79 & 1.47 & -0.32 \\
\hline Summer $(20 / 07 / 2011)$ & 1.79 & 2.18 & 0.39 & 1.23 & 1.50 & 0.27 \\
\hline Autumn (24/10/2011) & 1.78 & 2.19 & 0.41 & 1.20 & 1.45 & 0.25 \\
\hline
\end{tabular}

Tabla 3.1 - Valores extremos de los exponentes de singularidad $\left(\alpha_{\max }, \alpha_{\min }\right)$, su diferencia $\left(\Delta \alpha=\alpha_{\max }-\alpha_{\min }\right)$, valores extremos de las dimensiones fractales $\left(f\left(\alpha_{\max }\right), f\left(\alpha_{\min }\right)\right)$ y su diferencia $\left(\Delta f=f\left(\alpha_{\max }\right)-f\left(\alpha_{\min }\right)\right)$ para todas las fechas y años analizados (2005 y 2011). 
Estudiando la evolución de $\Delta \alpha$ a lo largo de un año, $\Delta \alpha$ presenta el valor más pequeño durante la primavera, incrementando su valor en verano y otoño, alcanzando el máximo valor en esta última estación, y volviendo a descender en invierno. Este comportamiento es similar en ambos años (2005 y 2011), y supone un comportamiento cíclico independientemente si el año es seco o húmedo. El significado de $\Delta \alpha$, aumentando a lo largo de las estaciones, es que los mapas de NDVI muestran una mayor estructura espacial de jerarquía de escalas, mostrando un máximo en otoño donde las lluvias comienzan a aparecer y las temperaturas descienden principalmente en el norte de la CAM.

Respecto a la evolución de $\Delta f$ a lo largo de un año, la simetría cambia desde "a derechas", en invierno y primavera, hacia "a izquierdas", en verano y otoño. Esto significa que los valores más bajos de NDVI están conduciendo el comportamiento entre escalas en invierno y primavera, ya que esa parte del EMF corresponde con los cálculos de $q$ negativos. Por el contrario, los valores más altos del NDVI están conduciendo el comportamiento entre escalas en verano y otoño, por ser la parte del EMF con $q$ positivos. La máxima asimetría "a derechas" es conseguida en primavera, con lluvias principalmente en el norte de la CAM e incrementos rápidos de temperatura en el sur. La máxima asimetría "a izquierdas" se consigue en verano, la estación más seca de la CAM, y donde los valores altos de NDVI están reflejando las zonas con mayor humedad en el suelo. El comportamiento general de $\Delta f$ a lo largo del año es independiente si el año es seco (2005) o húmedo (2011). Sin embargo, comparando ambos años nos encontramos con que la asimetría se incrementa en invierno y primavera el año húmedo. En cambio, la asimetría en verano disminuye en el año húmedo. En otoño es muy difícil establecer un patrón debido a la alta variabilidad de la estación, pero es razonable pensar que tenga un comportamiento parecido al verano.

El comportamiento cíclico en la evolución de $\Delta \alpha$ y $\Delta f$ está describiendo la variación en complejidad y la importancia de los valores altos y bajos de NDVI a través de las estaciones. El verano y el otoño presenta mayor complejidad y el comportamiento entre escalas está dominado por los valores más altos de NDVI. Por otro lado, el invierno y la primavera presentan menor complejidad y 
los valores más bajos de NDVI están dominando el comportamiento entre escalas. A través del análisis multifractal se revela el patrón espacial y sus propiedades de escalamiento de los mapas de NDVI en diferentes estaciones.

\subsubsection{Metodología Singularidad-CA}

En las Fig. 3.3 y 3.4 se muestran dos filas de imágenes: los mapas de NDVI y sus respectivos mapas de singularidad (fechas del 2005 en Fig. 3.3 y fechas del 2011 en Fig. 3.4). Para una mejor visualización de las imágenes se ha utilizado un mapa de color en MATLAB tipo "jet". En los mapas de NDVI, el color azul oscuro representa $N D V I_{\min }=0 \quad \mathrm{y}$ el rojo oscuro representa $N D V I_{\max }=1$. En los mapas de singularidades el mapa de color está invertido, los colores rojizos indican singularidades positivas (exponentes de singularidad $\alpha<2$ ) y los colores azulados indican singularidades negativas (exponentes de singularidad $\alpha>2$ ). Para una mejor visualización de los mapas, los valores de singularidad menores que 1.7 fueron colapsados en el valor de 1.7, y los valores mayores que 2.3 fueron colapsados en el valor de 2.3. De esta forma se consigue realzar las singularidades positivas y negativas.

El tamaño máximo de la ventana deslizante en los cálculos de los exponentes de singularidad (19 x 19 píxeles) provoca un efecto borde en las imágenes de 256 x 256 píxeles, por lo que no es posible calcular los exponentes en un marco de 9 píxeles de ancho. Esta es la razón por la que los mapas de singularidad tengan un tamaño de (256 - 9) x (256 - 9) píxeles (247 x 247 píxeles).

En todos los mapas de singularidades obtenidos aparecen zonas con singularidades positivas y negativas. Las zonas con singularidades positivas $(\alpha<2)$ están altamente correladas con las riveras de los ríos en la estación seca (verano) y las zonas con singularidades negativas $(\alpha>2)$ aparecen mayoritariamente en la ciudad de Madrid y en las ciudades circundantes. 

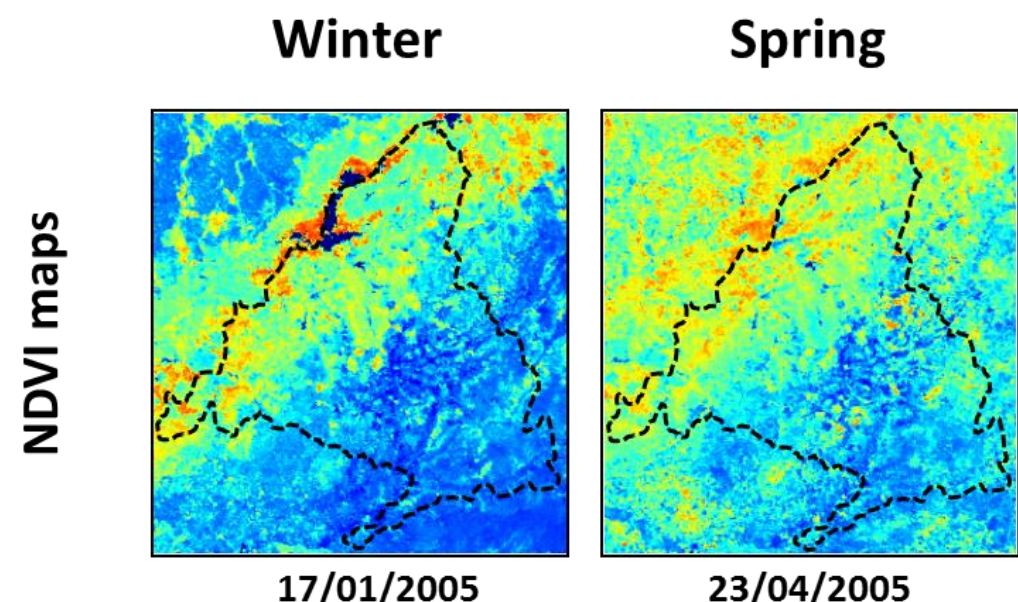

Summer

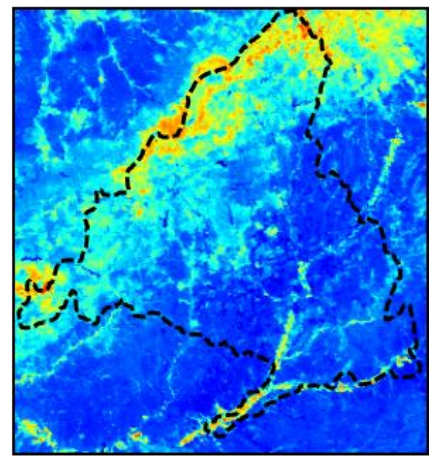

20/07/2005

$0-\mathrm{NDVI}$
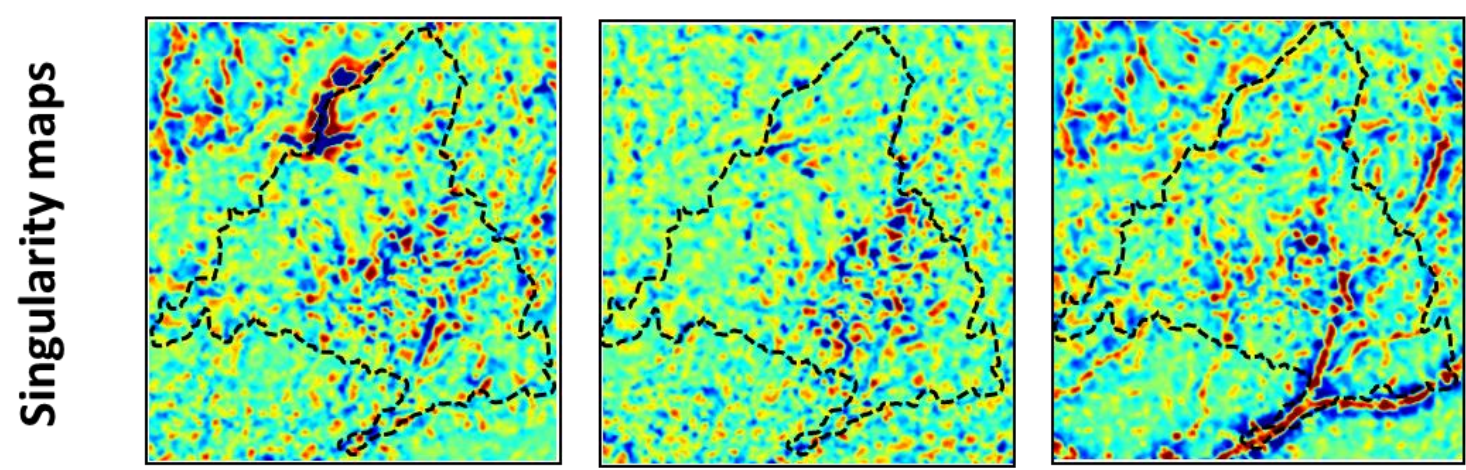

Autumn

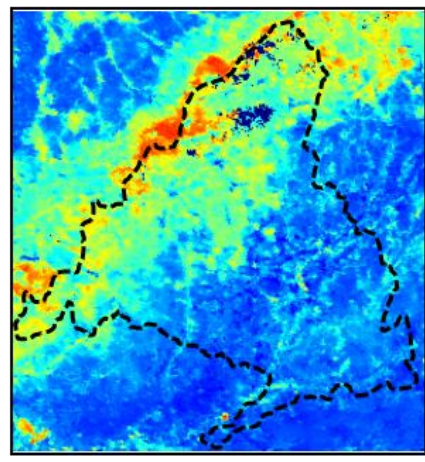

24/10/2005

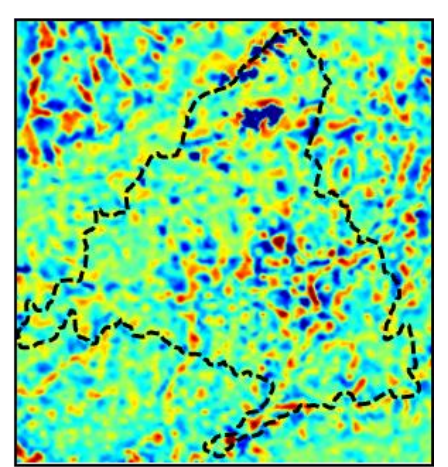

1.7

Singularity exponen

Fig. 3.3 - (Arriba) mapas NDVI ( 247 × 247 píxeles), y (abajo) mapas de singularidades ( 247 × 247 píxeles) para cada fecha analizada del año 2005. La línea discontinua representa los límites de la Comunidad Autónoma de Madrid. 


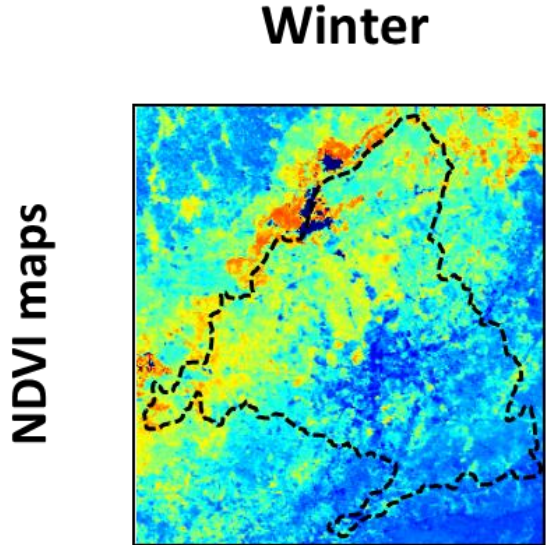

$25 / 01 / 2011$

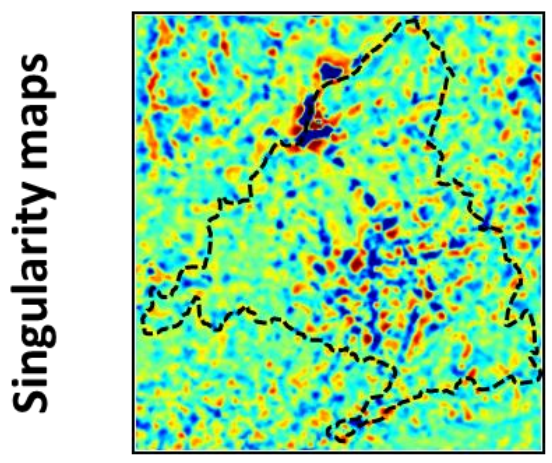

Spring

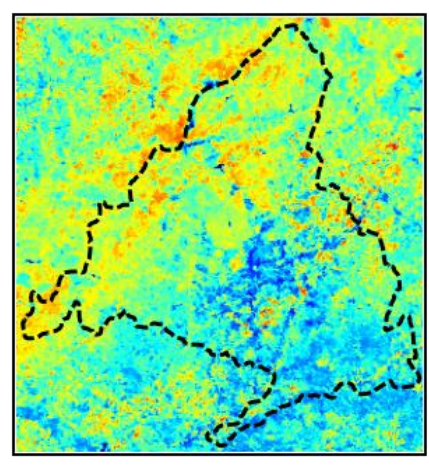

$17 / 04 / 2011$

0

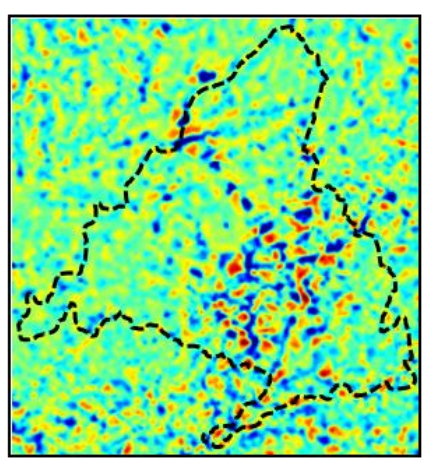

1.7
Summer

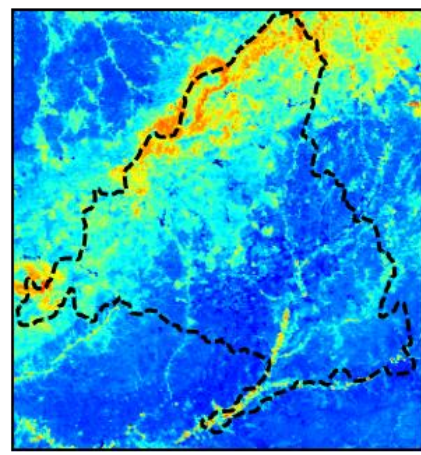

$20 / 07 / 2011$

1

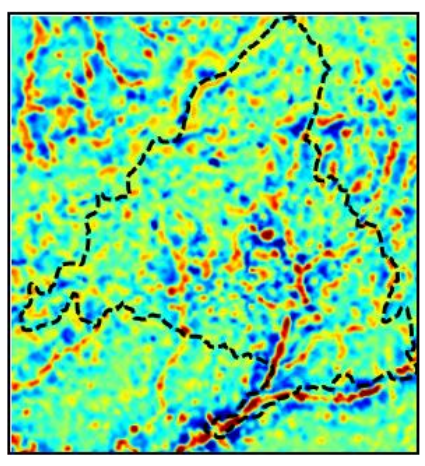

2.3

Singularity exponent

Fig. 3.4 - (Arriba) mapas NDVI ( 247 x 247 píxeles), y (abajo) mapas de singularidades ( 247 x 247 píxeles) para cada fecha analizada del año 2011. La línea discontinua representa los límites de la Comunidad Autónoma de Madrid.

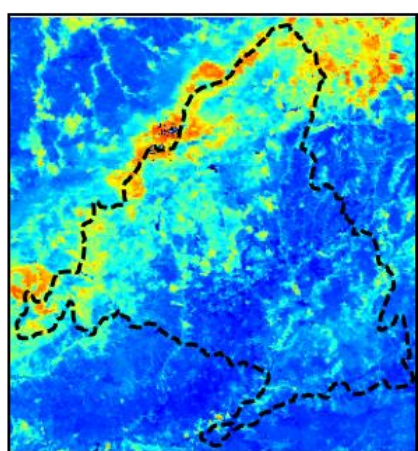

$24 / 10 / 2011$
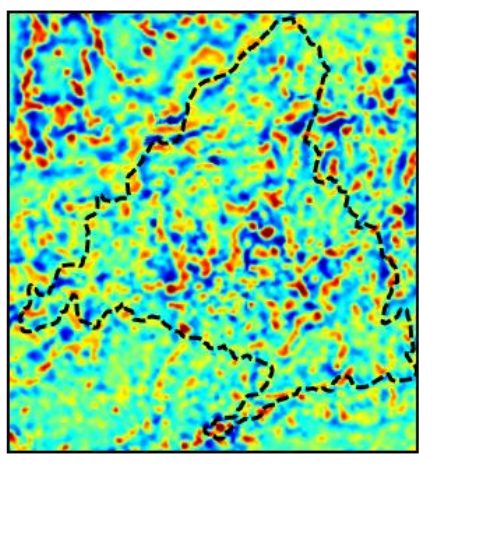
Los umbrales, $\alpha_{T \min }$ y $\alpha_{\text {Tmax }}$, fueron calculados por el método CA para delimitar la zona no singular del mapa de singularidades. El método CA suministró los umbrales superior e inferior $\left(\alpha_{T \min }, \alpha_{\text {Tmax }}\right)$ para cada una de las fechas analizadas. En la Fig. 3.5 (año 2005) y la Fig. 3.6 (2011) se muestran los gráficos log-log con los puntos de cambio de pendiente que definen los umbrales buscados. En todos los gráficos acumulados fue posible calcular los puntos de cambio de pendiente debido a la existencia de dos tramos lineales. El método de regresión lineal por mínimos cuadrados fue utilizado para obtener las ecuaciones de los dos tramos lineales y calcular el punto de cruce o punto de cambio de pendiente. La selección de los puntos utilizados para las rectas de regresión se basó en la obtención de un $\mathrm{R}^{2}$ de al menos 0.98 .
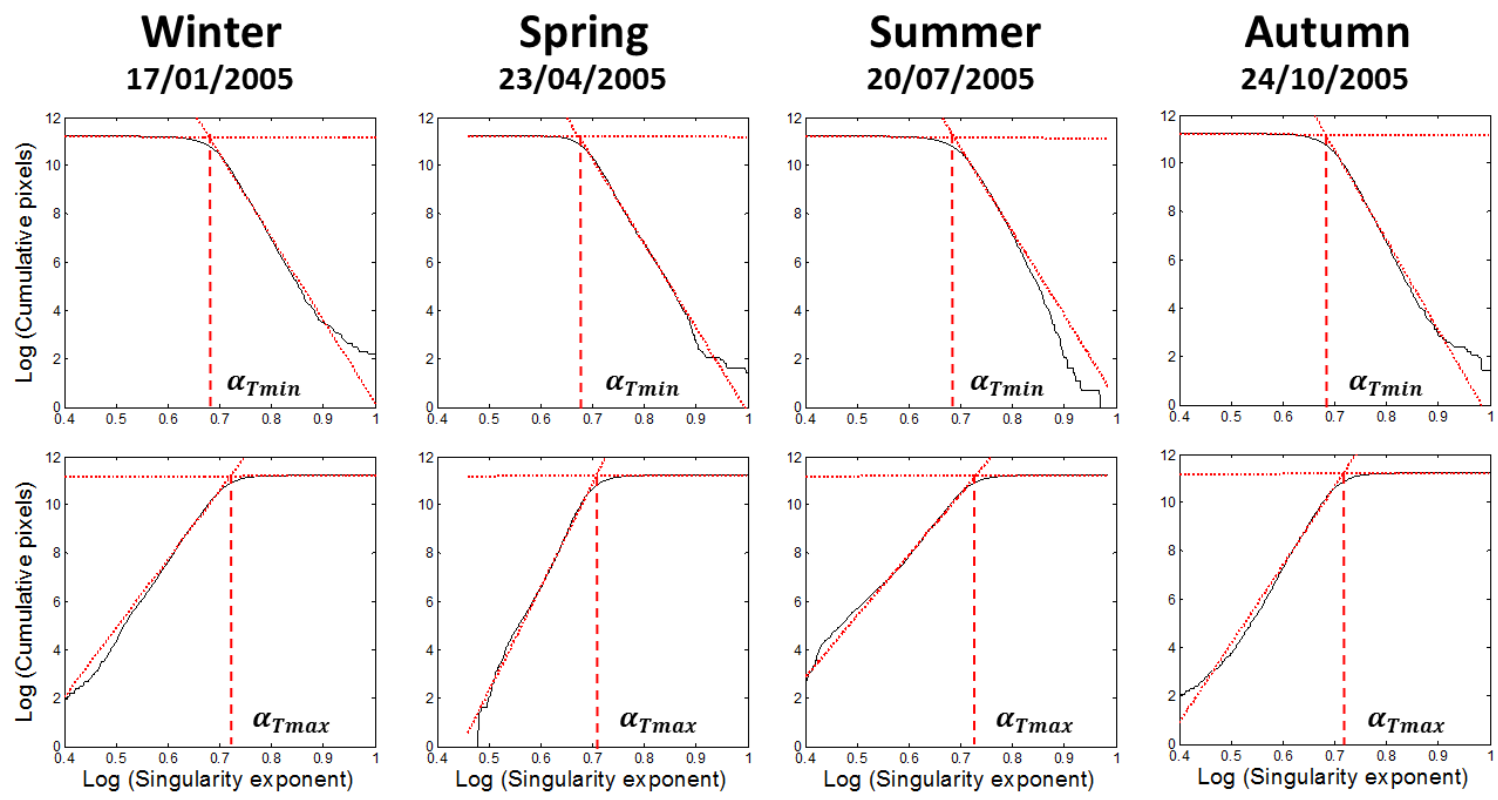

Fig. 3.5. Aplicación del método CA. Distribuciones acumuladas en escala log-log con el cruce de las dos rectas de regresión (en rojo) obteniendo (arriba) los umbrales inferiores: $\quad \alpha_{\text {Tmin }}($ invierno $)=1.973, \quad \alpha_{\text {Tmin }}($ primavera $)=1.961, \quad \alpha_{\text {Tmin }}($ verano $)=$ 1.988 y $\alpha_{\text {Tmin }}($ otoño $)=1.979$; y (abajo) los umbrales superiores:,$\alpha_{\text {Tmax }}($ invierno $)=$ 2.057, $\alpha_{\text {Tmax }}($ primavera $)=2.028, \alpha_{\text {Tmax }}($ verano $)=2.074$ and $\alpha_{\text {Tmax }}($ otoño $)=2.047$, para cada fecha analizada del año 2005. 

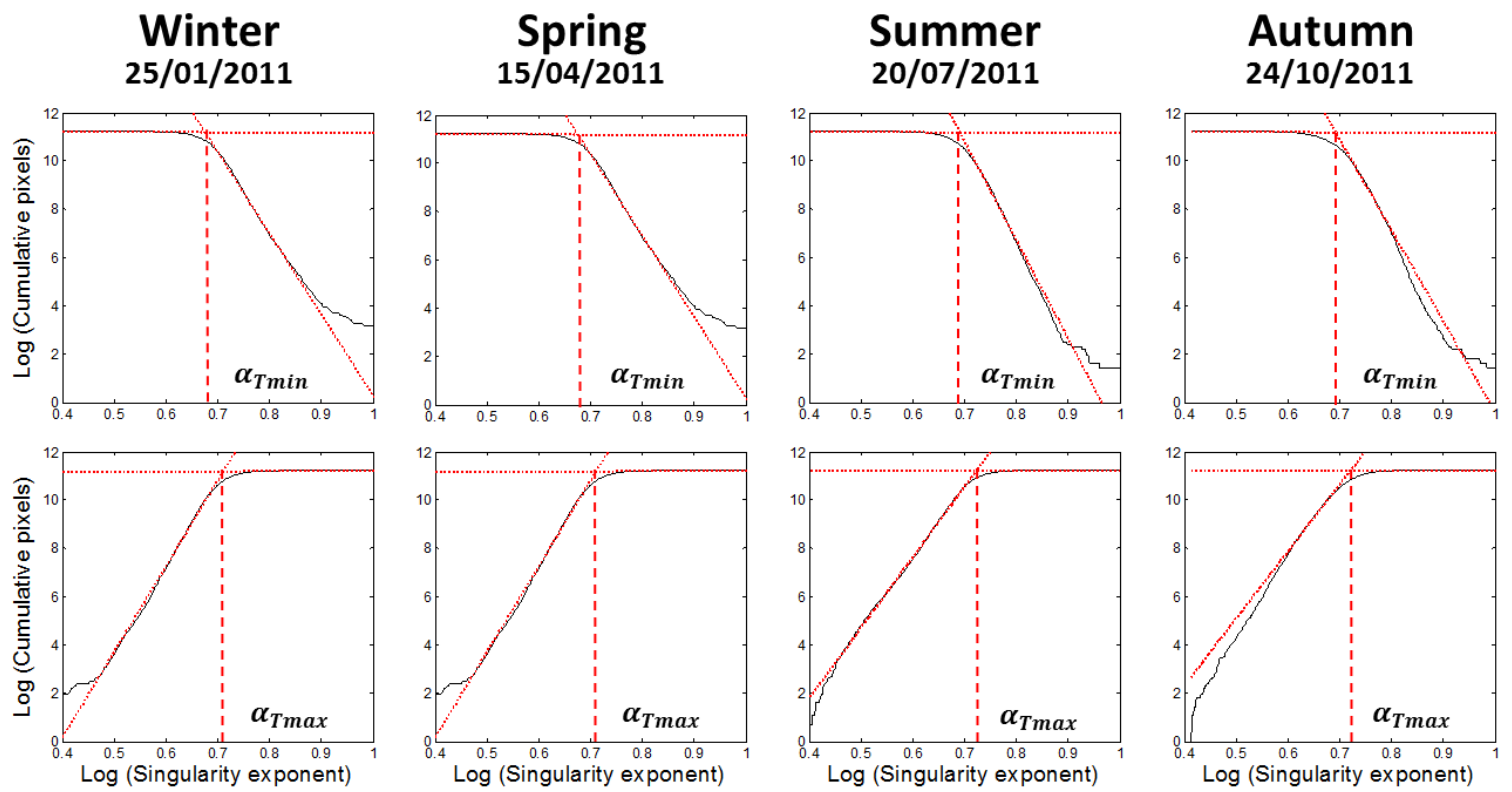

Fig. 3.6. Aplicación del método CA. Distribuciones acumuladas en escala log-log con el cruce de las dos rectas de regresión (en rojo) obteniendo (arriba) los umbrales inferiores: $\quad \alpha_{T \min }($ invierno $)=1.965, \quad \alpha_{T \min }($ primavera $)=1.953, \quad \alpha_{T \min }($ verano $)=$ 1.997 y $\alpha_{\text {Tmin }}($ otoño $)=1.999$; y (abajo) los umbrales superiores: , $\alpha_{\text {Tmax }}($ invierno $)=$ $2.036, \alpha_{\text {Tmax }}($ primavera $)=2.029, \alpha_{\operatorname{Tmax}}($ verano $)=2.059$ and $\alpha_{\operatorname{Tmax}}($ otoño $)=2.055$, para cada fecha analizada del año 2011.

\subsubsection{Las zonas no singulares}

En la Fig. 3.7 se muestran las zonas no singulares para cada fecha analizada, donde los píxeles negros representan dichas zonas $\left(\alpha_{\text {Tmin }} \leq \alpha(x) \leq \alpha_{\text {Tmax }}\right)$. Por tanto, los píxeles negros conectados constituyen áreas potenciales con estadísticas gaussianas.

En la Tabla 3.2 se muestra el porcentaje de zonas no singulares respecto del área total para todas las fechas analizadas. En el año seco (2005), el porcentaje de zonas no singulares es bastante similar en todas las estaciones, probablemente debido al menor contraste climático entre estaciones. Por otro lado, en el año húmedo (2011) la primavera es la estación con más zonas no singulares, probablemente por tener un mayor contraste climático con respecto al resto de estaciones de ese año. Por tanto, una mayoría de las distribuciones gaussianas se esperan en primavera. 


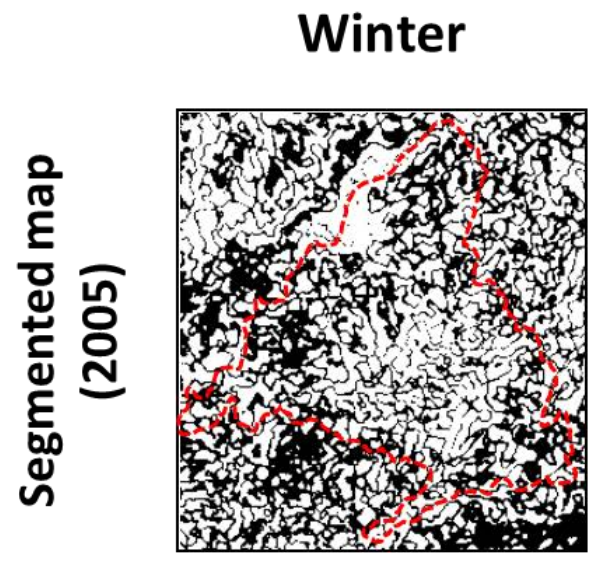

$17 / 01 / 2005$

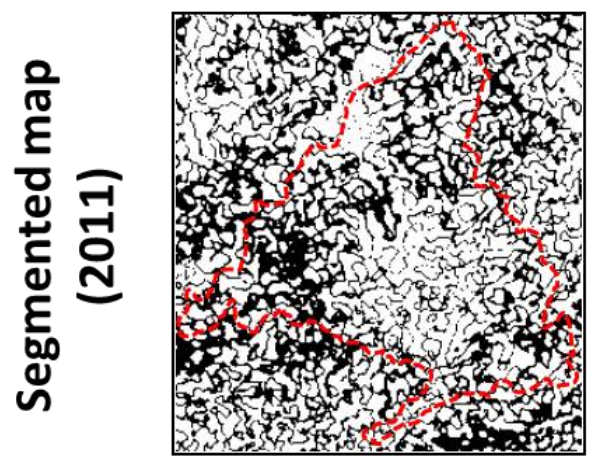

25/01/2011
Spring

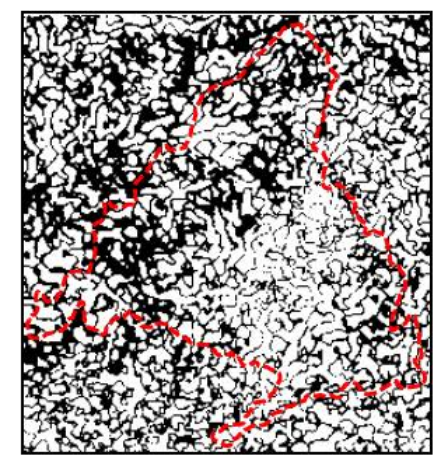

23/04/2005

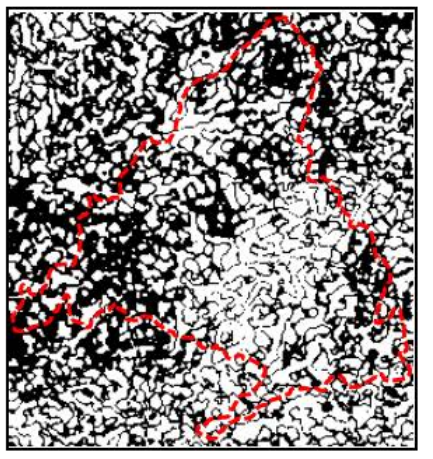

$15 / 04 / 2011$
Summer

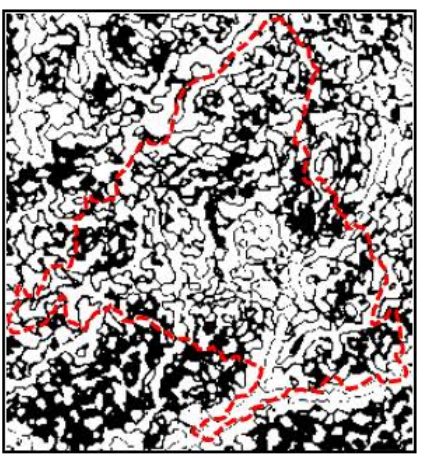

$20 / 07 / 2005$

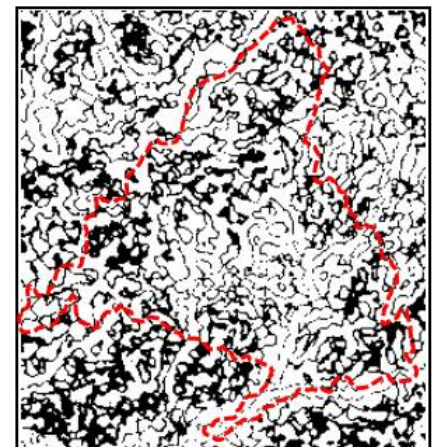

$20 / 07 / 2011$
Autumn

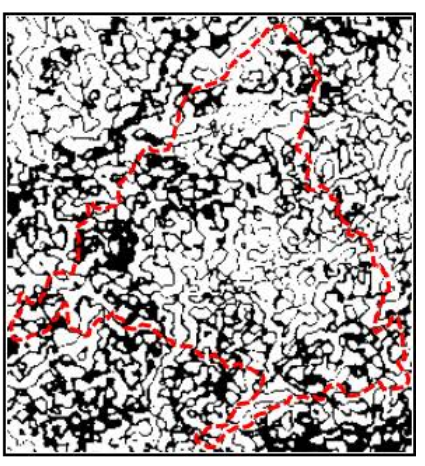

$24 / 10 / 2005$

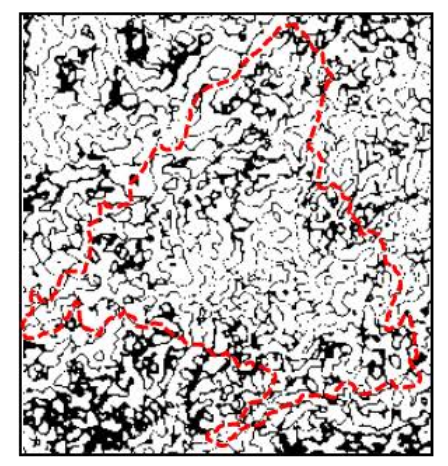

$24 / 10 / 2011$

Fig. 3.7 - Zonas no singulares mostradas como píxeles en color negro, donde $\alpha_{\text {Tmin }} \leq \alpha(x) \leq \alpha_{\text {Tmax }}$, para todas las fechas analizadas del 2005 y 2011. La línea discontinua representa los límites de la CAM. 
El porcentaje más bajo de zonas no singulares aparece siempre en otoño, independientemente del tipo de año (seco y húmedo). Esto es debido probablemente al incremento de la variabilidad espacial del NDVI, indicando que, por varias razones como por ejemplo la topografía o la heterogeneidad en las lluvias, existen determinadas zonas que alcanzan un valor alto de NDVI más rápidamente que otras.

\begin{tabular}{c|cccc} 
& Winter & Spring & Summer & Autumn \\
\hline Year 2005 (dry) & $41,6 \%$ & $39,9 \%$ & $39,7 \%$ & $34,5 \%$ \\
Year 2011 (wet) & $36,6 \%$ & $46,3 \%$ & $31,4 \%$ & $25,6 \%$ \\
\hline Intersection & $24,4 \%$ & $27,2 \%$ & $24,3 \%$ & $14,7 \%$
\end{tabular}

Tabla 3.2 - Porcentaje (\%) de zonas no singulares respecto del área total para todas las fechas analizadas (estaciones) y años $(2005,2011)$. La fila inferior muestra el \% de zonas no singulares de la intersección de dichos años.

La intersección de las zonas no singulares para cada estación fue obtenida intersectando las dos zonas no singulares (2005 y 2011) calculadas para cada estación (ver Fig. 3.8). Esta zona puede ser interpretada como la zona que mantiene la no singularidad sobre al menos los dos años analizados. El porcentaje de esta zona de intersección sobre el total del área es mostrada en la Tabla 3.2. Este porcentaje nos da una pista sobre la variabilidad espaciotemporal de las zonas no singulares al haber utilizado dos años de condiciones meteorológicas extremas (año seco y húmedo). En invierno y verano, este porcentaje es muy similar ( 24\%). El porcentaje más alto lo encontramos en primavera $(27.2 \%)$, por lo que es la estación que mantiene en mayor grado las mismas zonas no singulares en distintos años. El porcentaje más bajo lo encontramos en otoño (14.7\%), probablemente debido a la alta variabilidad espacial del NDVI. 

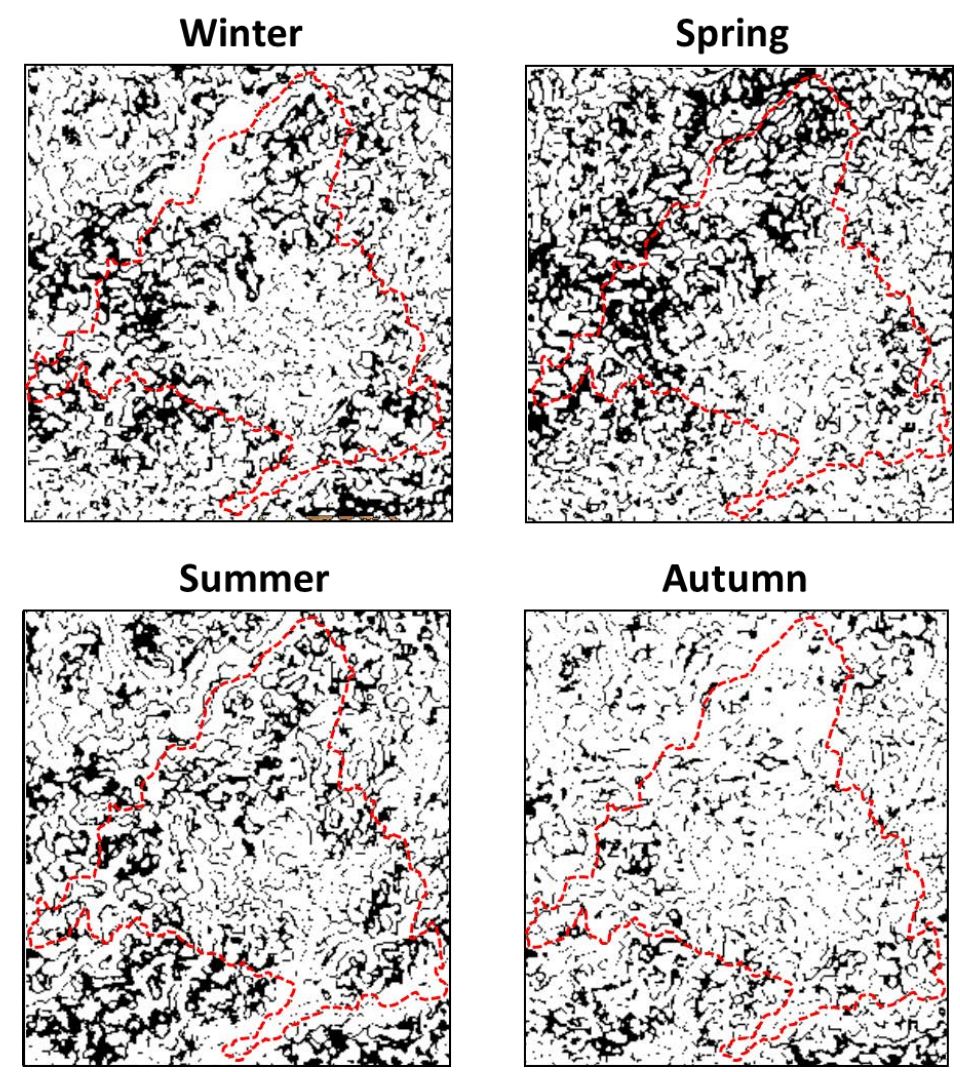

Fig. 3.8 - Intersección de las dos zonas no singulares (2005 y 2011) de cada estación (píxeles coloreados en negro). La línea discontinua representa los límites de la CAM.

La Fig. 3.8 muestra que la distribución espacial de las áreas no singulares es extremadamente dispersa para las distintas estaciones, confirmando el patrón multifractal de los mapas de NDVI donde, por definición, los diferentes $\alpha$ conjuntos están muy entrelazados. Al mismo tiempo se está reflejando la fuerte influencia que tienen los factores climáticos (precipitaciones, temperatura, etc) en los patrones temporales y espaciales de los mapas de NDVI.

En este punto es importante recordar que los ocho mapas de NDVI, y por tanto ocho fechas, fueron seleccionados como mapas representativos de cada estación en dos años bien distintos, año seco (2005) y húmedo (2011). Aunque los resultados obtenidos no son estadísticamente significativos, en sentido estricto, las diferencias encontradas en este estudio preliminar son relevantes, señalando que esta metodología podría delimitar zonas estadísticamente homogéneas. 


\section{CAPÍTULO 4}

\section{NUEVO MÉTODO DE}

\section{SEGMENTACIÓN BASADO EN LAS} PROPIEDADES FRACTALES DEL

\section{MAPA DE SINGULARIDADES EN IMÁGENES DE SUELOS}




\subsection{INTRODUCCIÓN}

El objetivo del siguiente estudio es aplicar el enfoque fractal a la estructura interna del suelo. Para ello se utiliza, por primera vez en este contexto, la metodología de segmentación Singularidad-CA para la delimitación del espacio de poros de una TAC de suelo en 2D. A continuación se realiza una comparativa con los métodos de segmentación tradicionales (Otsu, Iterativo y Máxima Entropía) para poner de manifiesto las principales diferencias entre ellos.

Además, se utiliza el nuevo método de los Multifractales Truncados (MT) para la creación de una imagen sintética de suelo, sobre la que también se realizará una comparativa con los métodos de segmentación tradicionales antes referidos.

\subsection{MATERIALES}

Se utilizó una muestra franco-arenosa de suelo arado de un campo de Escocia. Dicha muestra fue empaquetada en un cilindro de polipropileno de $6 \mathrm{~cm}$ de diámetro y $5 \mathrm{~cm}$ de altura, con una densidad de $1.2 \mathrm{Mg} \cdot \mathrm{m}^{-3}$. Para más detalles sobre la muestra ver Harris et al. (2003).

La muestra empaquetada fue escaneada mediante un sistema de microtomografía de rayos X modelo METRIS X-TEK de 160kV, $201 \mu \mathrm{A}$ y 3003 de proyección angular. Para minimizar los daños producidos por el haz de rayos $\mathrm{X}$, se utilizó un filtro de aluminio $(0.10 \mathrm{~mm})$. El proceso de reconstrucción de todas las radiografías para obtener una imagen en 3D se realizó mediante un CT-Pro Nikon y requirió varias correcciones. La imagen resultante en 3D fue importada en la aplicación software VGStudio Max (Volume Graphics, 2015) y convertida a una imagen de formato TIFF de 8 bits de resolución de vóxel. Finalmente se utilizó en este estudio una imagen de 260 × 260 × 260 vóxeles con un tamaño de lado de vóxel de 30 um. Para más detalles ver Pajor et al. (2010). 
Del conjunto total de imágenes (260 lonchas de 260 × 260 píxeles) se seleccionaron tres lonchas de 2D para chequear el método Singularidad-CA. Dichas imágenes presentaban diferentes patrones espaciales e histogramas de VG marcadamente unimodales. El cálculo del umbral de segmentación en imágenes con histogramas bimodales es típicamente más fácil que en histogramas unimodales, ya que en las primeras siempre se puede identificar más claramente dos objetos. En este estudio se seleccionaron imágenes con histogramas unimodales ya que el objetivo del estudio era chequear al método Singularidad-CA en las situaciones más exigentes.

\subsection{RESULTADOS}

\subsubsection{La imagen sintética de suelo}

Se creó una imagen sintética de suelo utilizando el método MT con un rango de 0 a 255 en los VG. Se siguieron los siguientes pasos del método:

Paso i): Primero se obtuvo un multifractal aleatorio de Sierpinski mediante un proceso de cascada multiplicativa (Perfect et al, 2006) de 8 iteraciones, y cuyo iniciador o generador se muestra en la Fig. 4.1. Las probabilidades iniciales que se utilizaron fueron las siguientes: $p_{1}=0.1167, p_{2}=0.1078, p_{3}=0.1156$, $p_{4}=0.1083, p_{5}=0.1144, p_{6}=0.1122, p_{7}=0.1100, p_{8}=0.1094$ y $p_{9}=0.1056$. El orden de las probabilidades $p_{i}$ fue aleatorizado antes de aplicar cada iteración.

\begin{tabular}{l|l|l|}
\multicolumn{3}{|c|}{$1^{\text {st }}$ ITERATION } \\
(generator) \\
$p_{1}$ & $p_{2}$ & $p_{3}$ \\
\hline$p_{4}$ & $p_{5}$ & $p_{6}$ \\
\hline$p_{7}$ & $p_{8}$ & $p_{9}$ \\
\hline
\end{tabular}

Fig. 4.1 - Generador de un multifractal de Sierpinski (1ª iteración). 
El proceso de truncado para la obtención del espacio de poros y de guijarros se muestra en la Fig. 4.2. Antes del truncamiento, la medida multifractal fue filtrada mediante un filtro paso-bajo de tipo "función rectangular" de 7 píxeles de lado. Los umbrales de truncamiento en VG para el espacio de poros y de guijarros fueron de $G V_{t h 1}=189$ and $G V_{t h 2}=215$, respectivamente.
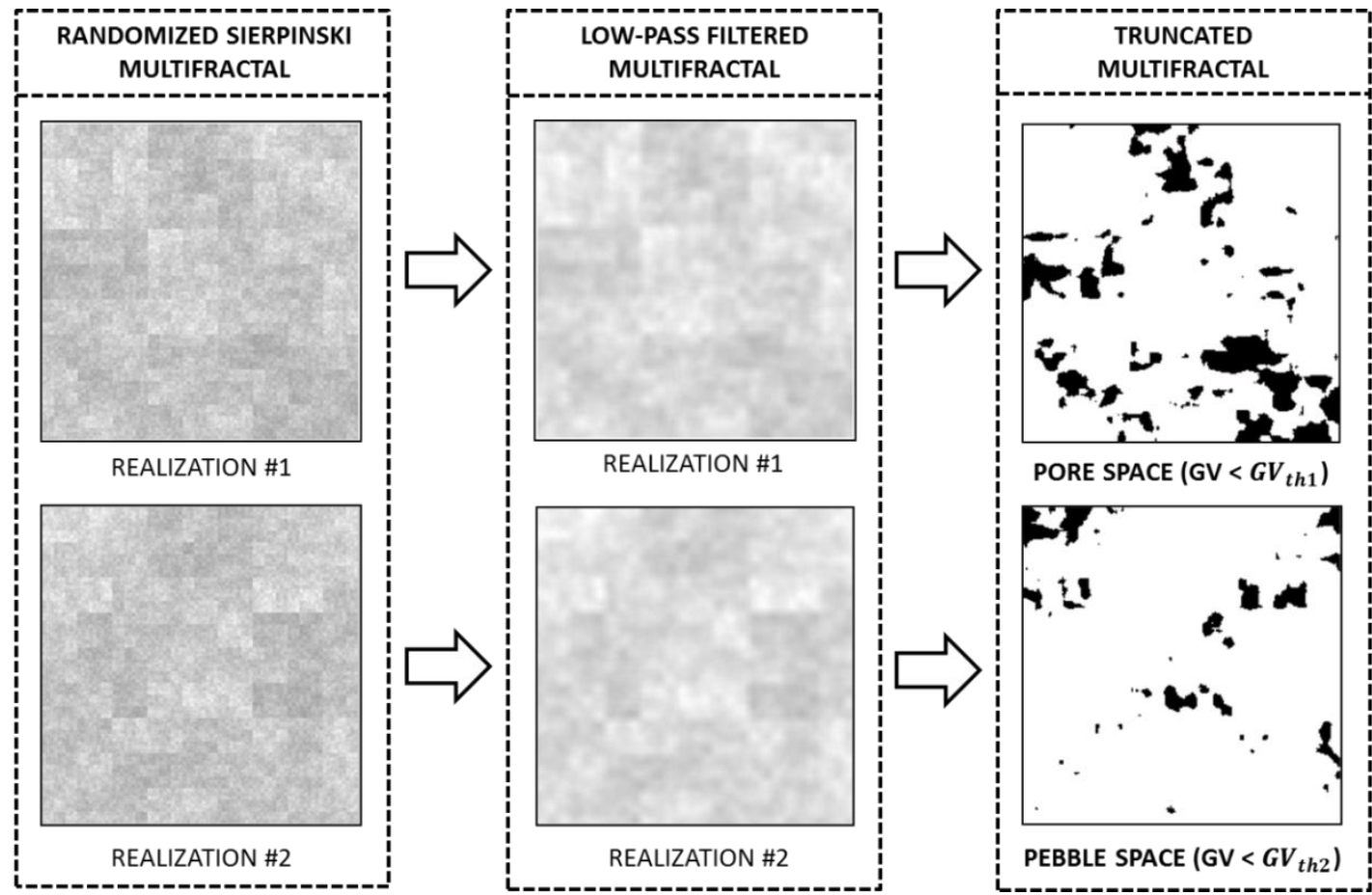

Fig. 4.2 - Proceso de truncamiento en el método de los MT (paso i). A la izquierda: dos realizaciones de un multifractal aleatorio de Sierpinski. En el medio: multifractal filtrado (filtro paso-bajo) mediante una función rectangular. A la derecha: multifractales truncados con dos umbrales diferentes.

Pasos ii, iii y iv): En el paso ii se definió la porosidad del ground-truth (poros llenos de aire) con un valor de 0.138 , solapando ambos espacios (poros y guijarros). Para la construcción del esqueleto del histograma de VG se tomaron los siguientes valores: $G V_{\text {Pore space }}=0, G V_{\text {Background }}$ medio $=70$ y $G V_{\text {Pebble space }}$ medio $=125$. En el paso iii se sumó un ruido blanco Gaussiano con una relación señal-ruido (RSR) de $5 \mathrm{~dB}$. Finalmente, en el paso iv) se filtró la imagen previa mediante un filtro paso-bajo de tipo "función rectangular" de 9 píxeles de lado. Los pasos ii, iii y iv se muestran en la Fig. 4.3. 


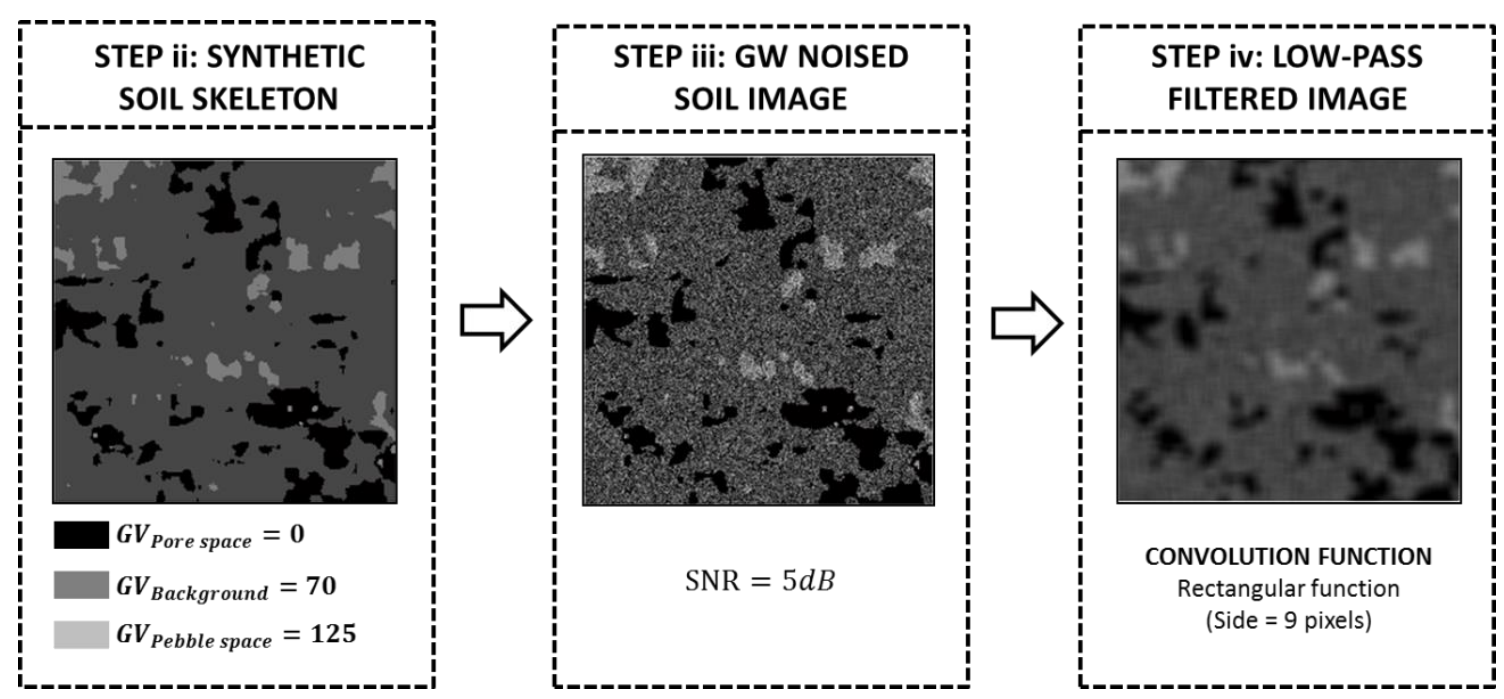

Fig. 4.3 - Resultados para los pasos ii, iii y iv en la construcción de una imagen sintética de suelo mediante el método de los MT.

\subsubsection{Mapas de singularidades}

Todas las imágenes de suelo seleccionadas en este estudio (sintética y reales) tienen dos características comunes: no muestran histogramas bimodales y presentan un bajo contraste en la interfaz poro-sólido (para una mejor visualización se mejoró el contraste en las figuras mediante la técnica de "contrast stretching" (Jain, 1989)). Las imágenes de suelos seleccionadas en escala de grises se muestran en la Fig. 4.4, con sus respectivos histogramas y principales estadísticos.

La parte superior de la Fig. 4.5 muestra el resultado de aplicar el cálculo del mapa de singularidades a todas las imágenes de suelo. Se utiliza un mapa de color "jet invertido" para una mejor visualización. Los colores rojizos indican singularidades positivas (exponentes $\alpha<2$ ), y los colores azulados indican singularidades negativas (exponentes $\alpha>2$ ). Las zonas de interés son aquellas con las singularidades negativas (azuladas) debido a la correlación que hemos establecido en la metodología Singularidad-CA entre el espacio de poros y la zona de disminución de la concentración media. En la parte inferior de la Fig. 4.6 se muestran los histogramas de VS. Se aprecia claramente que todos los histogramas son unimodales. 

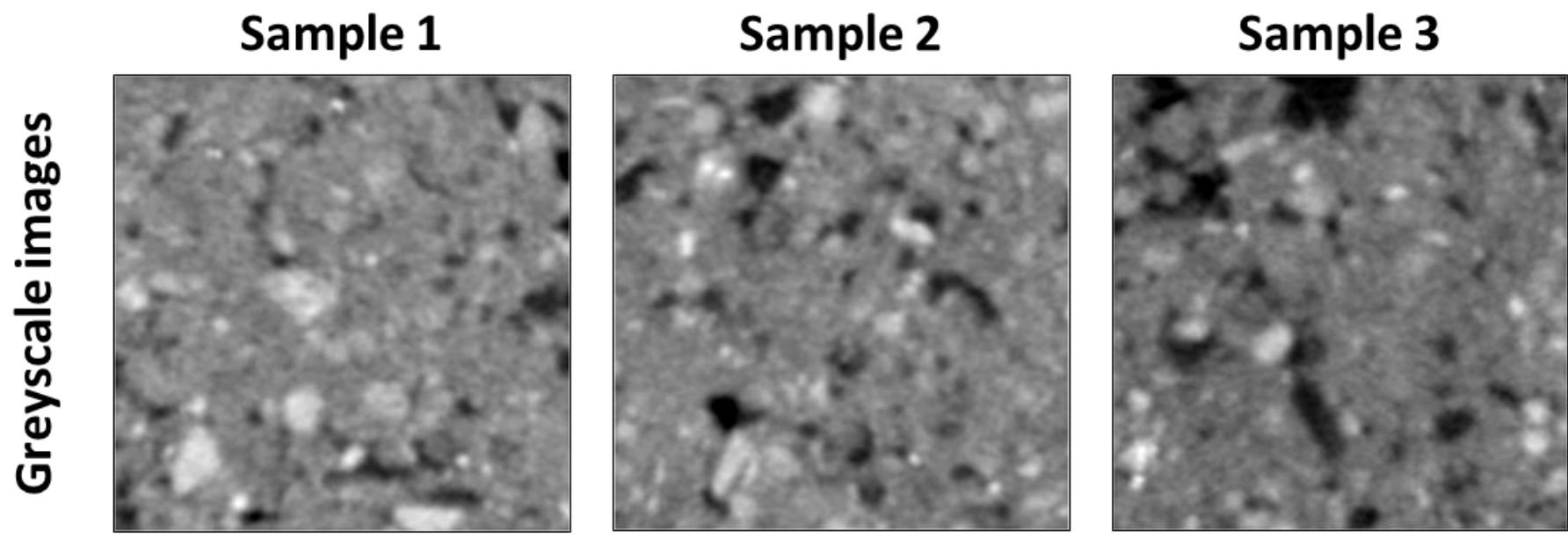

\section{Synthetic sample}
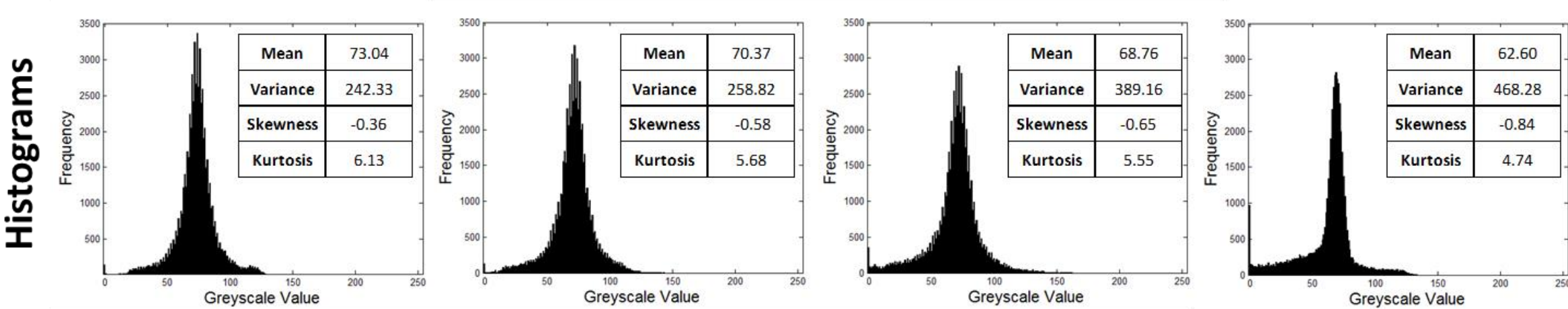

Fig. 4.4 - Arriba: imágenes en escala de grises de las muestras TAC reales ( 246 x 246 píxeles) y de la imagen sintética de suelo ( 215 x 215 píxeles). Abajo: histogramas de escala de grises de cada imagen. 

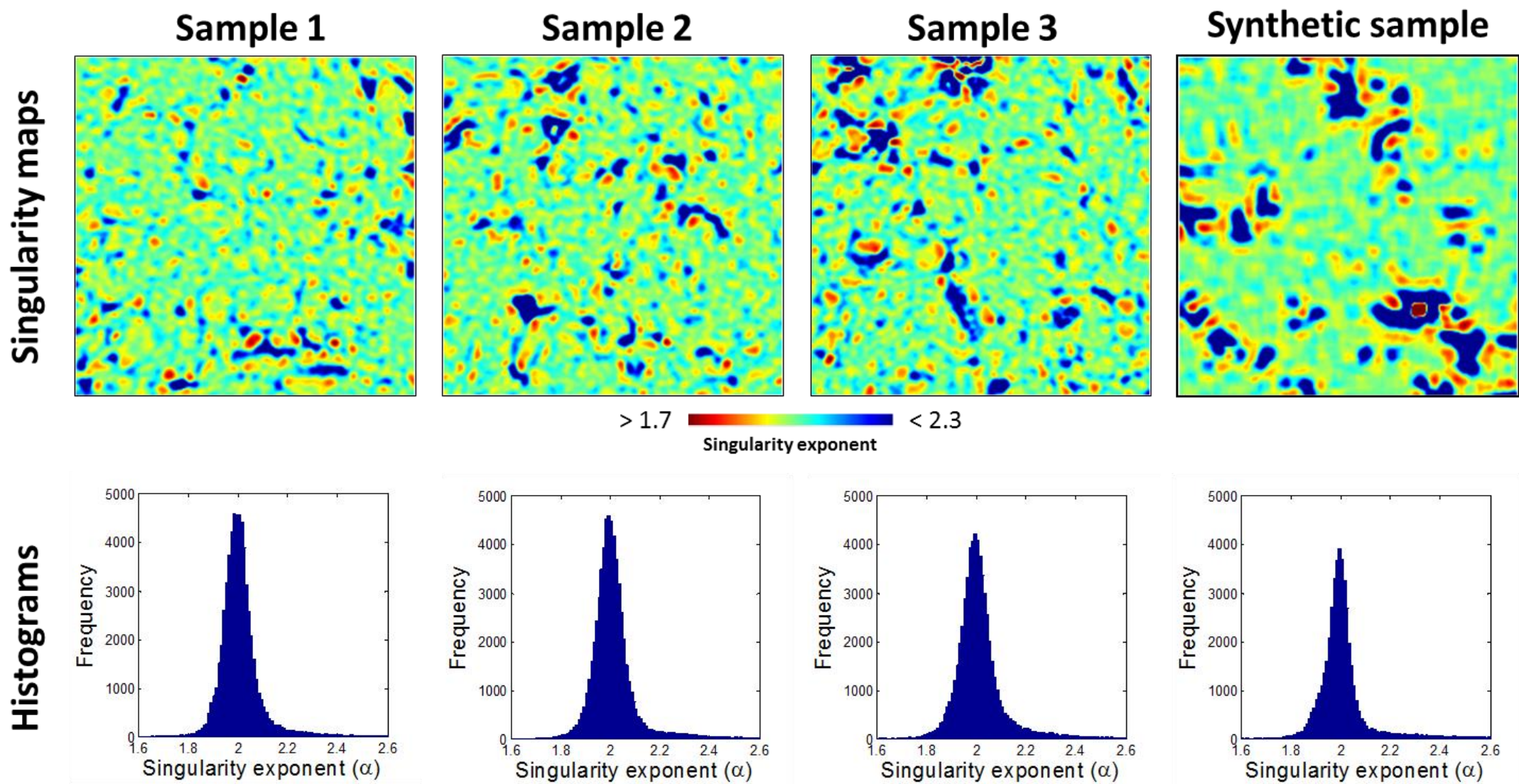

$>1.7$ Singularity exponent
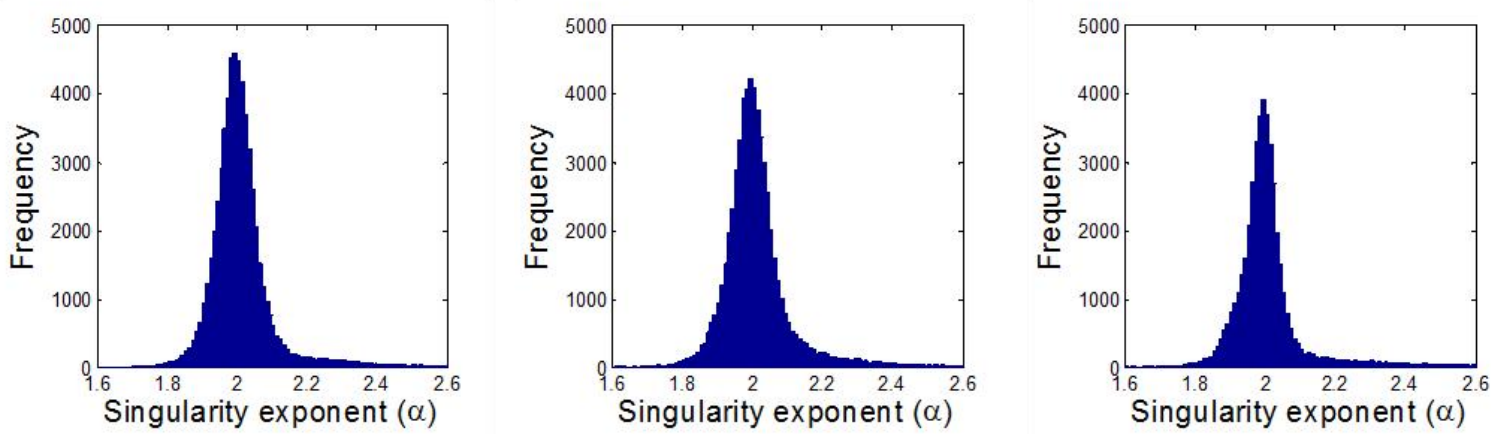

Fig. 4.5 - Arriba: mapas de singularidades de las muestras TAC reales $(246 \times 246$ píxeles) y de la imagen sintética de suelo $(215 \times 215$ píxeles). Abajo: histogramas de los exponentes de singularidad de cada imagen. 
Los principales estadísticos de los histogramas de los mapas de singularidades, a saber, la media, la mediana, la varianza, la asimetría y la curtosis, se muestran en la Tabla 4.1. La mediana es aproximadamente igual a 2 para todos los casos. En todas las imágenes de suelo los valores de la asimetría son altos y positivos, es decir, los valores están más esparcidos hacia la derecha de la media. Esto significa que hay más valores dispersos en las singularidades negativas $(\alpha>2)$. Los valores de la curtosis son muy superiores a 3 (leptocúrtica), valor que toman las distribuciones normales.

\begin{tabular}{|c|c|c|c|c|}
\hline \multicolumn{1}{|c|}{} & Sample 1 & Sample 2 & Sample 3 & $\begin{array}{c}\text { Synthetic } \\
\text { sample }\end{array}$ \\
\hline Median & 2.000 & 2.000 & 2.000 & 1.997 \\
\hline Mean & 2.011 & 2.018 & 2.023 & 2.065 \\
\hline Variance & 0.0183 & 0.0386 & 0.0312 & 0.1497 \\
\hline Skewness & 24.542 & 19.945 & 11.242 & 7.963 \\
\hline Kurtosis & 1038.356 & 557.108 & 208.872 & 86.991 \\
\hline
\end{tabular}

Tabla 4.1 - Principales estadísticos de la variable singularidad $(\alpha)$ para cada imagen de suelo: media, mediana, varianza, asimetría y curtosis.

\subsubsection{El método CA}

En la metodología S-CA calculamos los umbrales que definen el espacio de poros aplicando el método CA a los mapas de singularidades. Primero, calculamos las distribuciones acumuladas de los valores del mapa de singularidades y obtenemos los gráficos en escala log-log de la Fig. 4.6. En todas distribuciones, tanto en la sintética como en las TAC reales, aparecen tramos lineales con puntos de cambio de pendiente. Cada tramo corresponde con un conjunto diferente con algún tipo de auto-similitud.

Tal como se especifica en el método S-CA, estamos interesados en el punto de cambio de pendiente que está localizado inmediatamente después del valor $\alpha=$ 2, ya que éste es el primer punto de cambio de pendiente contenido en el área de las singularidades negativas. En la Fig. 4.6 se han marcado con un círculo 
negro todos los puntos de cambio de pendiente. Todos estos puntos definen límites en los tramos lineales en las distribuciones acumuladas.

Sample 1

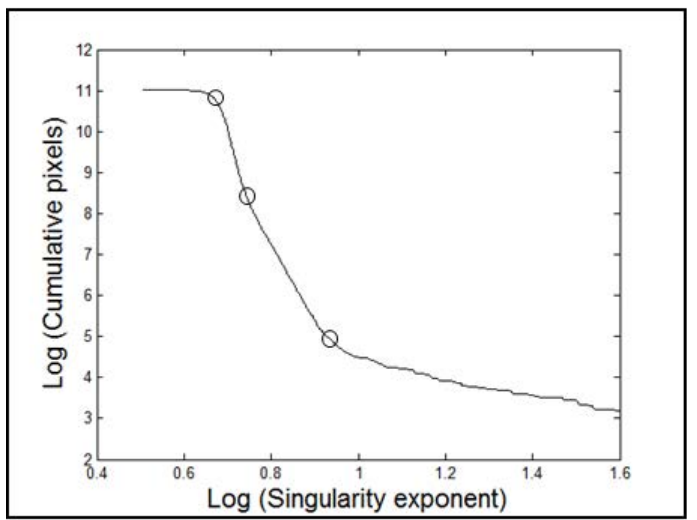

Sample 3

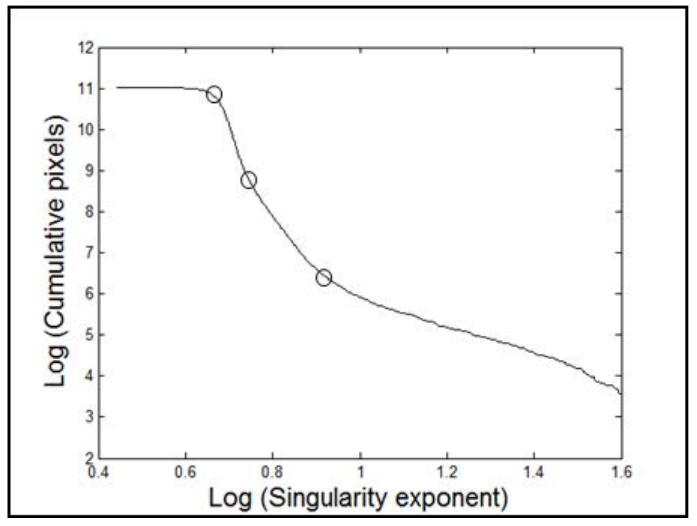

Sample 2

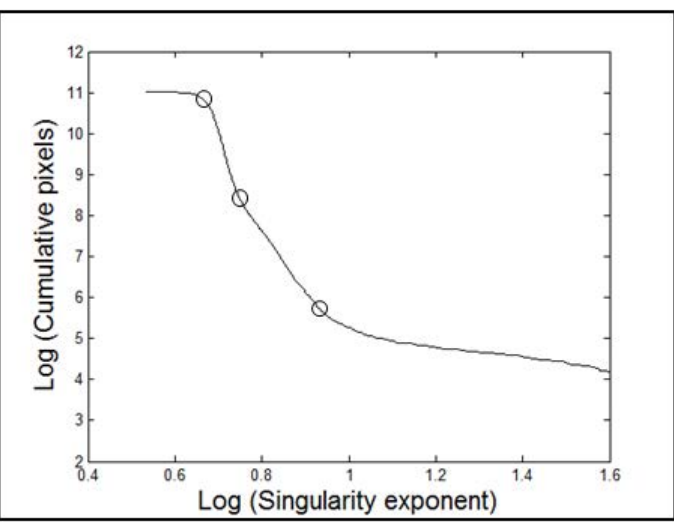

Synthetic sample

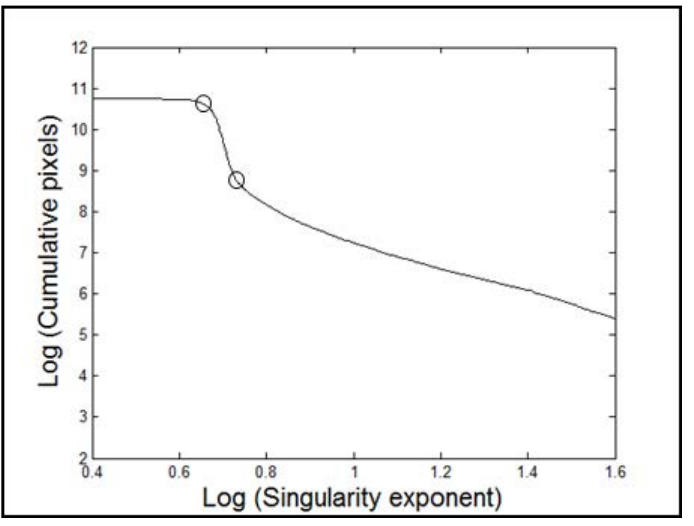

Fig. 4.6 - Distribuciones log-log acumuladas obtenidas mediante el método CA. Los círculos señalan los puntos de cambio de pendiente.

La localización exacta de los puntos de cambio de pendiente se calculó mediante el método de la Transformada Wavelet Módulo Máximo (TWMM). En la Fig. 4.7 se puede apreciar como las líneas de módulo máximo convergen en los puntos buscados a medida que el parámetro "escala" de la wavelet disminuye. Concretamente, el punto de cambio de pendiente que estamos buscando es el primero que cumple la condición $\alpha>2$, y son los que aparecen recuadrados en la Fig. 4.7. En resumen, los umbrales proporcionados por el método S-CA fueron: $\alpha_{c 1}=2.078, \alpha_{c 2}=2.092, \alpha_{c 3}=2.084$ and $\alpha_{c 4}=2.065$. 


\section{Sample 1}
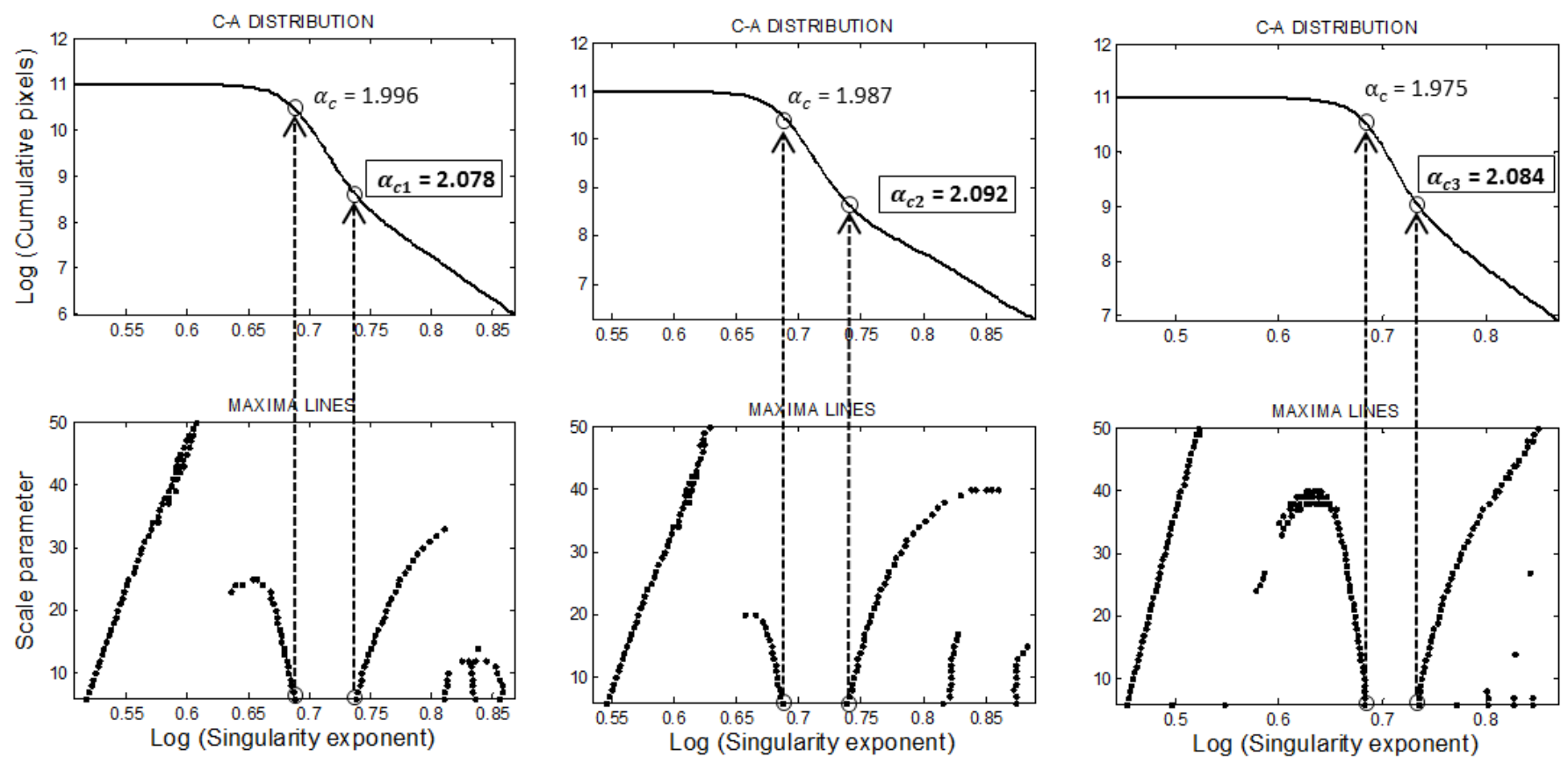

Synthetic sample

Fig. 4.7 - Arriba: Distribuciones acumuladas en escala log-log con los puntos de cambio de pendiente. Abajo: método TWMM aplicado a las distribuciones de arriba. Las líneas de máximos convergen hacia los puntos de cambio de pendiente.

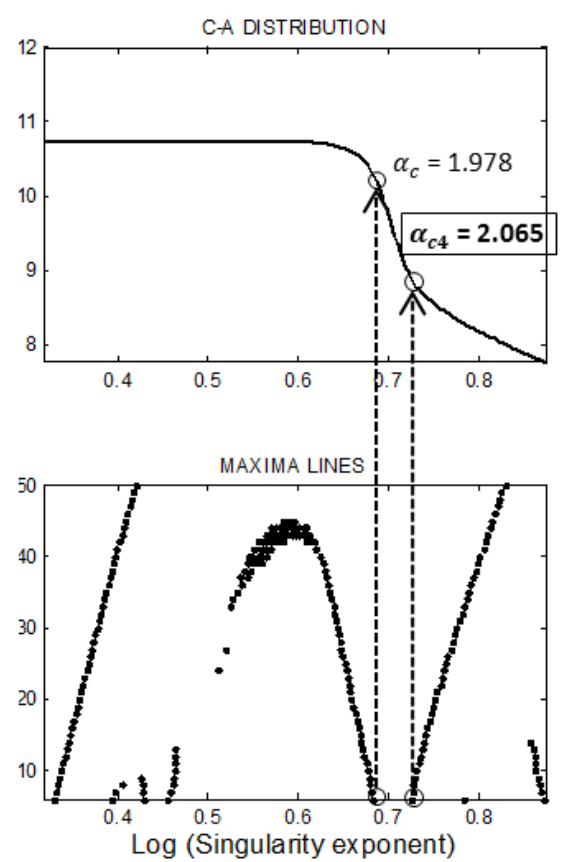

Log (Singularity exponent) 
El resultado de la binarización de los mapas de singularidades de las imágenes de suelo analizadas se muestra en el Fig. 4.8. En la parte inferior de la misma figura también podemos ver las imágenes en VG perfiladas con el borde de las imágenes binarizadas para comprobar como el método trabaja en la definición del espacio de poros.

Sample 1
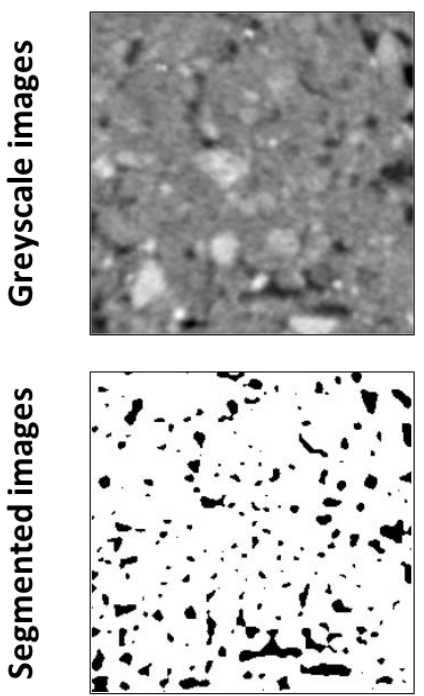

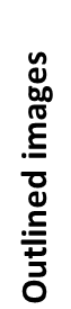

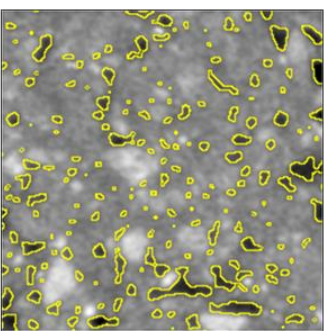

Sample 2
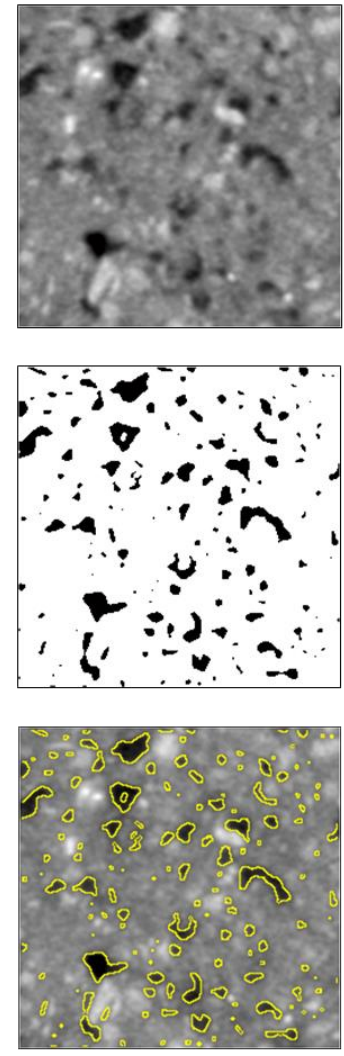

Sample 3
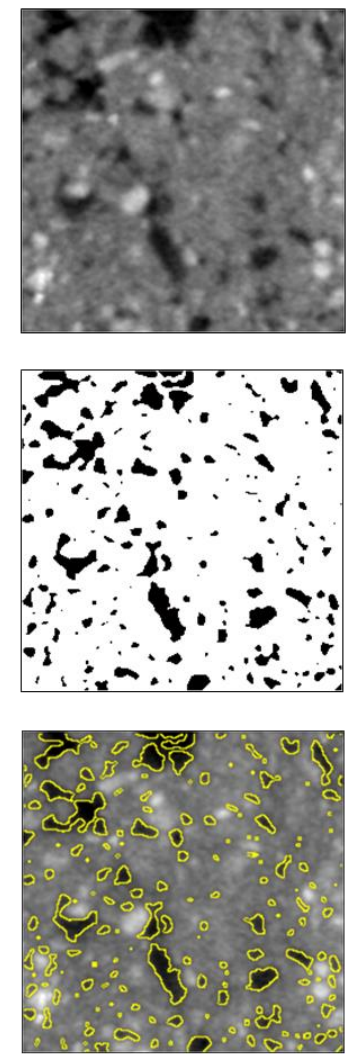

Synthetic sample
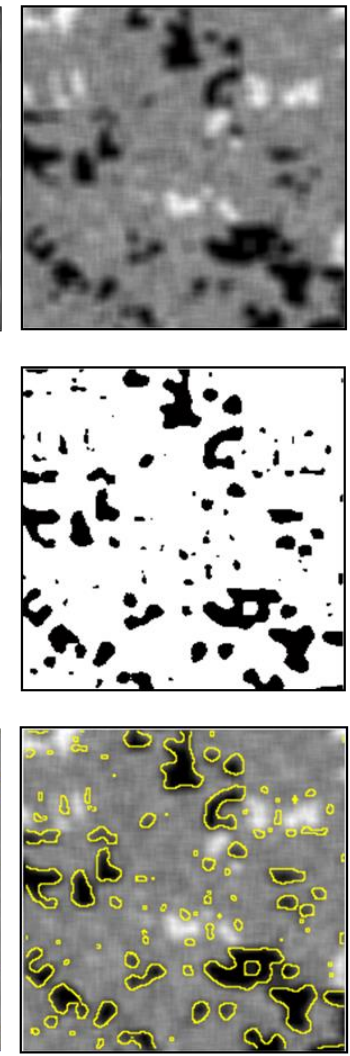

Fig. 4.8 - Arriba: imágenes en escala de grises de todas las imágenes de suelo. Medio: imágenes binarizadas después de aplicar el método S-CA (el espacio de poros está coloreado en negro). Abajo: solapamiento de las imágenes en escala de grises con los bordes de las imágenes binarizadas.

\subsubsection{Evaluación del método Singularidad-CA mediante una imagen sintética de suelo.}

Se realizó la comparación de los métodos de segmentación de Otsu, Iterativo, Máxima Entropía y S-CA utilizando el ground-truth de la imagen sintética de suelo. En la Fig. 4.9 se muestran todas las imágenes binarizadas después de aplicar todos los métodos analizados. Debido a que conocemos el ground-truth 
de la imagen sintética, pudimos calcular la Clasificación Errónea de Poros (CEP). El cálculo de algunos estadísticos, como la porosidad total y la distribución del tamaño de poros, junto con la CEP, nos permitieron evaluar mejor el método de Singularidad-CA.

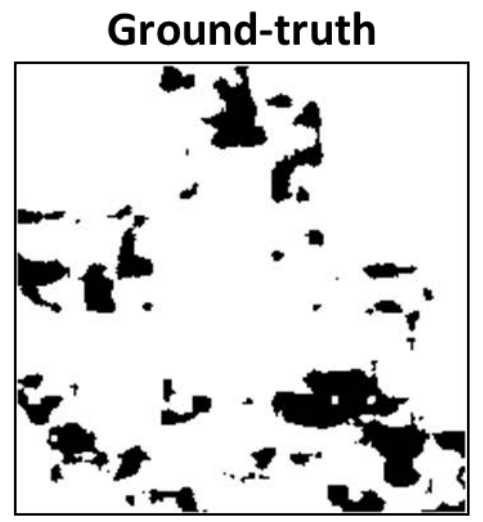

Porosity $=0.138$

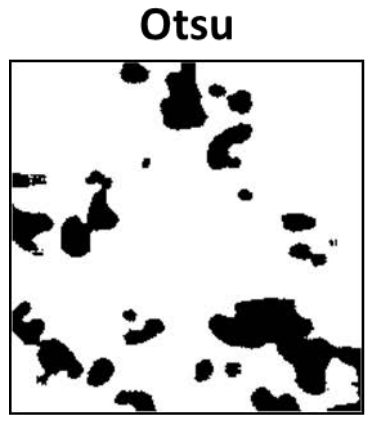

Porosity $=0.177$

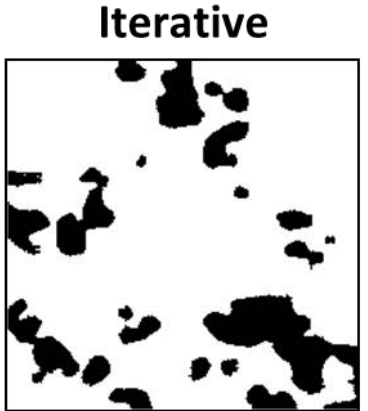

Porosity $=0.188$
Max. Entropy

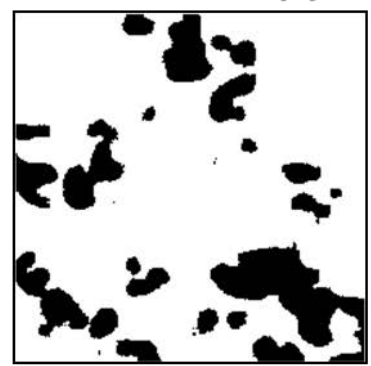

Porosity $=0.206$

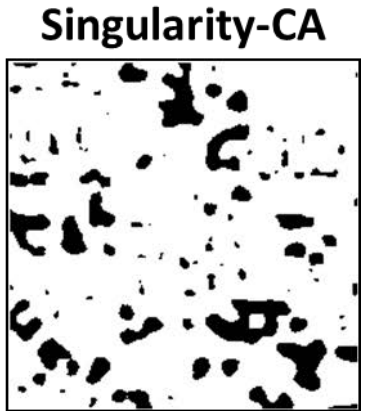

Porosity $=0.156$

Fig. 4.9 - Arriba: espacio de poros real (ground-truth) de la imagen sintética. Abajo: imágenes binarizadas obtenidas aplicando los diferentes métodos de segmentación (Otsu, Iterativo, Máxima Entropía y Singularidad-CA) a la imagen sintética de suelo (el espacio de poros está coloreado en negro).

\section{Porosidad}

La porosidad total fue calculada en base a las imágenes binarizadas que se muestran en la Fig. 4.9. La porosidad obtenida usando el método SingularidadCA (0.156) fue la más cercana a la del ground-truth (0.138). Los métodos de Otsu, Iterativo y de Máxima Entropía ofrecieron porosidades de 0.177, 0.188 y 0.206 , respectivamente, y fueron superiores a los valores verdaderos (ver Tabla 4.2). 
SYNTHETIC SAMPLE

\begin{tabular}{|c|c|c|c|c|c|}
\multicolumn{1}{c|}{} & Ground-Truth & Otsu & Iterative & Max. Entropy & Singularity-CA \\
\hline \# of Pores & 53 & 25 & 21 & 27 & 95 \\
\hline Max. Pore Size & 1790 & 2527 & 2616 & 2776 & 823 \\
\hline Avg. Pore Size & 120.36 & 327.44 & 413.81 & 353.44 & 76.05 \\
\hline Porosity & 0.138 & 0.177 & 0.188 & 0.206 & 0.156 \\
\hline ME & 0.000 & 0.056 & 0.064 & 0.078 & 0.063 \\
\hline
\end{tabular}

Tabla 4.2 - Comparación del número de poros, tamaño máximo de poro (en píxeles), tamaño medio de poro (en píxeles), porosidad total y clasificación errónea de poros (CEP) en la imagen sintética de suelo para los distintos métodos de segmentación analizados.

Distribución de Tamaño de Poros (DTP) y Distribución de Área de Poros (DAP)

La DTP acumulada y la DAP acumulada fueron obtenidas igualmente de las imágenes binarizadas de la Fig. 4.9, y se muestran en la Fig. 4.10 para todos los métodos de segmentación analizados. En la Tabla 4.2 también se muestran los principales estadísticos de la DTP, a saber, el número de poros, el tamaño del poro máximo y el tamaño medio de poro. En este estudio, el tamaño del poro fue definido como el número de píxeles contenidos en cada zona conectada de poro.
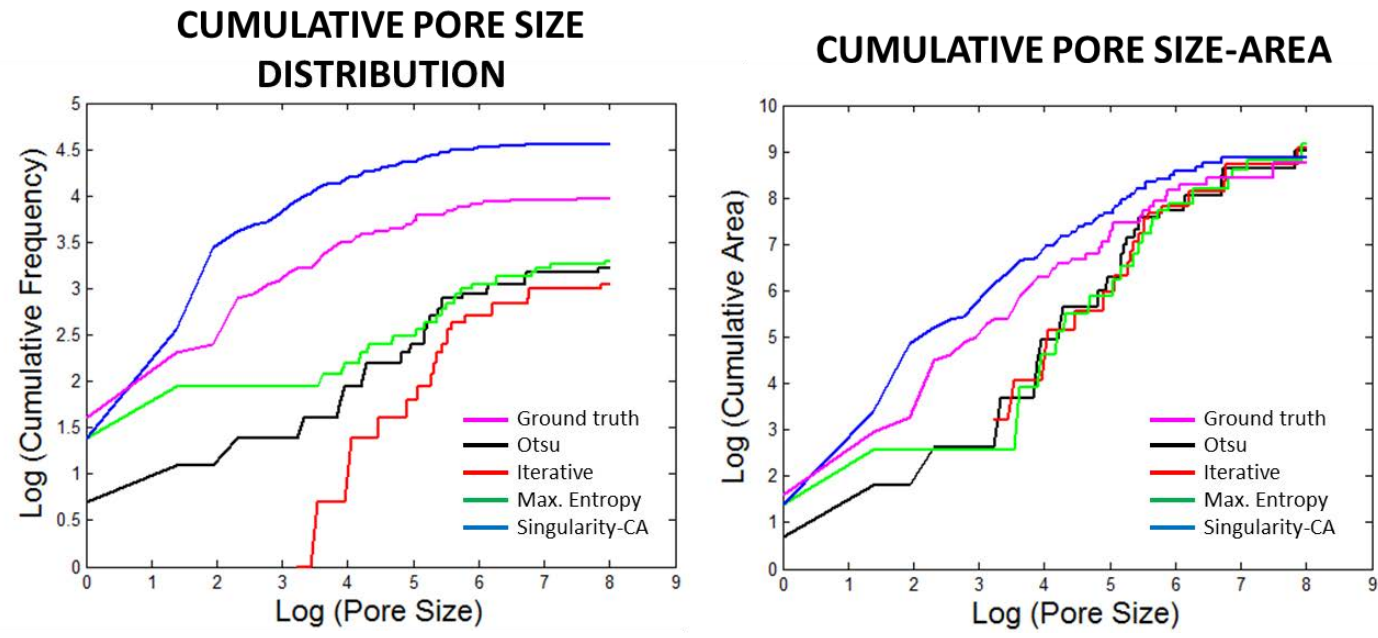

Fig. 4.10 - Comparación de la DTP acumulada (izquierda) y la DAP acumulada (derecha) para la imagen sintética de suelo y los métodos de segmentación comparados. 
Atendiendo a la forma de los gráficos mostrados en la Fig. 4.10, destacamos los siguientes puntos:

i) Los métodos de Otsu, Iterativo y Máxima Entropía tienen DTP acumuladas muy similares (ver parte izquierda de la Fig. 4.10), y todos ellos subestiman el $\mathrm{n}^{\circ}$ total de poros reales. Con respecto a la DAP acumulada (ver parte derecha de la Fig. 4.10), podemos ver como estos métodos acumulan el área de la misma forma, muy por debajo de la curva del ground-truth, hasta que reconocen los poros más grandes y la línea del ground-truth es sobrepasada. En resumen, los métodos referidos subestiman el $n^{\circ}$ de poros pequeños y sobrestiman el tamaño de los poros grandes.

ii) El método S-CA sobrestima el $n^{\circ}$ total de poros reales, particularmente el $n^{\circ}$ de los poros pequeños, tal como se puede apreciar en la DTP acumulada (ver parte izquierda de la Fig. 4.10). Al contrario que los métodos de Otsu, Iterativo y de Máxima Entropía, el método S-CA no sobrestima el tamaño de los poros medianos y grandes. Esto último se puede observar en la DAP acumulada, donde las pendientes de la curva del S-CA y el ground-truth son muy similares para tamaños de poros por encima de 10 píxeles aproximadamente $(\log (10$ píxeles $)=2.3)$.

El comportamiento tan especial del método S-CA de detectar más poros, particularmente más pequeños, es debido a la gran sensibilidad en detectar valores anómalos en los VG de las imágenes digitales, es decir, este método es capaz de ver más bordes que otros métodos.

\section{Clasificación Errónea de Poros (CEP)}

El criterio utilizado para evaluar la calidad de la segmentación fue la CEP. En la Tabla 4.2 se muestran los resultados obtenidos para todos los métodos analizados en este estudio. La CEP del método S-CA (0.063) fue baja y similar a los métodos de Otsu (0.056), Iterativo (0.064) y Máxima Entropía (0.078). 


\subsubsection{Comparación de los diferentes métodos de segmentación usando una TAC de suelo real.}

En este apartado comparamos el método de S-CA con los métodos tradicionales de Otsu, Iterativo y de Máxima Entropía. En la Fig. 4.11 se muestran las imágenes binarizadas obtenidas al aplicar los métodos anteriores a las 3 muestras (lonchas) seleccionadas de una TAC de suelo real.

\section{Sample 1}
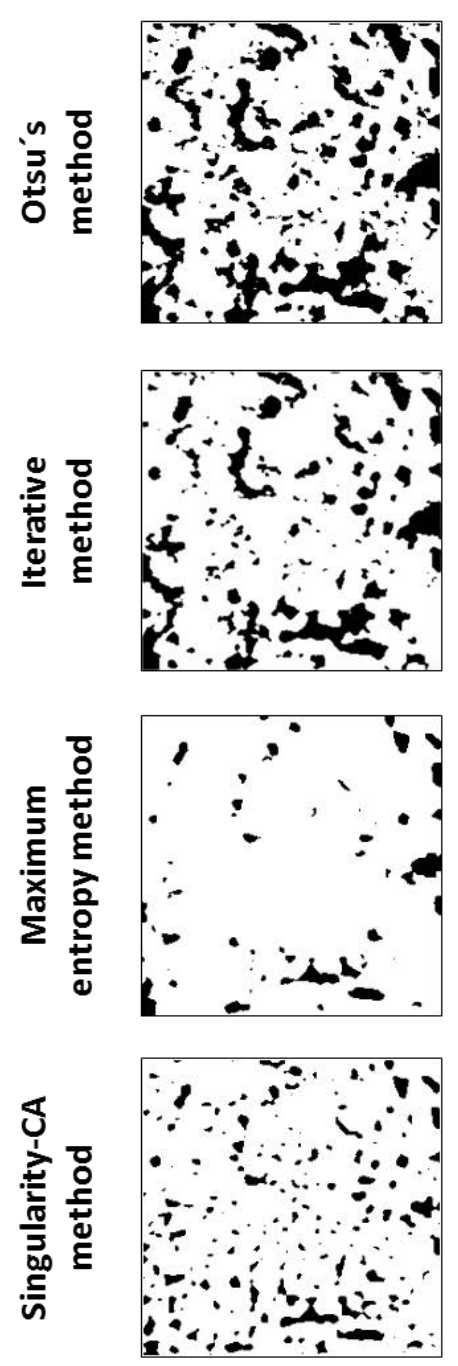

Sample 2
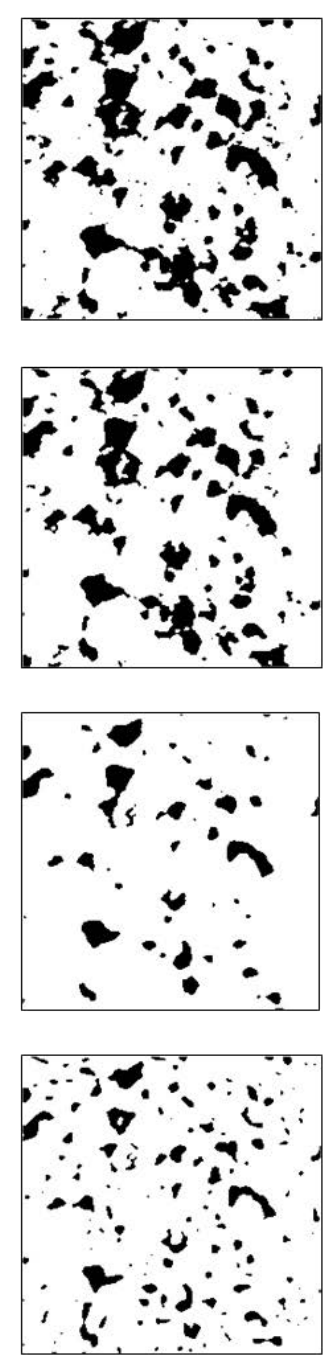

Sample 3
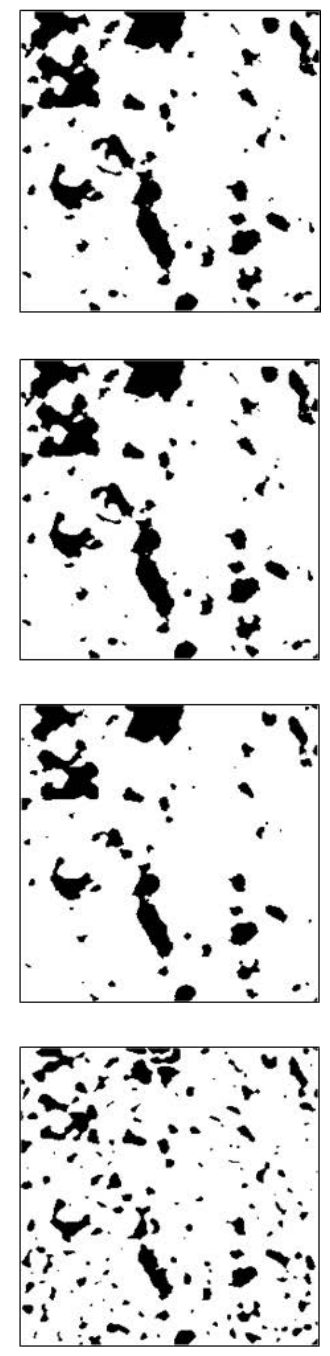

Fig. 4.11 - Imágenes binarizadas obtenidas aplicando los diferentes métodos de segmentación (Otsu, Iterativo, Máxima Entropía y Singularidad-CA) a las tres muestras en 2D de la TAC de suelo real (el espacio de poros está coloreado en negro). 


\section{Porosidad}

La porosidad fue calculada en base a las imágenes binarizadas que se muestran en la Fig. 4.11. En la Tabla 4.3 aparecen los resultados de porosidad obtenidos para todos los métodos analizados. Las porosidades obtenidas por los métodos de Otsu e Iterativo fueron siempre las más altas, mientras que las obtenidas por el método de Máxima Entropía fueron las más bajas. El método S-CA siempre suministró una porosidad intermedia entre el Otsu/lterativo y el de Máxima Entropía.

\begin{tabular}{|c|c|c|c|c|}
\hline \multicolumn{1}{|c|}{ Sample 1 } \\
\hline \# of Pores & Otsu & Iterative & Max. Entropy & Singularity-CA \\
\hline Max. Pore Size & 171 & 125 & 54 & 193 \\
\hline Avg. Pore Size & 91.64 & 1616 & 457 & 402 \\
\hline Porosity & 0.259 & 93.40 & 65.65 & 34.47 \\
\hline
\end{tabular}

\section{Sample 2}

\begin{tabular}{|c|c|c|c|c|}
\multicolumn{1}{c|}{} & Otsu & Iterative & Max. Entropy & Singularity-CA \\
\hline \# of Pores & 115 & 92 & 51 & 145 \\
\hline Max. Pore Size & 2028 & 1303 & 617 & 381 \\
\hline Avg. Pore Size & 112.42 & 119.33 & 92.61 & 41.22 \\
\hline Porosity & 0.214 & 0.181 & 0.078 & 0.099 \\
\hline
\end{tabular}

\section{Sample 3}

\begin{tabular}{|c|c|c|c|c|}
\multicolumn{1}{c|}{} & Otsu & Iterative & Max. Entropy & Singularity-CA \\
\hline \# of Pores & 67 & 67 & 59 & 176 \\
\hline Max. Pore Size & 1629 & 1629 & 1359 & 567 \\
\hline Avg. Pore Size & 152.20 & 152.20 & 132.49 & 47.33 \\
\hline Porosity & 0.168 & 0.168 & 0.129 & 0.138 \\
\hline
\end{tabular}

Tabla 4.3 - Comparación del número de poros, tamaño máximo de poro (en píxeles), tamaño medio de poro (en píxeles) y porosidad total de las tres muestras de la TAC de suelo real para los distintos métodos de segmentación analizados.

De los estadísticos de los histogramas de la Fig. 4.4, se puede observar que la muestra 3 es la más parecida a la imagen sintética de suelo utilizada en este 
estudio. Atendiendo a los resultados obtenidos para la imagen sintética podemos deducir que los métodos de Otsu e Iterativo sobrestiman la porosidad real de la muestra 3. Extrapolando los resultados a las muestras 1 y 2, los métodos de Otsu e Iterativo también están sobrestimando la porosidad real. En todos los casos es muy probable que el método de Máxima Entropía esté subestimando la porosidad real. Esta última afirmación no es del todo concluyente ya que no se ha conseguido reproducir el comportamiento de este método con la imagen sintética: mientras que en las muestras reales siempre ofrece la menor porosidad, en la imagen sintética obtenía la mayor porosidad.

Distribución de Tamaño de Poros (DTP) y Distribución de Área de Poros (DAP)

La DTP acumulada y la DAP acumulada (ver Fig. 4.12) fueron obtenidas de las imágenes binarizadas de la Fig. 4.11. En la Tabla 4.3 también se muestran los principales estadísticos de la DTP.

\section{Sample 1 \\ Sample 2 \\ Sample 3}

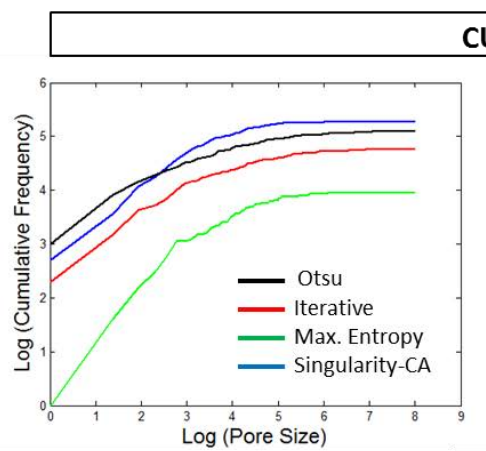
CUMULATIVE PORE SIZE DISTRIBUTION
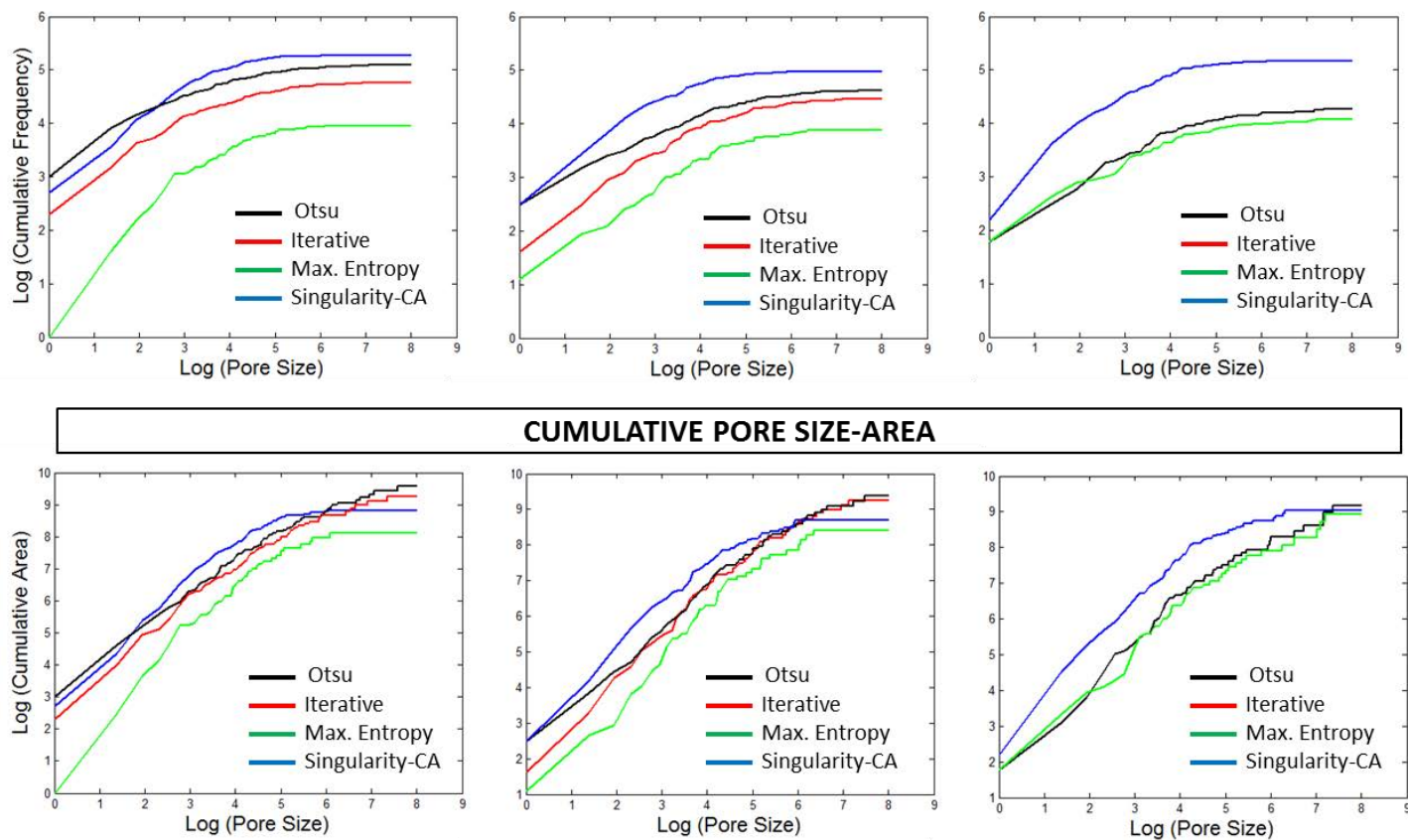

CUMULATIVE PORE SIZE-AREA
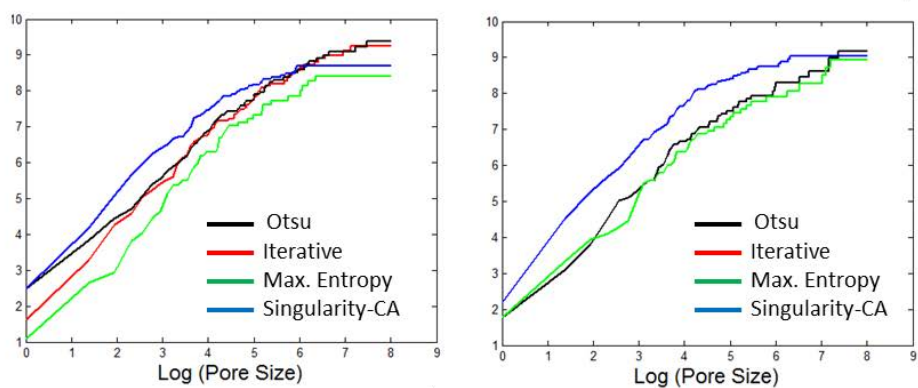

Fig. 4.12 - Comparación de la DTP acumulada (arriba) y la DAP acumulada (abajo) para las tres muestras de la TAC de suelo y los métodos de segmentación comparados. En la muestra 3 el método de Otsu y el Iterativo obtienen los mismos resultados. 
Para todas las muestras podemos observar como el método S-CA obtiene la mayor cantidad de poros (ver Tabla 4.3), al igual que sucedía con la imagen sintética. Algunos de estos poros, especialmente los de pequeño tamaño, han sido incorrectamente identificados, tal como resulta evidente al observar las imágenes perfiladas de la Fig. 4.8, por el motivo que ya habíamos señalado: gran sensibilidad en detectar valores anómalos en los VG de las imágenes digitales. Este error no cambia excesivamente la porosidad calculada, aunque pueda tener importantes implicaciones para algunas simulaciones físicoquímicas que empleen imágenes segmentadas.

En las muestras 1 y 2, el método de S-CA obtiene valores similares en los poros de tamaño más pequeño que el método Otsu; para poros de tamaño mayor, la frecuencia en el Otsu decae más rápidamente que en el de S-CA (ver DTP acumulada en Fig. 4.12).

En las tres muestras podemos observar cómo los métodos tradicionales analizados siempre obtienen los poros de mayor tamaño (ver Tabla 4.3), lo que también sucedía en la imagen sintética, si bien debemos recordar que uno de los resultados que habíamos obtenido era que estos métodos tradicionales siempre sobrestimaban el tamaño de los poros de mayor tamaño. 


\title{
CAPÍTULO 5
}

\section{SEGMENTACIÓN LOCAL EN 3D}

\author{
BASADA EN LAS PROPIEDADES
}

FRACTALES DEL MAPA DE

SINGULARIDADES EN IMÁGENES DE

SUELOS 


\subsection{INTRODUCCIÓN}

El objetivo del siguiente estudio es aplicar el enfoque fractal a la estructura interna en 3D del suelo. Para ello se utiliza la metodología de segmentación Singularidad-CV para la delimitación del espacio de poros de una TAC en 3D de suelo. A continuación se realiza una comparativa con los métodos de segmentación tradicionales de Otsu y de Máxima Entropía. Justificamos el uso de estos métodos tradicionales principalmente por dos razones: i) actualmente, estos métodos continúan siendo los referentes para la comparación de nuevas técnicas de segmentación y ii) el enfoque estadístico de ambas técnicas es diferente y complementario.

Además, se utiliza por primera vez el nuevo método de los Multifractales Truncados (MT) para la creación de una imagen sintética en 3D de suelo, sobre la que se realizará una comparativa con los todos métodos de segmentación antes referidos.

\subsection{MATERIALES}

Se utilizaron dos muestras franco-arenosas de suelo arado de un campo de Escocia. Dichas muestras fueron empaquetadas en cilindros de polipropileno de $6 \mathrm{~cm}$ de diámetro y $5 \mathrm{~cm}$ de altura. La densidad de la "muestra 1" es de 1.2 $\mathrm{Mg} \cdot \mathrm{m}^{-3}$, y la de la "muestra 2" es de $1.6 \mathrm{Mg} \cdot \mathrm{m}^{-3}$. Para más detalles sobre la muestra ver Harris et al. (2003).

Ambas muestras fueron escaneadas mediante un sistema de micro-tomografía de rayos X modelo METRIS X-TEK de 160kV, $201 \mu \mathrm{A}$ y 3003 de proyección angular. Para minimizar los daños producidos por el haz de rayos $X$, se utilizó un filtro de aluminio $(0.10 \mathrm{~mm})$. El proceso de reconstrucción de todas las radiografías para obtener imágenes en $3 \mathrm{D}$ se realizó mediante un CT-Pro Nikon y requirió varias correcciones. Las imágenes resultantes en 3D fueron importadas en la aplicación software VGStudio Max (Volume Graphics, 2015) y convertidas a imágenes de formato TIFF de 8 bits de resolución de vóxel. 
Finalmente se utilizaron para este estudio dos imágenes de $260 \times 260 \times 260$ vóxeles con un tamaño de lado de vóxel de $30 \mu \mathrm{m}$. Para más detalles ver Pajor et al. (2010). Las dos muestras de suelo fueron seleccionadas de un conjunto de muestras disponibles por tener patrones espaciales diferentes $\mathrm{e}$ histogramas de VG con forma unimodal. Las diferencias entre ambas muestran son el resultado de los distintos grados de compactación a que fueron sometidas.

\subsection{RESULTADOS}

\subsubsection{La imagen sintética de suelo en 3D}

Se creó una imagen sintética de suelo en 3D utilizando el método MT con un rango de 0 a 255 en los VG. Se siguieron los siguientes pasos del método:

Paso i): Primero se obtuvo un multifractal aleatorio de Sierpinski en 3D (Perfect et al, 2006) de 5 iteraciones, y cuyo cubo generador se muestra en la Fig. 5.1, con las probabilidades iniciales $p_{i}(\mathrm{i}=1, \ldots, 27)$. El orden de las probabilidades $p_{i}$ fue aleatorizado antes de aplicar cada iteración.

\section{D CUBE GENERATOR}

\begin{tabular}{|c|c|c|}
\hline $\boldsymbol{p}_{\mathbf{1}}=$ & $\boldsymbol{p}_{\mathbf{2}}=$ & $\boldsymbol{p}_{\mathbf{3}}=$ \\
0.0391 & 0.0359 & 0.0385 \\
\hline $\boldsymbol{p}_{\mathbf{4}}=$ & $\boldsymbol{p}_{\mathbf{5}}=$ & $\boldsymbol{p}_{\mathbf{6}}=$ \\
0.0361 & 0.0381 & 0.0374 \\
\hline $\boldsymbol{p}_{\mathbf{7}}=$ & $\boldsymbol{p}_{\mathbf{8}}=$ & $\boldsymbol{p}_{\mathbf{9}}=$ \\
0.0367 & 0.0365 & 0.0350 \\
\hline
\end{tabular}

Layer 1

\begin{tabular}{|l|l|l|}
\hline $\boldsymbol{p}_{\mathbf{1 0}}=$ & $\boldsymbol{p}_{\mathbf{1 1}}=$ & $\boldsymbol{p}_{\mathbf{1 2}}=$ \\
0.0352 & 0.0361 & 0.0367 \\
\hline $\boldsymbol{p}_{\mathbf{1 3}}=$ & $\boldsymbol{p}_{\mathbf{1 4}}=$ & $\boldsymbol{p}_{\mathbf{1 5}}=$ \\
0.0374 & 0.0365 & 0.0361 \\
\hline $\boldsymbol{p}_{\mathbf{1 6}}=$ & $\boldsymbol{p}_{\mathbf{1 7}}=$ & $\boldsymbol{p}_{\mathbf{1 8}}=$ \\
0.0385 & 0.0380 & 0.0389 \\
\hline
\end{tabular}

Layer 2

\begin{tabular}{|c|c|c|}
\hline $\boldsymbol{p}_{\mathbf{1 9}}=$ & $\boldsymbol{p}_{\mathbf{2 0}}=$ & $\boldsymbol{p}_{\mathbf{2 1}}=$ \\
0.0357 & 0.0389 & 0.0376 \\
\hline $\boldsymbol{p}_{\mathbf{2 2}}=$ & $\boldsymbol{p}_{\mathbf{2 3}}=$ & $\boldsymbol{p}_{\mathbf{2 4}}=$ \\
0.0361 & 0.0381 & 0.0354 \\
\hline $\boldsymbol{p}_{\mathbf{2 5}}=$ & $\boldsymbol{p}_{\mathbf{2 6}}=$ & $\boldsymbol{p}_{\mathbf{2 7}}=$ \\
0.0367 & 0.0365 & 0.0383 \\
\hline
\end{tabular}

Layer 3

$$
\sum_{i=1}^{27} p_{i}=1
$$

Fig. 5.1 - Cubo generador de un multifractal de Sierpinski en 3D ( $1^{\text {a }}$ iteración). El generador es representado en tres capas para una mejor visualización de las probabilidades iniciales $p_{i}(\mathrm{i}=1, \ldots, 27)$. 
El proceso de truncado para la obtención del espacio de poros y de guijarros se muestra en la Fig. 5.2. Antes del truncamiento, el multifractal de Sierpinski fue filtrado mediante un filtro paso-bajo de tipo "función rectangular" de 7 vóxeles de lado. Los umbrales de truncamiento en VG para el espacio de poros y de guijarros fueron de $G V_{t h 1}=204$ and $G V_{t h 2}=211$, respectivamente.

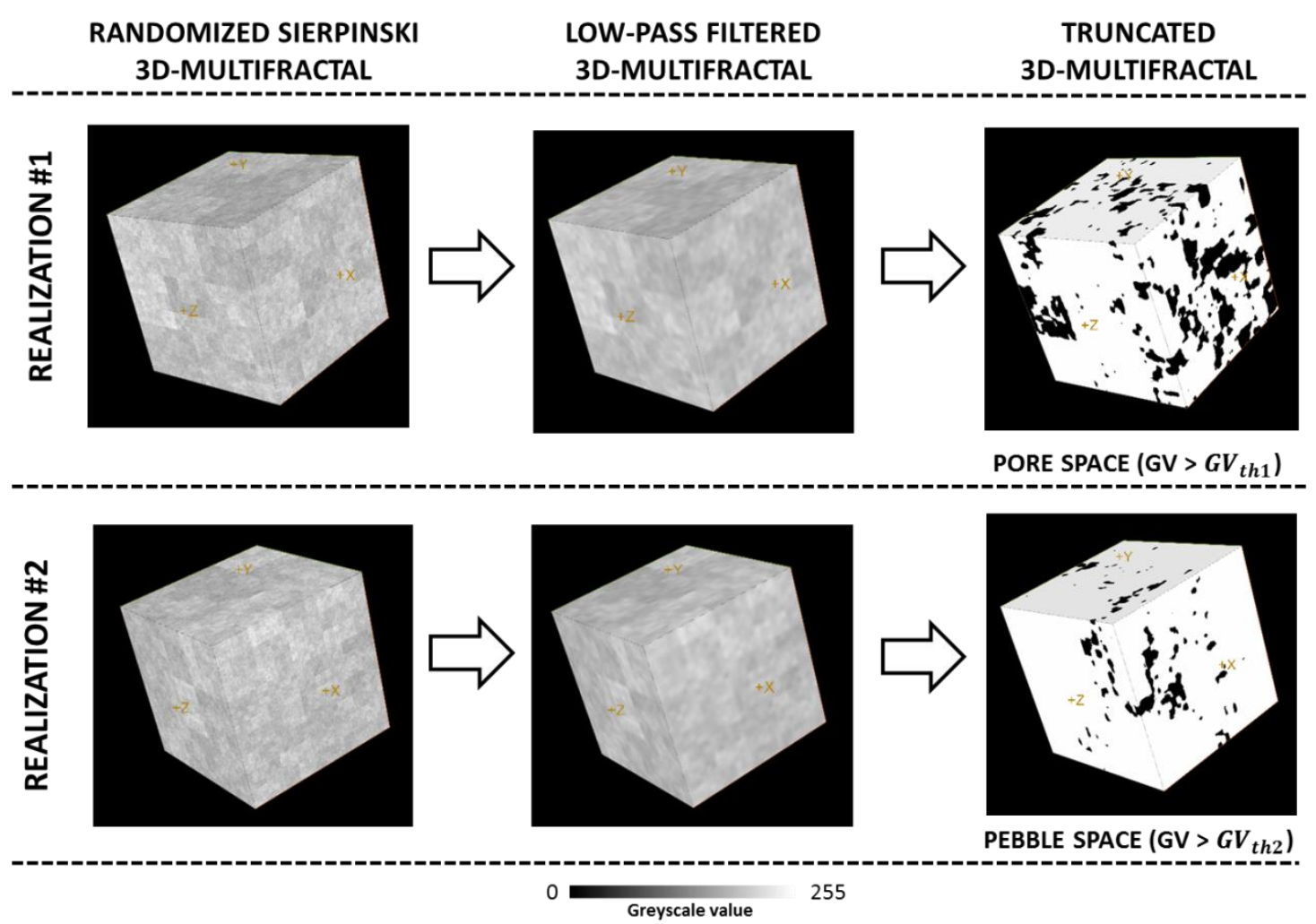

Fig. 5.2 - Etapa de truncamiento en el método MT (paso i). Izquierda: dos realizaciones de un multifractal aleatorio de Sierpinski en 3D. Medio: multifractales filtrados (filtro paso-bajo) mediante una función rectangular. Derecha: multifractales en 3D truncados mediante dos umbrales diferentes.

Pasos ii, iii y iv): En el paso ii se definió la porosidad del ground-truth en 3D (poros llenos de aire) con un valor de 0.141 , solapando ambos espacios (poros y guijarros). Para la construcción del esqueleto del histograma de VG se tomaron los siguientes valores: $G V_{\text {Pore space }}=0, G V_{\text {Background }}$ medio $=70 \mathrm{y}$ $G V_{\text {Pebble space }}$ medio $=125$. En el paso iii se sumó un ruido blanco Gaussiano con una relación señal-ruido (RSR) de $0 \mathrm{~dB}$. Finalmente, en el paso iv) se filtró 
la imagen previa mediante un filtro paso-bajo de tipo "función rectangular" de 9 píxeles de lado. Los pasos ii, iii y iv se muestran en la Fig. 5.3.

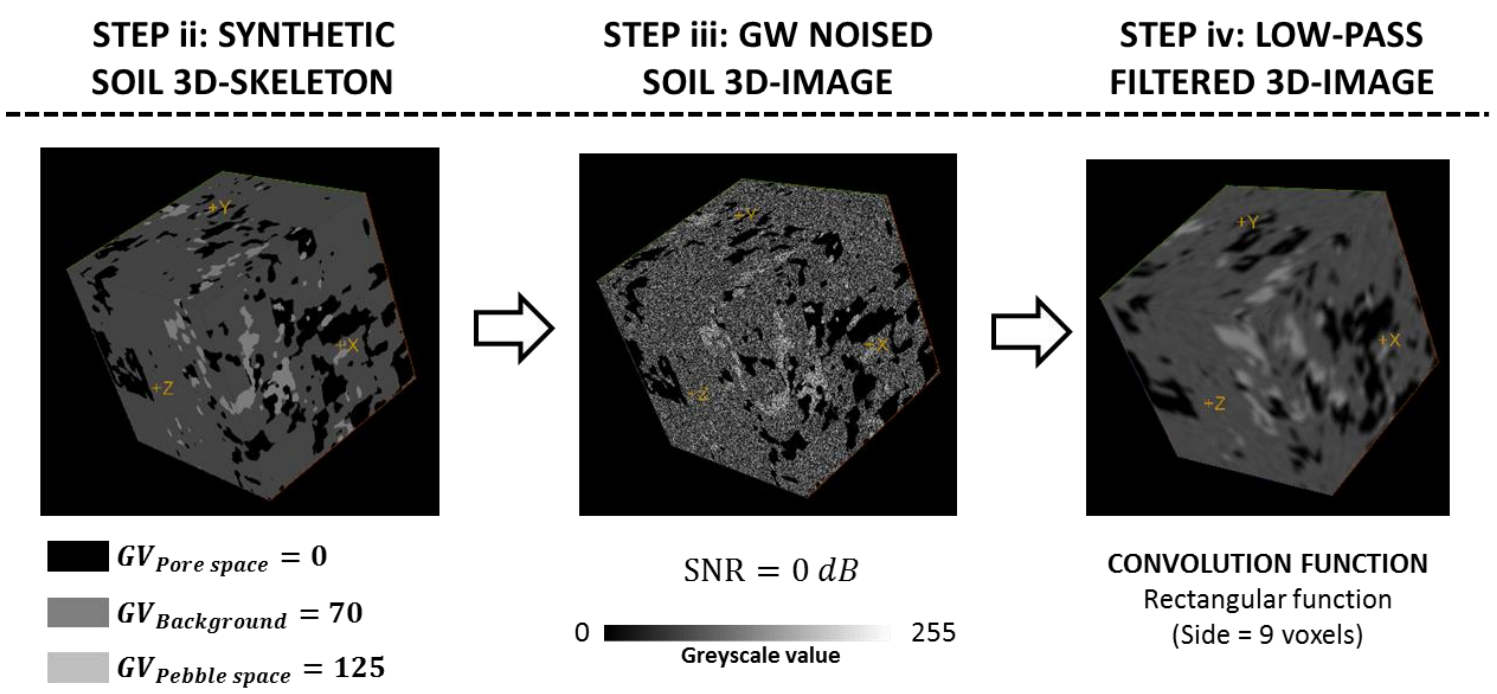

Fig. 5.3 - Resultados de los pasos ii, iii y iv en la construcción de una imagen sintética de suelo en 3D mediante el método MT.

\subsubsection{Las imágenes en 3D de suelo en escala de grises}

Primeramente se realizó un análisis estadístico de las imágenes en VG tanto de la sintética como de las dos TAC reales. Las imágenes en 3D y sus respectivos histogramas son mostrados en la Fig. 5.4. Debido al bajo contraste en las interfaces poro-sólido de las imágenes se realizó un ajuste de contraste y brillo para mejorar la visualización, no alterando los valores reales para el análisis posterior.

Podemos ver dos diferencias principales entre el histograma de la imagen sintética y los reales: 1) el histograma de la imagen sintética es más puntiagudo y 2) tiene más valores próximos a $0(\mathrm{VG}=0)$ que las imágenes reales. La apariencia del histograma de la imagen sintética puede ser modificada cambiando las probabilidades iniciales del multifractal de Sierpinski, introduciendo más o menos ruido (variando la RSR), o seleccionando otro tipo de filtro paso-bajo. 

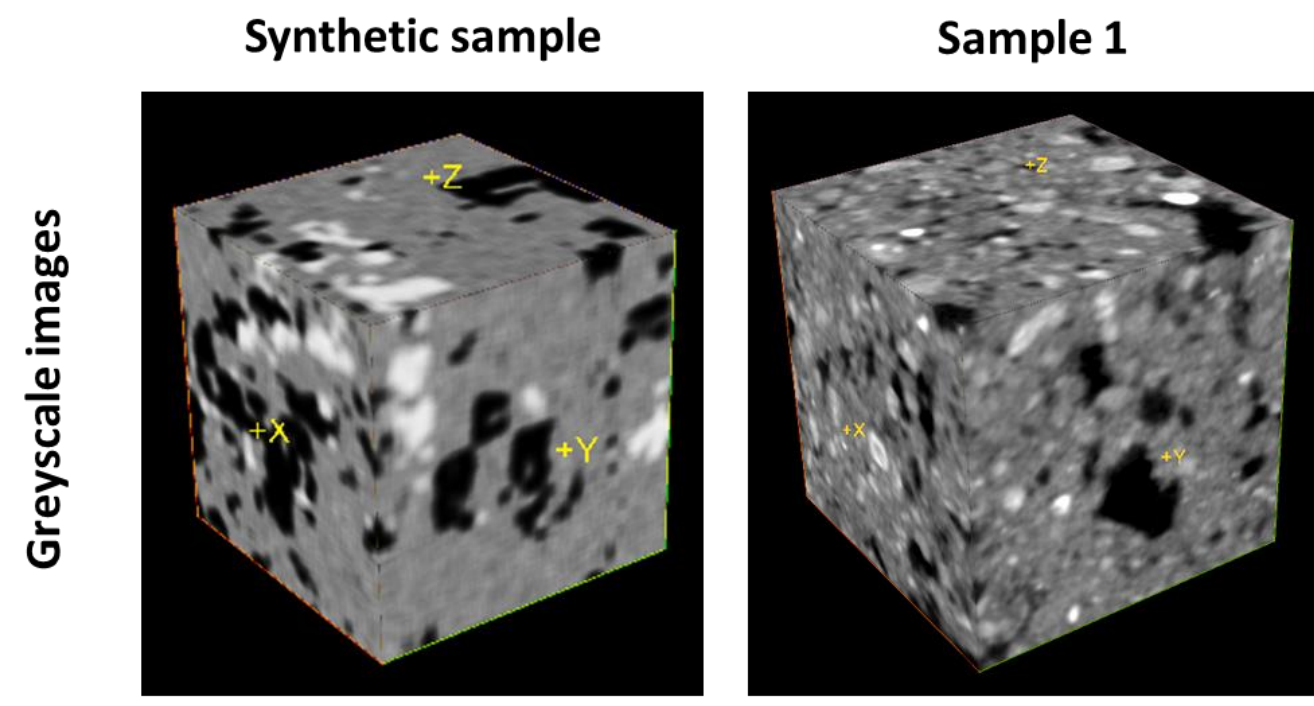

Sample 2
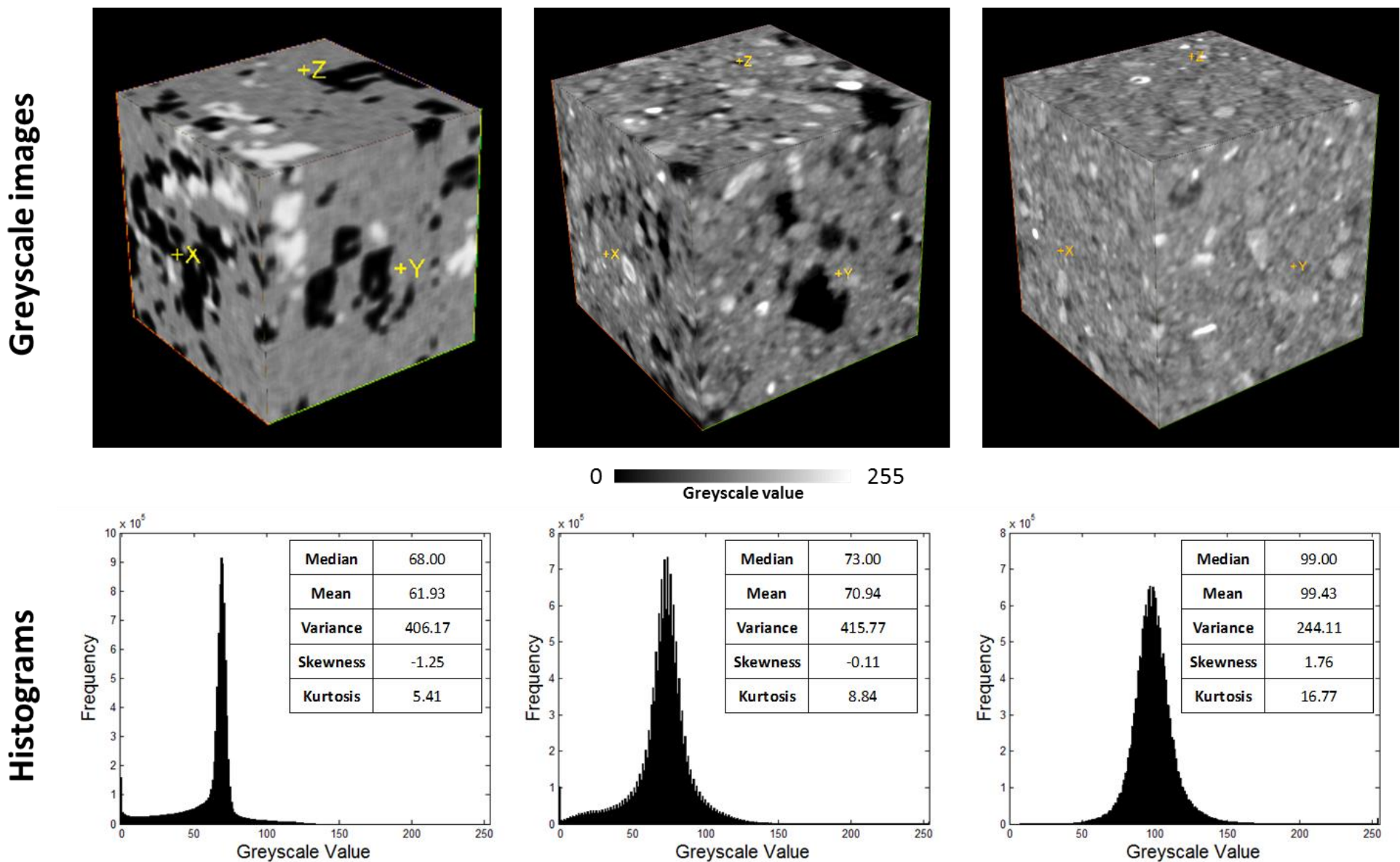

Fig. 5.4 - Arriba: imágenes en escala de grises de las tomografías reales en 3D ( $246 \times 246 \times 246$ vóxeles) y de la imagen sintética de suelo en 3D ( 215 × 215 × 215 vóxeles). Abajo: histogramas de escala de grises de cada imagen. 
Al comparar los dos histogramas de las TAC reales vemos que la muestra 1 contiene una cantidad significativa de VG iguales a 0 , una media mucho más baja y una varianza más alta que la muestra 2. Por el contrario, la muestra 2 tiene una curtosis más alta que la muestra 1 (ver inferior Fig. 5.4). Estas diferencias confirman que la muestra 2 tiene un histograma mucho más unimodal que la muestra 1, con menos dispersión de valores debido a que la muestra 2 está más compactada.

\subsubsection{Los mapas de singularidades en 3D}

Los mapas de singularidades en 3D de todas las imágenes de suelo analizadas se muestran en la parte superior de la Fig. 5.5. Para una mejor diferenciación entre las singularidades positivas $(\alpha<3)$ y las negativas $(\alpha>3)$ se utilizó en MATLAB un mapa de color "jet invertido". Así, las localizaciones con singularidades positivas aparecen en colores rojizos, mientras que las localizaciones con singularidades negativas aparecen en colores azulados. Las localizaciones con valores próximos a $3(\alpha=3)$ se distinguen por aparecer en tonos verdosos.

Los histogramas de los Valores de Singularidad (VS) se muestran en la parte inferior de la Fig. 5.5. En todos los histogramas la mediana y la media son valores cercanos a 3 . Las diferencias más significativas aparecen en la varianza. La imagen sintética tiene una varianza $\left(\sigma^{2}=0.25\right)$ mucho más alta que la muestra $1\left(\sigma^{2}=0.1\right)$ y la $2\left(\sigma^{2}=0.004\right)$. La asimetría es positiva en todos los histogramas, es decir, los VS están más dispersos en la parte derecha del histograma, que corresponde con las singularidades negativas $(\alpha>3)$. La muestra 2 tiene una asimetría muy baja $(s k w=0.25)$, lo que nos apunta a que la forma del histograma es relativamente simétrica. La curtosis de la imagen sintética $(k u r \cong 196)$ y la muestra 1 ( $k u r \cong 796)$ son muy altas. En cambio la curtosis de la muestra 2 ( $k u r \cong 6.34$ ) es más parecida a la de una distribución gaussiana ( $k u r=3)$. 

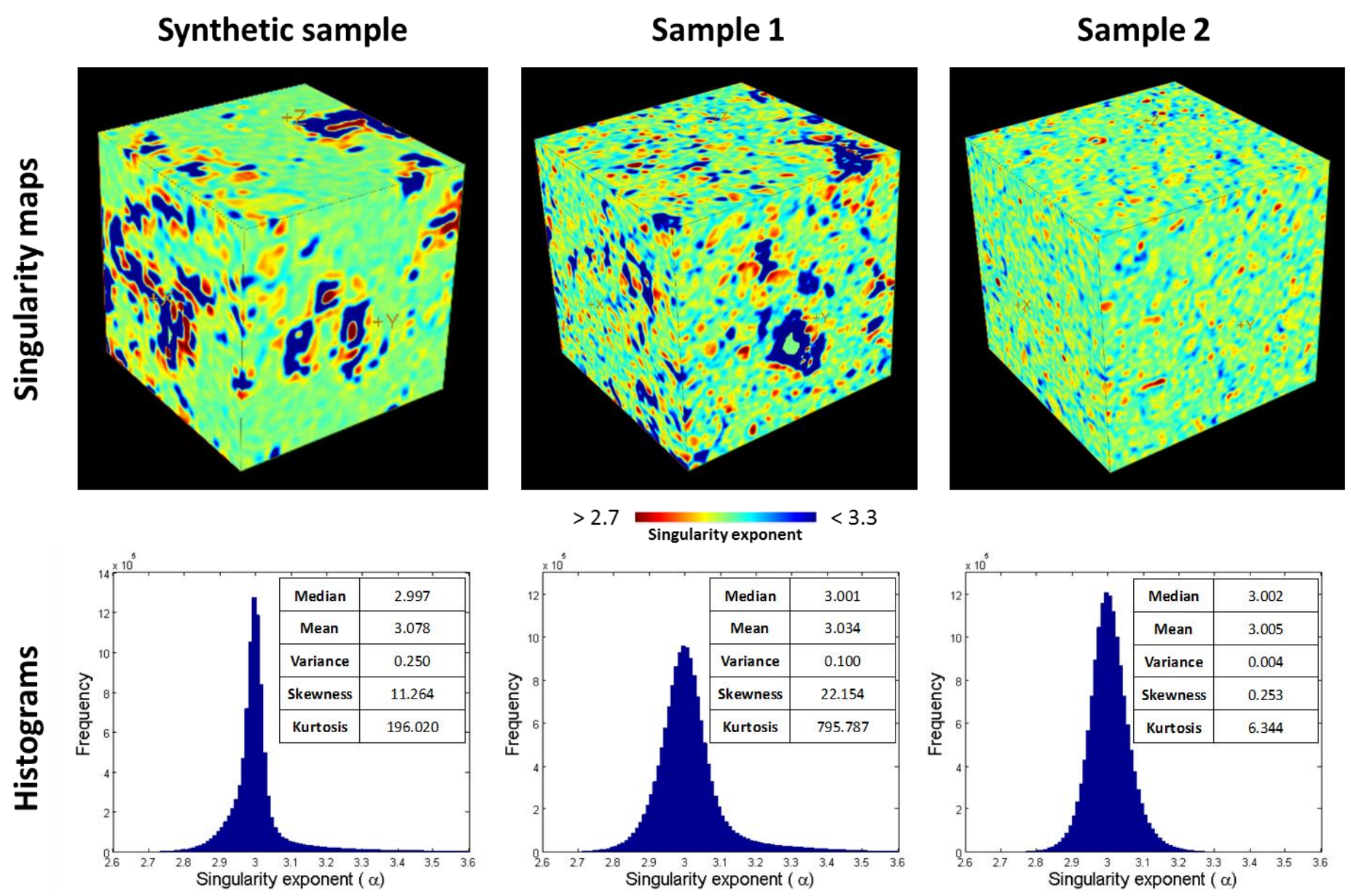

Fig. 5.5 - Arriba: mapas de singularidades de las tomografías reales en 3D ( 246 × 246 x 246 vóxeles) y de la imagen sintética de suelo en 3D ( 215 x 215 x 215 vóxeles). Abajo: histogramas de los exponentes de singularidad de cada imagen. 
En el mapa de singularidades de la muestra 1 llama la atención una zona verdosa ( $\alpha \cong 3$ ) en el interior de un área de singularidades negativas (azulada). Esta zona debe ser considerada parte del espacio de poros ya que representa a localizaciones de concentración media constante rodeadas de localizaciones con una disminución de la concentración media (singularidades negativas).

\subsubsection{Aplicación del método CV}

La parte superior de la Fig. 5.6 muestra las distribuciones acumuladas en escala log-log resultado de aplicar el método CV a las tres imágenes de suelo. Todas las distribuciones muestran claramente tramos lineales respecto a la variable "exponente de singularidad". En la imagen sintética y la muestra 1 se pueden distinguir 3 tramos lineales con sus respectivos puntos de cambio de pendiente. En cambio en la muestra 2 aparecen 2 tramos lineales con un único punto de cambio de pendiente localizado en la zona de singularidades positivas $(\alpha<3)$.

El método S-CV utiliza los puntos de cambio de pendiente como candidatos a ser los umbrales en la segmentación. Tal como se explicó en la sección de "Métodos", estamos interesados en el primer punto de cambio de pendiente que cumpla la condición de $\alpha>3$, ya que este valor será considerado como el umbral de segmentación. Para la localización exacta de estos umbrales aplicaremos el método de la TWMM (wavelet de sombrero Mejicano). La parte inferior de la Fig. 5.6 muestra las líneas de módulo máximo para todas las imágenes en 3D de suelo. La longitud de estas líneas indica la importancia de los puntos de cambio de pendiente (anomalías en la curvatura), cuanto más larga sea la línea, mayor será la relevancia del cambio de pendiente a escalas grandes. En la muestra 2 el método TWMM identifica más puntos de cambio de pendiente que una inspección visual.

En la Fig. 5.6 se han marcado mediante círculos rojos los 2 puntos de cambio de pendiente más significativos de cada imagen de suelo. 


\section{Synthetic sample}
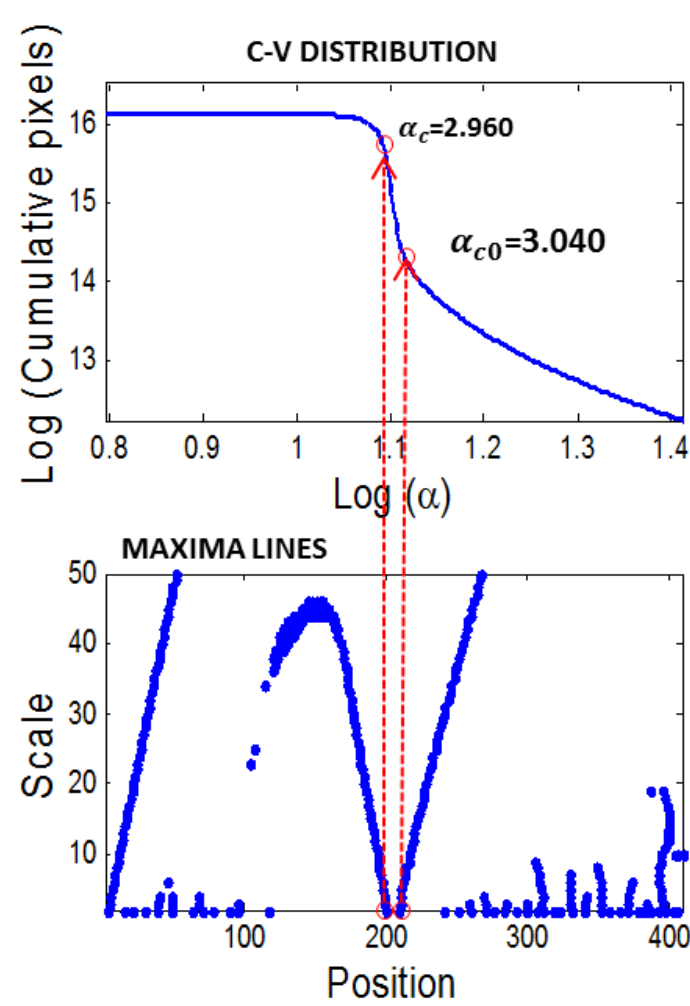

Sample 1

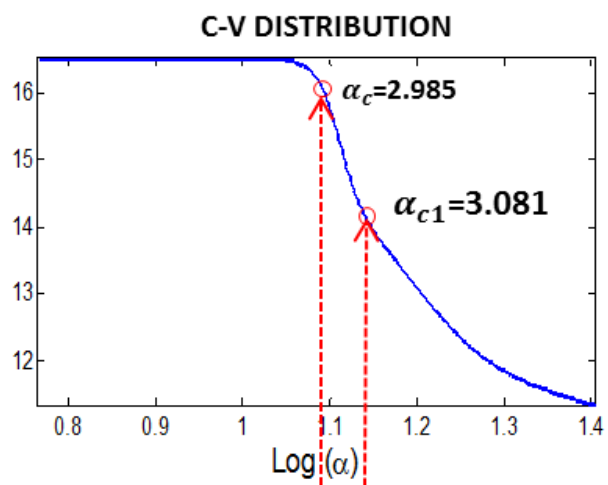

MAXIMA LINES

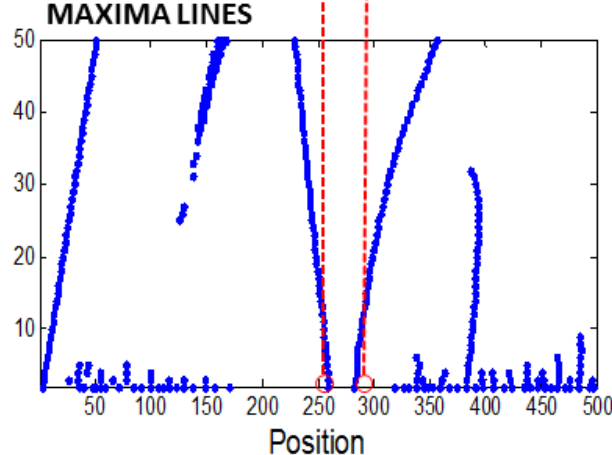

Sample 2

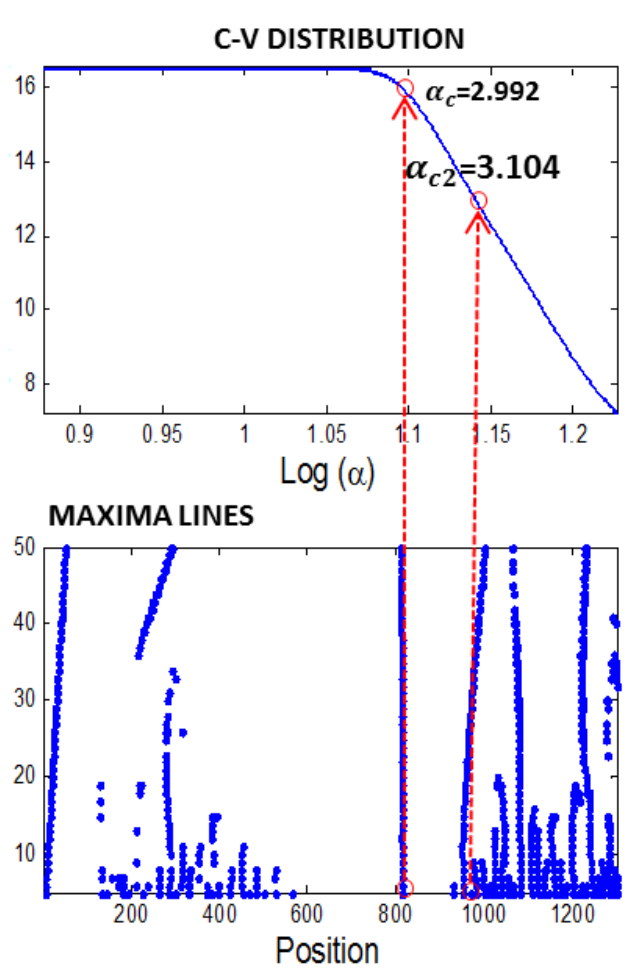

Fig. 5.6 - Arriba: Distribuciones log-log acumuladas obtenidas mediante el método CV con los puntos de cambio de pendiente. Abajo: el método TWMM aplicado a las distribuciones anteriores. Las líneas de módulo máximo convergen hacia los puntos de cambio de pendiente. 
Los umbrales que seleccionó el método Singularidad-CV fueron $\alpha_{c 0}=3.040$ para la imagen sintética, $\alpha_{c 1}=3.081$ para la muestra 1 y $\alpha_{c 2}=3.104$ para la muestra 2. Estos umbrales fueron utilizados para segmentar los mapas de singularidades, resultando las imágenes binarizadas que se muestran en la Fig. 5.7 (en todas las imágenes, el espacio de poros está representado por el color negro).

Synthetic sample
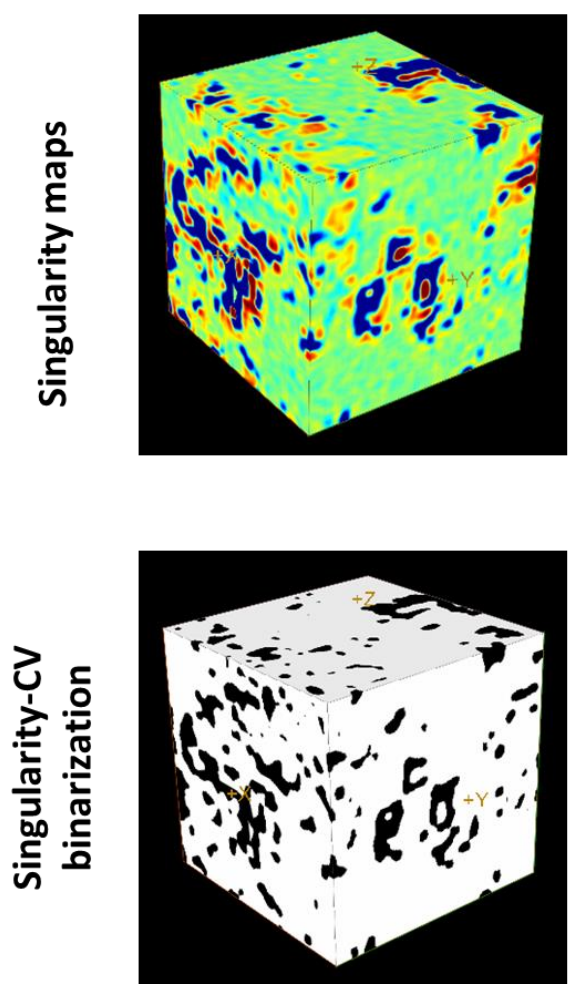

Sample 1

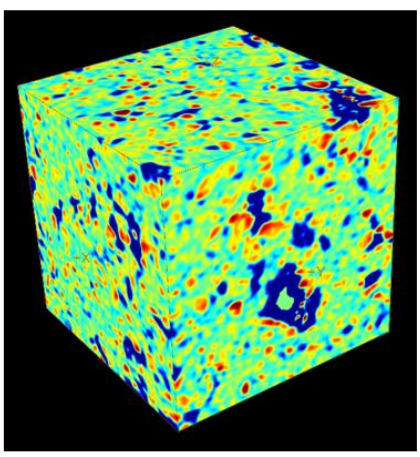

$>2.7$ Singularity exponent $<3.3$

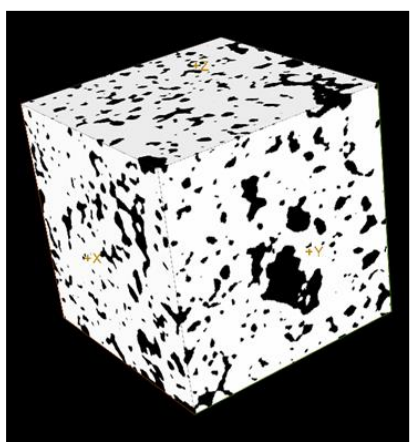

Sample 2
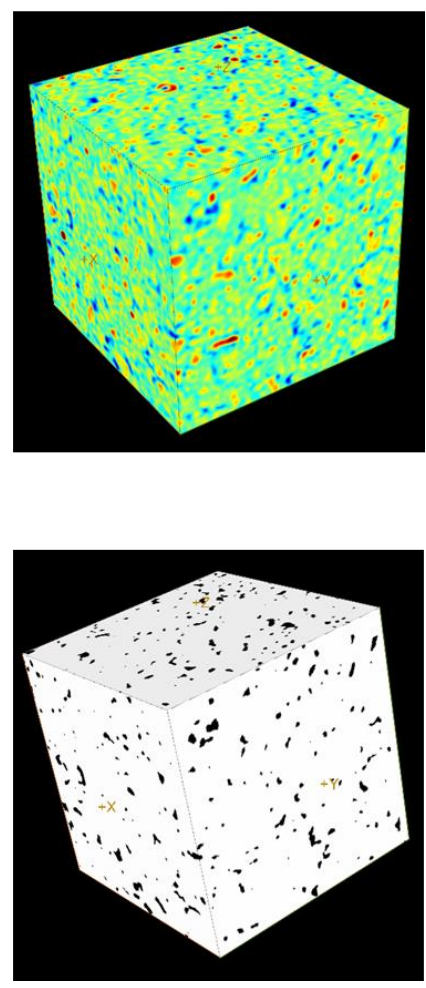

Fig. 5.7 - Arriba: mapas de singularidades en 3D de todas las imágenes de suelo. Abajo: imágenes binarizadas después de aplicar el método Singularidad-CV (el espacio de poros está coloreado en negro).

\subsubsection{Evaluación del método Singularidad-CV mediante una imagen sintética en 3D de suelo.}

Se realizó la comparación de los métodos de segmentación de Otsu, Máxima Entropía y S-CV utilizando el ground-truth de la imagen sintética en 3D de suelo. En la Fig. 5.8 se muestran las imágenes binarizadas obtenidas al aplicar todos los métodos de segmentación antes referidos. Gracias a que disponemos del ground-truth de la imagen sintética fuimos capaces de calcular la Clasificación Errónea de Poros (CEP). Los estadísticos que se obtuvieron 
(porosidad total y distribución de tamaño de poros) junto con el CEP nos permitió realizar una mejor evaluación del método de S-CV.

El umbral que se obtuvo para el método de Otsu fue de $V G_{t h}=45$. Asimismo, la entropía total de la imagen fue calculada para determinar el umbral de máxima entropía, dando un valor de $V G_{t h}=52$.

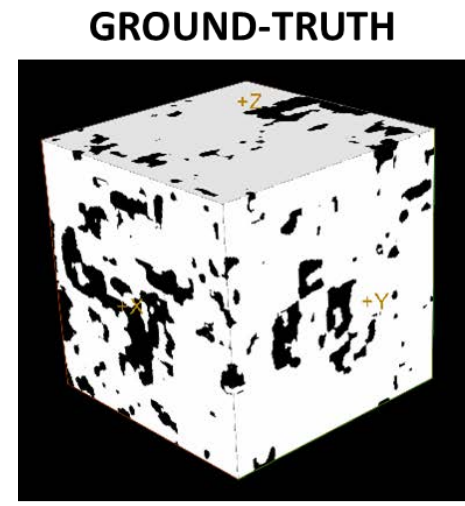

Porosity $=14.1 \%$

\section{OTSU}

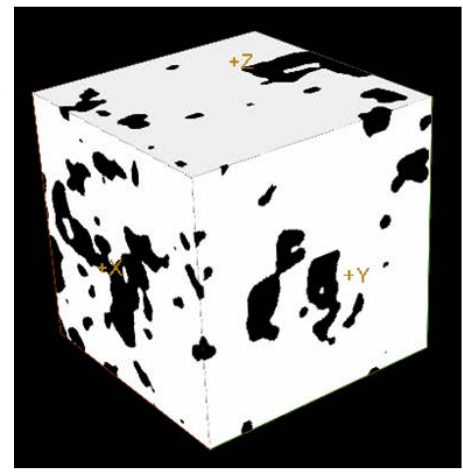

Porosity $=15.1 \%$

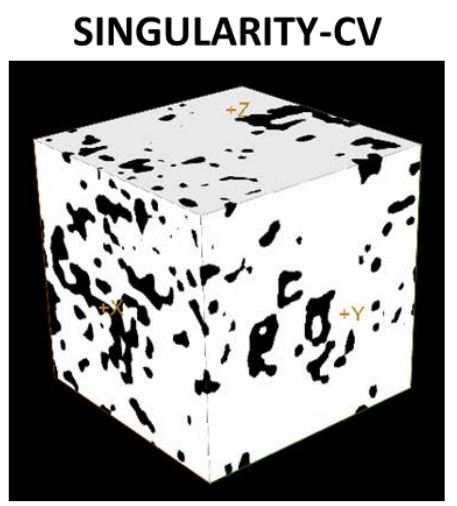

Porosity $=14.6 \%$

MAX. ENTROPY

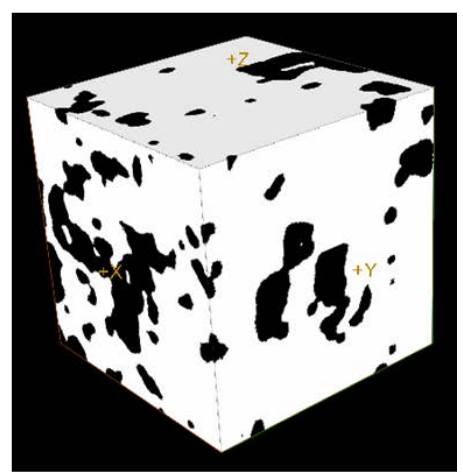

Porosity $=18.5 \%$

Fig. 5.8 - Imágenes binarizadas obtenidas aplicando los diferentes métodos de segmentación (Otsu, Máxima Entropía y Singularidad-CV) a la imagen sintética de suelo en 3D (el espacio de poros está coloreado en negro). La imagen superiorizquierda corresponde con el espacio de poros real (ground-truth) de la imagen sintética.

\section{Porosidad}

La porosidad fue calculada en base a las imágenes binarizadas mostradas en la Fig. 5.8. La porosidad obtenida mediante el método S-CV fue de 14.6\%. Los 
métodos de Otsu y de Máxima Entropía dieron valores de $15.1 \%$ y $18.5 \%$ respectivamente (ver Tabla 5.1). Todos los métodos obtuvieron porosidades por encima de la porosidad real (14.1\%), aunque el método de S-CV logró la mejor aproximación.

\begin{tabular}{|c|c|c|c|c|}
\hline \multicolumn{7}{|c|}{ SYNTHETIC SAMPLE } \\
\hline Ground-Truth & Otsu & Max. Entropy & Singularity-CV \\
\hline \# of Pores & 568 & 120 & 149 & 401 \\
\hline Max. Pore Size & $1,002,371$ & $1,059,808$ & $1,319,908$ & 970,892 \\
\hline Mean Pore Size & $2,460.1$ & $1,250.0$ & $1,236.6$ & $3,617.5$ \\
\hline Median Pore Size & 23 & 234 & 81 & 78 \\
\hline Porosity & $14.1 \%$ & $15.1 \%$ & $18.5 \%$ & $14.6 \%$ \\
\hline ME & 0.000 & 0.044 & 0.063 & 0.046 \\
\hline
\end{tabular}

Tabla 5.1 - Comparación de: número de poros, tamaño máximo, medio y mediano de poro (en vóxeles), porosidad total y clasificación errónea de poros (CEP), para los distintos métodos de segmentación analizados.

Distribución de Tamaño de Poros (DTP)

La DTP y la DTP acumulada fueron obtenidas en base a las imágenes binarizadas de la Fig. 5.8. Ambas distribuciones se muestran en la Fig. 5.9. En la Tabla 5.1 aparecen los principales estadísticos de la DTP: número de poros, tamaño máximo, medio y mediano de poro (en vóxeles). En este estudio, el tamaño del poro fue definido como el número de vóxeles contenidos en cada zona conectada de poro.

Atendiendo a la forma de las distribuciones mostradas en la Fig. 5.9 y los estadísticos de la Tabla 5.1 destacamos los siguientes puntos:

i) Los métodos de Otsu y de Máxima Entropía tienen DTP acumuladas muy similares (gráfica inferior de la Fig. 5.9), y ambos subestiman el número real de poros en todos los tamaños. 
ii) El método de Singularidad-CV también subestima el $n^{\circ}$ real de poros, tal como se aprecia en su DTP acumulada, aunque detecta más poros (en todos los tamaños) comparado con los métodos tradicionales analizados. También podemos observar que algunos de los poros de menor tamaño son incorrectamente detectados debido a la alta sensibilidad que presenta el método a las anomalías en los VS.
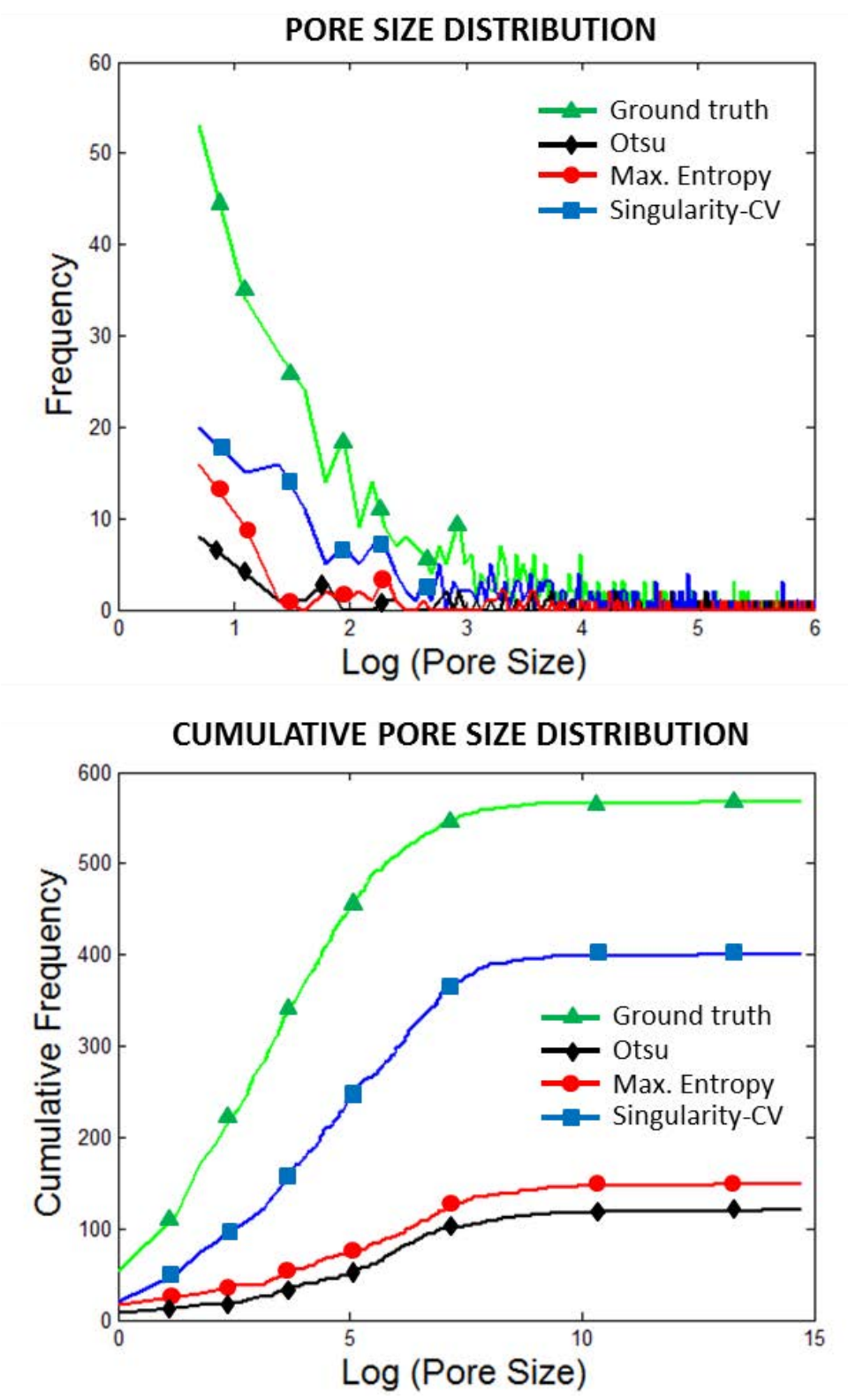

Fig. 5.9 - Comparación de la DTP (arriba) y el DTP acumulada (abajo) para la imagen sintética de suelo en 3D y los métodos de segmentación analizados. 
Clasificación Errónea de Poros (CEP)

El criterio usado para evaluar la calidad de la segmentación fue la CEP. En la Tabla 5.1 se muestran los resultados obtenidos por todos los métodos utilizados en este estudio. La CEP del S-CV (0.046) es baja y similar a las CEP del Otsu (0.044) y Máxima Entropía (0.063).

\subsubsection{Comparación de los diferentes métodos de segmentación usando TAC de suelo real.}

Esta sección presenta los resultados obtenidos al comparar el método S-CV con los métodos de Otsu y de Máxima Entropía en dos TAC reales de suelo (muestra 1 y muestra 2).

Los umbrales obtenidos por el método de Otsu para la muestra 1 y 2 fueron $V G_{t h}=57$ y $V G_{t h}=102$ respectivamente. En la fila superior de la Fig. 5.10 podemos ver donde están localizados estos umbrales dentro de sus histogramas.

Los umbrales obtenidos por el método de Máxima Entropía para la muestra 1 y 2 fueron $V G_{t h}=50$ y $V G_{t h}=71$ respectivamente. En la fila del medio de la Fig. 5.10 podemos ver donde están localizados estos umbrales dentro de sus histogramas.

La fila inferior de la Fig. 5.10 muestra como los umbrales en los VS $\left(\alpha_{c 1}=\right.$ 3.081 para la muestra 1 y $\alpha_{c 2}=3.104$ para la muestra 2) afectan a la variable VG del histograma cuando aplicamos el método S-CV. Los histogramas apilados muestran el carácter local del método de segmentación, es decir, los VG pueden ser parte del espacio de poros o del espacio de sólidos dependiendo de los VG más cercanos espacialmente. 


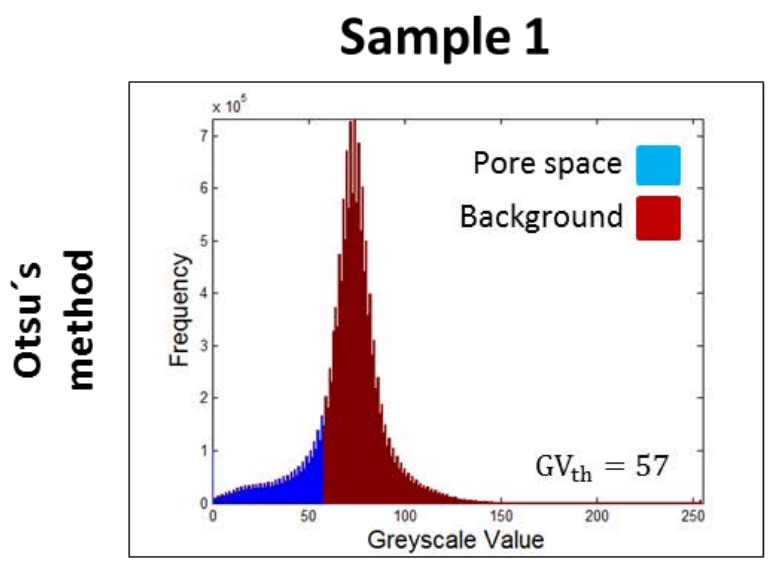

\section{Sample 2}
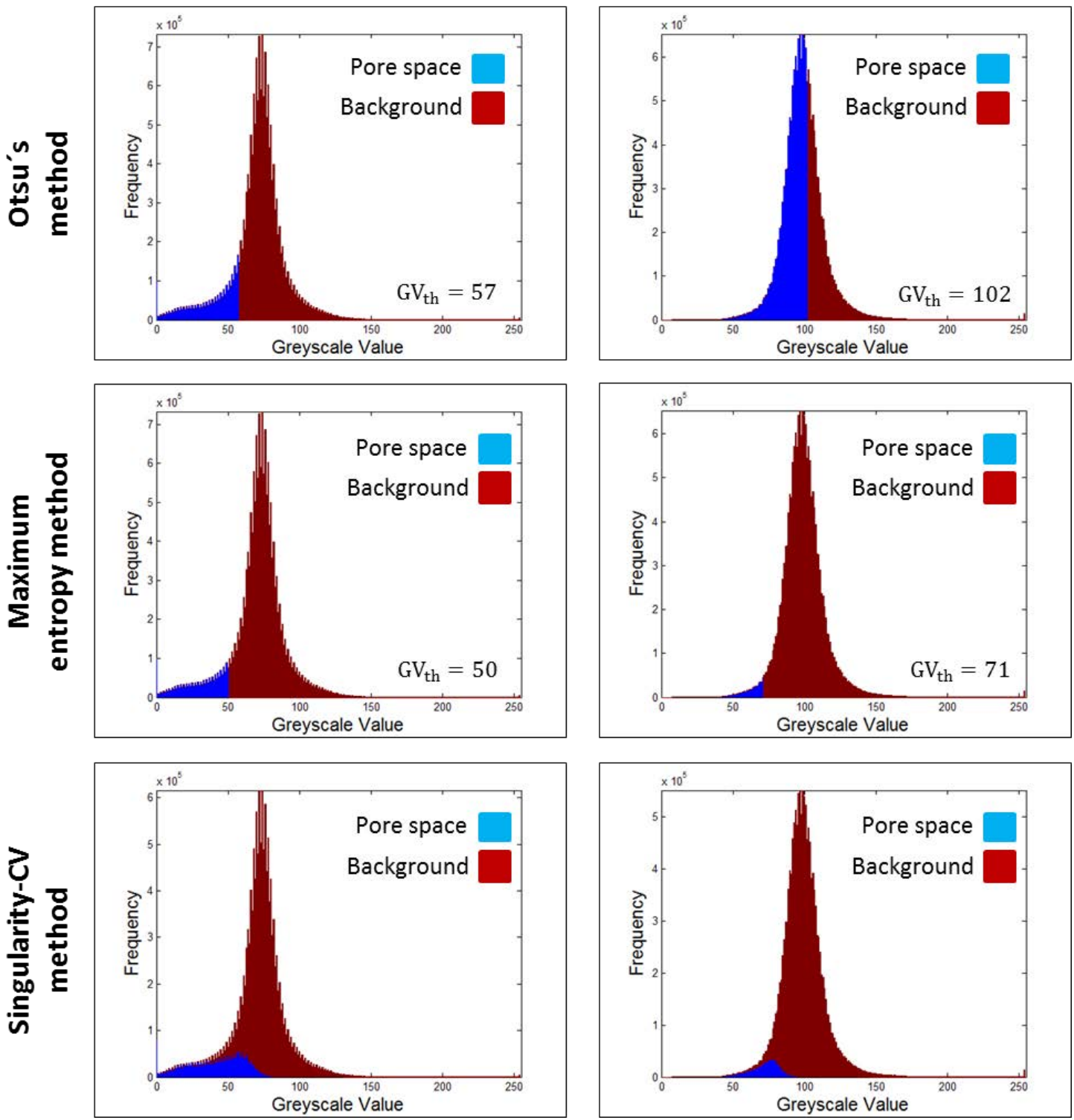

Fig. 5.10 - Histogramas con valores en escala de grises apilados para las dos tomografías reales de suelo en 3D. El espacio de poros y los valores de fondo están representados por los colores azul y rojo respectivamente.

En la Fig. 5.11 se muestran las imágenes binarizadas en 3D obtenidas después de aplicar todos los métodos de segmentación analizados. 


\section{Sample 1}
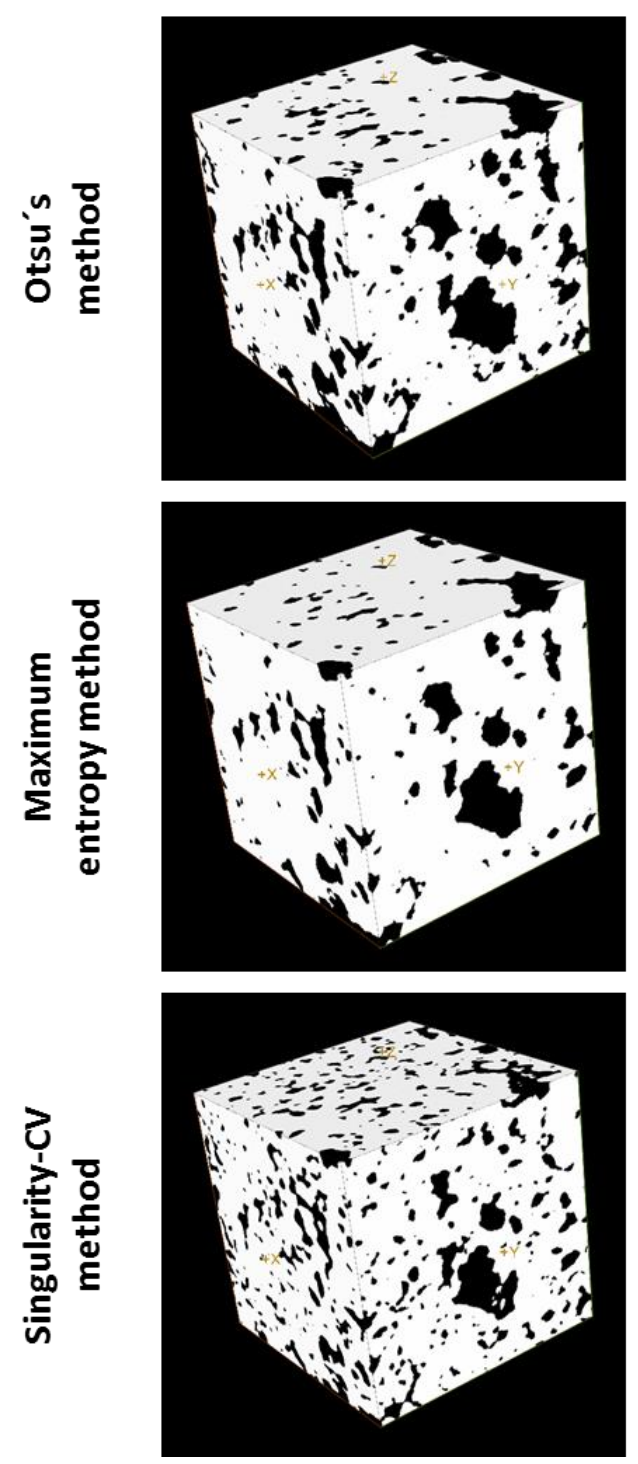

Sample 2
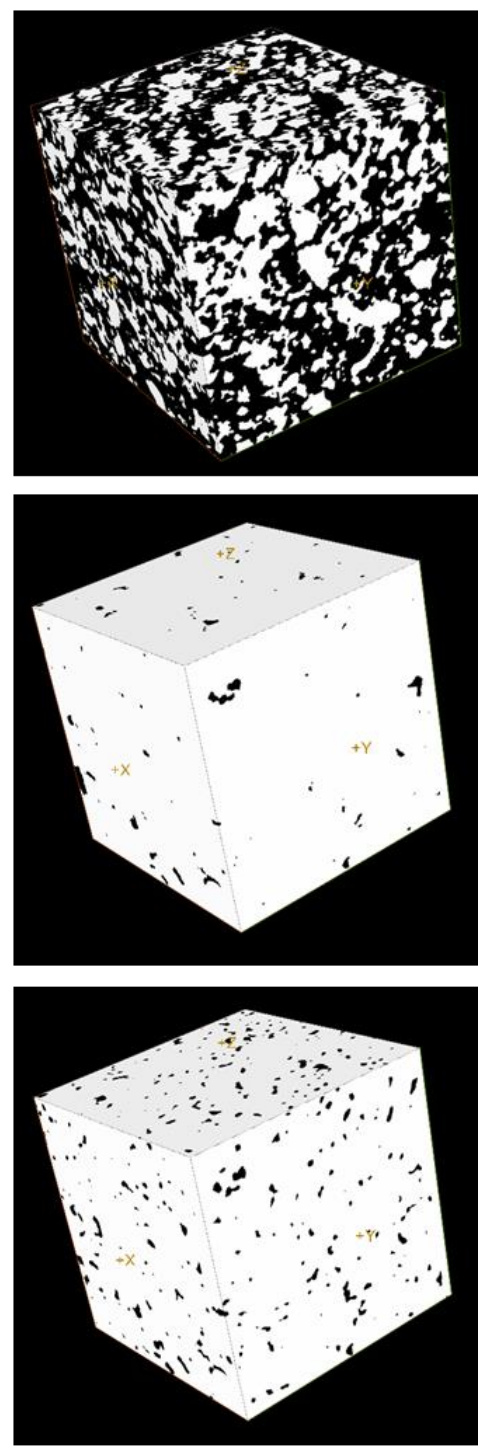

Fig. 5.11 - Imágenes binarizadas obtenidas aplicando los diferentes métodos de segmentación (Otsu, Máxima Entropía y Singularidad-CV) a las dos tomografías reales de suelo. El espacio de poros está coloreado en negro.

\section{Porosidad}

La porosidad y varios estadísticos de la DTP, tales como el tamaño máximo, medio y mediano de poro (en vóxeles), fueron obtenidos para comparar el funcionamiento de todos los métodos analizados (ver Tabla 5.2). 


\begin{tabular}{|c|c|c|c|}
\hline \multicolumn{5}{|c|}{ Sample 1 } \\
\hline \# of Pores & 1,703 & 1,041 & 3,069 \\
\hline Max. Pore Size & $1,904,649$ & 892,248 & $1,678,167$ \\
\hline Mean Pore Size & $1,377.9$ & $1,577.7$ & 744.2 \\
\hline Median Pore Size & 15.0 & 34.0 & 28.0 \\
\hline Porosity & $15.76 \%$ & $11.03 \%$ & $15.34 \%$ \\
\hline \multirow{2}{*}{ Sample 2 } & Max. Entropy & Singularity-CV \\
\hline \# of Pores & 265 & 2,023 & 4,203 \\
\hline Max. Pore Size & $9,563,761$ & 23,195 & 13,260 \\
\hline Mean Pore Size & $36,098.0$ & 196.6 & 178.2 \\
\hline Median Pore Size & 3.0 & 14.0 & 31.0 \\
\hline Porosity & $64.26 \%$ & $2.67 \%$ & $5.03 \%$ \\
\hline
\end{tabular}

Tabla 5.2 - Comparación del número de poros, tamaño máximo, medio y mediano de poro (en vóxeles) y porosidad total en las dos tomografías reales de suelo para los distintos métodos de segmentación analizados.

En la muestra 1, porosidades de $15.76 \%, 11.03 \%$ y $15.35 \%$ fueron obtenidas mediante los métodos de Otsu, Máxima Entropía y S-CV, respectivamente. Una de las estadísticas más destacable es el tamaño máximo de poro (poro máximo), que toma valores de $\cong 1,900,000$ vóxeles, $\cong 900,000$ vóxeles $\mathrm{y} \cong$ $1,700,000$ vóxeles para los métodos de Otsu, Máxima Entropía y S-CV, respectivamente. Debido a que el tamaño total de la muestra es de $246^{3}$ vóxeles, el poro máximo explica el $81 \%, 51 \%$ y $73 \%$ respectivamente de la porosidad detectada por los métodos antes referidos. La localización de los poros máximo de la muestra 1 se presenta en la columna de la izquierda de la Fig. 5.12. Se puede apreciar que existen conexiones del poro máximo con las caras exteriores de la muestra 1 en todos los métodos analizados, aunque en el caso del método de Máxima Entropía está menos ramificado. 


\section{Sample 1}

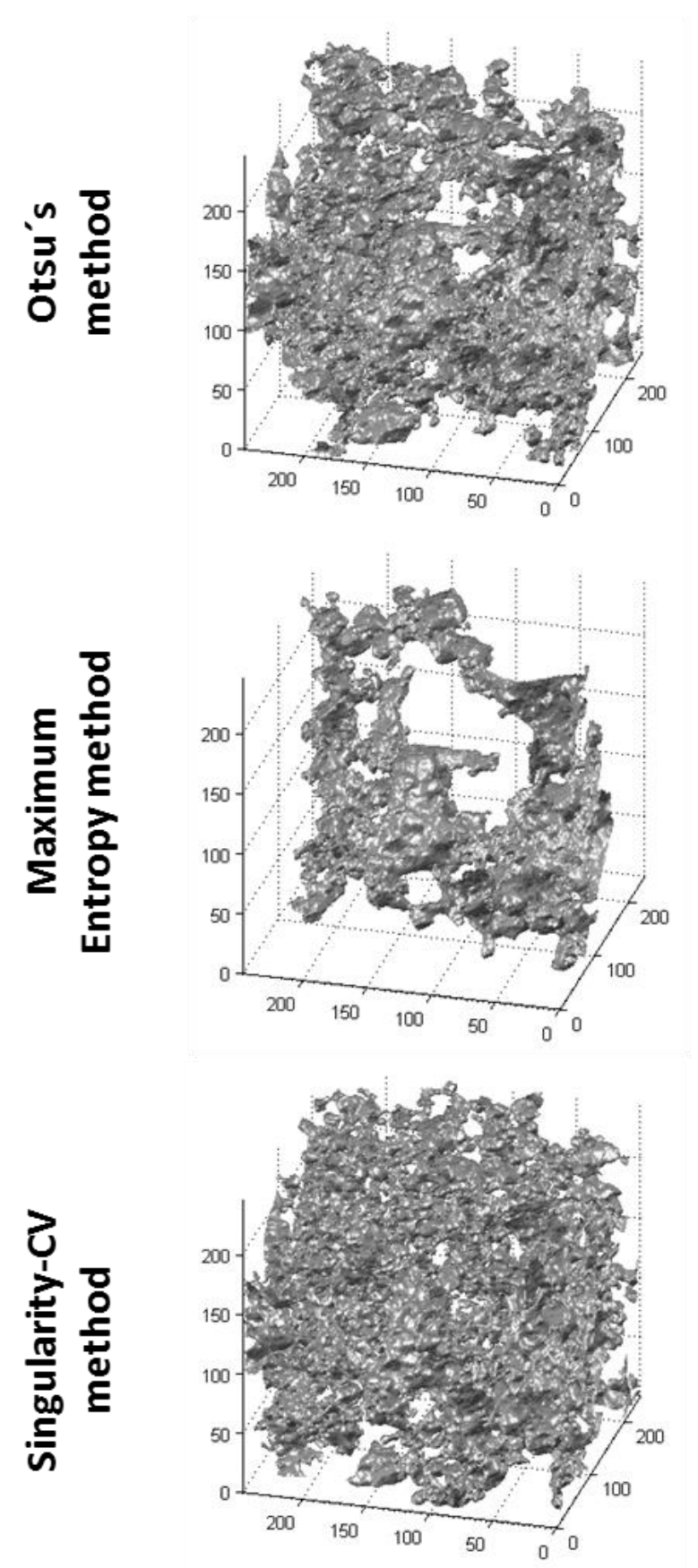

Sample 2
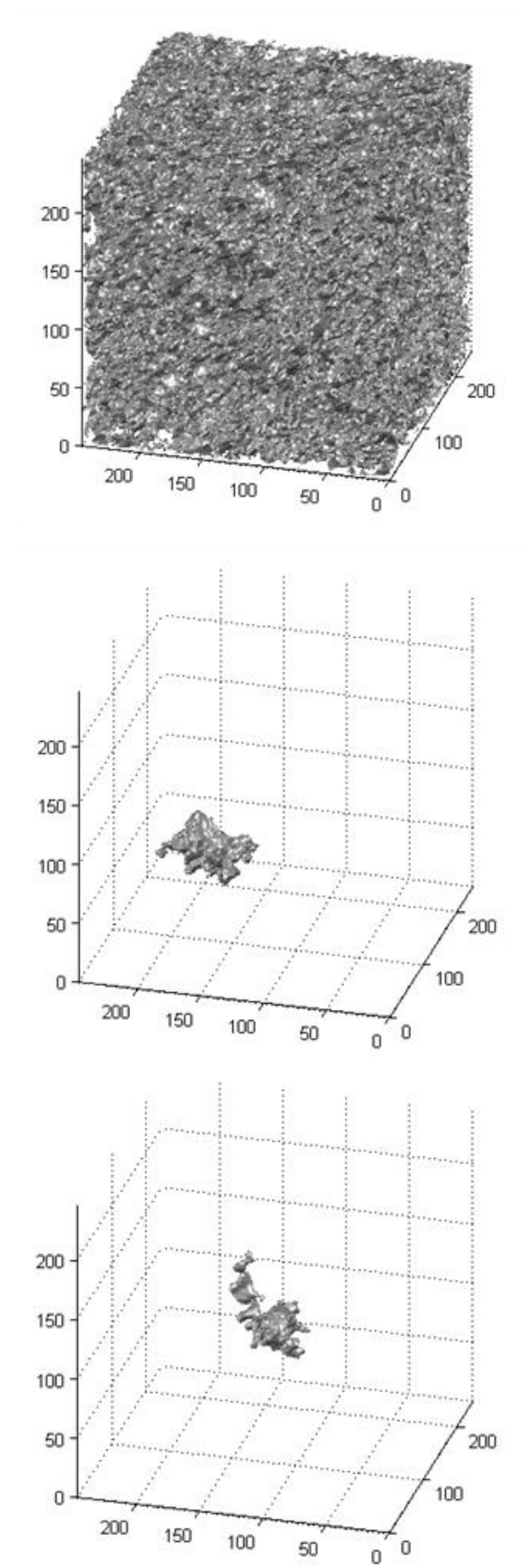

Fig. 5.12 - Poro de tamaño máximo para las dos tomografías reales de suelo y los métodos de segmentación comparados.

En la muestra 2, porosidades de $64.26 \%, 2.67 \%$ y $5.03 \%$ fueron obtenidas mediante los métodos de Otsu, Máxima Entropía y S-CV, respectivamente. El tamaño máximo de poro (poro máximo) tomó valores de $\cong 9,500,000$ vóxeles, $\cong 23,000$ vóxeles $y \cong 13,000$ vóxeles para los métodos de Otsu, Máxima 
Entropía y S-CV, respectivamente. Es importante llamar la atención sobre el hecho de que el poro máximo detectado por el método de Otsu explica el 99.9\% de su porosidad, lo que es totalmente ilógico. Los poros máximo detectados por los métodos de Máxima Entropía y S-CV explican el 6\% y $2 \%$ de la porosidad, respectivamente. La localización de los poros máximo de la muestra 2 se presenta en la columna de la derecha de la Fig. 5.12. Se puede apreciar que el poro máximo está localizado en el centro de la muestra y que ya no existen conexiones con las caras exteriores de la muestra, exceptuado los resultados anómalos obtenidos por el método de Otsu.

\section{Distribución de Tamaño de Poros (DTP)}

La DTP de la muestra 1 (gráfico superior izquierdo de la Fig. 5.13) muestra que el método S-CV detecta la mayor cantidad de poros en todas las escalas (tamaños). Nos encontramos con una excepción en poros de menos de 3 vóxeles donde los métodos de Otsu y S-CV detectan la misma cantidad. La DTP acumulada (gráfico inferior izquierdo de la Fig. 5.13) muestra que la cantidad total de poros detectada por el S-CV es la mayor de los métodos analizados. El método de S-CV identifica 3,069 poros, comparado con los 1,703 del método Otsu y los 1,041 poros del de Máxima Entropía.

La DTP de la muestra 2 (gráfico superior derecho de la Fig. 5.13) muestra un escenario muy similar al de la muestra 1 . El método S-CV detecta la mayor cantidad de poros en todas las escalas (tamaños). Sin embargo, en este caso la excepción nos la encontramos en el método de Máxima Entropía, detectan la misma cantidad de poros de menos de 3 vóxeles. La DTP acumulada (gráfico inferior derecho de la Fig. 5.13) muestra que la cantidad total de poros detectada por el método Otsu es de 256 poros, comparado con los 4,203 del método S-CV y los 2,023 poros del de Máxima Entropía. 


\section{Sample 1}
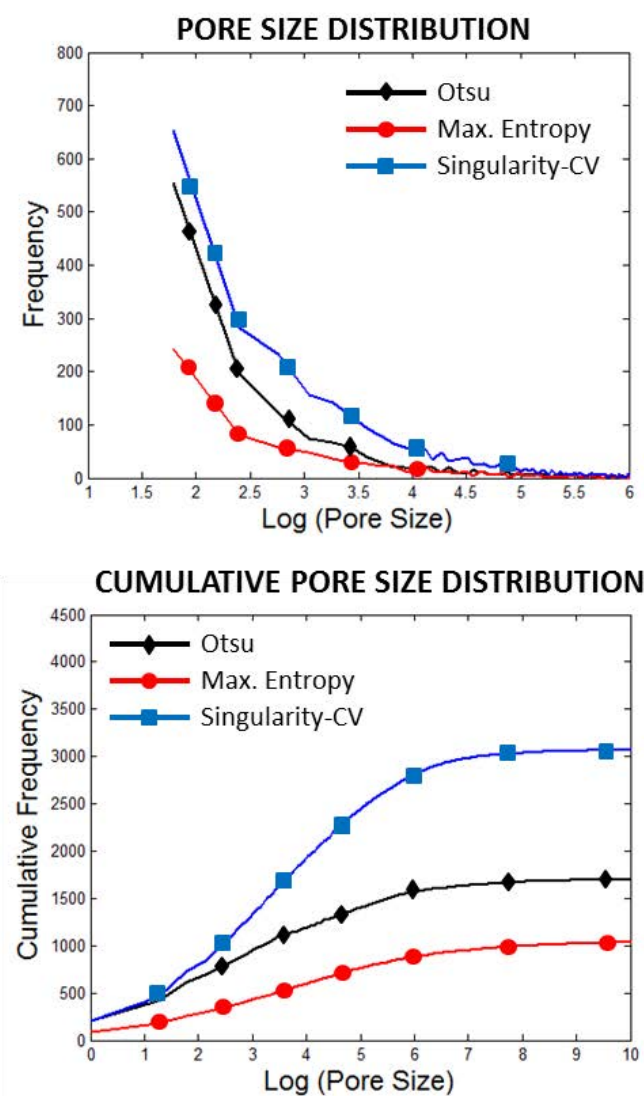

\section{Sample 2}
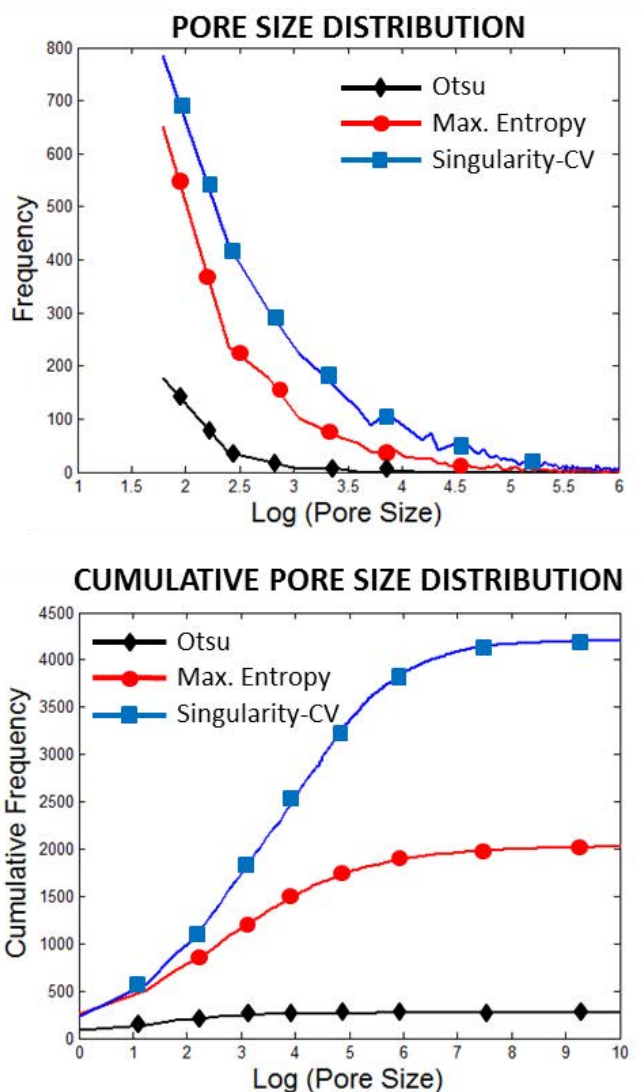

Fig. 5.13 - Comparación de la DTP (arriba) y la DTP acumulada (abajo) en las dos tomografías reales de suelo y los métodos de segmentación comparados.

Cuanta más precisión necesitemos en la detección del espacio de poros, mayor será la carga computacional requerida en la binarización de la imagen. En general, los métodos de umbralización local emplean más tiempo de computación que los métodos globales ya que deben realizar cálculos a nivel local. En este estudio las muestras analizadas contienen $246^{3}$ vóxeles y el método de S-CV realiza cálculos de pendiente (exponentes de singularidad) para cada vóxel. Este proceso puede llevar varios minutos de tiempo de computación, mientras que los métodos globales tradicionales requieren sólo segundos. En el caso de la muestra 2, que tiene un histograma muy unimodal, el método de Otsu no es efectivo y su prestación es inválida. Más aun, la porosidad obtenida por el método de Máxima Entropía fue la mitad de la obtenida por el método S-CV. Por tanto, para la muestra 2, un mayor tiempo de computación es compensado por una mejor calidad de segmentación. 


\section{CAPÍTULO 6}

\section{COMBINACIÓN DE MÉTODOS DE SEGMENTACIÓN GLOBALES Y DE ESCALAMIENTO LOCAL PARA}

DETECTAR EL ESPACIO DE POROS EN IMÁGENES DE SUELOS 


\subsection{INTRODUCCIÓN}

El objetivo del siguiente estudio es:

1) Primero, evaluar el método S-CA Combinado para la delimitación del espacio de poros en imágenes de suelo en 2D. Para ello, se realiza una comparativa con los métodos de segmentación S-CA y de Máxima Entropía.

2) Por último, comparar los métodos de Regresión Lineal $(R L)$ y de la Transformada Wavelet Módulo Máximo (TWMM), ambos métodos usados en la localización de los puntos de cambio de pendiente que aparecen en las distribuciones acumuladas de VS.

\subsection{MATERIALES}

Para este estudio se utilizó un conjunto de imágenes sintéticas de suelo creadas mediante el método de los Multifractales Truncados, con porosidades en los siguientes rangos: de $0 \%$ a $5 \%$ (rango 1), de 5\% a 10\% (rango 2), de $10 \%$ a $15 \%$ (rango 3 ), de $15 \%$ a $20 \%$ (rango 4 ) y de $20 \%$ a $25 \%$ (rango 5 ). Todas las imágenes sintéticas tienen un tamaño de $229 \times 229$ píxeles con VG en el rango de 0 a 255 (8 bits de resolución) y una relación señal-ruido de 5 dB. Se crearon 50 imágenes sintéticas por cada rango para poder así obtener una estadística significativa (ver Tabla 6.1).

En la Fig. 6.1 se muestran los espacios de poros (ground-truth) de cinco imágenes sintéticas de suelo como un ejemplo de cada rango, con porosidades reales de $3.45 \%, 7.31 \%, 12.84 \%, 17.13 \%$ y $22.90 \%$ respectivamente. Este conjunto de imágenes, nombrado como "el conjunto ejemplo", será utilizado para visualizar el funcionamiento del nuevo método de segmentación. En la Fig. 6.1 también se muestran las imágenes sintéticas en VG y sus histogramas. 

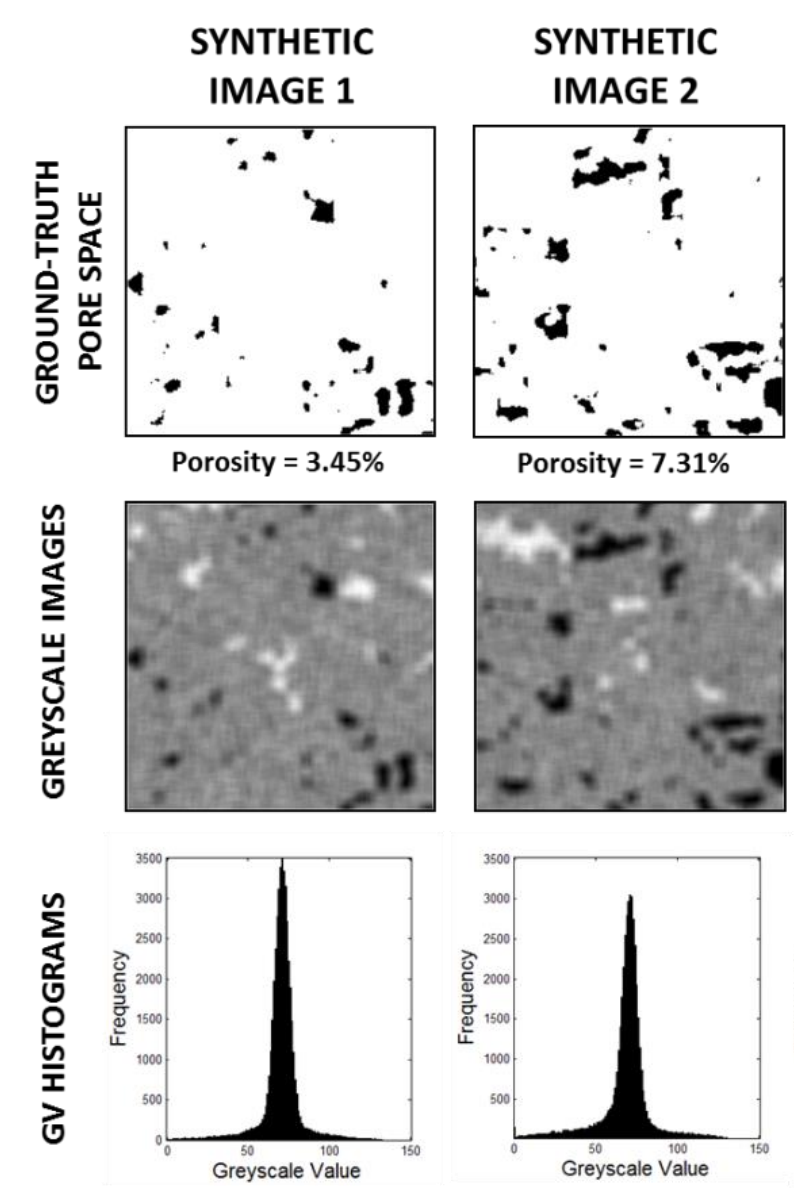
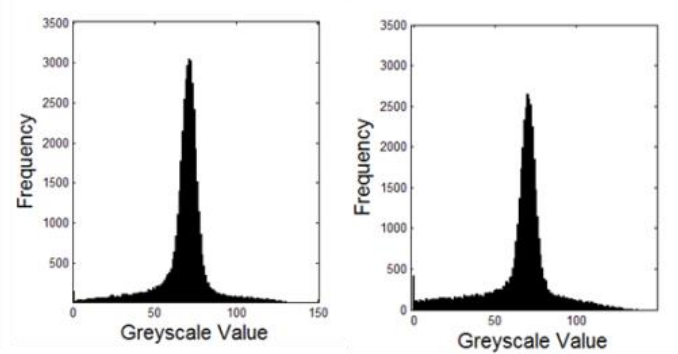
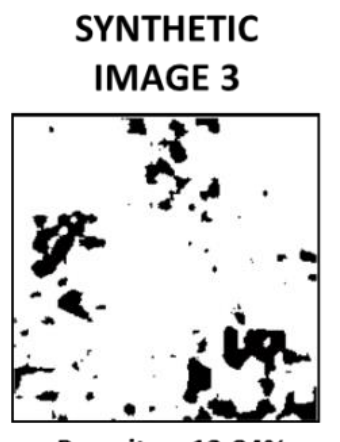

Porosity = $12.84 \%$

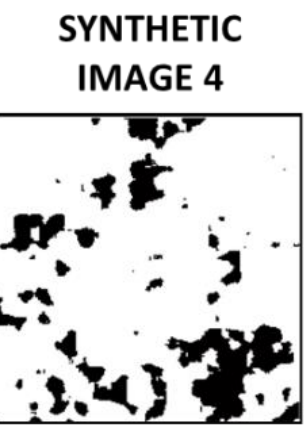

Porosity = $17.13 \%$
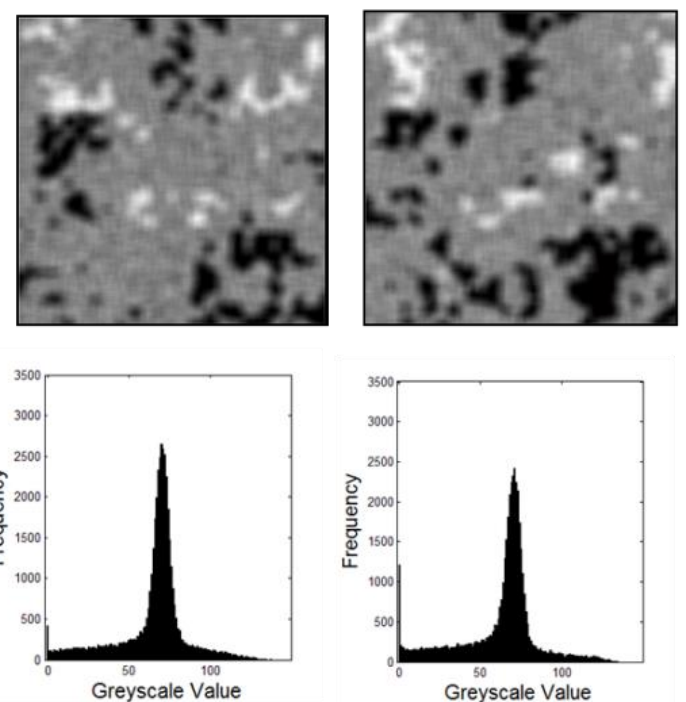

Greyscale Value
SYNTHETIC

IMAGE 5

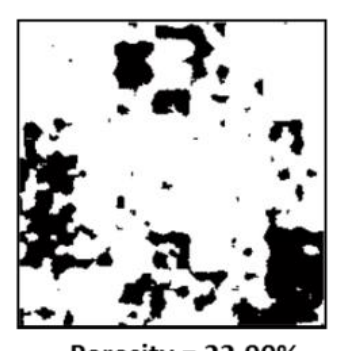

Porosity $=\mathbf{2 2 . 9 0 \%}$
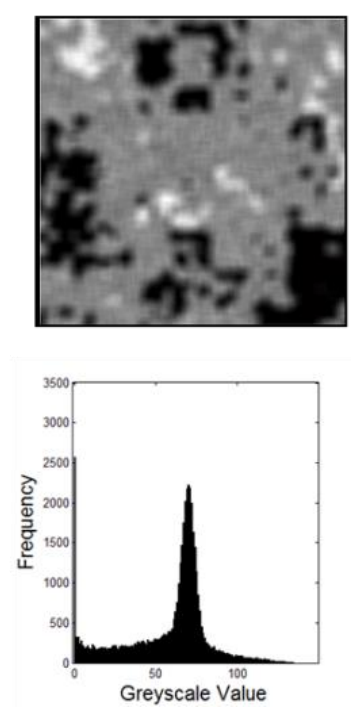

Fig. 6.1 - (Arriba): espacios de poros reales (representados por píxeles en negro) de las imágenes sintéticas de suelo obtenidas mediante el método de los Multifractales Truncados (MT). (Medio): imágenes en valores de grises (VG) de las imágenes sintéticas. (Abajo): histogramas de VG de las imágenes sintéticas. 


\begin{tabular}{|cc|c|c|}
\cline { 3 - 4 } \multicolumn{2}{c|}{} & \multicolumn{2}{c|}{ POROSIDAD GROUND-TRUTH } \\
\cline { 3 - 4 } \multicolumn{2}{c|}{} & Media & Desv. estándar \\
\hline RANGO 1 & $(0-5 \%)$ & $3.3 \%$ & $0.04 \%$ \\
\hline RANGO 2 & $(5-10 \%)$ & $7.2 \%$ & $0.08 \%$ \\
\hline RANGO 3 & $(10-15 \%)$ & $13.6 \%$ & $0.14 \%$ \\
\hline RANGO 4 & $(15-20 \%)$ & $16.8 \%$ & $0.11 \%$ \\
\hline RANGO 5 & $(20-25 \%)$ & $22.7 \%$ & $0.09 \%$ \\
\hline
\end{tabular}

Tabla 6.1. Media y desviación estándar de la porosidad de 50 realizaciones (imágenes sintéticas) para cada rango.

\subsection{RESULTADOS}

\subsubsection{Evaluación del método Singularidad-CA Combinado.}

\subsubsection{El método S-CA Combinado aplicado al "conjunto ejemplo".}

El método S-CA Combinado fue aplicado al conjunto ejemplo para mostrar la implementación y funcionamiento de la nueva metodología. Primeramente, el método S-CA fue aplicado al conjunto ejemplo que se muestra en la Fig. 6.1. Los 3 pasos que definen la metodología S-CA se muestran en la parte superior de la Fig. 6.2 para las imágenes sintéticas seleccionadas 2, 3 y 4. Los 3 pasos son los siguientes:

- Paso i). Cálculo del mapa de singularidades de las imágenes en VG.

- Paso ii). Aplicación del método CA para obtener las distribuciones acumuladas de los VS.

- Paso iii). Cálculo de los puntos de cambio de pendiente mediante en método TWMM. Estos puntos definen los umbrales de binarización que serán aplicados a los mapas de singularidades.

En la parte inferior de la Fig. 6.2 se muestran los espacios de poros resultado de aplicar los umbrales a los mapas de singularidades. Los umbrales de VS 
obtenidos por el método TWMM son mostrados en la Tabla 6.2 para las 5 imágenes sintéticas del conjunto ejemplo.
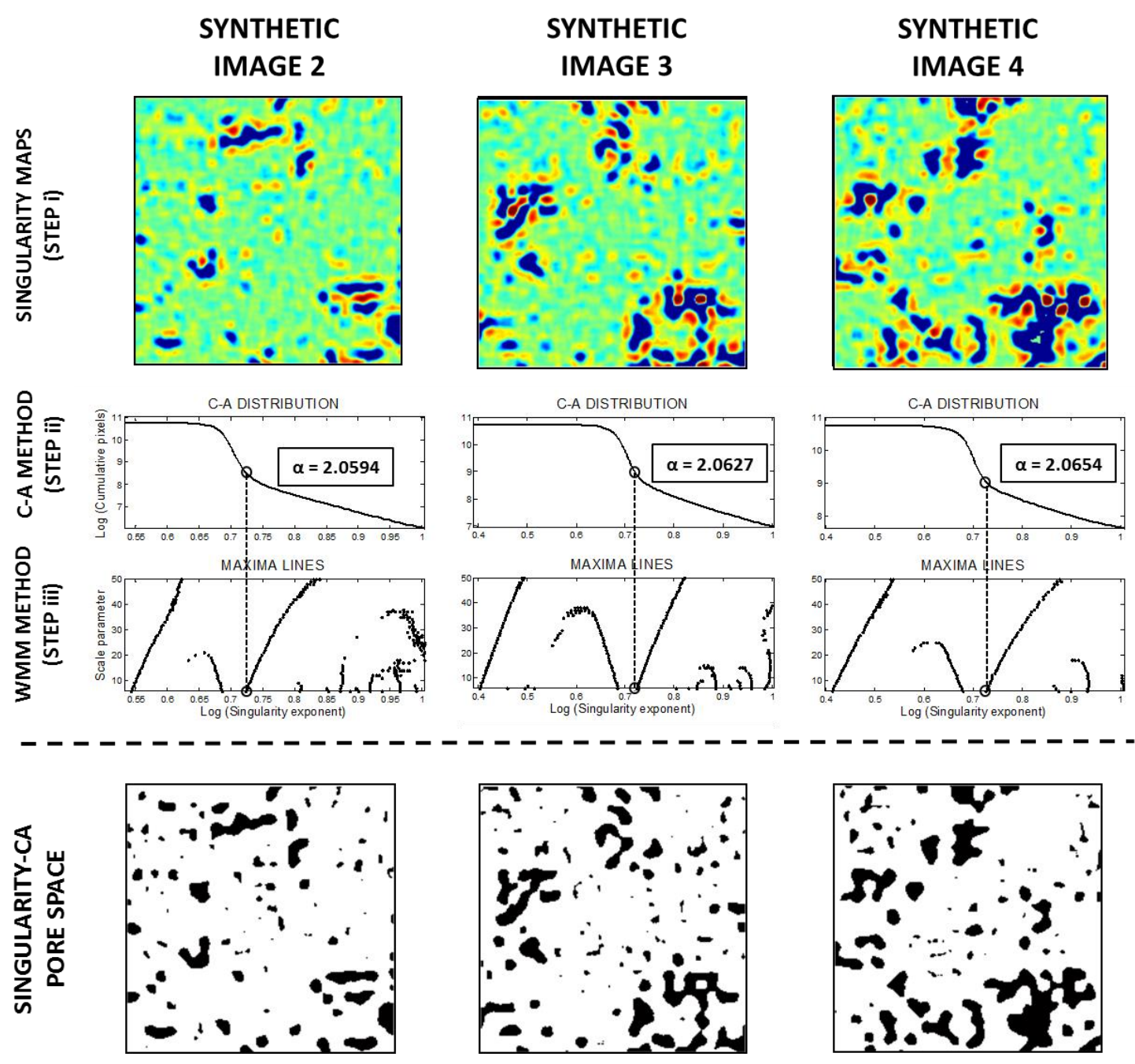

Fig. 6.2 - (Arriba): mapas de singularidades (paso i), aplicación del método CA (paso ii) y detección del umbral mediante TWMM (paso iii), en la metodología SingularidadCA. (Abajo): espacios de poros (representados por píxeles en negro) detectado por el método S-CA (sólo se muestran las imágenes 2, 3 y 4 como ejemplos).

La aplicación del método S-CA Combinado a las imágenes sintéticas seleccionadas 2, 3 y 4 se muestra en la Fig. 6.3. Para obtener el espacio de poros combinado se combina el método S-CA con el método de umbralización global de Máxima Entropía. En este punto, se puede apreciar visualmente que la mayoría de los poros de pequeño tamaño desaparecen en el espacio de poros combinado. 


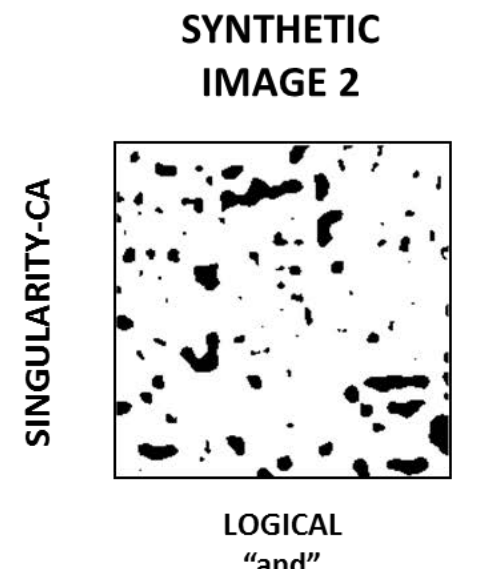

\section{SYNTHETIC \\ IMAGE 3}

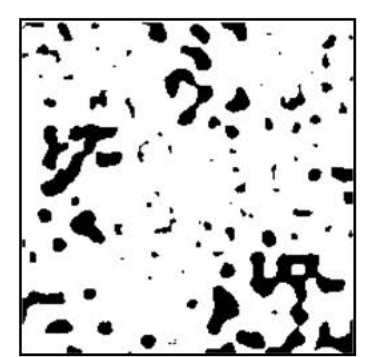

LOGICAL

"and"
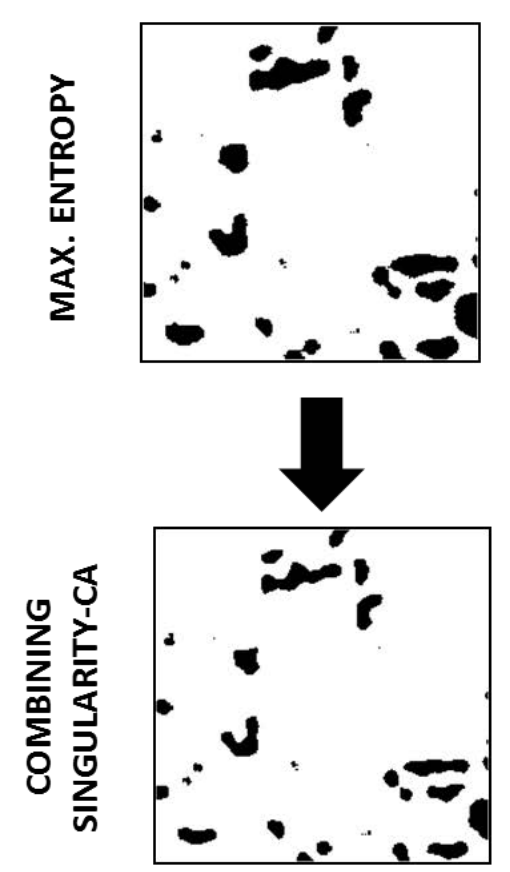
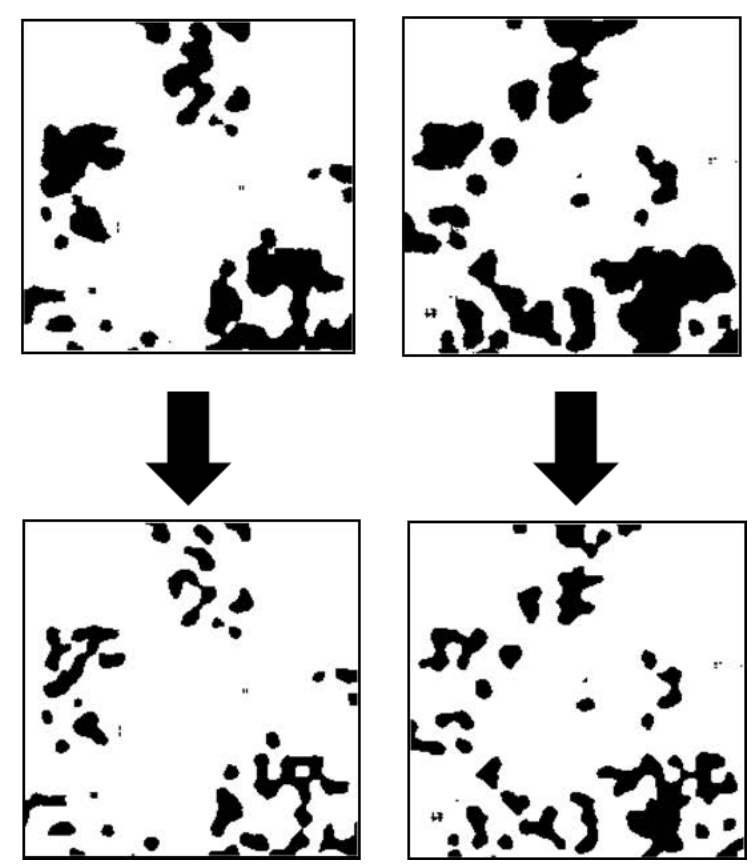

Fig. 6.3 - (Arriba): espacios de poros detectados por el método S-CA. (Medio): espacios de poros detectados por el método de Máxima Entropía (los umbrales de VG se muestran en la Tabla 6.2). (Abajo): espacios de poros combinados resultado del solapamiento de ambos métodos ("y" lógico). Todos los espacios de poros están representados por píxeles negros. (Sólo se muestran las imágenes sintéticas 2, 3 y 4 como ejemplos).

La porosidad, el error relativo de la porosidad y la clasificación errónea de poros (CEP) fueron obtenidos para los métodos de Máxima Entropía, S-CA y SCA Combinado en todas las imágenes del conjunto ejemplo. En la parte superior de la Fig. 6.4 se comparan las porosidades obtenidas por todos los métodos analizados junto con la porosidad real (ground-truth). Los errores 
relativos de la porosidad respecto del ground-truth también se comparan en la parte inferior de la Fig. 6.4.

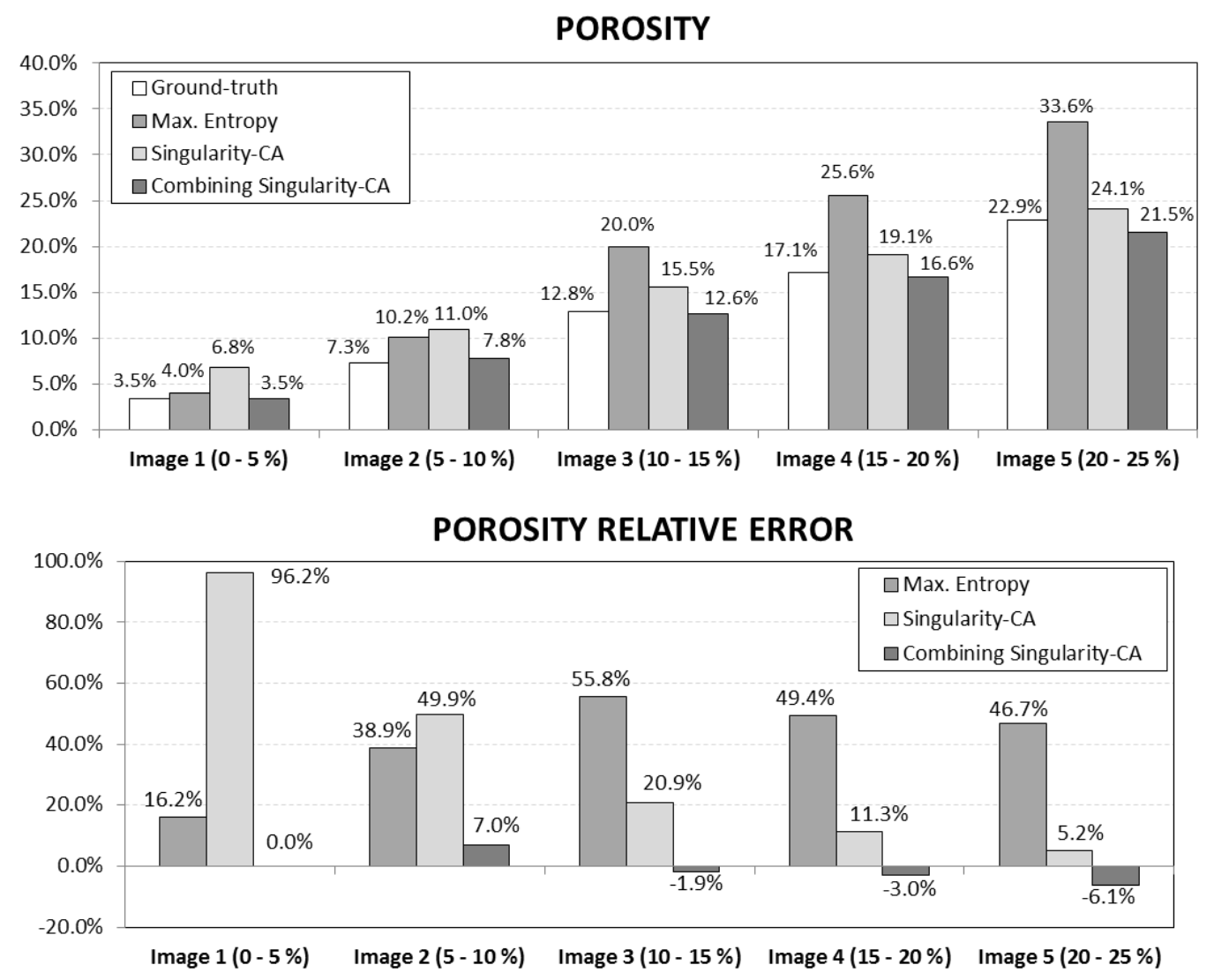

Fig. 6.4 - (Arriba): porosidades obtenidas por todos los métodos analizados comparado con las porosidades reales. (Abajo): Errores relativos de la porosidad para todos los métodos analizados. (Para el conjunto ejemplo).

A continuación se presentan los resultados más significativos de la comparación:

i) El método de Máxima Entropía sobrestima la porosidad en todo el conjunto ejemplo. La sobrestimación toma valores desde el 15\% al 55\% de error relativo, aproximadamente. Los valores más altos del error relativo aparecen a medida que la porosidad real de las imágenes sintéticas aumenta.

ii) El método S-CA también sobrestima la porosidad, aunque obtiene mejor error relativo que el de Máxima Entropía para las imágenes sintéticas con porosidades $>10 \%$. En estos casos, la sobrestimación toma valores 
desde $5 \%$ al $20 \%$ de error relativo, mejorando este valor a medida que la porosidad real de las imágenes aumenta.

iii) El método S-CA Combinado sobrestima ligeramente la porosidad para las imágenes con porosidades reales $<10 \%$, y subestima en poco la porosidad para las imágenes con porosidades reales $>10 \%$. El error relativo toma valores desde $-6 \%$ al $7 \%$.

Un caso especial se presenta en la imagen sintética 1 con la menor porosidad real $(<5 \%)$ donde al método S-CA sobrestima la porosidad excesivamente. Este problema se debe a que los poros incorrectamente detectados representan un porcentaje alto de la porosidad real. El método S-CA Combinado resuelve este problema eficientemente al eliminar todos estos poros incorrectamente detectados.

La comparación de la CEP para los tres métodos de segmentación analizados se muestra en la Fig. 6.5.

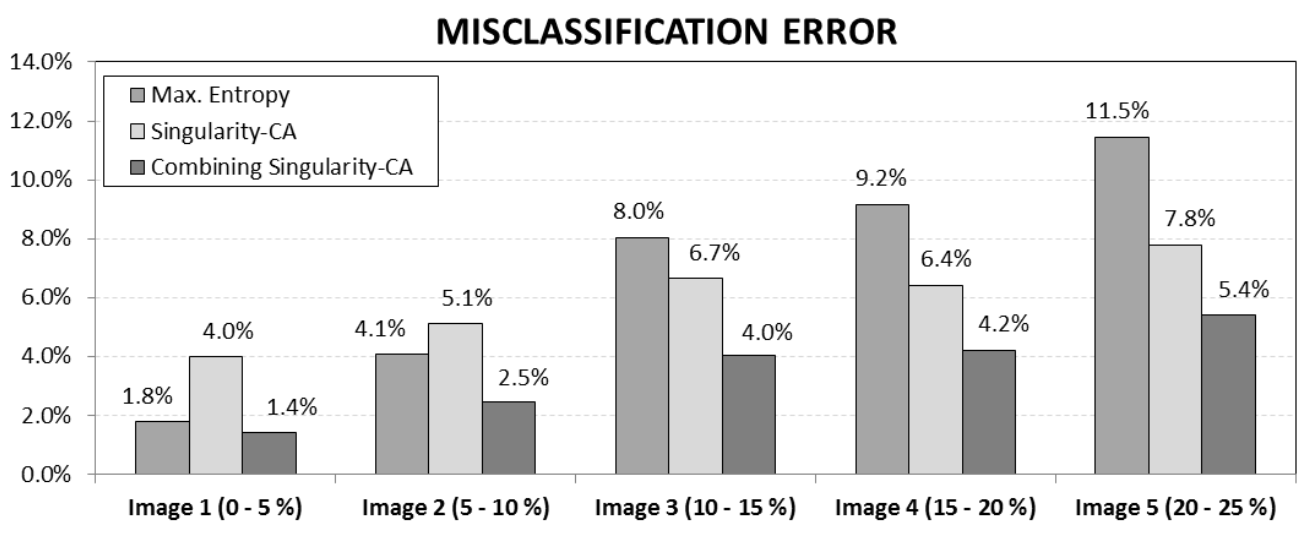

Fig. 6.5 - CEP calculada para todos los métodos analizados. (Para el conjunto ejemplo).

La CEP del método S-CA Combinado es la menor de todos los métodos analizados, y aumenta a medida que la porosidad real de las imágenes sintéticas aumenta. En el caso de la imagen sintética 5 (porosidad $=20.9 \%$ ) los errores relativos de la porosidad son muy similares para los métodos S-CA y SCA Combinado. Sin embargo, cuando se tiene en cuenta la CEP, el 
funcionamiento del S-CA Combinado es mejor, mejorando la CEP de $7.8 \%$ a $5.4 \%$.

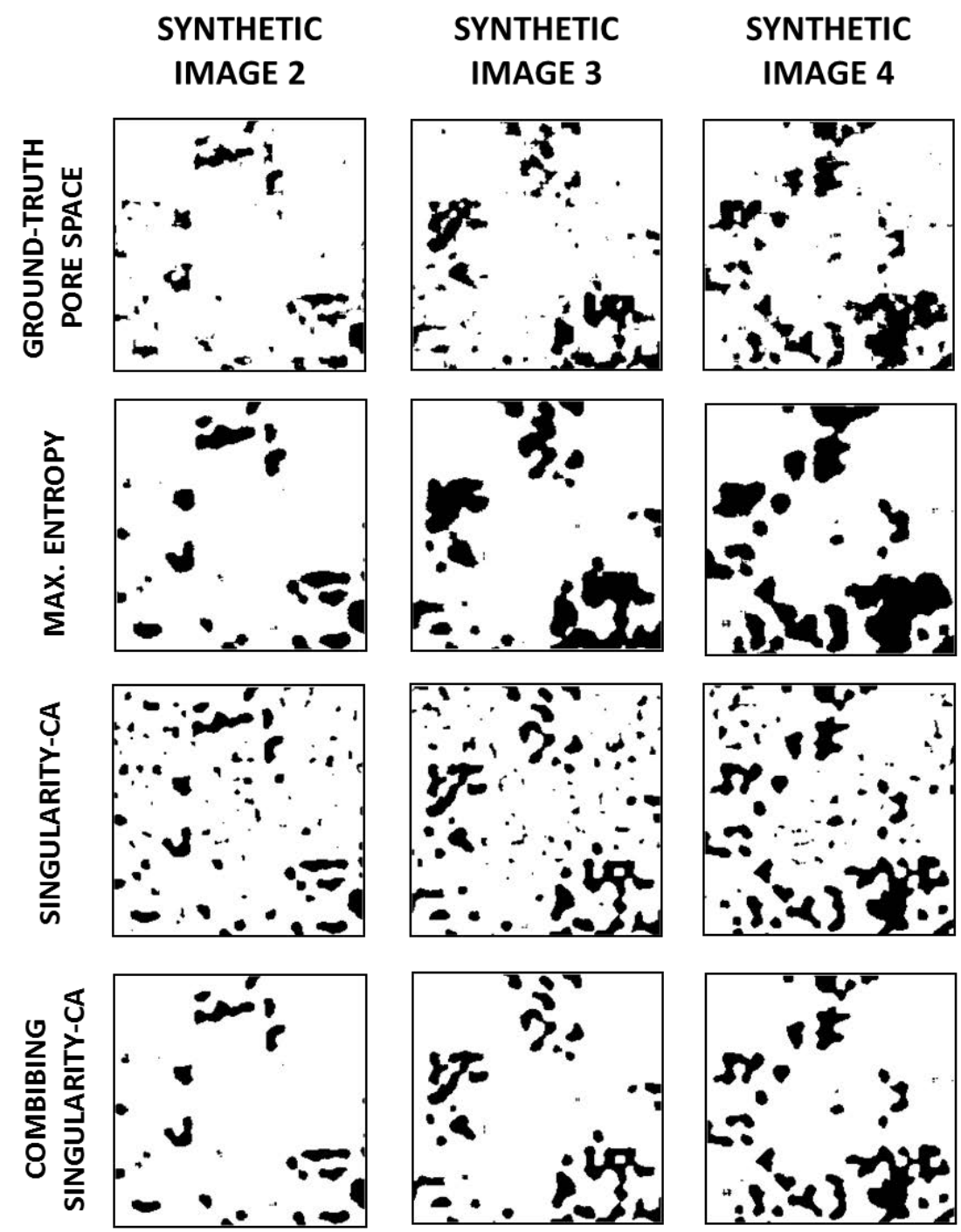

Fig. 6.6 - Espacios de poros reales comparados con los espacios de poros obtenidos por los métodos de Máxima Entropía, S-CA y S-CA Combinado. Todos los espacios de poros están representados por píxeles negros. (Sólo se muestran las imágenes sintéticas 2, 3 y 4 como ejemplos).

En la Fig. 6.6 se comparan los espacios de poros del ground-truth y los detectados mediante los métodos de S-CA, Máxima Entropía y S-CA Combinado, en las imágenes sintéticas seleccionadas 2, 3 y 4 . Se puede apreciar que, usando el método S-CA Combinado, los pequeños poros incorrectamente detectados por el método S-CA son eliminados y, al mismo 
tiempo, se obtiene una buena delimitación de los poros de mediano y gran tamaño.

\begin{tabular}{|lc|c|c|c|c|c|c|}
\cline { 5 - 8 } \multicolumn{1}{c|}{} & \multicolumn{2}{c}{ MÁXIMA } & \multicolumn{4}{|c|}{ SINGULARIDAD-CA } \\
\cline { 5 - 8 } \multicolumn{1}{c|}{} & ENTROPÍA & \multicolumn{2}{c|}{ MÉTODO LR } & \multicolumn{2}{c|}{ MÉTODO WTMM } \\
\hline Imagen 1 & $(0-5 \%)$ & VG & 48 & VS & 2.0765 & VS & 2.0585 \\
\hline Imagen 2 & $(5-10 \%)$ & VG & 50 & VS & 2.0746 & VS & 2.0594 \\
\hline Imagen 3 & $(10-15 \%)$ & VG & 54 & VS & 2.0734 & VS & 2.0627 \\
\hline Imagen 4 & $(15-20 \%)$ & VG & 55 & VS & 2.0714 & VS & 2.0654 \\
\hline Imagen 5 & $(20-25 \%)$ & VG & 56 & VS & 2.0716 & VS & 2.0594 \\
\hline
\end{tabular}

Tabla 6.2 - Umbrales de VG obtenidos por el método de Máxima Entropía y umbrales de VS obtenidos por el método S-CA (utilizando los métodos de RL y TWMM) para las imágenes sintéticas del conjunto ejemplo.

\subsubsection{Validación estadística}

El método S-CA Combinado fue aplicado a 50 imágenes sintéticas de suelo por cada rango para incrementar la significatividad estadística. Parámetros estadísticos tales como la media y la desviación estándar de: la porosidad, el error relativo y la CEP fueron obtenidos para completar el análisis estadístico.

En la parte superior de la Fig. 6.7 se muestran la media y la desviación estándar (barras de error) de las porosidades detectadas por los métodos de Máxima Entropía, S-CA y S-CA Combinado, junto con las porosidades reales de cada uno de los rangos. La media y la desviación estándar (barras de error) de los errores relativos de la porosidad son mostrados en la parte inferior de la Fig. 6.7. Los resultados más importantes de esta comparación son los siguientes:

i) El método de Máxima Entropía sobrestima la porosidad en todos los rangos. La sobrestimación toma valores de $48 \%$ a $58 \%$ (errores relativos medios), aproximadamente. Al contrario de lo que ocurría con el conjunto ejemplo, la sobrestimación puede ser considerada constante para todos los rangos $(\sim 50 \%)$. 
ii) El método S-CA también sobrestima la porosidad, pero obtiene mejor error relativo que el método de Máxima Entropía para los rangos con porosidades $>10 \%$ (rangos 3, 4 y 5 ). En estos rangos, la sobrestimación toma valores de $20 \%$ a $9 \%$ (errores relativos medios), mejorando el error a medida que la porosidad real media aumenta.

iii) El método S-CA Combinado sobrestima ligeramente para los rangos con porosidades $<10 \%$ (rangos 1 y 2 ), y estima muy acertadamente para los rangos con porosidades $>10 \%$ (rangos 3,4 y 5 ). El error relativo medio toma valores de $-3 \%$ a $16 \%$, siendo la mejor estimación de todos los rangos.

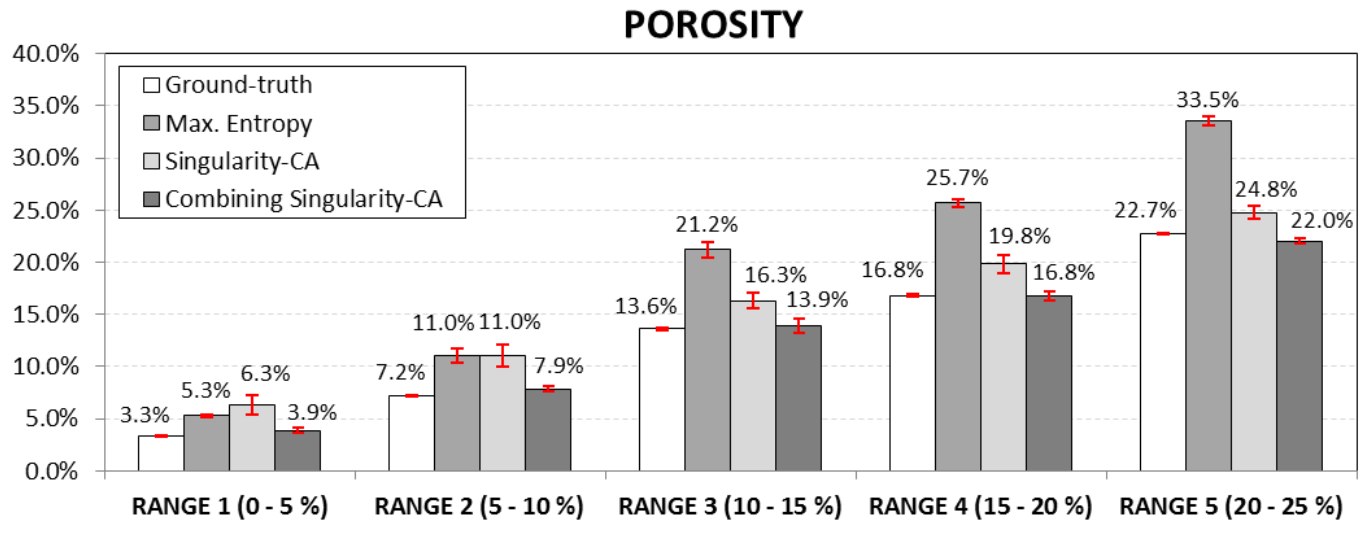

POROSITY RELATIVE ERROR

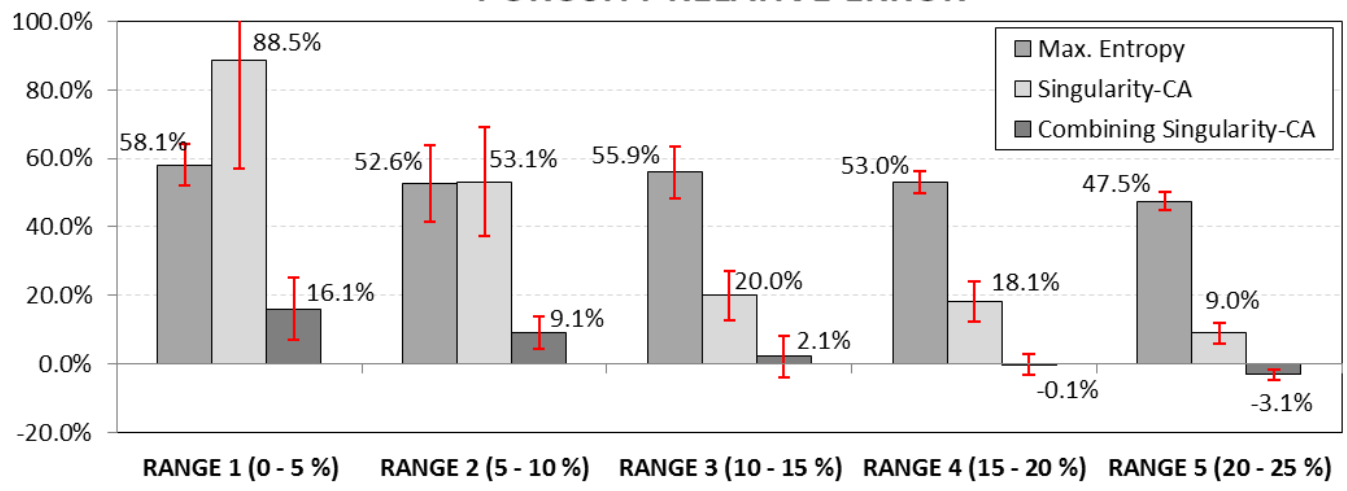

Fig. 6.7 - (Arriba): porosidades medias obtenidas por todos los métodos analizados comparado con las porosidades medias reales. (Abajo): errores relativos medios de la porosidad para todos los métodos analizados. La información numérica de las barras de error se muestra en la Tabla 6.3.

De la misma forma que sucedía con la imagen sintética 1 del conjunto ejemplo, el método S-CA trabaja mal para el rango de porosidades más pequeñas 
(rango 1) debido a la misma razón: los poros incorrectamente detectados representan un alto porcentaje de la porosidad real.

La comparación de la media de la CEP para los tres métodos analizados se muestra en la Fig. 6.8. La CEP media para el método S-CA Combinado es de nuevo el más bajo de todos los métodos analizados y, tal como sucedía con el conjunto ejemplo, se incrementa a medida que la porosidad real media de las imágenes sintéticas aumenta.

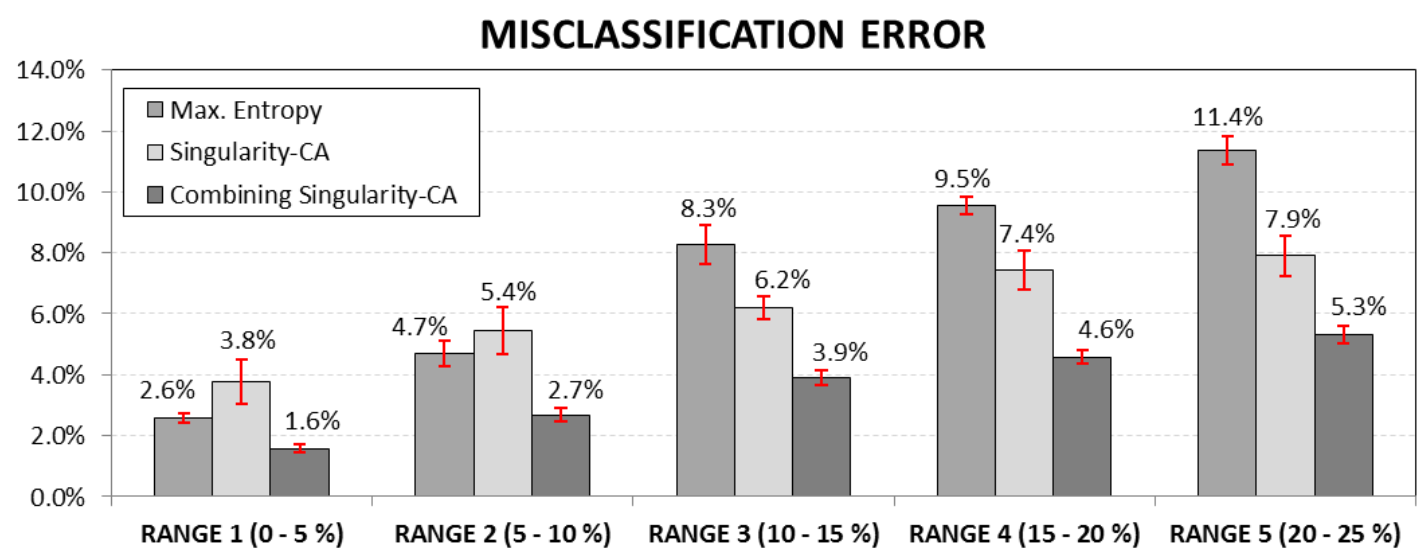

Fig. 6.8 - CEP media calculada para todos los métodos analizados. La información numérica de las barras de error se muestra en la Tabla 6.3.

La información numérica de la desviación estándar (barras de error) de: la porosidad, el error relativo de la porosidad y la CEP se resume en la Tabla 6.3 para los tres métodos analizados.

\begin{tabular}{|l|c|c|c|c|c|c|c|c|c|}
\cline { 2 - 10 } \multicolumn{1}{c|}{} & \multicolumn{3}{c|}{ MAX. ENTROPÍA } & \multicolumn{3}{c|}{ SINGULARIDAD-CA } & \multicolumn{2}{c|}{ S-CA COMBINADO } \\
\cline { 2 - 10 } \multicolumn{1}{c|}{} & (P) & (ER) & (CEP) & (P) & (ER) & (CEP) & (P) & (ER) & (CEP) \\
\hline RG 1 (0 - 5 \%) & $0.14 \%$ & $5.94 \%$ & $0.15 \%$ & $0.98 \%$ & $31.34 \%$ & $0.72 \%$ & $0.26 \%$ & $9.02 \%$ & $0.13 \%$ \\
\hline RG 2 (5 - 10 \%) & $0.68 \%$ & $10.99 \%$ & $0.42 \%$ & $1.03 \%$ & $15.97 \%$ & $0.77 \%$ & $0.26 \%$ & $4.75 \%$ & $0.21 \%$ \\
\hline RG 3 (10 - 15 \%) & $0.79 \%$ & $7.40 \%$ & $0.64 \%$ & $0.80 \%$ & $7.15 \%$ & $0.38 \%$ & $0.66 \%$ & $5.90 \%$ & $0.25 \%$ \\
\hline RG 4 (15 - 20 \%) & $0.36 \%$ & $3.10 \%$ & $0.29 \%$ & $0.87 \%$ & $5.95 \%$ & $0.63 \%$ & $0.43 \%$ & $3.18 \%$ & $0.22 \%$ \\
\hline RG 5 (20 - 25 \%) & $0.47 \%$ & $2.66 \%$ & $0.46 \%$ & $0.60 \%$ & $3.08 \%$ & $0.67 \%$ & $0.25 \%$ & $1.51 \%$ & $0.27 \%$ \\
\hline
\end{tabular}

Tabla 6.3 - Desviaciones estándar de: la porosidad $(P)$, el error relativo de la porosidad (ER) y la clasificación errónea de poros (CEP), para los tres métodos analizados. 


\subsubsection{Comparación de los métodos de RL y TWMM aplicados al método Singularidad-CA Combinado}

\subsubsection{Los métodos RL y TWMM aplicados al "conjunto ejemplo"}

Para el cálculo del umbral en el método S-CA Combinado se requiere localizar un punto de cambio de pendiente especial en la distribución acumulada de VS. Este punto puede ser calculado principalmente mediante dos métodos:

i) El método de RL (mínimos cuadrados). El punto de cambio de pendiente se tradicionalmente se calcula por el cruce de dos rectas de regresión.

ii) El método TWMM. El punto de cambio de pendiente está definido por la convergencia de las líneas de módulo máximo en la transformada wavelet de la distribución acumulada de VS (en escala log-log).

Primeramente, los métodos RL y TWMM fueron aplicados al conjunto ejemplo para mostrar la implementación de ambas metodologías. La Tabla 6.2 muestra todos los umbrales obtenidos en las 5 imágenes sintéticas. En la Fig. 6.9 podemos ver gráficamente ambos cálculos para las imágenes seleccionadas 1 y 2. Atendiendo a los valores de los umbrales de la Tabla 6.2 y los gráficos de la Fig. 6.9 se pueden extraer los siguientes resultados:

i) Los umbrales de VS $\left(\alpha_{\mathrm{th}}\right)$ obtenidos por el método TWMM son inferiores a los obtenidos por el método RL. Esto significa que el espacio de poros obtenido mediante TWMM es mayor que el espacio de poros obtenido mediante RL ya que, por definición, el espacio de poros está definido como $\forall \alpha / \alpha \geq \alpha_{\text {th }}$, donde $\alpha$ son los SV.

ii) En la Fig. 6.9 se puede apreciar que es difícil calcular la recta de regresión denominada por "recta b". Existe un amplio rango de error al hacer el ajuste lineal ya que el comportamiento lineal en las cercanías del punto de cambio de pendiente buscado no es siempre evidente. Esta dificultad aparece en todas las imágenes sintéticas analizadas, siendo 
más acuciante cuando las porosidades reales son bajas. Por otro lado, el cálculo del umbral mediante en método TWMM es más objetivo en este sentido.

SYNTHETICIMAGE 1
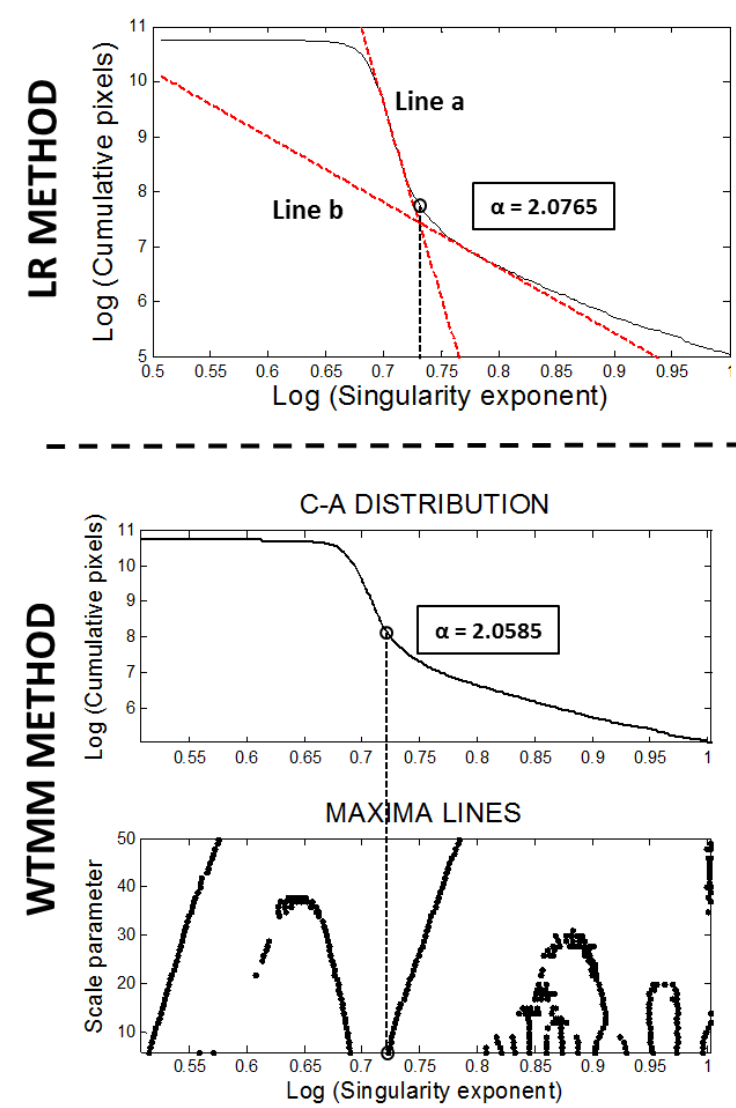

SYNTHETICIMAGE 2
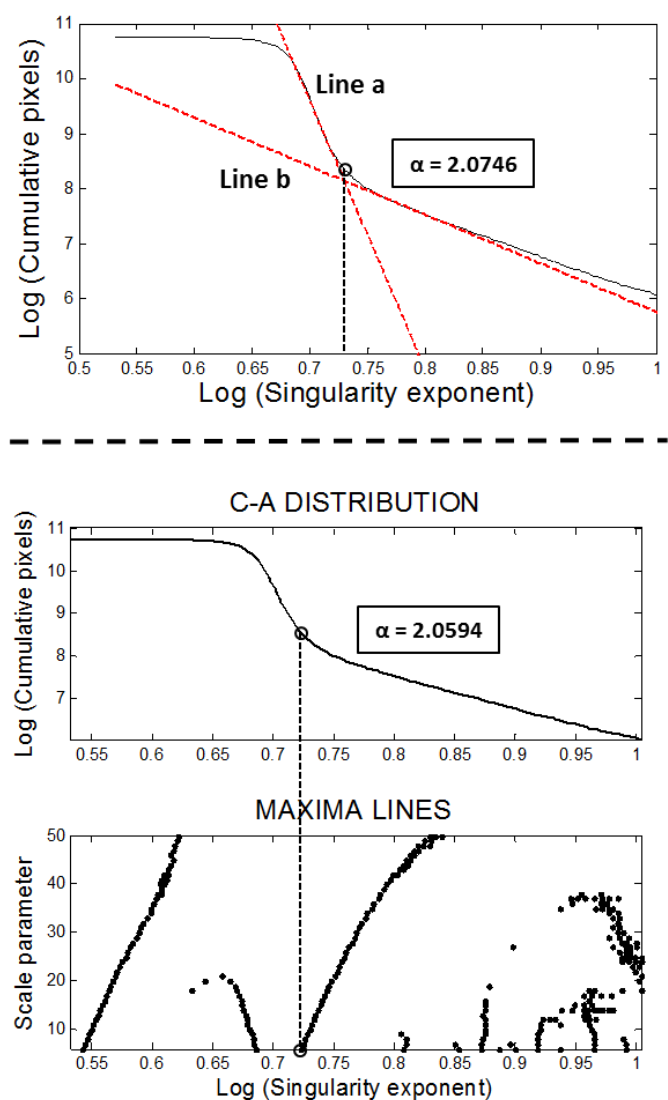

Fig. 6.9 - (Arriba): aplicación del método de RL a las distribuciones acumuladas de VS (escala log-log). Las rectas a y b fueron obtenidas con $R^{2}>0.98$. (Abajo): aplicación del método de TWMM a las mismas distribuciones. (Sólo se muestran las imágenes 1 y 2 como ejemplos).

El punto i) significa que las porosidades obtenidas mediante el método TWMM son siempre mayores que las obtenidas mediante el método RL. Esto último puede implicar una ventaja para el método $\mathrm{RL}$, sin embargo, la ambigüedad que existe en algunos casos en el cálculo del punto de cambio de pendiente, tal como se expone en el punto ii), nos conduce a elegir la solución ofrecida por el método de TWMM. 
En la parte superior de la Fig. 6.10 se muestran las porosidades obtenidas por el método S-CA Combinado cuando se aplican los métodos TWMM y RL al conjunto ejemplo de imágenes sintéticas. Los errores relativos de la porosidad respecto al ground-truth también fueron calculados y se muestran en la parte inferior de la misma figura. Atendiendo a los valores del error relativo, el método TWMM funciona mejor para porosidades reales $>10 \%$.

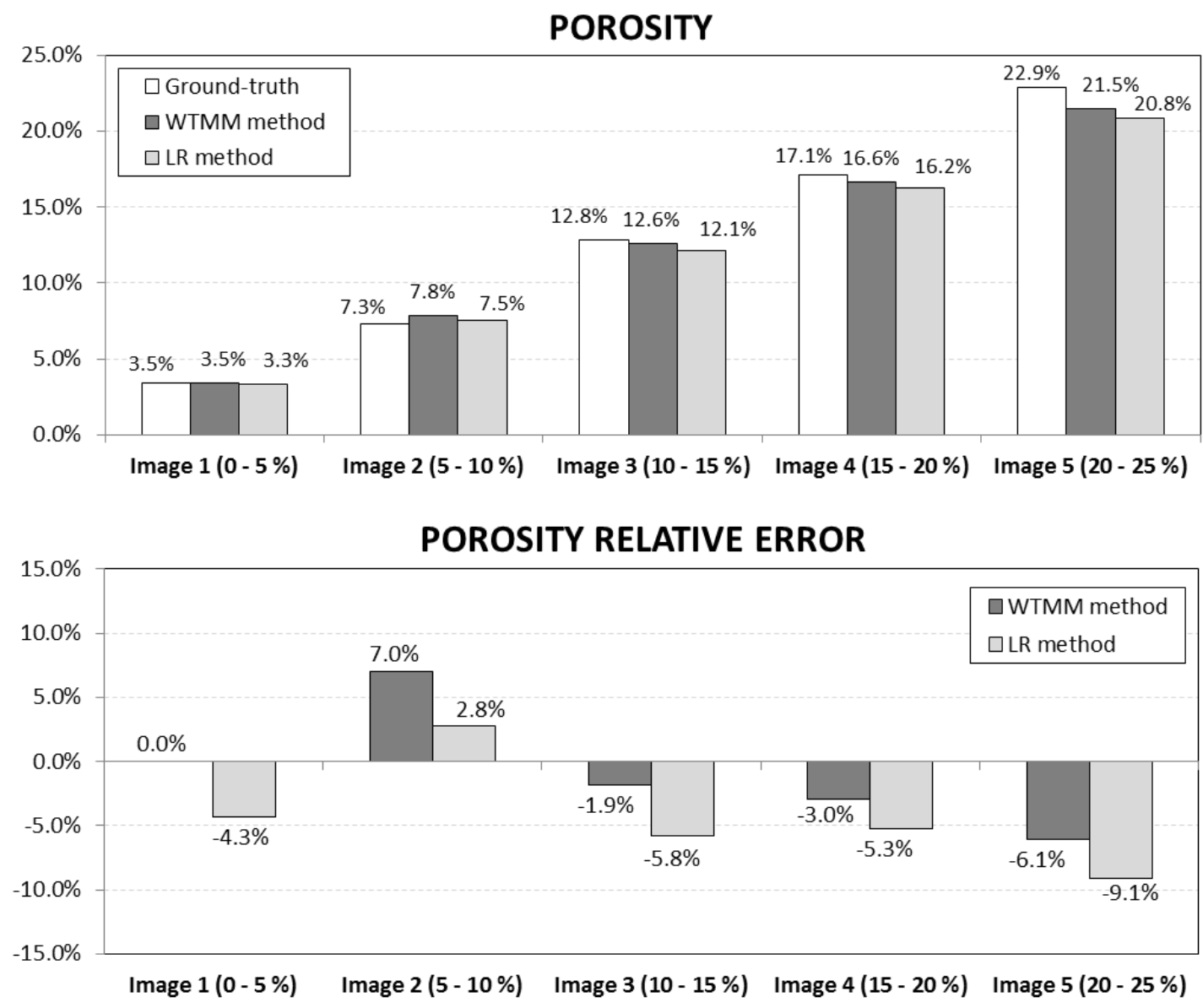

Fig. 6.10 - (Arriba): Porosidades obtenidas por el método S-CA Combinado comparada con las porosidades reales utilizando los métodos de RL y TWMM. (Abajo): errores relativos de la porosidad para ambas metodologías. (Para el conjunto ejemplo).

La comparación de la CEP para ambas metodologías se muestra en la Fig. 6.11. Atendiendo a los resultados obtenidos, la CEP no es un criterio decisivo ya que ambos métodos dan los mismos niveles de CEP. 


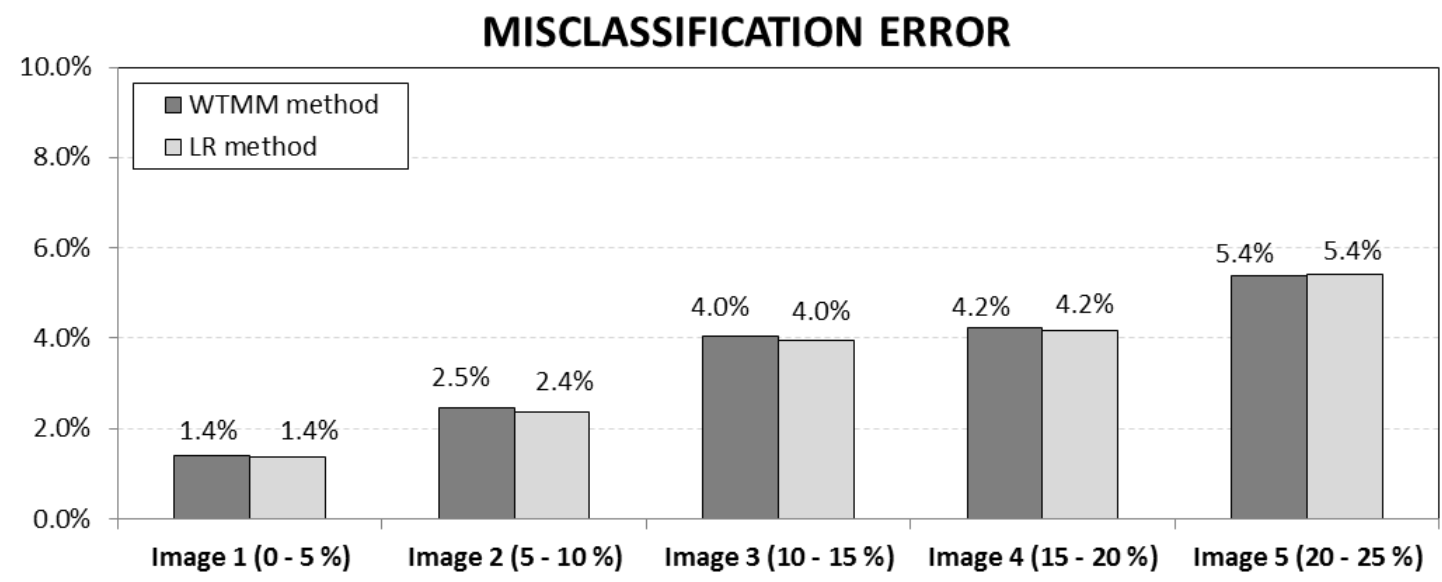

Fig. 6.11 - CEP calculada por el método S-CA Combinado utilizando los métodos de RL y TWMM. (Para el conjunto ejemplo).

\subsubsection{Validación estadística}

Finalmente, para incrementar la validez estadística, los métodos de RL y TWMM fueron aplicados a 50 imágenes sintéticas de suelo en cada uno de los 5 rangos de porosidades definidos. Estadísticos tales como la media y la desviación estándar de: la porosidad, el error relativo de la porosidad y la CEP, fueron obtenidos para completar el análisis.

La media y la desviación estándar de la porosidad obtenidos por ambos métodos se muestran en la parte superior de la Fig. 6.12. La media y la desviación estándar del error relativo de la porosidad se muestran también en la parte inferior de la misma figura. Atendiendo a los resultados del error relativo, el método de TWMM funciona mejor para porosidades $>10 \%$ (rangos 3,4 y 5 ), validando y apoyando los resultados obtenidos para el conjunto ejemplo. 

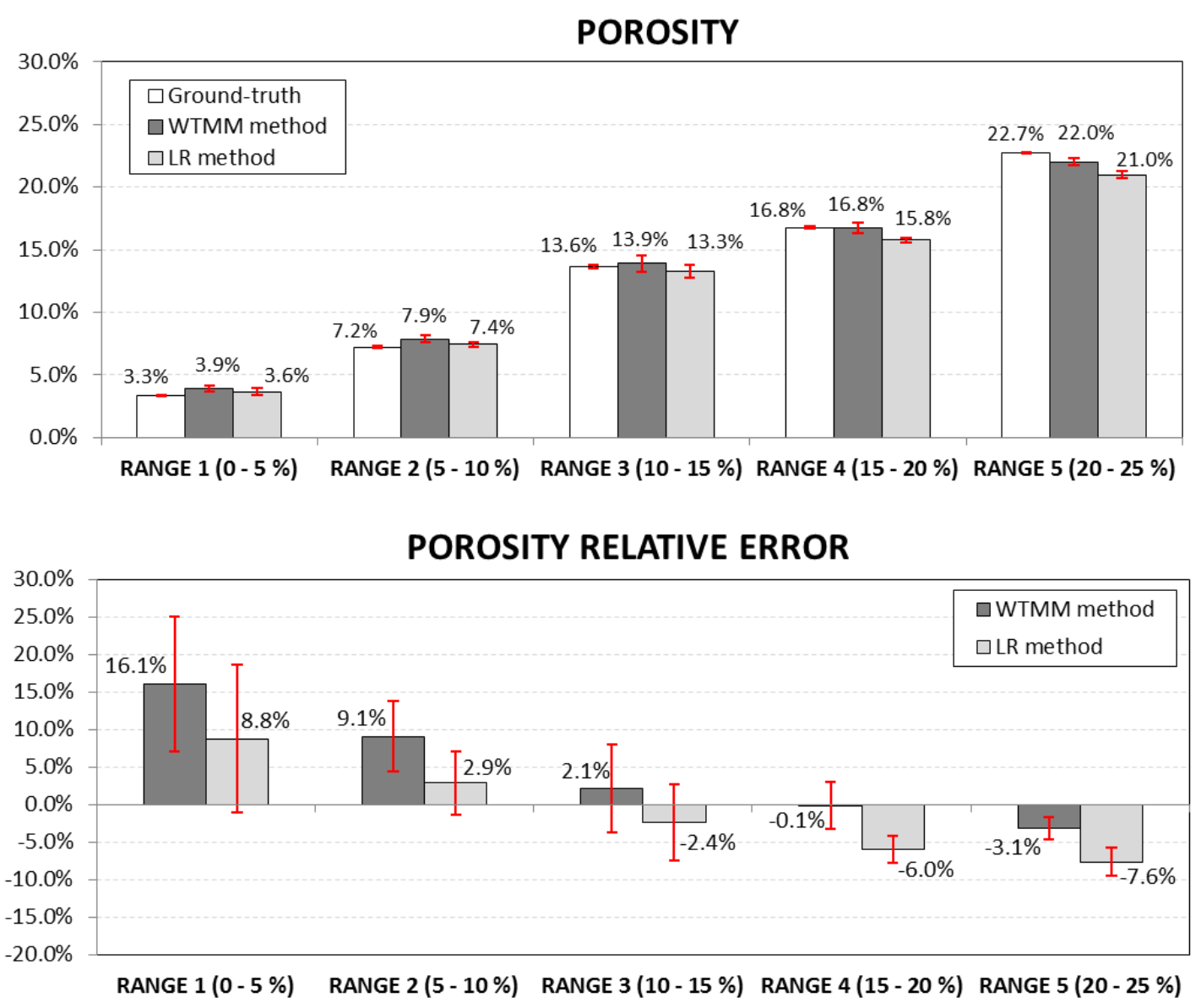

Fig. 6.12 - (Arriba): porosidades medias obtenidas por el método S-CA Combinado comparada con las porosidades medias reales utilizando los métodos de RL y TWMM. (Abajo): errores relativos medios de la porosidad para ambas metodologías. La información numérica de las barras de error se muestra en la Tabla 6.4.

La comparación de la CEP para ambas metodologías (ver Fig. 6.13) también confirman los resultados obtenidos para el conjunto ejemplo, a saber, la CEP es aproximadamente la misma cuando aplicamos ambos métodos. 


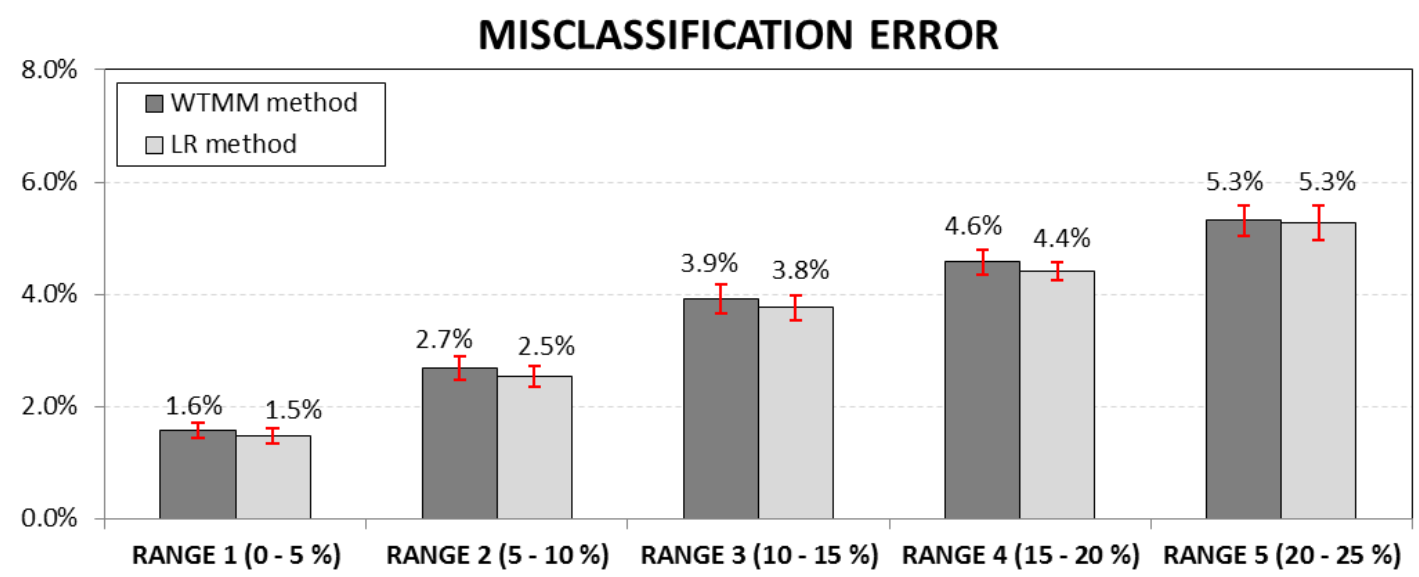

Fig. 6.13 - CEP media calculada por el método S-CA Combinado utilizando los métodos de RL y TWMM. La información numérica de las barras de error se muestra en la Tabla 6.4.

La información numérica de la desviación estándar (barras de error) de: la porosidad, el error relativo de la porosidad y la CEP se resume en la Tabla 6.4 para ambas metodologías.

\begin{tabular}{|l|c|c|c|c|c|c|}
\cline { 2 - 7 } \multicolumn{1}{c|}{} & \multicolumn{3}{c|}{$\begin{array}{c}\text { S-CA COMBINADO } \\
\text { (MÉTODO WTMM) }\end{array}$} & \multicolumn{3}{c|}{$\begin{array}{c}\text { S-CA COMBINADO } \\
\text { (MÉTODO RL) }\end{array}$} \\
\cline { 2 - 7 } \multicolumn{1}{c|}{} & (P) & (ER) & (CEP) & (P) & (ER) & (CEP) \\
\hline RANGO 1 (0 - 5 \%) & $0.26 \%$ & $9.02 \%$ & $0.13 \%$ & $0.29 \%$ & $9.83 \%$ & $0.14 \%$ \\
\hline RANGO 2 (5 - 10 \%) & $0.26 \%$ & $4.75 \%$ & $0.21 \%$ & $0.22 \%$ & $4.17 \%$ & $0.18 \%$ \\
\hline RANGO 3 (10 - 15 \%) & $0.66 \%$ & $5.90 \%$ & $0.25 \%$ & $0.54 \%$ & $5.05 \%$ & $0.23 \%$ \\
\hline RANGO 4 (15 - 20 \%) & $0.43 \%$ & $3.18 \%$ & $0.22 \%$ & $0.19 \%$ & $1.80 \%$ & $0.16 \%$ \\
\hline RANGO 5 (20 - 25 \%) & $0.25 \%$ & $1.51 \%$ & $0.27 \%$ & $0.32 \%$ & $1.83 \%$ & $0.30 \%$ \\
\hline
\end{tabular}

Tabla 6.4 - Desviaciones estándar de: la porosidad $(P)$, el error relativo de la porosidad (ER) y la clasificación errónea de poros (CEP), utilizando los métodos de RL y TWMM. 


\section{CAPÍTULO 7}

\section{CONCLUSIONES}




\subsection{CONCLUSIONES}

En base a los resultados obtenidos en los capítulos anteriores llegamos a las siguientes conclusiones:

1. En cuanto a la delimitación de regiones estadísticamente homogéneas (estadísticas gaussianas) en mapas de NDVI aplicando el método de segmentación "S-CA".

Se ha probado que la variabilidad espacial del índice NDVI en las zonas estudiadas sigue un patrón multifractal dentro de un rango limitado de escalas, coherente con los trabajos de otros autores en otras zonas.

El patrón multifractal detectado es diferente dependiendo de la estación astronómica del año y de los ciclos interanuales (años secos y húmedos).

El espectro multifractal durante las épocas de primavera tiene un ancho espectral $\Delta \alpha$ muy pequeño confirmando el hecho de que en este periodo existe una mayor homogeneidad espacial, es decir, una menor variabilidad espacial del índice, con la mayoría de las localizaciones con un exponente de singularidad aproximadamente igual a 2 .

El hallazgo de tramos lineales en los gráficos log-log de la distribución acumulada de exponentes de singularidad (método CA) nos ha permitido utilizar la metodología de Cheng et al. (1994) para la detección de concentraciones anómalas.

En los mapas de NDVI analizados hemos podido calcular los umbrales que separan las zonas de valores singulares (valores de concentración NDVI anómalos) de las no singulares.

Las zonas no singulares de los mapas de NDVI representan zonas con estadísticas normales o log-normales. Por tanto, la delimitación de estas zonas mediante umbrales en el mapa de singularidades constituye un método válido para la zonificación de mapas de NDVI. 
Las zonas no singulares cambian a lo largo de las estaciones astronómicas del año y ciclos interanuales. En primavera nos encontramos con la mayor cantidad de estas áreas, es decir, cuando aparece la mayor cantidad de zonas con estadísticas normales o log-normales. En otoño nos encontramos justo lo contrario, la menor cantidad de áreas no singulares, debido a la alta variabilidad espacial del NDVI.

La superposición de las zonas no singulares de distintos años (seco y húmedo) de una misma estación astronómica nos permite establecer zonas estadísticamente estables en el tiempo, es decir, que mantienen su estadística normal o log-normal a lo largo de los años.

Una de las aplicaciones prácticas del cálculo de zonas no singulares estables en el tiempo está relacionada con la delimitación de zonas homogéneas en los seguros indexados de daños por sequía. Los valores del NDVI de estas zonas pueden ser utilizados para calcular los principales estadísticos de sus distribuciones normales, a saber, la media y la varianza, generalmente utilizados para el cálculo del umbral de sequía.

\section{En cuanto a la delimitación del espacio de poros en TAC de suelos aplicando el método de segmentación "S-CA" en la versión 2D y "S- CV" en la versión 3D.}

La transformación de las TAC (de niveles de grises) a un mapa de singularidades mejora el contraste de la interfaz sólido-poro al amplificar las zonas de anomalías (espacio de poros) presentes en la imagen.

La aplicación del método CA a la distribución acumulada del mapa de singularidades (método S-CA) ha puesto de manifiesto las propiedades autosimilares o autosemejantes de la distribución espacial de anomalías (espacio de poros) al aparecer varios tramos lineales en los gráficos acumulados log-log.

En las imágenes de suelos analizadas hemos obtenido tres tramos lineales bien definidos con sus respectivos puntos de cambio de pendiente y no sólo 
dos como aparecían en los trabajos anteriores de Cheng sobre concentraciones anómalas de elementos químicos. El punto de cambio de pendiente seleccionado como umbral mediante el método TWMM resuelve de forma satisfactoria el problema de la binarización en el caso de TAC de suelos.

En el caso tridimensional nos encontramos con los mismos inconvenientes que se presentaban en el caso bidimensional, e igualmente el uso combinado de la técnica de mapa de singularidades en 3D y el método CV, que define el método $\mathrm{S}-\mathrm{CV}$, resuelve de forma satisfactoria el problema de la binarización en el caso de TAC de suelos.

\section{En cuanto a la evaluación y validación del método de segmentación "S-CA" y "S-CV" aplicado a TAC de suelos.}

Se compararon los resultados de aplicar el método S-CA a una imagen sintética de suelo en 2D (método MT) con los métodos de segmentación tradicionales: método de Otsu, método Iterativo y método de Máxima Entropía. Los criterios de comparación fueron: la porosidad total (\%), la DTP acumulada, la DAP acumulada y la CEP.

El método propuesto extrae los poros de tamaño medio y grande con un buen nivel de ajuste, por contra introduce pequeños poros debido a la amplificación de las pequeñas anomalías en la transformación del mapa de singularidades (los pequeños poros no aumentan significativamente la porosidad total).

Los métodos tradicionales analizados detectaron menor cantidad de poros y sobreestimaron el tamaño de los poros grandes, por lo que al final la porosidad total quedaba sobreestimada. El método S-CA lograba la porosidad total más cercana a la real. Respecto a la CEP, el método S-CA obtuvo los mismos niveles de calidad que los métodos tradicionales analizados.

La evaluación del método S-CA también se complementó testeando tres TAC reales de suelos en 2D, comparando los resultados con los métodos tradicionales de segmentación antes indicados. Los resultados más significativos fueron: 
a) Los métodos de Otsu, Iterativo y Máxima Entropía obtienen menos cantidad de poros. Sin embargo, entre ellos se encuentran los poros de mayor tamaño.

b) El método S-CA obtiene mayor cantidad de poros, aunque principalmente son poros de pequeño tamaño.

Extrapolando los resultados obtenidos en la imagen sintética podemos deducir que en las TAC reales de suelo:

a) Los métodos tradicionales Otsu e Iterativo sobreestiman la porosidad total al sobreestimar el tamaño de los poros grandes en las tres TAC reales analizadas. La porosidad calculada por el método de Máxima Entropía se queda muy por debajo de las del resto debido al reducido número de poros que detecta, infraestimando la porosidad en las imágenes reales, al contrario de lo que sucedía en la imagen sintética.

b) El método S-CA consigue obtener la porosidad total más cercana a la real al delimitar mejor los poros de tamaño grande y mediano, aunque debemos tener en cuenta, como sucedía en la imagen sintética, que el método introduce incorrectamente poros de pequeño tamaño.

En cuanto a la validación del método S-CV también se utilizó el método MT para la creación de una imagen sintética de suelo en 3D. De igual manera que en el caso bidimensional se realizó una comparativa entre el método S-CV y los métodos de segmentación tradicionales de Otsu y de Máxima Entropía. Los criterios de comparación adoptados fueron: la porosidad total (\%), la DTP acumulada y la CEP.

El comportamiento del nuevo método de segmentación en 3D es similar al de su predecesor en 2D, encontrando también el mismo inconveniente, esto es, que introduce pequeños poros debido a la amplificación de las pequeñas anomalías en la transformación del mapa de singularidades. 
En el caso 3D también se complementó la evaluación testeando el método S$\mathrm{CV}$ en dos muestras TAC reales de un mismo suelo de diferentes densidades $\left(1.2 \mathrm{Mg} / \mathrm{m}^{3}\right.$ y $\left.1.6 \mathrm{Mg} / \mathrm{m}^{3}\right)$. Los resultados más significativos de la comparación del método S-CV con los métodos tradicionales fueron:

a) Los métodos de Otsu y Máxima Entropía obtienen menos cantidad de poros, aunque algunos de ellos son de gran tamaño.

b) El método S-CV obtiene mayor cantidad de poros, aunque principalmente son poros de pequeño tamaño.

Extrapolando los resultados obtenidos en la imagen sintética podemos deducir que en las TAC reales de suelo:

a) El método de Otsu sobreestima la porosidad total al sobreestimar el tamaño de los poros grandes en la TAC de $1.2 \mathrm{Mg} / \mathrm{m}^{3}$. El método de Máxima Entropía subestima la porosidad total debido al reducido número de poros que detecta, al contrario de lo que sucedía en la imagen sintética. En la TAC de $1.6 \mathrm{Mg} / \mathrm{m}^{3}$ el método de Otsu es incapaz de obtener resultados coherentes.

b) El método S-CV consigue obtener la porosidad más cercana a la real al delimitar mejor los poros de tamaño grande y mediano.

\section{En cuanto a la mejora del método "S-CA". Definición y evaluación del método de segmentación "S-CA Combinado" para la delimitación del espacio de poros en TAC.}

El principal inconveniente del método S-CA es la introducción de manera errónea de poros de pequeño tamaño, ya que el mapa de singularidades amplifica las pequeñas fluctuaciones de intensidad de la TAC de suelo. Para solventar este inconveniente se propone combinar el método "S-CA" con un método de umbralización global, en este caso el método de Máxima Entropía.

Para la evaluación y validación estadística del método S-CA Combinado se generaron imágenes sintéticas de suelo mediante el método MT para 5 rangos 
diferentes de porosidad $(0 \%-5 \%, 5 \%-10 \%, 10 \%-15 \%, 15 \%-20 \%$ y $20 \%-$ $25 \%$ ). Los métodos que se utilizaron en la comparación fueron el S-CA y el tradicional de Máxima Entropía, además del "ground-truth" de las imágenes sintéticas.

Los resultados obtenidos en base a los parámetros de porosidad media, error relativo medio de la porosidad y CEP media indicaron que el método combinado conseguía superar a su antecesor. Según los valores del error relativo de porosidad, el método combinado fue el que más se aproximó a la porosidad real en los cinco rangos definidos, con valores que se situaron entre $-3.1 \%$ y $+16.1 \%$. Según la CEP media, el método combinado también obtuvo mejores resultados (entre $1.6 \%$ y $5.3 \%$ ).

El nuevo método consigue que: i) la mayoría de los poros de pequeño tamaño que no corresponden a poros reales es eliminada y, ii) se respeta la delimitación que hace el Singularidad-CA de los poros de mediano y gran tamaño.

Por último, se evalúa el uso de los métodos de RL y TWMM para la detección de los umbrales de segmentación en el método S-CA Combinado. Los resultados obtenidos en base a los parámetros de porosidad media, error relativo medio de la porosidad y CEP media indicaron que el método TWMM obtiene mejores resultados que el método RL para porosidades $>10 \%$.

\section{En cuanto a la definición de un nuevo método para crear imágenes sintéticas de suelo: método de los “Multifractales Truncados" (MT) en la versión 2D y 3D.}

El método MT nos permite simular las dos características principales de las TAC de suelos, a saber, el bajo contraste de la interfaz sólido-poro y la distribución espacial del espacio de poros:

a) El bajo contraste que aparece en la interfaz sólido-poro de las TAC reales de suelos daba lugar a histogramas de niveles de 
grises muy unimodales, muy parecidos a los resultantes de las imágenes sintéticas generadas por el nuevo método MT.

b) Las propiedades autosimilares en la distribución espacial de anomalías (espacio de poros) de las TAC reales de suelos son conseguidas mediante el método MT. 


\subsection{FUTURAS LÍNEAS DE INVESTIGACIÓN}

Se proponen como futuras líneas de investigación los siguientes temas:

1. La aplicación de la metodología S-CA a mapas de NDVI se ha realizado en 8 mapas de resolución 500 m x 500 m. Será necesario validar los resultados en un conjunto de mapas más amplio y para otras resoluciones.

2. La búsqueda de una mejora del método S-CV que discrimine entre los poros de pequeño tamaño reales y los incorrectamente obtenidos por el método, tal como ya se ha realizado con el S-CA. La eliminación de estos poros es importante ya que afecta al cálculo de parámetros tales como la conductividad, la difusividad y la dispersividad de la red de poros utilizados en muchas simulaciones.

3. La exploración de que el método de segmentación propuesto pueda identificar no solo el espacio de poros llenos de aire sino también el espacio de poros llenos de agua.

4. La mejora del método de creación de imágenes sintéticas de suelos, es decir, el método de los multifractales truncados, para que tanto los histogramas en niveles de grises obtenidos como la distribución espacial de los poros se aproximen mejor a las TC reales.

5. Los métodos S-CA y S-CV se basan principalmente en las propiedades autosimilares (fractales) de las imágenes de suelos. Por tanto también será necesario chequear si la hipótesis de autosimilitud es cierta para otros tipos de suelos. 


\section{REFERENCIAS}

\section{BIBLIOGRÁFICAS}




\section{BIBLIOGRAFÍA}

Afzal, P., Fadakar Alghalandis, Y., Khakzad, A., Moarefvand, P. and Rashidnejad Omran, N. (2011). Delineation of mineralization zones in porphyry $\mathrm{Cu}$ deposits by fractal concentration-volume modeling. Journal of Geochemical Exploration, 108, 220-232.

Agterberg, F. P., Cheng, Q. and Wright, D.F. (1993). Fractal modeling of mineral deposits. In: Elbrond J, Tang X (eds) 24th APCOM symposium proceeding, Montreal, Canada, p 43-53.

Agterberg, F. P. (1995). Power-law versus lognormal models in mineral exploration. In: Mitri, H.S. (Ed.), Computer Applications in the Mineral Industry, Proceedings of the Third Canadian Conference on Computer Applications in the Mineral Industry, pp. 17-26.

Alonso, C., Tarquis, A. M. and Benito, R.M. (2005). Multifractal Characterization of Multispectrum Satellite Images. Geophysical Research Abstracts, Vol. 7, 05413.

Alonso, C., Tarquis, A. M., Benito, R. M. and Zúñiga, I. (2007). Scaling properties of vegetation and soil moisture indices: multifractal and joint multifractal analysis. Geophysical Research Abstracts, Vol. 9, 11643.

Alonso, C., Tarquis, A. M., Benito, R. M. and Zúñiga, I. (2008). Influence of spatial and radiometric resolution of satellite images in scaling/multiscaling behavior. Geophysical Research Abstracts, Vol. 10, EGU2008-A-06184.

Alonso, C., Tarquis, A. M., Zúñiga, I., and Benito, R. M. (2017). Spatial and radiometric characterization of multi-spectrum satellite images through multifractal analysis, Nonlin. Processes Geophys., 24, 141-155.

Arneodo A., Audit B., Decoster N., Muzy J. F., Vaillant C. (2002). A wavelet based multifractal formalism: application to DNA sequences, satellite images of the cloud structure and stock market data, in The Science of Disasters: Climate Disruptions, Heart Attacks, and Market Crashes, eds Bunde A., Kropp J., Schellnhuber H. J., editors. (Berlin: Springer Verlag; ), 26-102. 
Barnsley, M.F. (1993). Fractals everywhere (2nd edition). London: Academic Press Professional.

Bird, N., Diaz, M. C., Saa, A. and Tarquis, A. M. (2006). Fractal and multifractal analysis of pore-scale images of soil. J. Hydrol. 322, 211-219.

BOE (2013). 6638 - Orden AAA/1129/2013. N 145, III, p-46077.

Cheng, Q. (2001). Singularity analysis for image processing and anomaly enhancement, in: Proceedings IAMG'01, International Association for Mathematical Geology, Cancun, Mexico, 6-12 September, CD-ROM.

Cheng, Q. (2007). Multifractal imaging filtering and decomposition methods in space, Fourier frequency, and eigen domains. Nonlin. Processes Geophys., 14, 293-303.

Cheng, Q. (2008). Modeling Local Scaling Properties for Multiscale Mapping. Vadose Zone J., vol. 7, 525-532.

Cheng, Q., Agterberg, F. P. and Ballantyne, S. B. (1994). The separation of geochemical anomalies from background by fractal methods. J. Geochem. Explor., 51, 109-130.

Cheng, Q. and Agterberg, F.P. (1996). Multifractal modeling and spatial statistics. Math. Geol. Vol 28, 1-16.

Cortina-Januchs, M. G., Quintanilla-Dominguez, J., Vega-Corona, A., Tarquis, A. M. and Andina, D. (2011). Detection of pore space in CT soil images using artificial neural networks. Biogeosciences, 8, 279-288.

Dalezios, N. R., Blanta, A., and Spyropoulos, N. V. and Tarquis, A. M. (2014). Risk identification of agricultural drought for sustainable Agroecosystems. Nat. Hazards Earth Syst. Sci., 14, 2435-2448.

De Guzmán, M., Martín, M.A., Morán, M. and Reyes, M. (1993). Estructuras fractales y sus aplicaciones. Barcelona: Labor.

Dullien, F.A.L. (2012). Porous Media: Fluid Transport and Pore Structure. Academic Press, Inc. Second Edition. 574 pp. 
Evertsz, C. J. G. and Mandelbrot, B. B. (1992). Multifractal Measures (Appendix B). In: Peitgen, H., Jürgens, H. and Saupe, D. (ed) Chaos and fractal new frontiers of science. Springer-Verlag, New York, p. 922-953.

Falconer, K. (2003). Fractal Geometry. Mathematical foundations and applications (2nd edition). West Sussex: John Wiley \& Sons.

Feder, J. (1989). Fractals. New York: Plenum Press.

Flint A. L. and Flint L. E. (2002). Porosity. In: Dane J.H., Topp G.C., editors. Methods of soil analysis. Physical methods. Madison: American Society of Agronomy; Soil Science Society of America, Pt 4, 241-54.

Flynn E. S. (2006). Using NDVI as a pasture management tool. Master Thesis. University of Kentucky.

González-Torre, I., Losada, J. C., and Tarquis, A. M. (2016). Multiscaling properties of soil images. Biosystems Engineering, available online: https://doi.org/10.1016/j.biosystemseng.2016.11.006

González-Torre, I., Losada, J. C., Heck, R. J., and Tarquis, A. M. (2017). Multifractal analysis of 3D images of tillage soil. Geoderma, available online: https://doi.org/10.1016/i.geoderma.2017.02.013

Gouveia, C., Trigo, R. M. and DaCamara, C.C. (2009). Drought and vegetation stress monitoring in Portugal using satellite data. Nat. Hazards Earth Syst. Sci., 9, 185-195.

Grau, J., Méndez, V., Tarquis, A.M., Díaz, M.C., and Saa, A. (2006). Comparison of gliding box and box-counting methods in soil image analysis. Geoderma, Vol. 139, issues 3 - 4, pp. 349-359.

Halsey, T. C., Jensen, M. H., Kadanoff, L. P., Procaccia, I. and Shraiman, B. I. (1986). Fractal measures and their singularities: the characterization of strange sets. Phys. Rev. A 33, 1141-1151.

Hapca, S.M., Houston, A.N., Otten, W. and Baveye, P.C. (2013). New objective segmentation method based on minimizing locally the intra-class variance of grayscale images. Vadose Zone J. 12 (3). 
Harris, K., Young, I. M., Gilligan, C. A., Otten, W. and Ritz, K. (2003). Effect of bulk density on the spatial organisation of the fungus Rhizoctonia solani in soil. FEMS Microbiology Ecology, 44, 44 - 56.

Hayes, M. (2004). Comparison of Major Drought Indices. National Drought Mitigation Centre. http://drought.unl.edu/Planning/Monitoring/ComparisonofIndices/ntro.aspx Houston, A. N., Otten, W., Baveye, P.C. and Hapca, S. M. (2013a). AdaptiveWindow Indicator Kriging: A Thresholding Method for Computed Tomography. Computers \& Geosciences, 54, 239-248.

Houston, A. N., Schmidt, S., Tarquis, A. M., Otten, W., Baveye, P. C. and Hapca, S. M. (2013b). Effect of scanning and image reconstruction settings in X-ray computed microtomography on quality and segmentation of 3D soil images. Geoderma 207-208, 154-165.

Jain, A. (1989). Fundamentals of Digital Image Processing. Prentice-Hall.

Journel, A. G. and Huijbregts, Ch. J. (1978). Mining geostatistics. San Diego: Academic Press.

Kapur, J. N., Sahoo, P. K. and Wong, A. K. C. (1985). A new method for gray level picture thresholding using the entropy of the histogram. Computing Vision Graphics Image Process, 29, 273-285.

Ketcham, R. A., and W. D. Carlson (2001), Acquisition, optimization, and interpretation of X-ray computed tomographic imagery: Applications to the geosciences, Comput. Geosci., 27, 381-400.

Keyantash, J. and Dracup, J. A. (2002). The Quantification of Drought: An Evaluation of Drought Indices. B. Am. Meteorol. Soc., 83, 1167-1180.

Kravchenko, A., Martin, M. A., Smucker, A. J. M. and Rivers, M. L. (2009). Limitations in determining multifractal spectra from pore-solid soil aggregate images. Vadose Zone J., 8, 220-226.

Kravchenko, A., Falconer, R., Grinev, D., and Otten, W. (2011). Fungal colonization in soils of contrasting managements: modelling fungal growth in 3D pore volumes of undisturbed soil samples. Ecol Appl., 21(4), 1202-1210. 
Lavallee, D., Lovejoy, S., Schertzer, D. and Ladoy, P. (1993). Nonlinear variability of landscape topography: multifractal analysis and simulation. In: De Cola, L., Lam, N. (Eds.), Fractals in Geography. PTR, Prentice Hall, Englewood Cliffs, New Jersey, pp. 158-192.

Lovejoy, S., Tarquis, A. M., Gaonac'h, H. and Schertzer, D. (2008). Single and Multiscale remote sensing techniques, multifractals and MODIS derived vegetation and soil moisture. Vadose Zone Journal, 7(2), 533-546.

LP DAAC (Land Processes Distributed Active Archive Center) (2014). Surface Reflectance 8-Day L3 Global 500m (MOD09A1). NASA and USGS. https://lpdaac.usgs.gov/products/modis products table/mod09a1

Li, C. H. and Lee, C. K. (1993). Minimum Cross Entropy Thresholding. Pattern Recognition 26(4): 617-625.

Liu, Y., Xia, Q., Cheng and Q., Wang, X. (2013). Application of singularity theory and logistic regression model for tungsten polymetallic potential mapping. Nonlinear Processes in Geophysics, 20, 445-453.

Malamud, B. D., Turcotte, D. L., Guzzetti, F., and Reichenbach, P. (2004). Landslide inventories and their statistical properties. Earth Surf. Processes Landforms 29:687-711.

Mallat, S. (1999). A wavelet tour of signal processing (2 ed.). San Diego: Academic Press.

Mallat, S. and Hwang, W. L. (1992). Singularity detection and processing with wavelets. IEEE Trans. on Information Theory, 38 (2), 617-643.

Mandelbrot, B. (1977). Fractals: Form, Chance and Dimension. New York: W. H. Freeman \& Co.

Mandelbrot, B. (1982). The Fractal Geometry of Nature. New York: W. H. Freeman \& Co.

Mandelbrot, B. (2002). Gaussian Self-Affinity and Fractals. New York: Springer. Martín-Sotoca, J. J., Saa-Requejo, A., Borondo, J., and Tarquis, A. M. (2017c). Singularity maps applied to a vegetation index. Biosystems Engineering. http://dx.doi.org/10.1016/j.biosystemseng.2017.08.008 
Martín-Sotoca, J. J., Saa-Requejo, A., Grau, J. B., Paz-González, A., and Tarquis, A. M. (2017b). Combining global and local scaling methods to detect soil pore space. J. of Geo. Expl. http://dx.doi.org/10.1016/j.gexplo.2017.06.017

Martín-Sotoca, J. J., Saa-Requejo, A., Grau, J. B. and Tarquis, A. M. (2017a). New segmentation method based on fractal properties using singularity maps. Geoderma, 287, 40-53. http://dx.doi.org/10.1016/j.geoderma.2016.09.005 Martín-Sotoca, J. J., Saa-Requejo, A., Grau, J. B. and Tarquis, A. M. (2016). Local 3D segmentation of soil pore space based on fractal properties using singularity maps. Geoderma. http://dx.doi.org/10.1016/i.geoderma.2016.11.029 Martín-Sotoca, J. J. (2014). Estructura espacial de la sequía en pastos y sus aplicaciones en el seguro agrario indexado. Master tesis. ETSIAAB (UPM).

Oh, W. and Lindquist, B. (1999). Image thresholding by indicator kriging. IEEE Transactions on Pattern Analysis and Machine Intelligence, vol. 21, 590-602.

Ojeda-Magaña, B., Quintanilla-Domínguez, J., Ruelas, R., Tarquis, A.M., Gómez-Barba, L. and Andina, D. (2014). Identification of pore spaces in 3D CT soil images using PFCM partitional clustering. Geoderma, 217-218, 90-101.

Otsu, N. (1979). A threshold selection method from gray-level histograms. IEEE Transactions on Systems, Man and Cybernetics, vol. 9, 62-66.

Pajor, R., Falconer, R., Hapca, S. and Otten, W. (2010). Modelling and quantifying the effect of heterogeneity in soil physical conditions on fungal growth. Biogeosciences, 7, 3731-3740.

Perfect, E., Gentry, R.W., Sukop, M.C. and Lawson, J.E. (2006). Multifractal Sierpinski carpets: Theory and application to upscaling effective saturated hydraulic conductivity. Geoderma, 134, 240-252.

Piñuela, J., Alvarez, A., Andina, D., Heck, R.J. and Tarquis, A.M. (2010). Quantifying a soil pore distribution from 3D images: multifractal spectrum through wavelet approach. Geoderma, 155, 203-210.

Poveda, G. and Salazar, L. F. (2004). Annual and interannual (ENSO) variability of spatial scaling properties of a vegetation index (NDVI) in Amazonia. Remote Sensing of Environment, 93, 391 - 401. 
Ridler, T.W. and Calvard, S. (1978). Picture thresholding using an iterative selection method. IEEE Transactions on Systems, Man and Cybernetics, vol. 8, 630-632.

Rockhold, M. L., Yarwood, R. R. and Selker, J. S. (2004). Coupled Microbial and Transport Processes in Soils. Vadose Zone Journal, 3, 368-383.

Sahoo, P., Wilkins, C. and Yeager, J. (1997). Threshold selection using Renyi's entropy. Pattern Recognition, vol. 30, 1, 71-84.

Saravia, L. A., Giorgi, A. and Momo, F. (2012). Multifractal Spatial Patterns and Diversity in an Ecological Succession. PLoS ONE, 7(3): doi:10.1371/journal.pone.0034096.

Schertzer, D. and Lovejoy, S. (1987). Physical modeling and analysis of rain and clouds by anisotropic scaling of multiplicative processes. J. Geophys. Res. 92:9693-9714.

Schertzer, D. and Lovejoy, S. (Eds.) (1991). Nonlinear Variability in Geophysics. Kluwer Academic Publishers, Dordrecht, The Netherlands, 318 pp.

Scheuring, I. and Riedi, R. H. (1994). Application of multifractals to the analysis of vegetation pattern. J. Veg. Sci. 5, 489-496.

Schlüter, S., Weller, U., Vogel and H.-J., (2010). Thresholding of X-ray microtomography images of soil using gradient masks. Comput. Geosci. 36, 1246-1251.

Sepulcre-Canto, G., Horion, S., Singleton, A., Carrao, H. and Vogt, J. (2012). Development of a Combined Drought Indicator to detect agricultural drought in Europe. Nat. Hazards Earth Syst. Sci., 12, 3519-3531.

Sezgin, M. and Sankur, B. (2004). Survey over image thresholding techniques and quantitative performance evaluation. J. Electron. Imaging, 13 (1), 146-165.

Solé, R.V. and Bascompte, J. (2006). Self-organization in complex ecosystems. Princeton University Press.

Sornette, D. (2nd Ed.) (2004). Critical phenomena in natural sciences: Chaos, fractals, self-organization, and disorder. Springer, New York. 
Stock, S. R. (1999). X-ray microtomography of materials, Int. Mater. Rev., 44, $141-164$.

Tarquis, A.M., Losada, J.C., Benito, R. and Borondo, F. (2001). Multifractal analysis of the Tori destruction in a molecular Hamiltonian System. Phys. Rev. E. 65, 0126213(9).

Tarquis, A. M., Heck, R. J., Grau, J. B., Fabregat, J., Sanchez, M. E. and Antón, J. M. (2008). Influence of thresholding in mass and entropy dimension of 3-D soil images. Nonlinear Processes in Geophysics, 15 (6), 881-891.

Tarquis, A. M., Heck, R. J., Andina, D., Alvarez, A. and Anton, J. M. (2009). Pore network complexity and thresholding of 3D soil images. Ecological Complexity, Vol. 6(3), 230-239.

Tarquis, A. M., Sánchez, M. E., Antón, J. M., Jimenez, J., Saa-Requejo, A., Andina, D. and Crawford, J. W. (2012). Variation in Spectral and Mass Dimension on Three-Dimensional Soil Image Processing. Soil Science, 177 (2), 88-97.

Turcotte, D.L. (1997). Fractals and chaos in geology and geophysics (2nd Ed.). Cambridge Univ. Press, Cambridge, UK.

Van Geet, M., Swennen, R. and Wevers, M. (2000). Quantitative analysis of reservoir rocks by microfocus X-ray computerised tomography, Sediment. Geol., 132, 25-36.

Veneziano, D. (2002). Multifractality of rainfall and scaling of intensity-durationfrequency curves. Water Resour. Res. 38:1-12.

Vogel, H.J. (2000). A numerical experiment on pore size, pore connectivity, water retention, permeability, and solute transport using network models. European Journal of Soil Science, 51(1), 99-105.

Volume Graphics, GmbH (2015). http://www.volumegraphics.com/.

Wang, W., Kravchenko, A. N., Smucker, A. J. M. and Rivers, M. L. (2011). Comparison of image segmentation methods in simulated $2 \mathrm{D}$ and $3 \mathrm{D}$ microtomographic images of soil aggregates. Geoderma, 162, 231-241. 
Wildenschild, D., Hopmans, J. W., Vaz, C. M. P., Rivers, M. L., Rikard, D. and Christensen, B. S. B. (2002). Using X-ray computed tomography in hydrology: Systems, resolutions, and limitations, J. Hydrol., 267, 285-297.

Yasnoff, W. A., Mui, J. K., and Bacus, J. W. (1977). Error measures for scene segmentation. Pattern Recognit. 9, 217-231.

Young, I. M., Crawford, J. W., Nunan, N., Otten, W. and Spiers, A. (2008). Microbial distribution in soils: physics and scaling. Advances in Agronomy, vol. $100,81-121$.

Zhang, Y. J. (1996). A survey on evaluation methods for image segmentation. Pattern Recognit. 29, 1335-1346.

Zhang, Y. J. (2001). A review of recent evaluation methods for image segmentation: International symposium on signal processing and its applications. Kuala Lumpur, Malaysia, 13-16, pp. 148-151.

Zhou, H., Perfect, E., Lu, Y. Z., Li, B. G. and Peng, X. H. (2011). Multifractal analyses of grayscale and binary soil thin section images. Fractals, vol. 19, 3, 299-309. 